\title{
Revision of the Afrotropical species of Pristomerus (Ichneumonidae: Cremastinae), with descriptions of 31 new species
}

\author{
Pascal ROUSSE ${ }^{1} \&$ Simon van NOORT ${ }^{2}$ \\ ${ }^{1,2}$ Natural History Department, Iziko South African Museum, PO Box 61, Cape Town, 8000, South Africa. \\ ${ }^{1}$ Stellenbosch University, Department of Botany and Zoology, Evolutionary Genomics Group, \\ Private Bag X1, Stellenbosch, 7602, South Africa. \\ ${ }^{2}$ Department of Biological Sciences, University of Cape Town, \\ Private Bag, Rondebosch, 7701, South Africa. \\ ${ }^{1}$ Email: rousse.pascal@wanadoo.fr (corresponding author) \\ ${ }^{1}$ urn:1sid:zoobank.org:author:B06C2640-700A-429B-AA2F-1BE09251C845 \\ ${ }^{2}$ urn:lsid:zoobank.org:author:7CCD166F-F1FA-43DA-B582-4E84EAF59AD1
}

\begin{abstract}
We revised the species of the genus Pristomerus Curtis, 1836 in the Afrotropical Region. Fortynine species are recognized, of which 31 are newly described. The following new species are described: $P$. afrikaner, P. aka, P. babinga, P. bemba, P. dikidiki, P. herero, P. hutu, P. kagga, P. khoikhoi, P. kuku, P. masai, P. mbaka, P. mbama, P. mboum, P. nzakara, P. protea, P. restio, P. san, P. sara, P. sotho, P. swahili, P. teke, P. tutsi, P. venda, P. wolof, P. xhosa, P. yakoma, P. yangere, P. yoccolo, P. zande and $P$. zulu spp. nov. New synonyms: $P$. africator, $P$. cunctator and $P$. luteolus are new junior synonyms of $P$. pallidus. New records: new host records are reported for the widespread $P$. pallidus; new country-level distribution records are added for P. bullis, P. keyka, P. kelikely and P. pallidus; and reports of Trathala concolor and P. veloma in South Africa are shown to have been erroneous. An illustrated dichotomous key to females is provided; an online Lucid interactive matrix key is also available at www.waspweb.org. Finally, the ecological and geographical correlates of colour patterns exhibited by Pristomerus in the Afrotropical region are discussed.
\end{abstract}

Keywords. Africa, Hymenoptera, identification key, parasitoid wasp, solitary koinobiont endoparasitoid.

Rousse P. \& van Noort S. 2015. Revision of the Afrotropical species of Pristomerus (Ichneumonidae: Cremastinae), with descriptions of 31 new species. European Journal of Taxonomy 124: 1-129. http://dx.doi.org/10.5852/ejt.2015.124

\section{Introduction}

Most of the biodiversity in the tree of life evolved in the tropics and diversified later into temperate latitudes (Jansson et al. 2013). The genus Pristomerus Curtis, 1836 is no exception, with Townes (1971) already stating that its diversity peaks in the tropics. Paradoxically only eight of the approximately 100 described Pristomerus species are recorded from the Afrotropical region (Yu et al. 2012). This gap between expected and documented species richness pinpoints the poor knowledge we still have of the entomofauna in this region. This general rule concerning entomology in Subsaharan Africa is even more evident when considering the huge family of Ichneumonidae, especially when dealing with diverse genera such as Pristomerus. 
As a result of its high species-richness and the related differentiation difficulties for most of the species, Pristomerus is still a poorly investigated genus. This leads to major identification issues in biological control programs. These parasitoid wasps are indeed often reared from pests of cultivated Poaceae (rice or corn), Solenaceae (potato, tomato, tobacco), Fabaceae (peanuts), Rosaceae (apple, peach), or Malvaceae (cotton) (Yu et al. 2012), but the collected species usually remain unidentified, because proper identification tools are still lacking. As a consequence, their efficiency as pest population regulators is still underestimated. Only scattered descriptions of the Afrotropical species were published during the $19^{\text {th }}$ and $20^{\text {th }}$ centuries. The first regional revision was recently provided, using André Seyrig's collections from Madagascar (Rousse et al. 2013): significantly, 12 species out of 15 were new. We now extend the revision of the genus to the whole Afrotropical region. Simultaneously, this works aims to be an overview of present knowledge, a set of descriptions for the expansion of this knowledge, a comprehensive identification tool for taxonomists and agronomists, and a prospective framework to provide a basis for future research dealing with the genus.

\section{Material and methods}

\section{Photographs}

Specimens were point mounted on black, acid-free cards for examination (using a Leica M205C stereomicroscope with LED light source), photography and long-term preservation. Images were acquired using either the EntoVision ${ }^{\circledR}$ multiple-focus imaging system or the Leica LAS 4.4 imaging system. The EntoVision ${ }^{\circledR}$ system comprised a Leica ${ }^{\circledR}$ M16 microscope with a JVC® KY-75U 3-CCD digital video camera attached that feeds image data to a notebook computer. The program Cartograph ${ }^{\circledR}$ 5.6.0 was used to manage image acquisition using an automated Z-stepper and merging of the image series into a single in-focus image. The Leica LAS 4.4 system comprised a Leica ${ }^{\circledR}$ Z16 microscope with a Leica DFC450 Camera with a $0.63 \times$ video objective attached. Leica Application Suite V 4.4 software was installed on a desk top computer. Lighting was achieved using techniques summarized in Buffington et al. (2005), Kerr et al. (2008) and Buffington \& Gates (2009). All images presented in this paper are available at http://www.waspweb.org.

\section{Depositories}

BMNH $=$ Natural History Museum, London, UK (Gavin Broad)
CASC $=$ California Academy of Sciences, San Francisco, USA (Brian Fisher)
CBGP $=$ Centre de Biologie et de Génétique des Populations, Montpellier, France (Gérard Delvare)
ISNB $=$ Institut Royal des Sciences Naturelles de Belgique, Brussels, Belgium (Patrick Grootaert)
MNHN $=$ Muséum national d'Histoire naturelle, Paris, France (Claire Villemant)
MNK $=$ Museum für Naturkunde, Berlin, Germany (Frank Koch)
MZLS $=$ Musée Zoologique, Lausanne, Switzerland (Anne Freitag)
MCSN $=$ Museo Civico di Storia Naturale, Genova, Italy (Maria Tavano)
SAMC $=$ Iziko South African Museum, Cape Town, South Africa (Simon van Noort)
SANC $=$ South African National Collection of Insects, Pretoria, South Africa (Ros Urban)

\section{Nomenclature and abbreviations}

The morphological terminology follows Wahl \& Sharkey (1993), except the wing venation (Gauld 1991). Most morphological terms are also defined on the HymAToL website (http://www.hymatol.org) and $\mathrm{HAO}$ website (http://portal.hymao.org/projects/32/public/ontology/). If not indicated otherwise, all geographical records are extracted from the Taxapad database (Yu et al. 2012). Label data are cited verbatim, except that commas are inserted between label components if they are absent on the original label. The following morphometric abbreviations are used:

$\mathrm{B}=$ body length, from torulus to metasomal apex (mm)

A = antenna length, from base of scape to flagellar apex ( $\mathrm{mm})$

$\mathrm{ASM}=($ area superomedia index $)$ : maximum length of area superomedia/maximum width of area superomedia 
$\mathrm{F} \quad$ = forewing length, from tegula to wing apex (mm)

$\mathrm{ML}=($ malar line index): shortest distance between eye and mandible/basal mandibular width

$\mathrm{CT}=$ (clypeus transversality index): distance between outer edges of tentorial pits/median height of clypeus

$\mathrm{POL}=$ (post-ocellar line index): shortest distance between posterior ocelli/posterior ocellus longest diameter

$\mathrm{OOL}=$ (oculo-ocellar line index): shortest distance between eye and posterior ocellus/posterior ocellus longest diameter

$\mathrm{Fl}_{\mathrm{n}-1}=$ (elongation index of penultimate flagellomere): length/width of penultimate flagellomere

OT $=$ (ovipositor length index): length of ovipositor sheath/length of hind tibia

FFT $=$ (female femoral tooth index): 0 : totally absent, without any trace of denticles; 1 : present, hardly distinct to distinctly smaller than basally wide, sometimes with following denticles; 2: present and strong, about as long as basally wide or longer, always with following denticles (see key couplet 27)

\section{Results}

Forty-nine Pristomerus species are now reported in the Afrotropical Region, of which 31 are newly described here. Based on the large proportion of singletons or isolated collection events in these descriptions, many further Pristomerus species are expected to be found in the region. Females are keyed in the following dichotomous (or trichotomous) key, which often relies on gender-linked characters (ocelli, femoral tooth index and ovipositor length). It was functionally impossible to build a robust and relatively user-friendly key for both sexes because the males of many species are still unknown. An online interactive Lucid matrix key is also available at http://www.waspweb.org. The descriptions and diagnoses follow. If not otherwise indicated, all new species names refer to African ethnical groups living at the type locality.

\section{Key to females of Pristomerus}

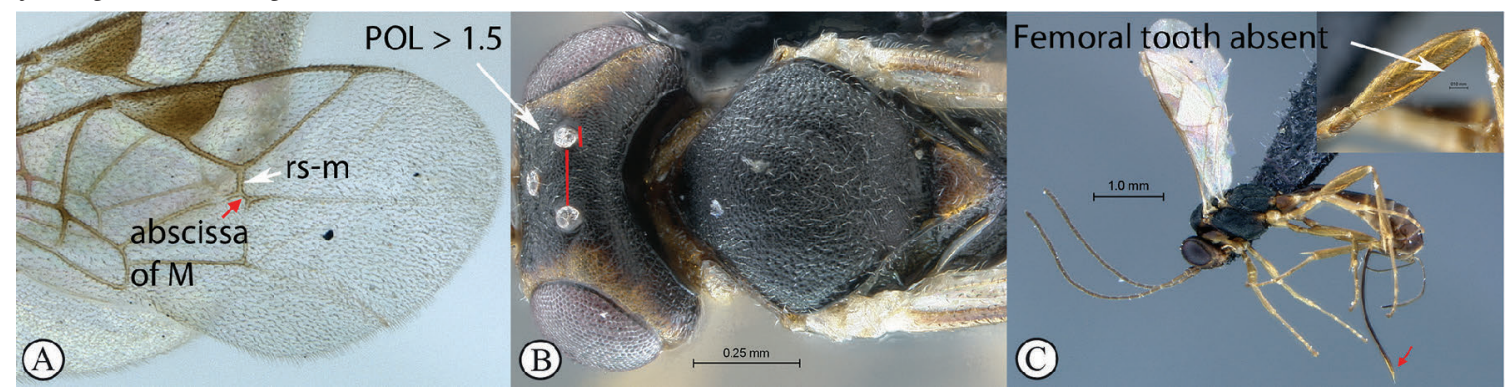

1. Fore wing with abscissa of $\mathrm{M}$ between $\mathrm{rs}-\mathrm{m}$ and $2 \mathrm{~m}$-cu short, less than $0.5 \times \mathrm{rs}-\mathrm{m}(\mathrm{A})$; female ocelli distinctly reduced $(\mathrm{POL}>1.5)(\mathrm{B})$; ovipositor stout and evenly up-curved with apex down-curved $(\mathrm{C})$; female femoral tooth absent $(\mathrm{FFT}=0)(\mathrm{C})$; south-western South Africa

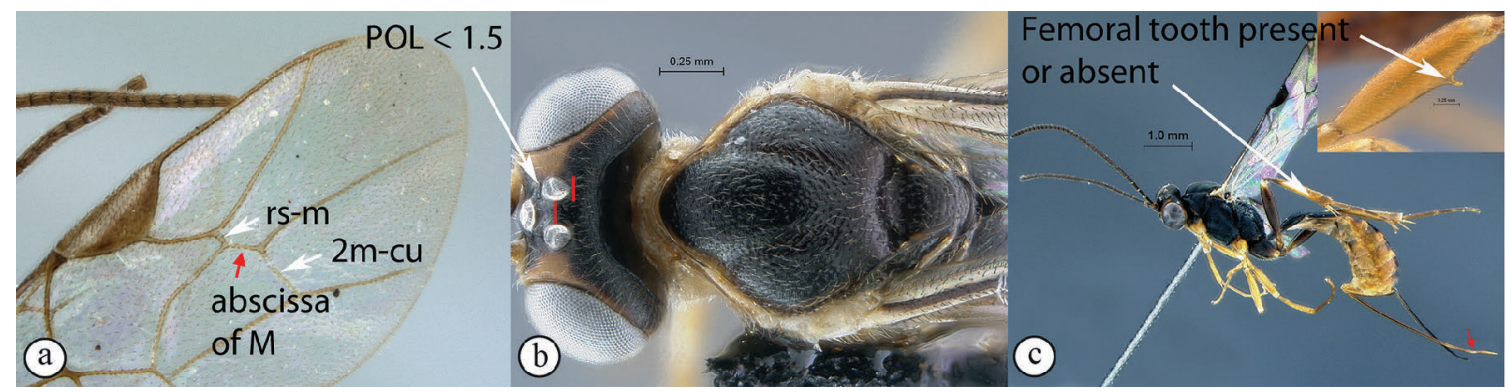

- Fore wing with abscissa of $\mathrm{M}$ between rs-m and $2 \mathrm{~m}$-cu longer, distinctly longer than $0.5 \times \mathrm{rs}-\mathrm{m}$ (a); female ocelli larger $(\mathrm{POL}<1.5)(\mathrm{b})$; ovipositor straight to slightly down-curved, usually more slender and apically unevenly sinuous (c); female femoral tooth present or absent (FFT various) (c) ............. 3 


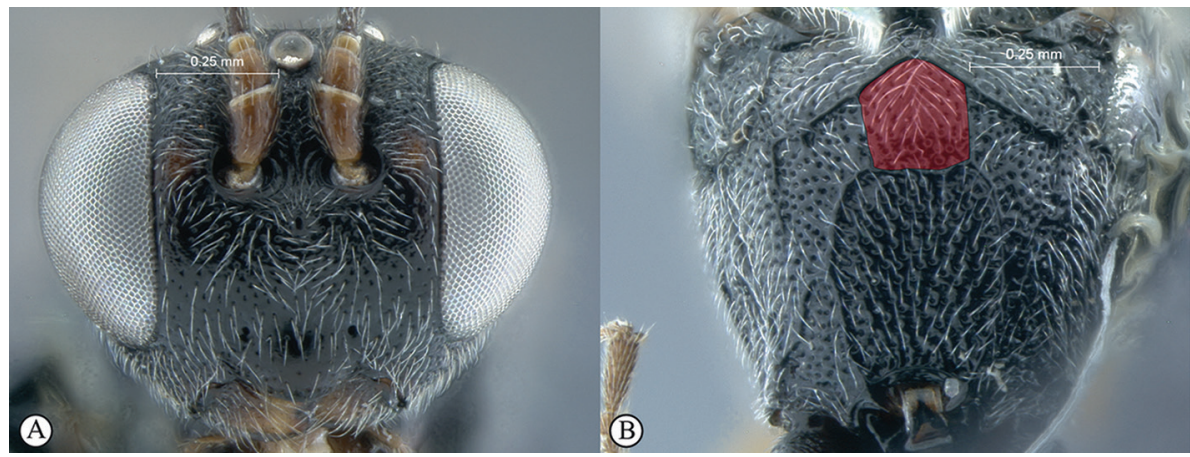

2. Face totally black, deeply and densely punctate, inter-puncture area smooth (A); area superomedia subquadrate $(\mathrm{ASM}<1)(\mathrm{B})$

P. protea sp. nov.

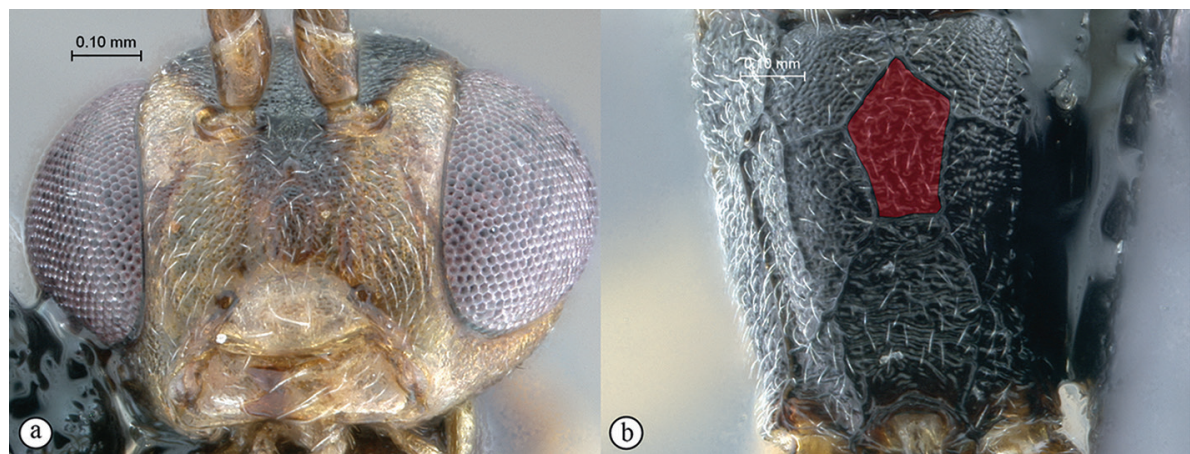

- Face mostly lighter, densely punctate-granulate (a); area superomedia longer than wide (ASM >1) (b) .P. restio sp. nov.

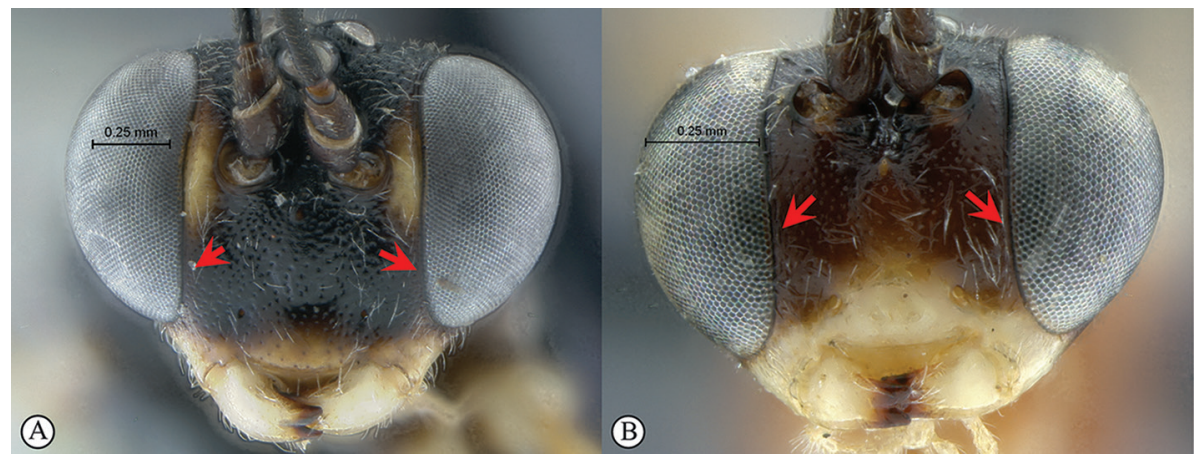

3. Entire face black to dark brown, including orbits (A, B)
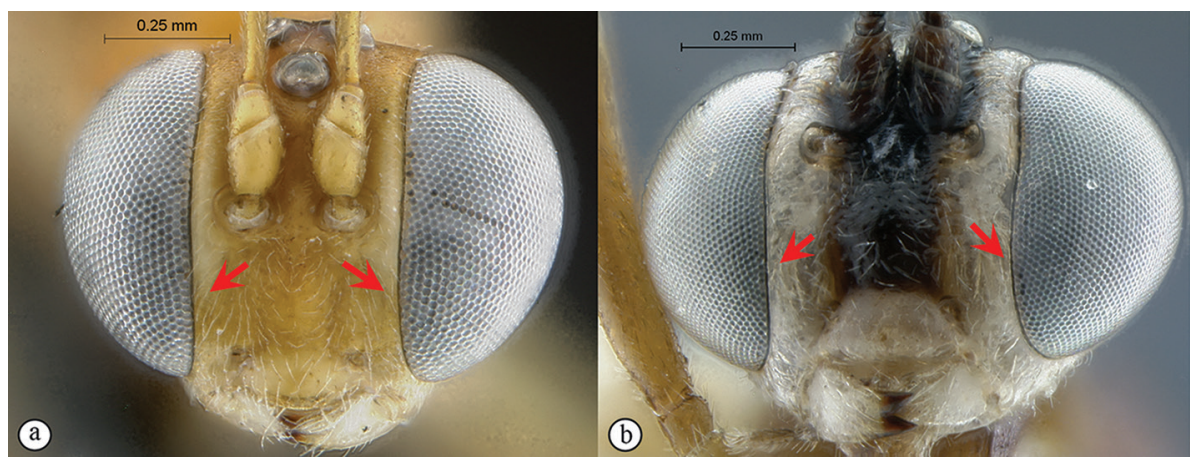

- At least facial orbits distinctly lighter, pale yellow to testaceous-orange; median face almost always similarly coloured though sometimes more or less infuscate $(a, b)$ 


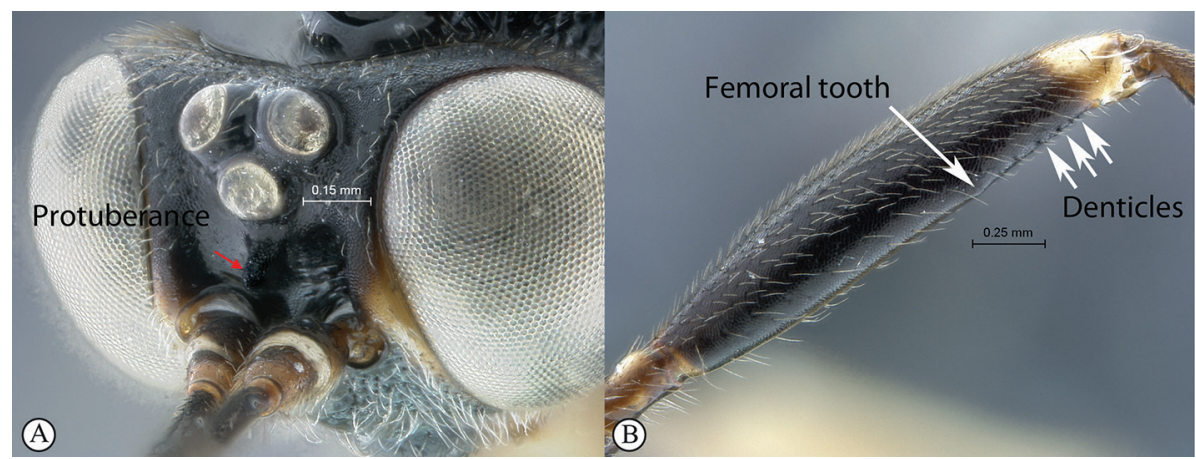

4. Frons with a strong mid-longitudinal flattened protuberance (A); femoral tooth nearly absent with minute following denticles (B); ovipositor short $(\mathrm{OT}<1.5)$.

P. $k$ uku sp. nov.

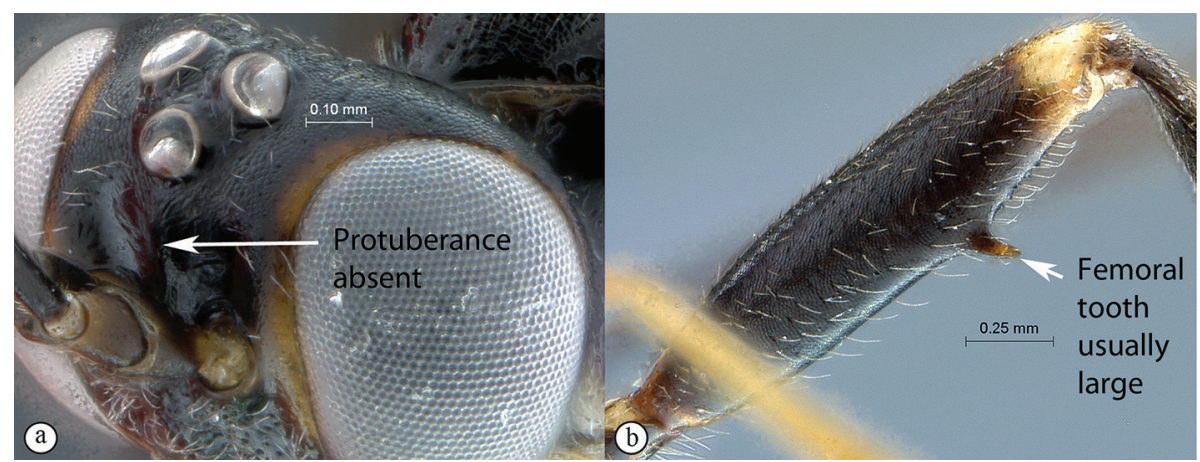

- Frons without distinct mid-longitudinal protuberance (a); femoral tooth and ovipositor various, usually both longer (b).

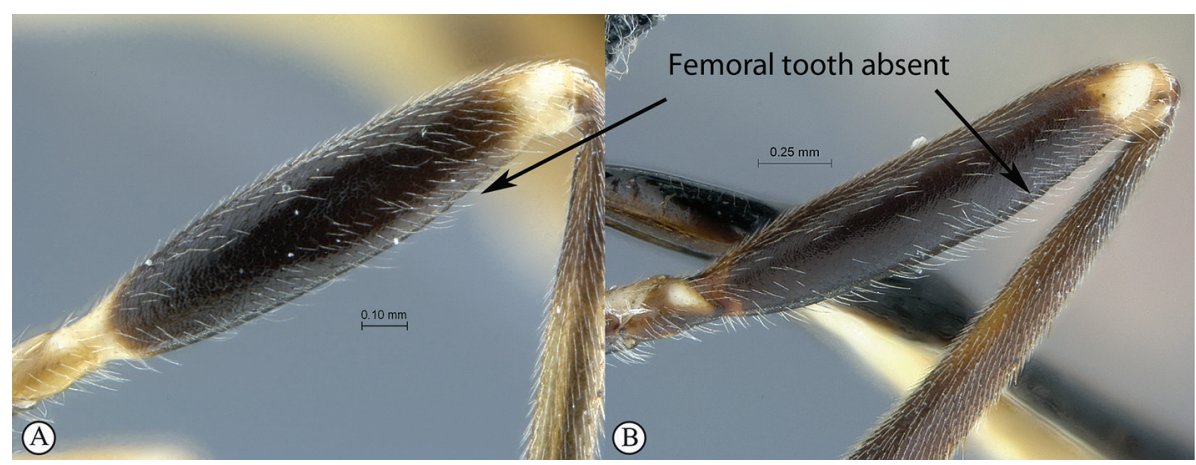

5. Female femoral tooth absent, femur without any distinct subapical protuberance ventrally $(\mathrm{FFT}=0)$ (A, B); tropical rainforest of central mainland Africa

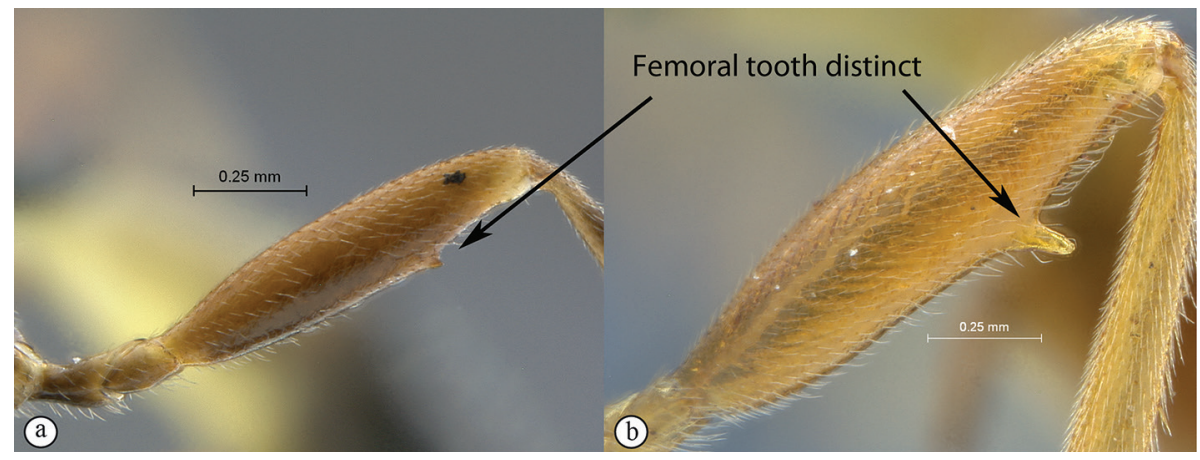

- Female femoral tooth distinct, small to very strong $($ FFT $>0)(a, b)$ 


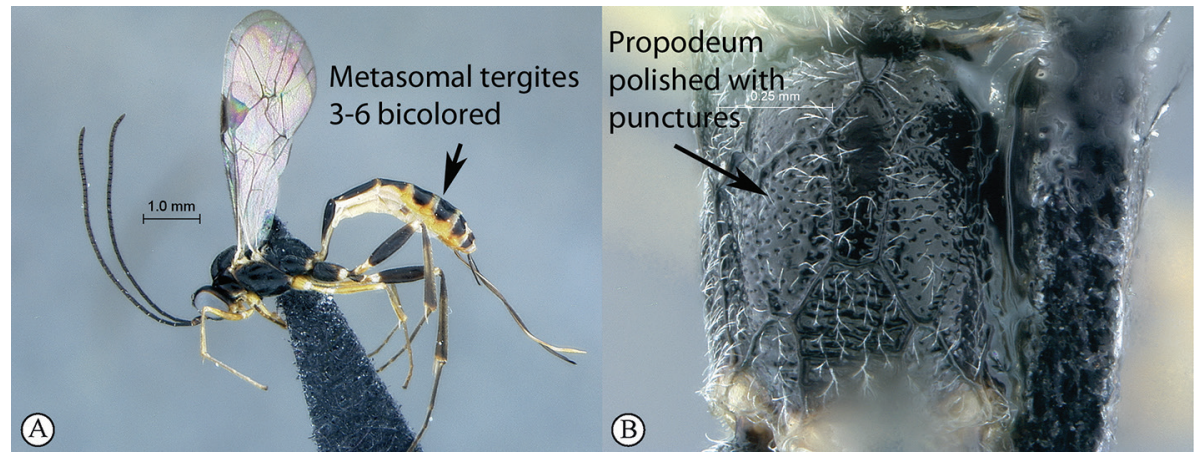

6. Female with tergites 3-6 bicoloured, black and yellowish-orange (A); propodeum polished with punctures (B) P. tutsi sp. nov.
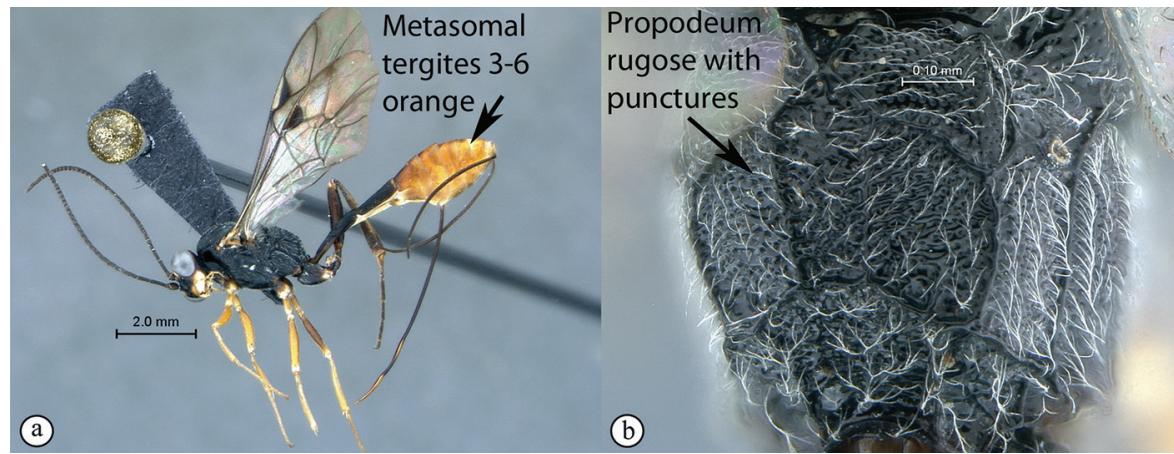

- Female with tergites 3-6 entirely orange (a); propodeum rugose with punctures (b)

P. yangere sp. nov.

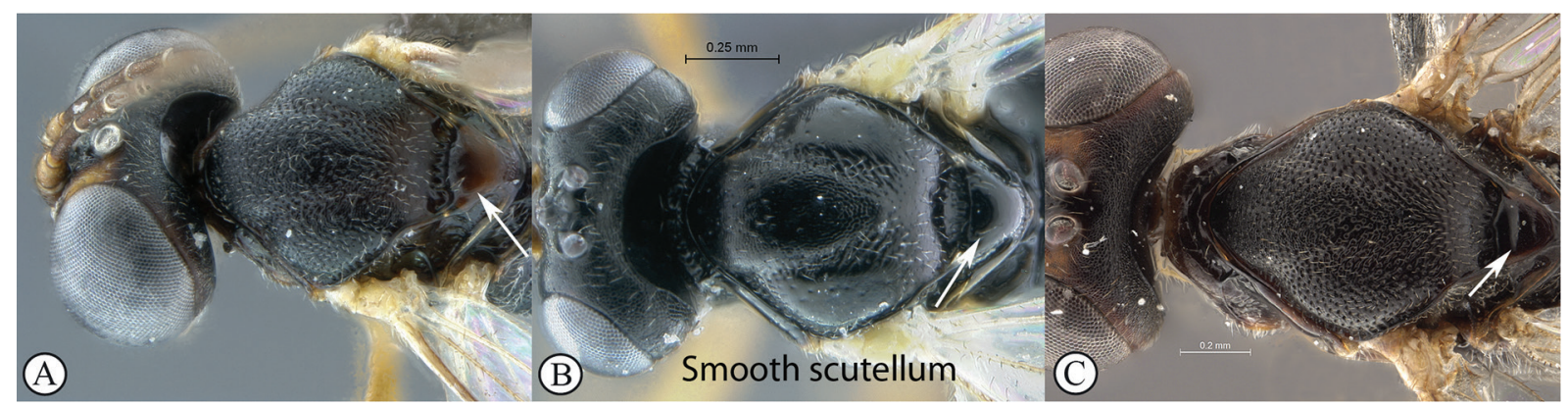

7. Scutellum smooth or nearly so, distinctly smoother than mesoscutum (A-C). 8

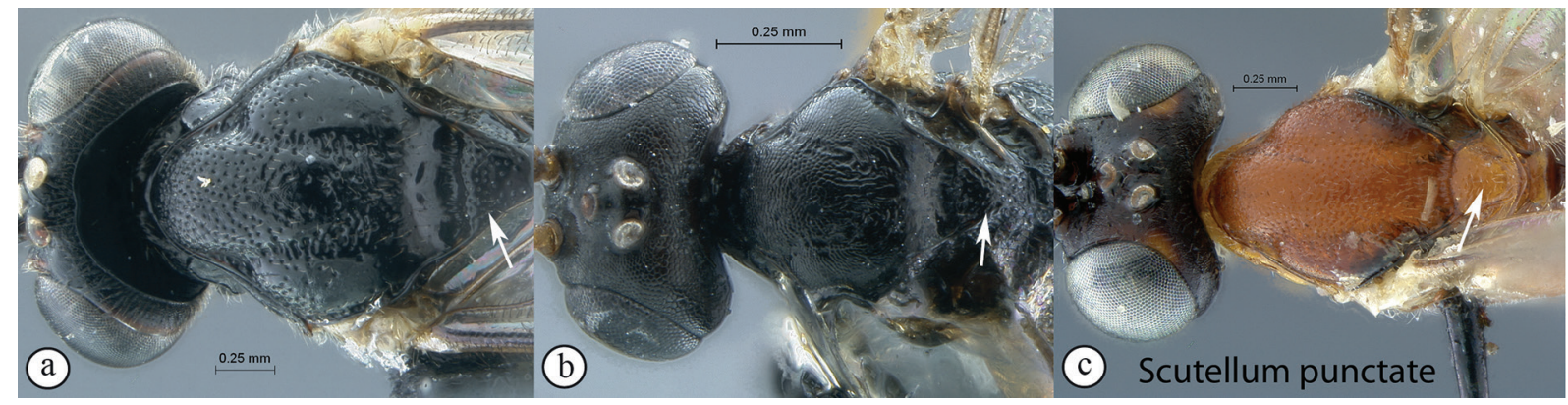

- Scutellum distinctly punctate, punctation denser than on mesoscutum $(\mathrm{a}-\mathrm{c})$ 


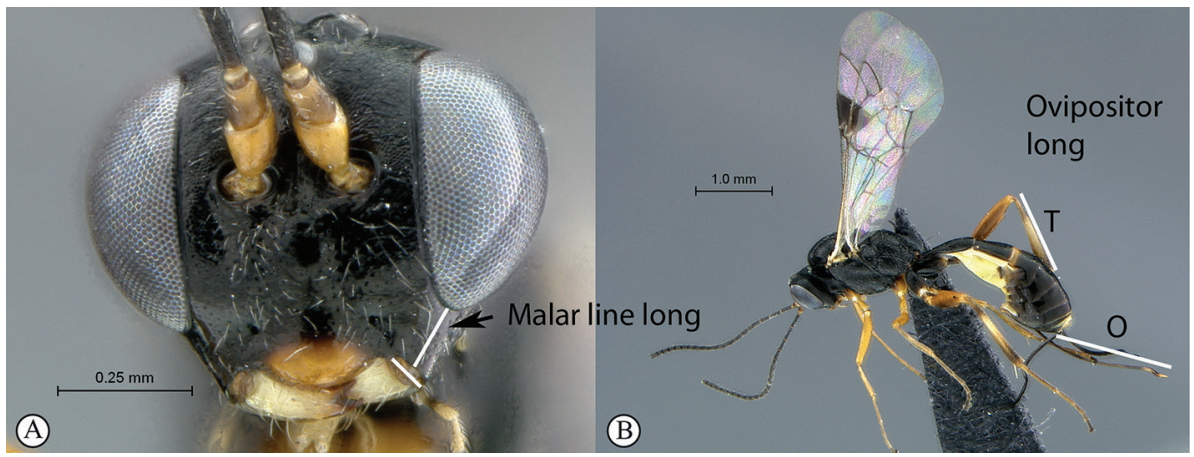

8. Small (fore wing length $<3.5 \mathrm{~mm}$ ); malar line very long $(\mathrm{ML}>1.2)$ (A); ovipositor moderately long $(\mathrm{OT}>1.5)(\mathrm{B})$; South Africa

P. khoikhoi sp. nov.

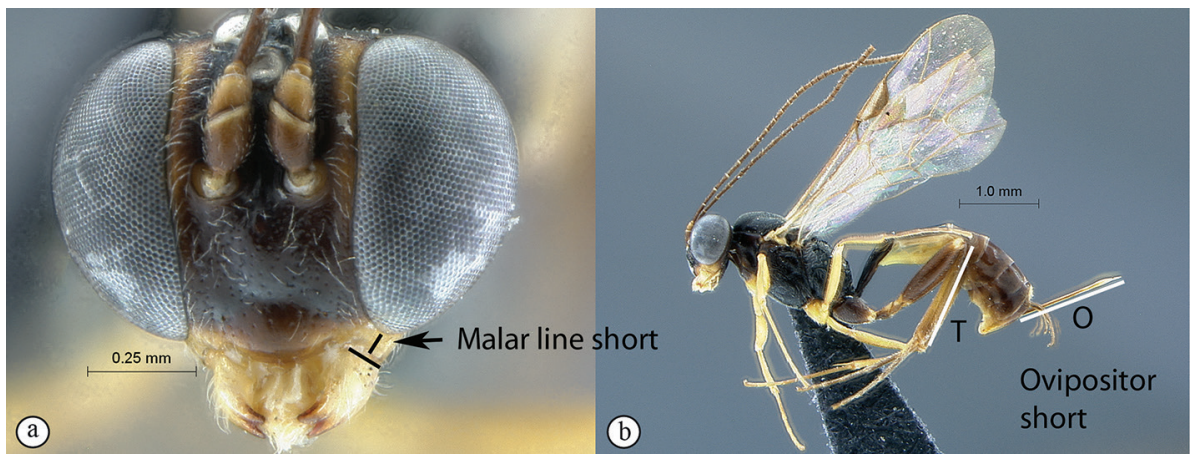

- Larger (fore wing length $>3.5 \mathrm{~mm}$ ); malar line short to very short $(\mathrm{ML}<0.7)$ (a); ovipositor short $(\mathrm{OT}<1.5)(\mathrm{b})$; tropical rainforest of central mainland Africa.

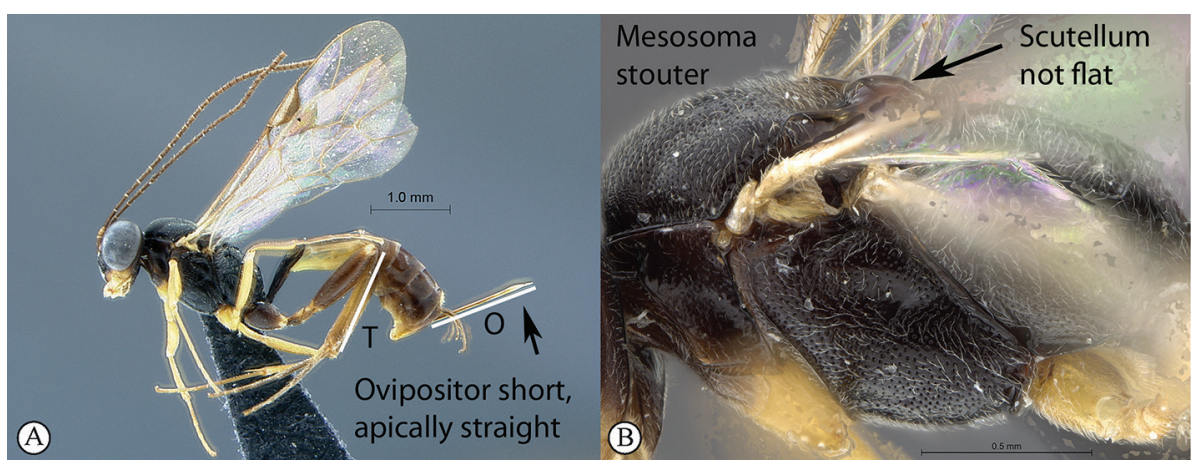

9. Ovipositor very short $(\mathrm{OT}<1)$ and apically straight $(\mathrm{A})$; mesosoma rather stout, scutellum not unusually flat $(\mathrm{A})$.....

P. $\boldsymbol{m b a k a}$ sp. nov.

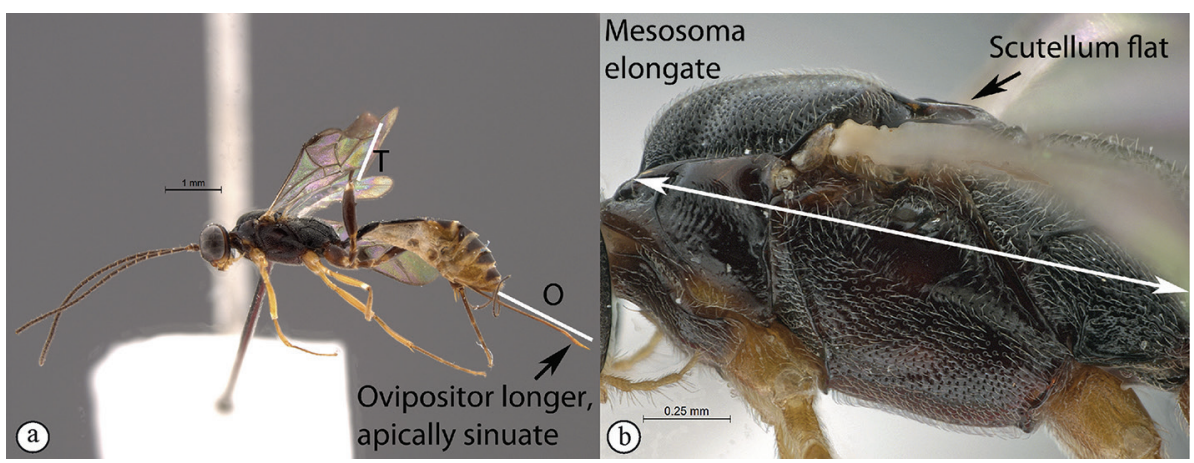

- Ovipositor longer (OT > 1) and apically sinuous (a); mesosoma distinctly elongate with scutellum quite flat (b).

.P. teke sp. nov. 


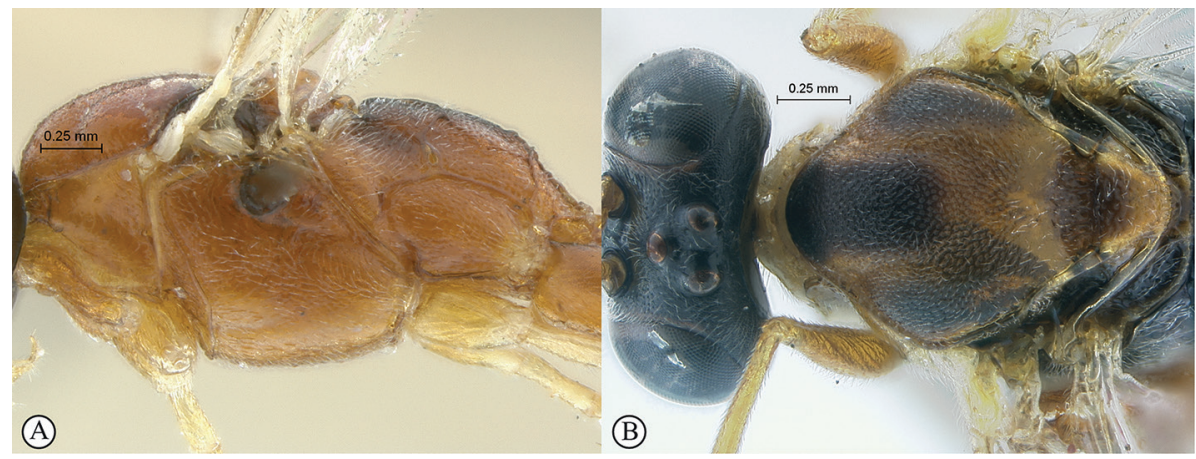

10. Mesosoma partly to totally yellowish-orange (A) to testaceous (B); Southern Africa and Indian Ocean islands

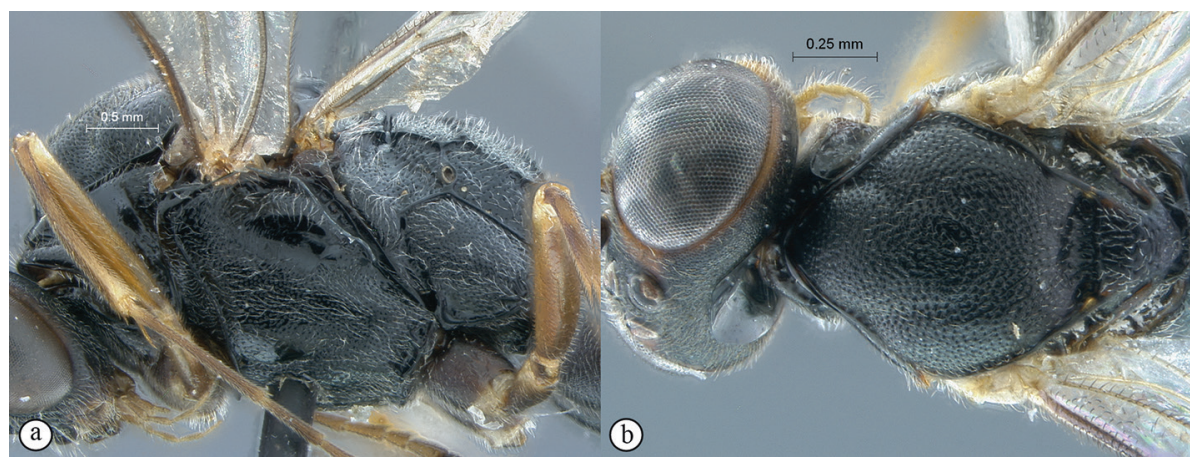

- Mesosoma entirely black (a, b); tropical mainland Africa
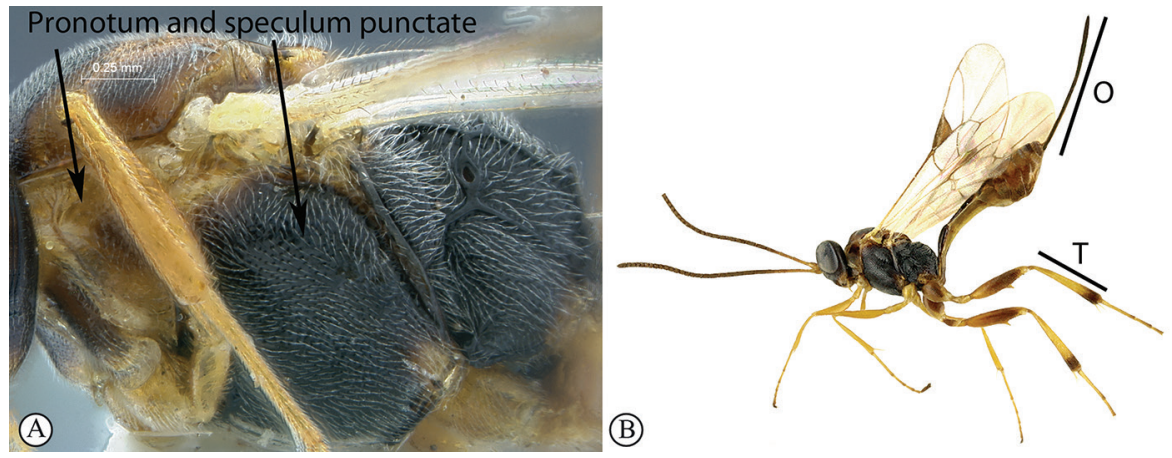

11. Speculum and pronotum entirely punctate $(A)$; ovipositor long $(\mathrm{OT}>1.5)(\mathrm{B})$; Réunion

.. P. rivier Rousse \& Villemant, 2012

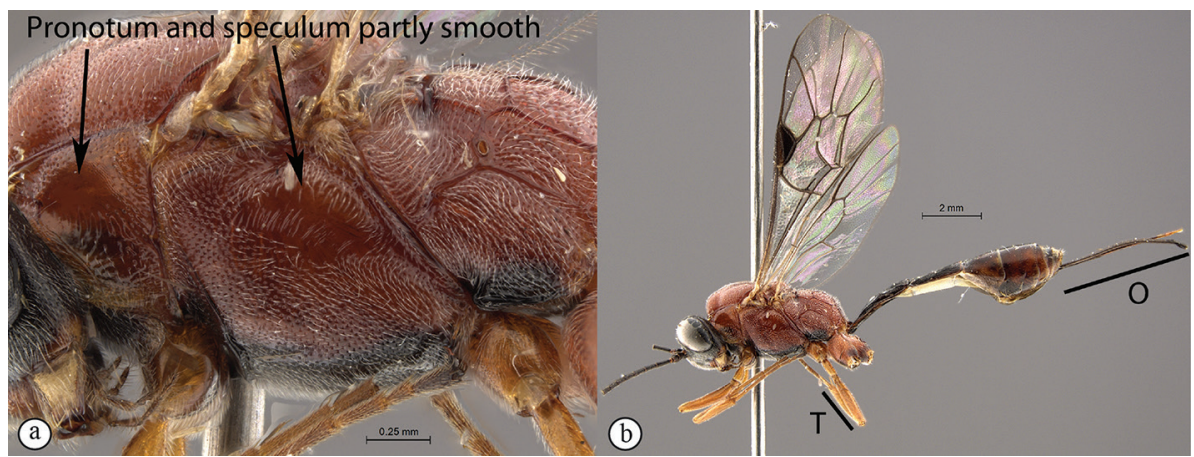

- Pronotum centrally and ventral half of speculum smoother (a); ovipositor short $(\mathrm{OT}<1.5)$ (b) ....... 


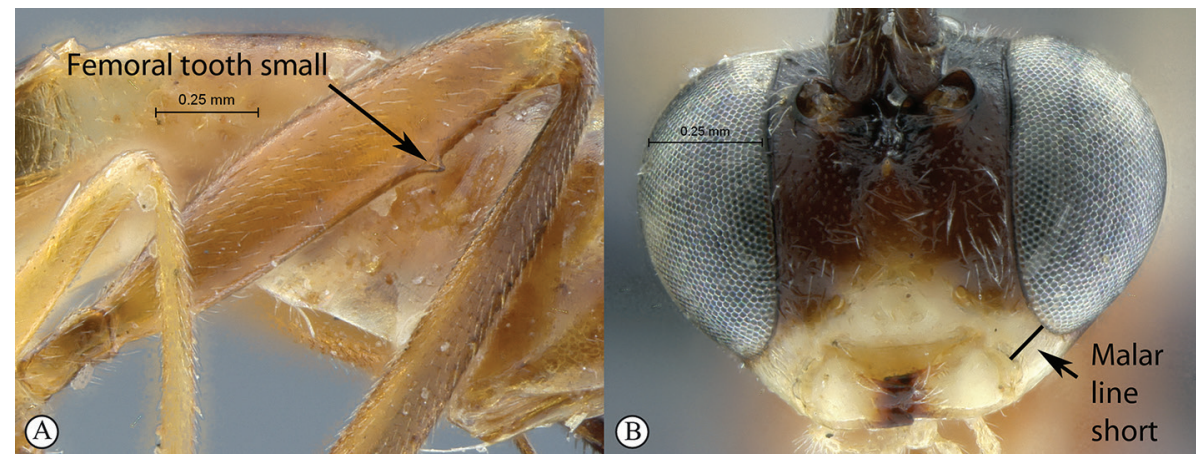

12. Female femoral tooth distinctly smaller than basally wide $(\mathrm{FFT}=1)(\mathrm{A})$; malar line short $(\mathrm{ML}<0.6)$ (B); Madagascar.

P. melissa Rousse, Villemant \& Seyrig, 2013

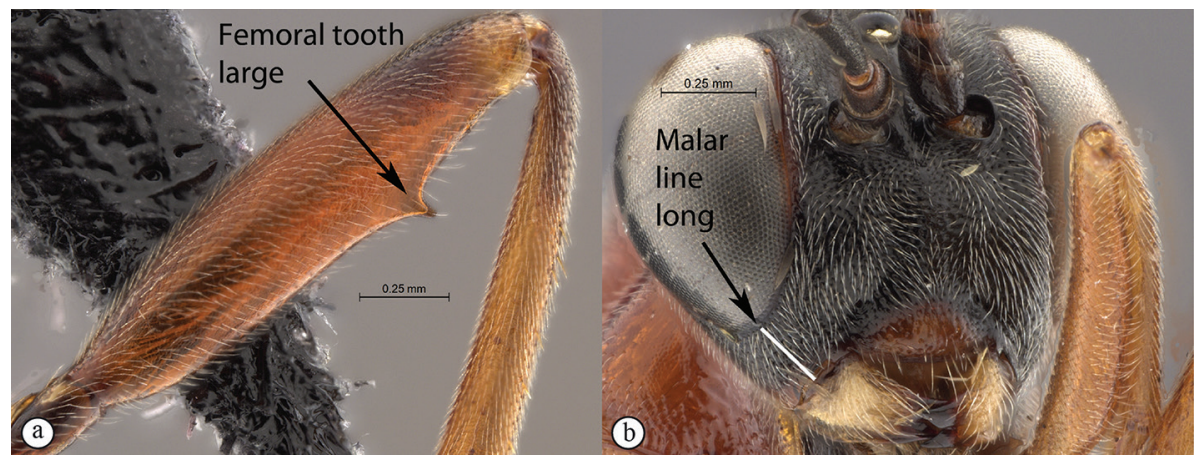

- Female femoral tooth longer than basally wide $(\mathrm{FFT}=2)(\mathrm{a})$; malar line long $(\mathrm{ML}>0.6)(\mathrm{b})$; Southern Africa. P. sotho sp. nov.

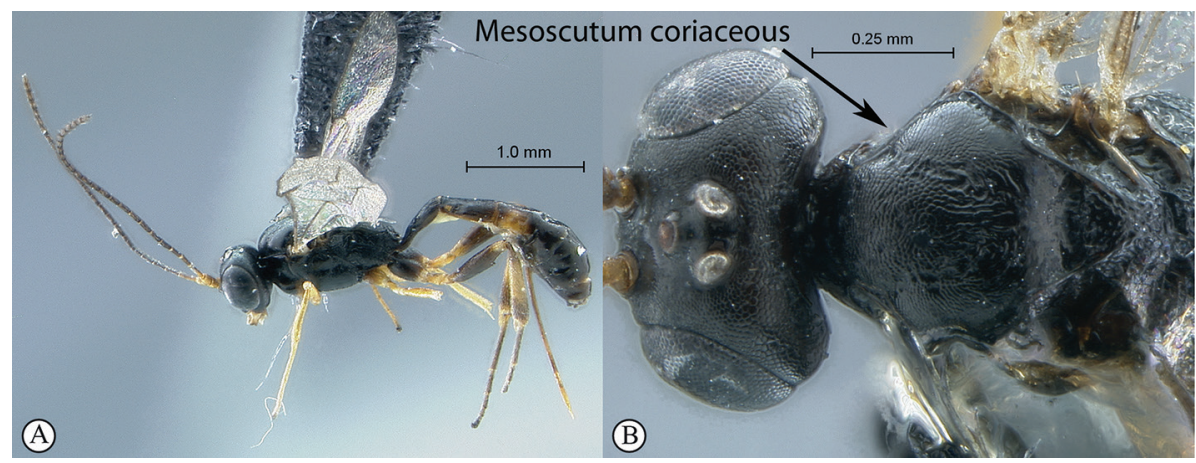

13. Small (fore wing length $<3.5 \mathrm{~mm}$ ) (A); mesoscutum coriaceous without punctures (B) P. aka sp. nov.
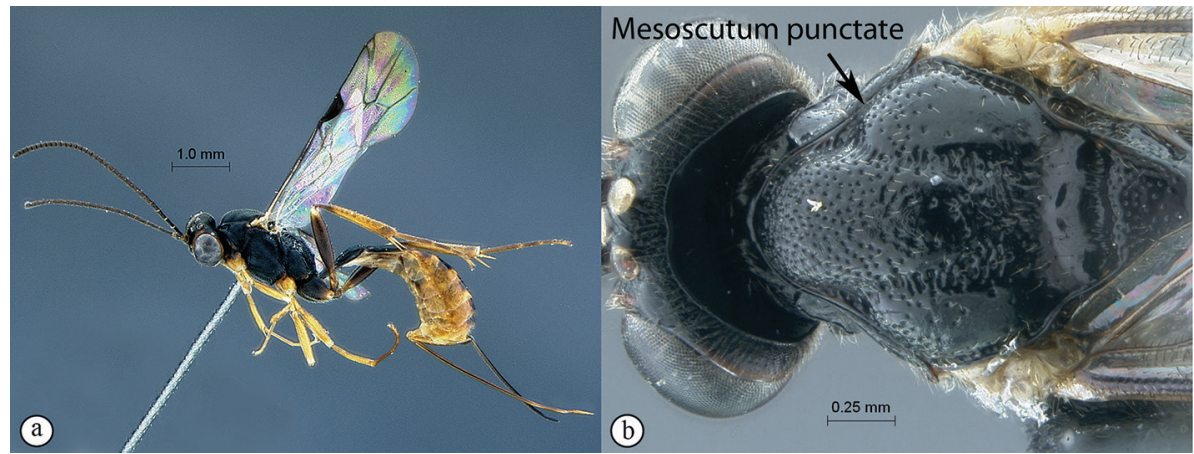

- Larger (fore wing length $>3.5 \mathrm{~mm}$ ) (a); mesoscutum distinctly punctate (b). 

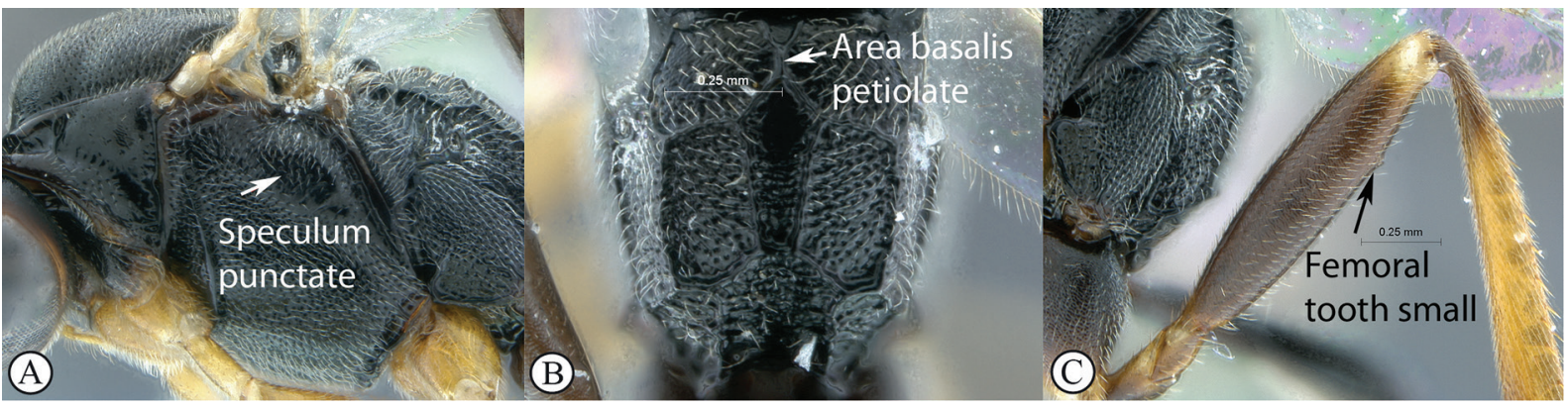

14. Speculum entirely punctate (A); propodeum with area basalis strongly petiolate (B); female femoral tooth much shorter than basally wide $(\mathrm{FFT}=1)(\mathrm{C})$; antenna with less than 32 flagellomeres

P. mbama sp. nov.

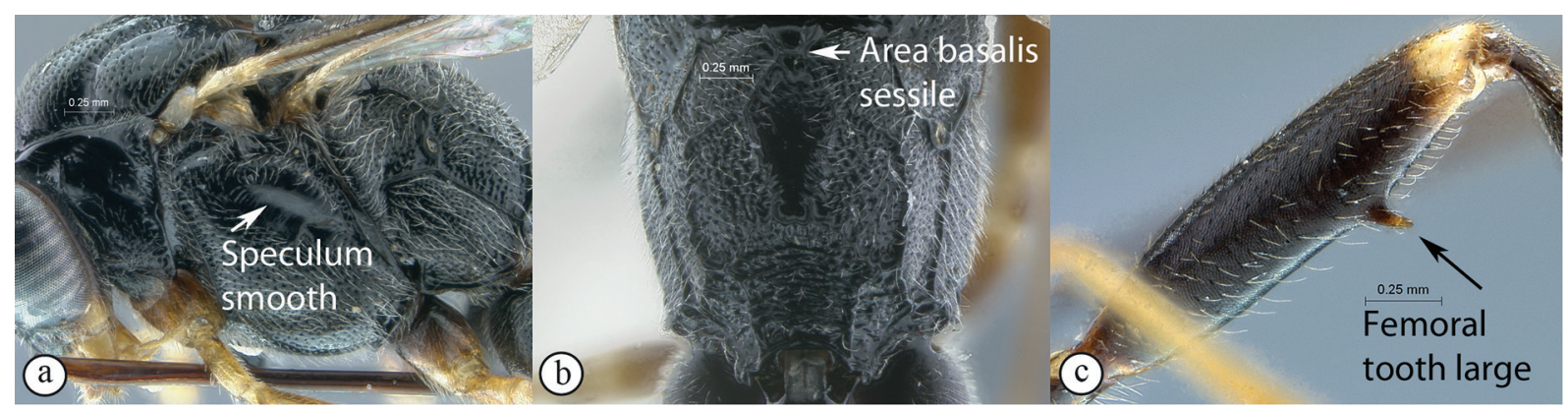

- Speculum distinctly smoother ventrally (a); propodeum with area basalis widely sessile (b); female femoral tooth much longer than basally wide $(\mathrm{FFT}=2)(\mathrm{c})$; antenna with more than 32 flagellomeres 15

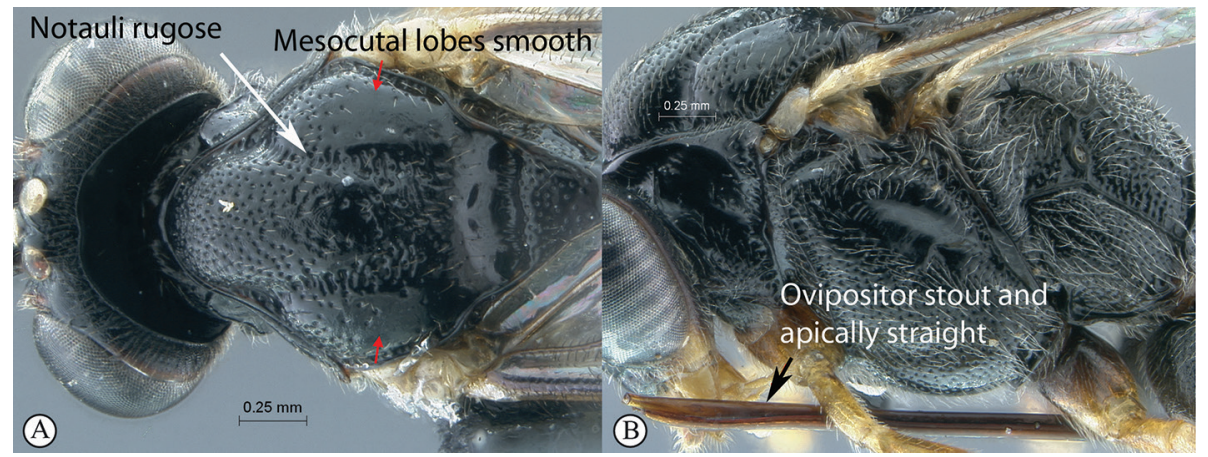

15. Notauli coarsely rugose and lateral lobes of mesoscutum apically nearly smooth (A); ovipositor stout and apically straight (B).....

P. nzakara sp. nov.

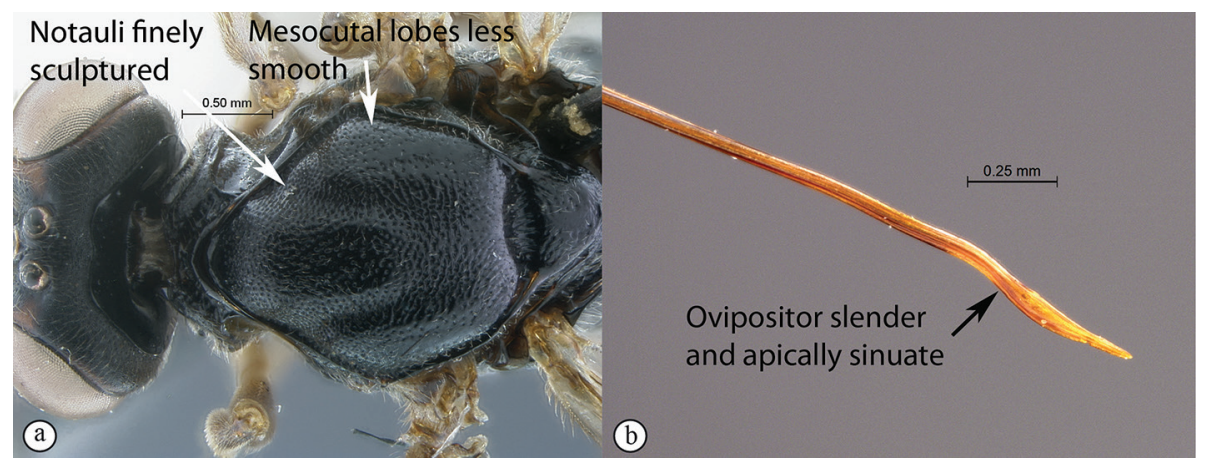

- Notauli more finely sculptured and lateral lobes of mesoscutum apically more uniformly punctate (a); ovipositor slender and apically sinuous (b). .P. dikidiki sp. nov. 

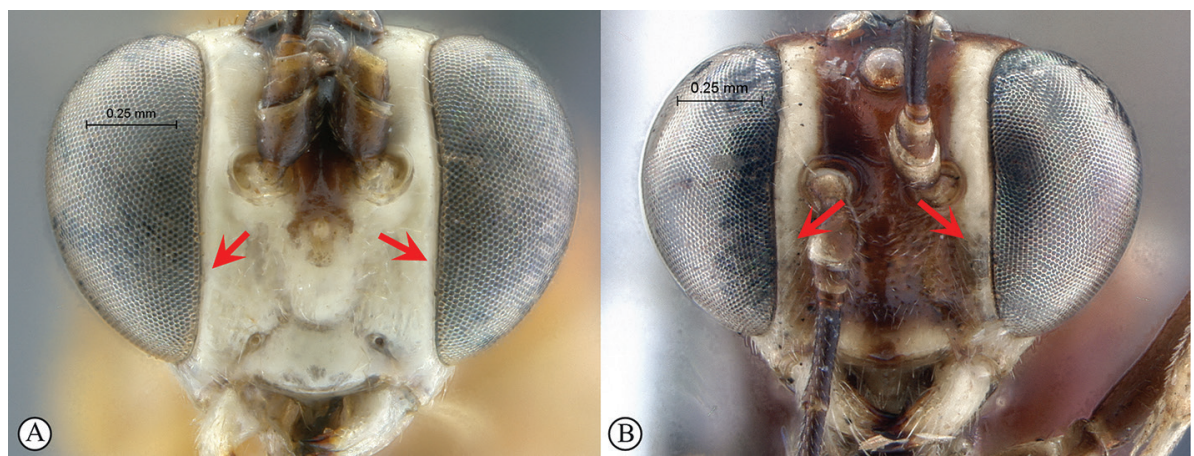

16. Facial orbits, and most often entire face, whitish (A, B); Madagascar and Southern Africa

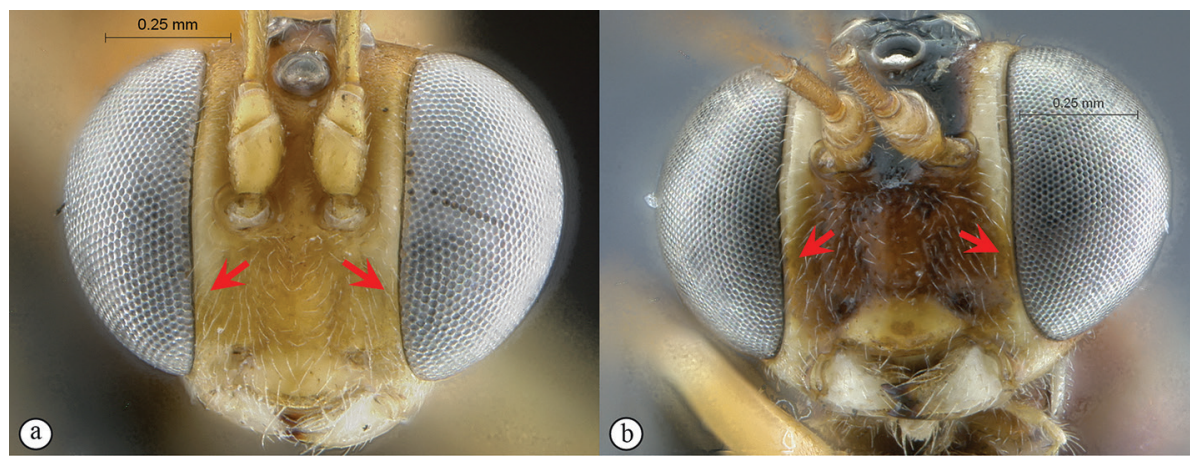

- Facial orbits, and most often entire face, yellow to testaceous orange $(a, b)$

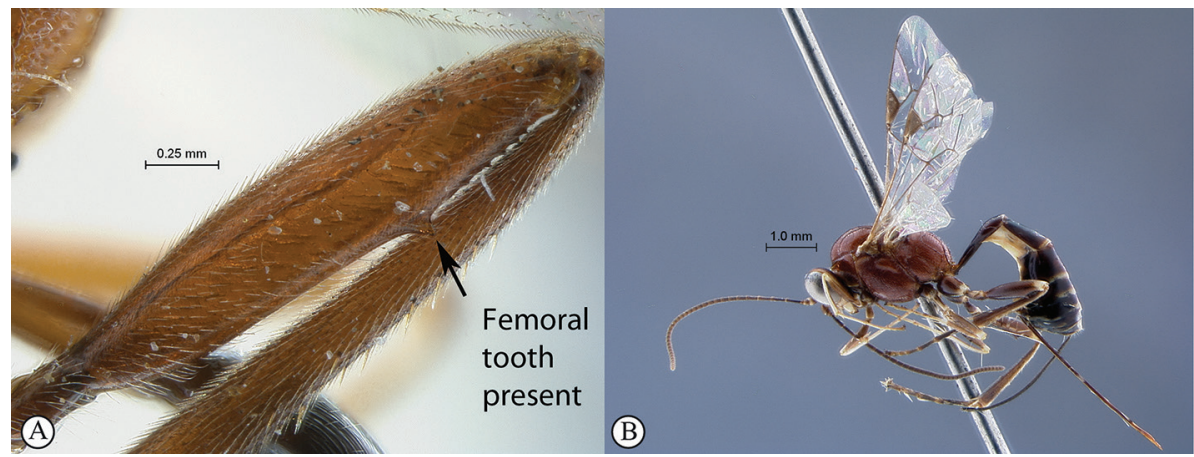

17. Female femoral tooth present $($ FFT $>0)(A)$; metasoma mostly black with apical margins of most tergites white (B); Madagascar and South Africa

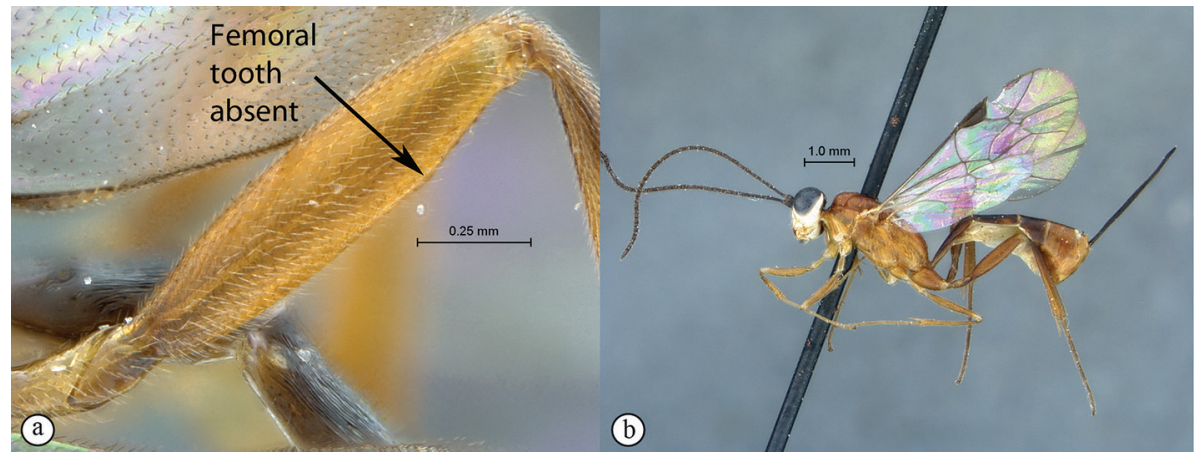

- Female femoral tooth totally absent $(\mathrm{FFT}=0)(\mathrm{a})$; metasoma differently coloured, mostly orange with sometimes infuscate markings (b); Madagascar..... 


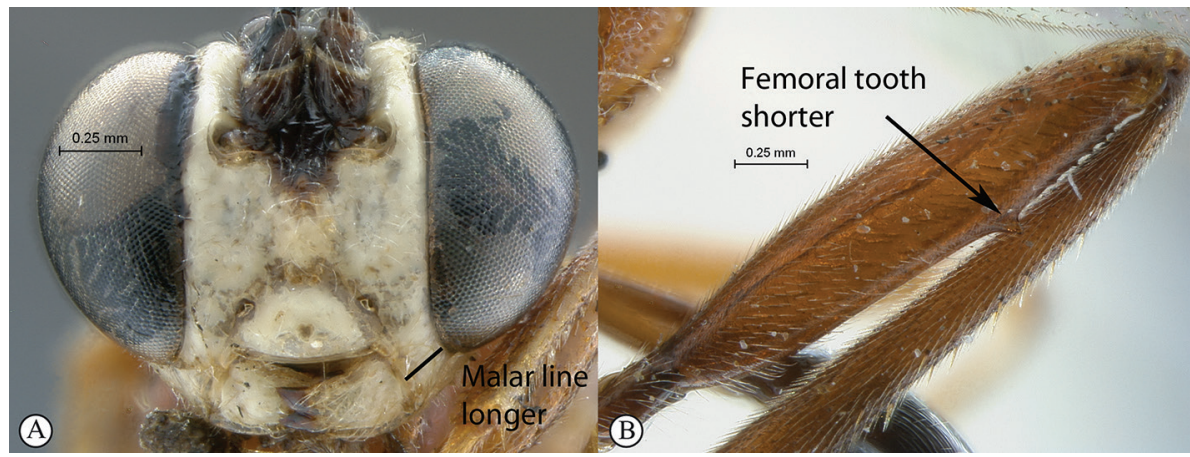

18. Face entirely whitish, malar line moderately long $(\mathrm{ML}>0.5)(\mathrm{A})$; hind femur uniformly orange, female femoral tooth nearly as long as basally wide (FFT $=1-2)(B)$; Madagascar

P. guinness Rousse, Villemant \& Seyrig, 2013

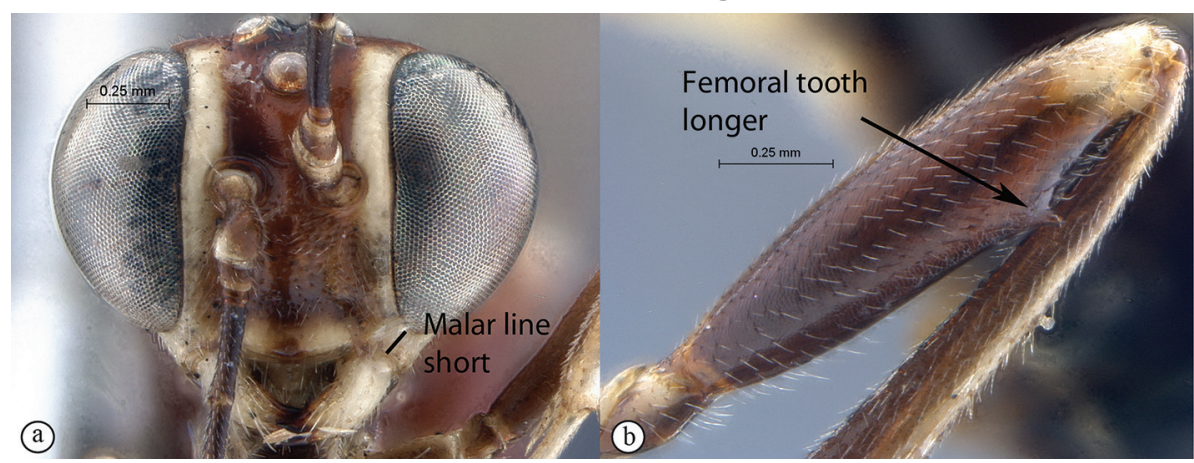

- Face medially testaceous, malar line short $(\mathrm{ML}<0.5)(\mathrm{a})$; hind femur testaceous, apically pale, female femoral tooth distinctly longer than basally wide $(\mathrm{FFT}=2)(\mathrm{b})$; South Africa

P. zulu sp. nov.

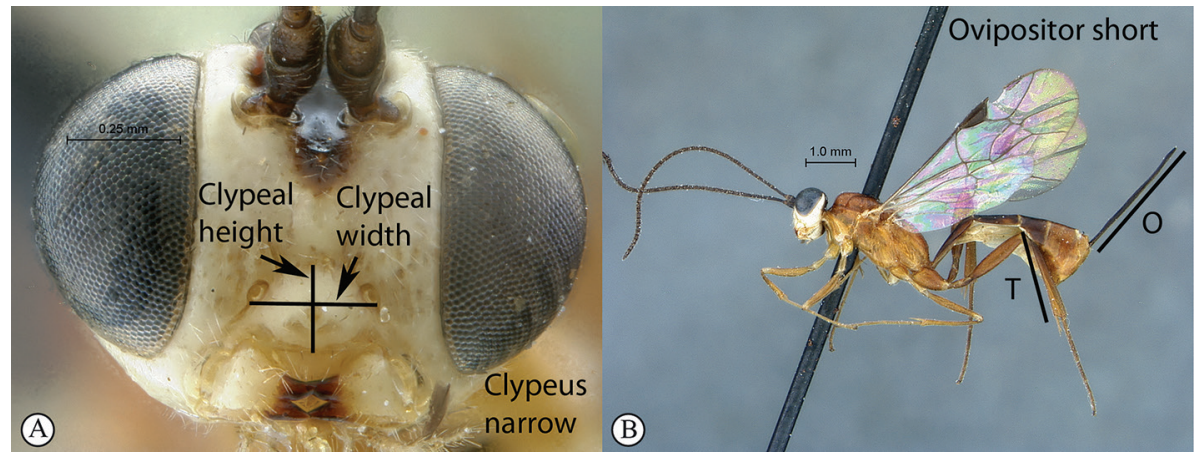

19. Clypeus narrow $(\mathrm{CT}<1.7)(\mathrm{A})$; ovipositor short $(\mathrm{OT}<1.5)(\mathrm{B})$.

P. vahaza Rousse, Villemant \& Seyrig, 2013

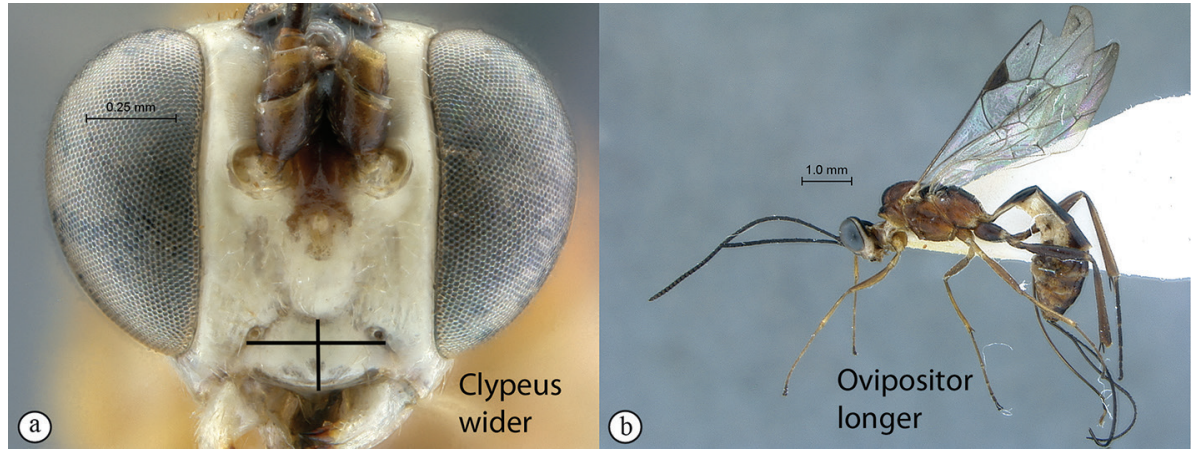

- Clypeus wider $(\mathrm{CT}>1.7)(\mathrm{a})$; ovipositor longer $(\mathrm{OT}>1.5)(\mathrm{b})$ 


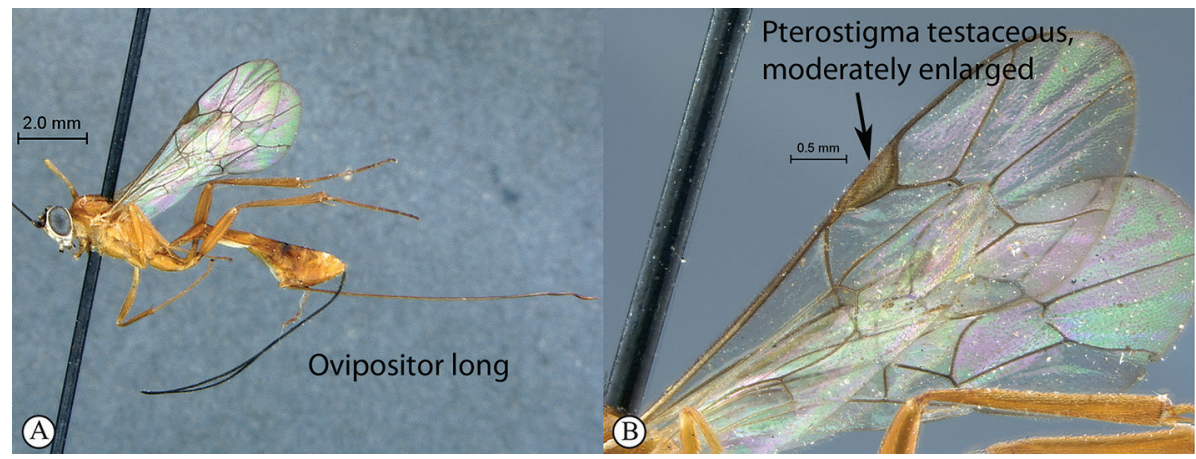

20. Ovipositor very long $(\mathrm{OT}>2.5)(\mathrm{A})$; pterostigma light testaceous, moderately enlarged (B).

.. P. hansoni Rousse, Villemant \& Seyrig, 2013

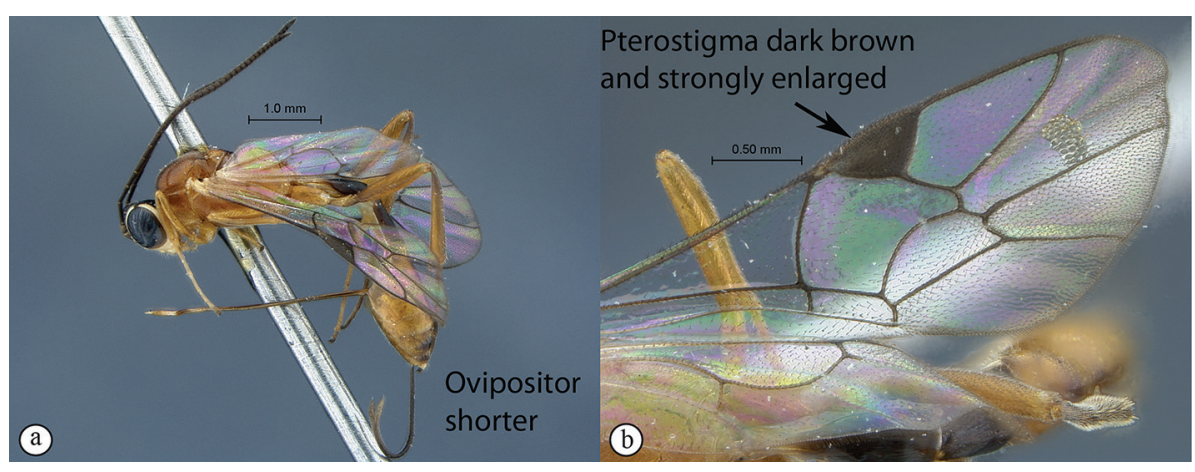

- Ovipositor shorter (OT < 2.5) (a); pterostigma dark brown and strongly enlarged (b) .
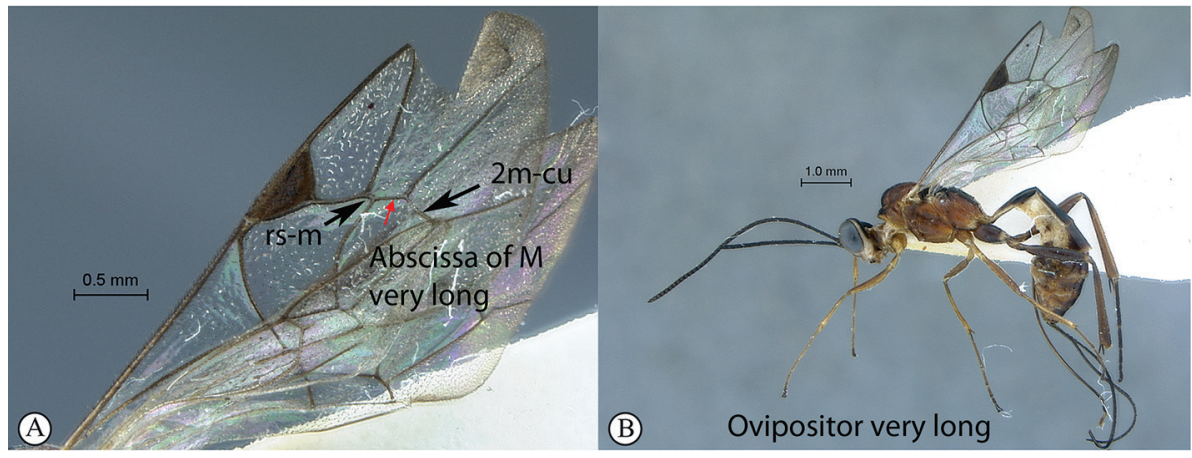

21. Fore wing with abscissa of $M$ between rs-m and $2 \mathrm{~m}$-cu very long, far longer than rs- $\mathrm{m}$ (A); ovipositor very long $(\mathrm{OT}>2.0)(\mathrm{B})$

P. ranomafana Rousse, Villemant \& Seyrig, 2013

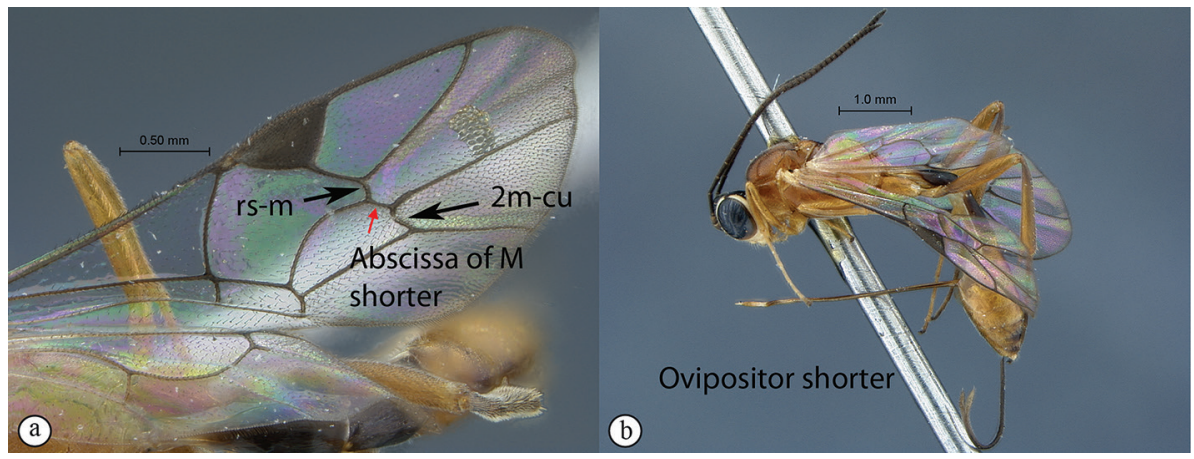

- Fore wing with abscissa of M between rs-m and 2m-cu shorter, about as long as rs-m (a); ovipositor shorter, moderately long $(\mathrm{OT}<2.0)$ (b) P. caris Fitton, 1994 


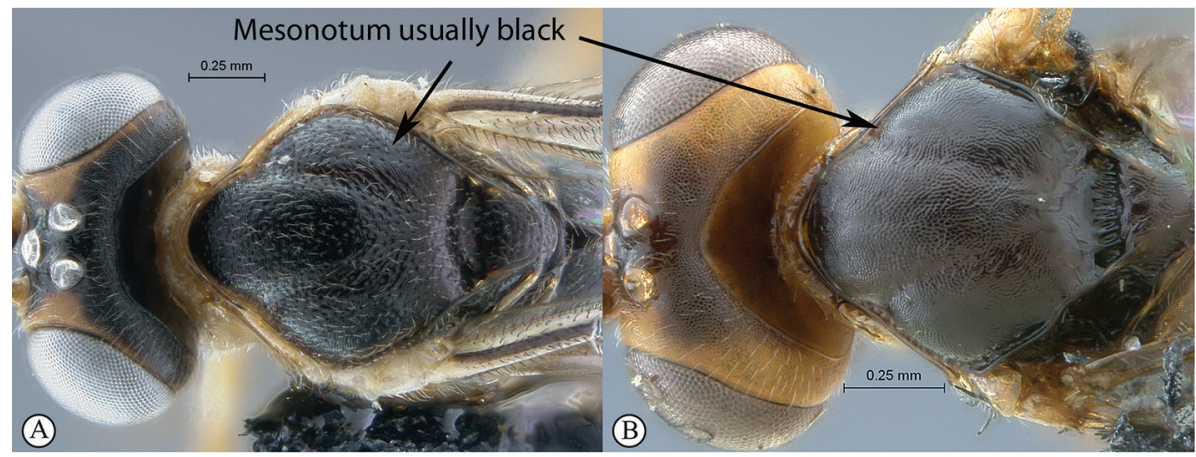

22. Mesonotum usually entirely black (A, B), sometimes mesoscutum partially lighter with scutellum totally black; female femoral tooth always distinct though sometimes reduced (FFT $>0$ ) . 23

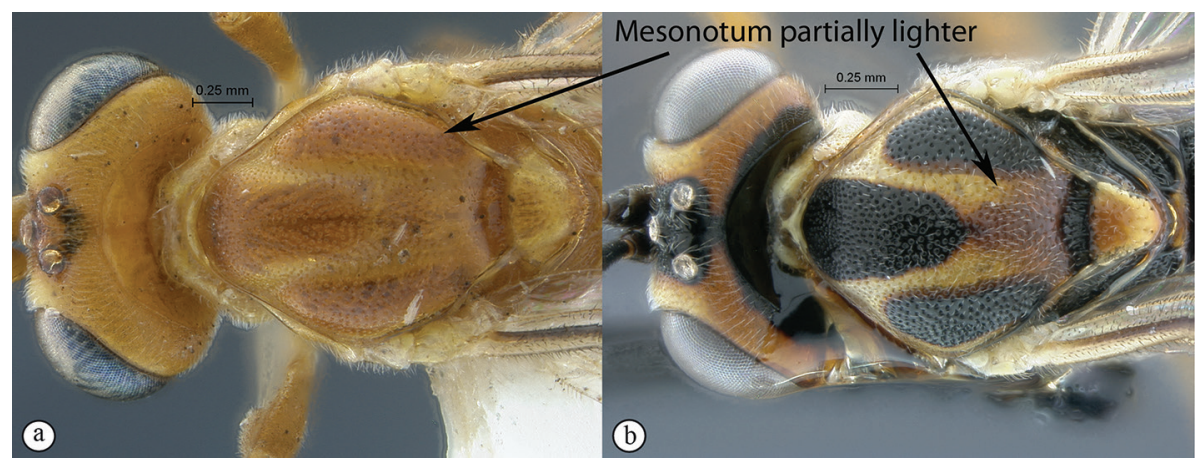

- Mesonotum nearly always distinctly lighter, yellowish orange to partially testaceous (a, b); female femoral tooth variable; if, rarely, mesoscutum almost entirely dark testaceous (some P. moramora), then female femoral tooth absent $(\mathrm{FFT}=0)$. 24

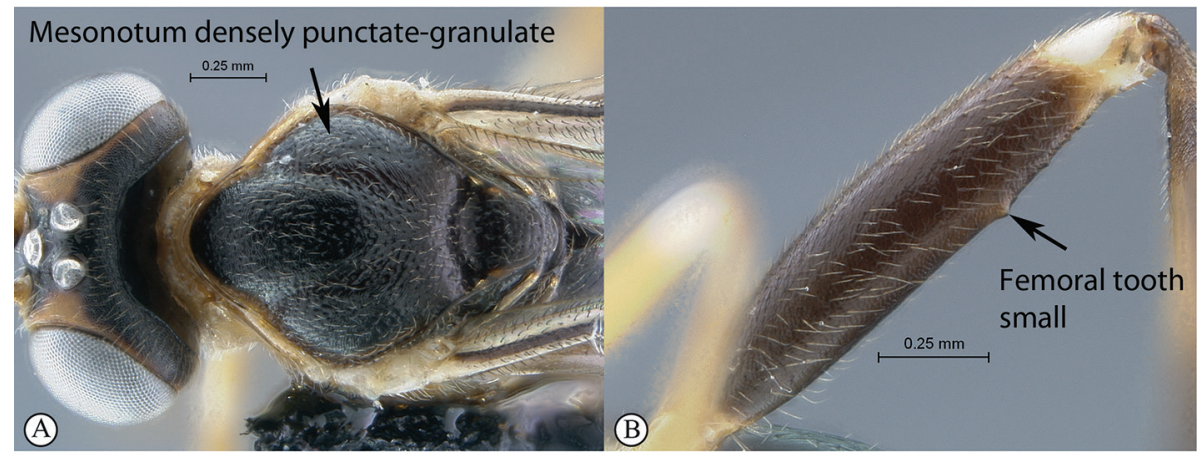

23. Mesonotum densely punctate-granulate, punctures somewhat confluent along notaulus line (A); femoral tooth weak (B); tropical central Africa. P. hutu sp. nov.

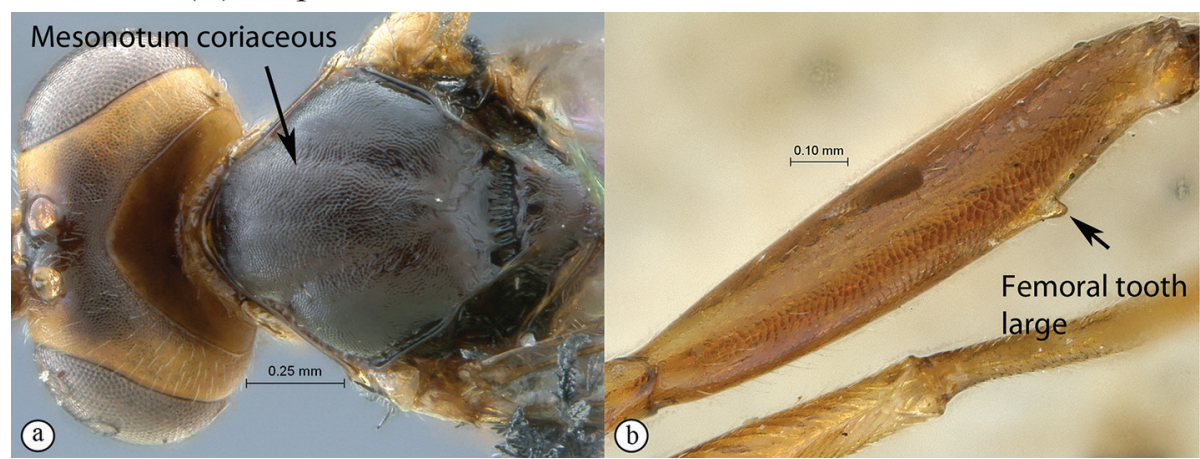

- Mesonotum coriaceous, without punctures (a); femoral tooth strong (b); Seychelles P. ruficaput (Morley, 1912) 


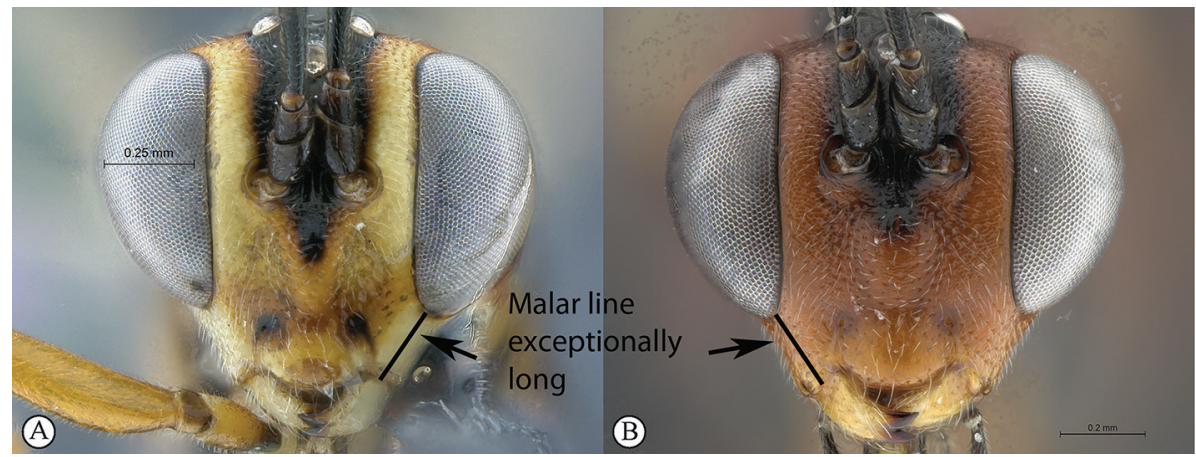

24. Malar line exceptionally long, longer than mandible base (ML > 1) (A, B); South Africa

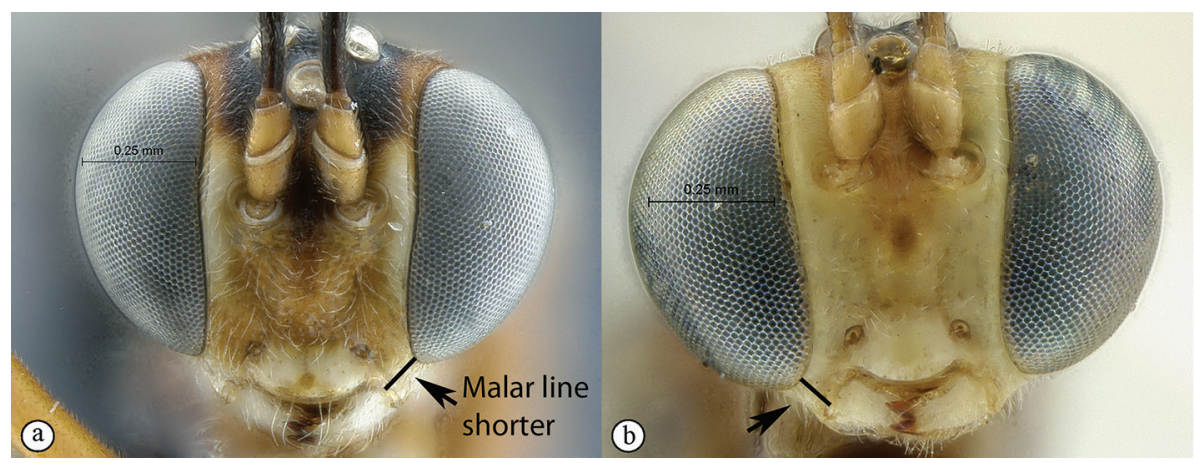

- Malar line shorter, usually much shorter than mandible base $(\mathrm{ML}<1)(\mathrm{a}, \mathrm{b})$

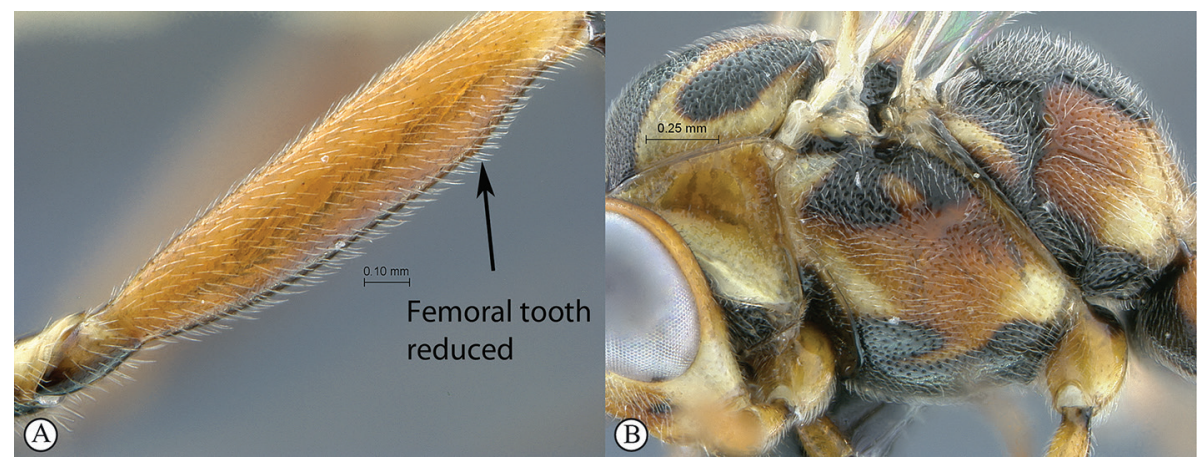

25. Femoral tooth reduced to a subapical point, followed by minute denticles (A); mesosoma mottled black, orange and pale yellow (B)

P. $x$ hosa sp. nov.

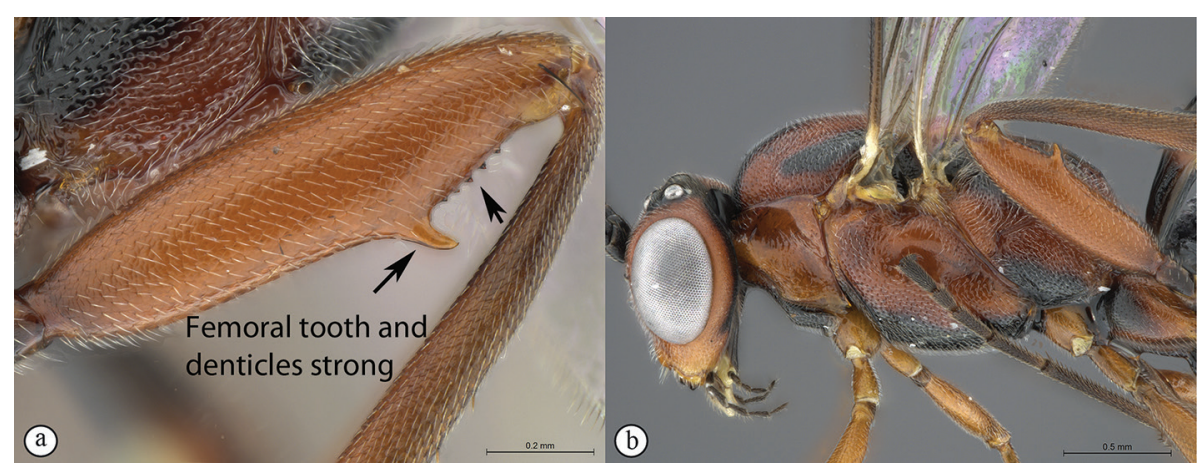

- Femoral tooth strong, followed by 5 strong denticles (a); mesosoma reddish-orange with black markings (b). P. kagga sp. nov. 

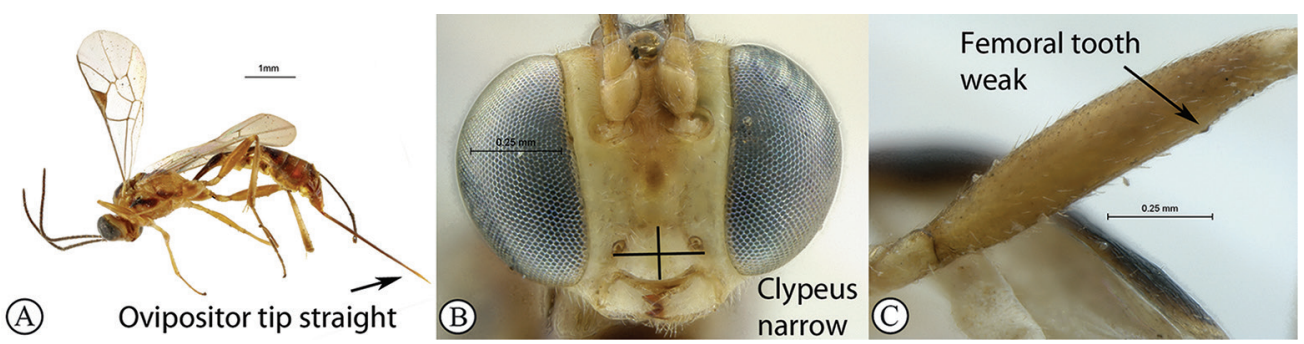

26. Ovipositor tip straight $(\mathrm{A})$; clypeus unusually narrow and long $(\mathrm{CT}=1.5)$ with eyes slightly converging ventrally (B); small (F $\leq 3.5)$; female femoral tooth present but often hardly distinct (C); Madagascar, Eastern and Southern Africa

.P. albescens (Morley, 1917)

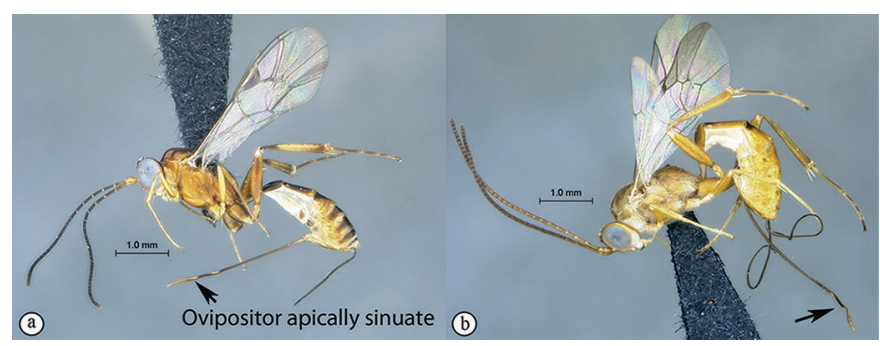

- Ovipositor most often at least slightly sinuous apically $(a, b)$; if, rarely, ovipositor tip barely sinuous, then not fully agreeing with the above combination

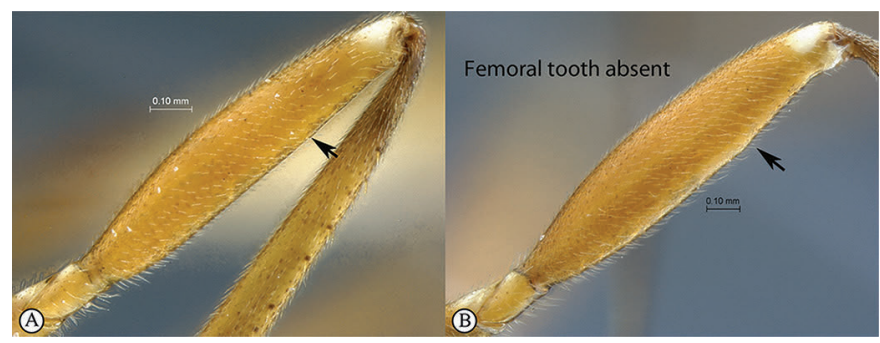

27. Female femoral tooth totally absent, not even distinct as a subapical protuberance, and never with following denticles $(\mathrm{FFT}=0)(\mathrm{A}, \mathrm{B})$.

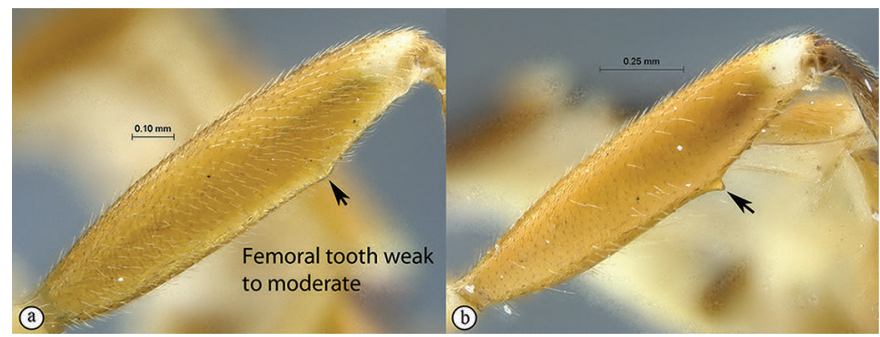

- Female femoral tooth weak to moderate, at least distinct as a subapical ventral protuberance (a) and distinctly shorter than basally wide, sometimes followed by secondary denticles $(\mathrm{FFT}=1)$ (b) ... 34

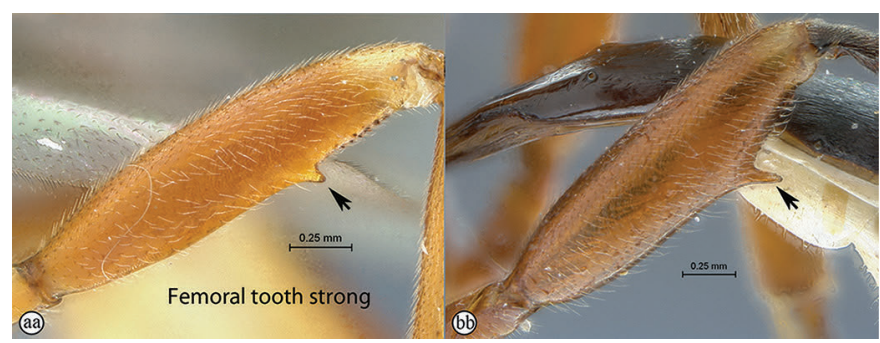

- Female femoral tooth strong, about as high as wide (aa) to strongly higher than basally wide (bb), always followed by secondary denticles $(\mathrm{FFT}=2)$. 


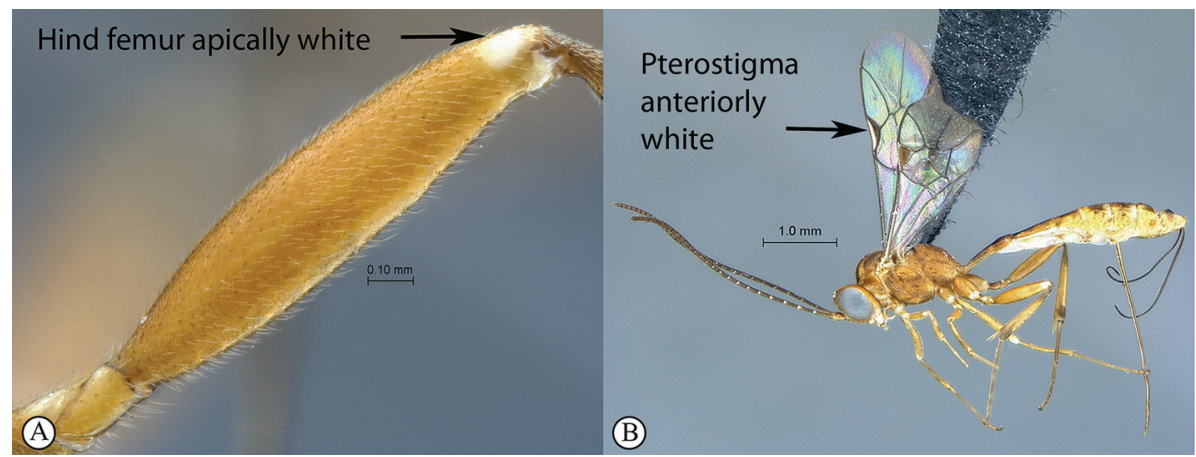

28. Hind femur, and often other femora, with an obvious apical white patch (A); anterior margin of pterostigma white (B); tropical mainland Africa

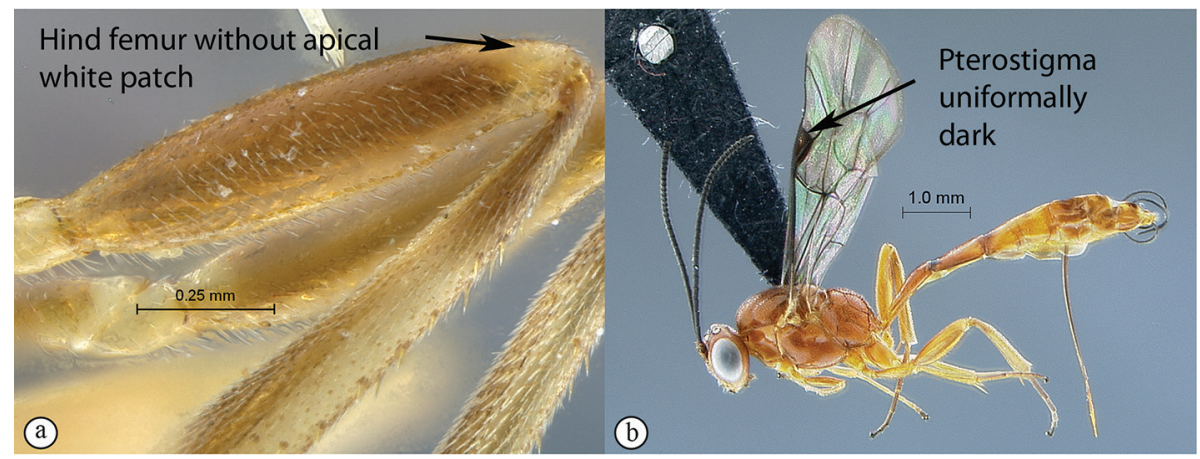

- Femora without distinct apical white patches, though often lighter apically (a); pterostigma uniformly dark (b); southern Africa and Madagascar.....

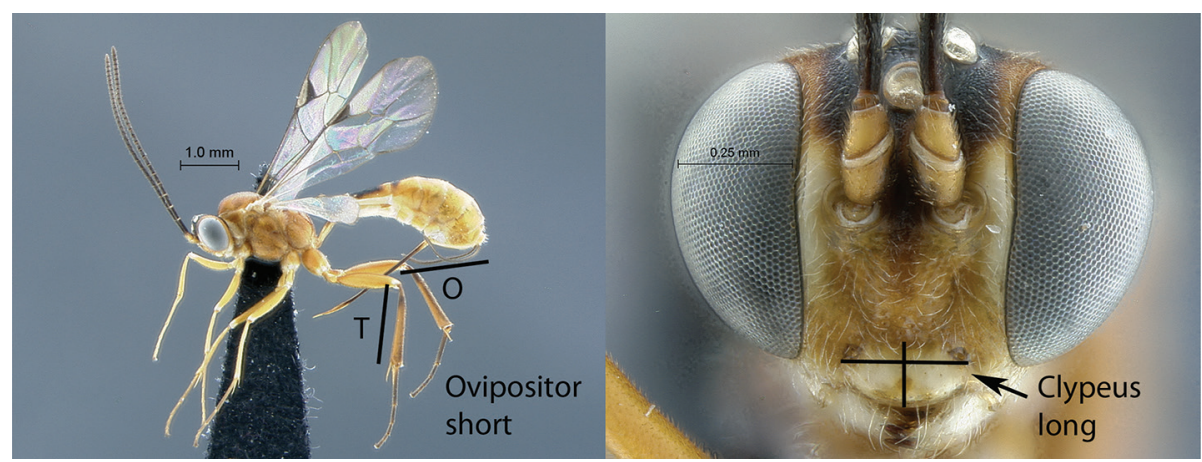

29. Ovipositor short $(\mathrm{OT}<1.4)$ and apically nearly straight $(\mathrm{A})$; clypeus long $(\mathrm{CT}<2)(\mathrm{B})$

..P. zande sp. nov.

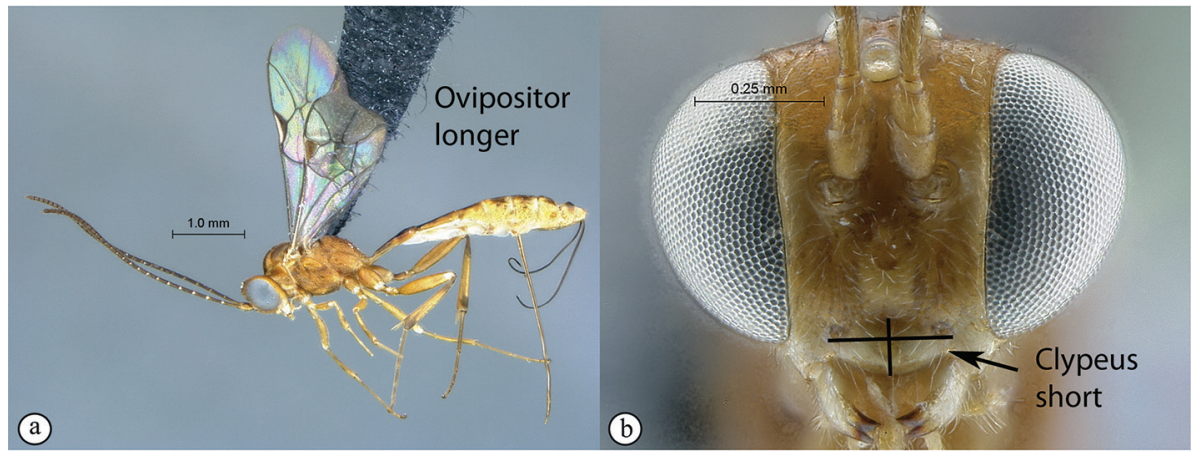

- Ovipositor moderately long (OT > 1.4), apically sinuous (a); clypeus shorter (CT > 2) (b)

P. sara sp. nov. 


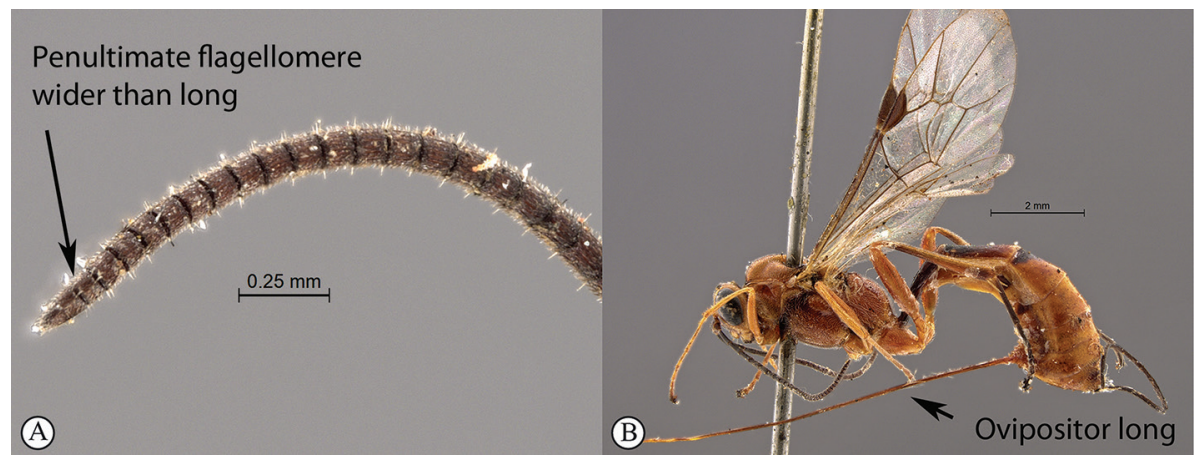

30. Penultimate flagellomere distinctly wider than long $\left(\mathrm{Fl}_{\mathrm{n}-1} \leq 0.9\right)(\mathrm{A})$; large $(\mathrm{F}>5 \mathrm{~mm})$; ovipositor very long $(\mathrm{OT}>2.0)(\mathrm{b})$; Namibia

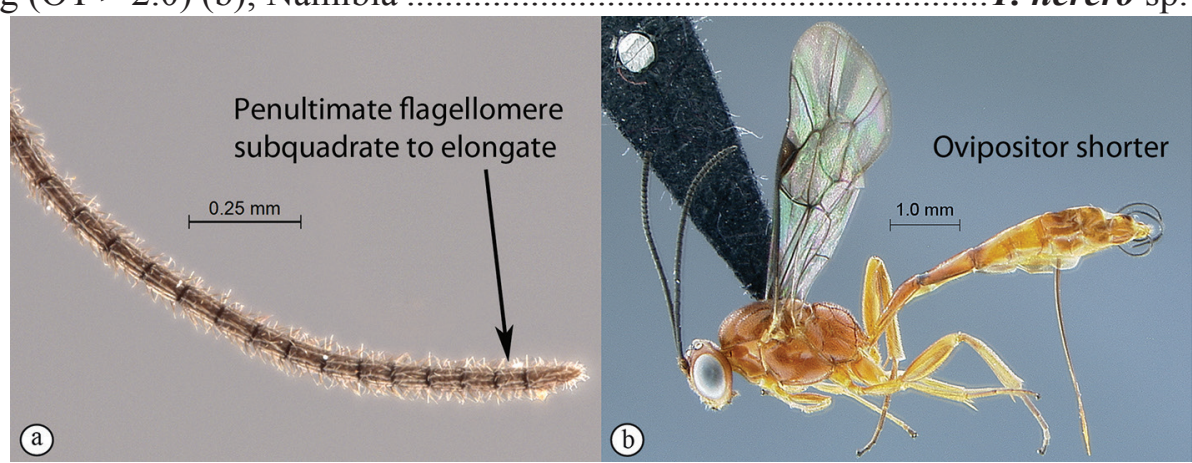

- Penultimate flagellomere subquadrate to distinctly elongate (a); distinctly smaller $(\mathrm{F}<5 \mathrm{~mm}$ ); ovipositor shorter $(\mathrm{OT}<2.0)(\mathrm{b})$.

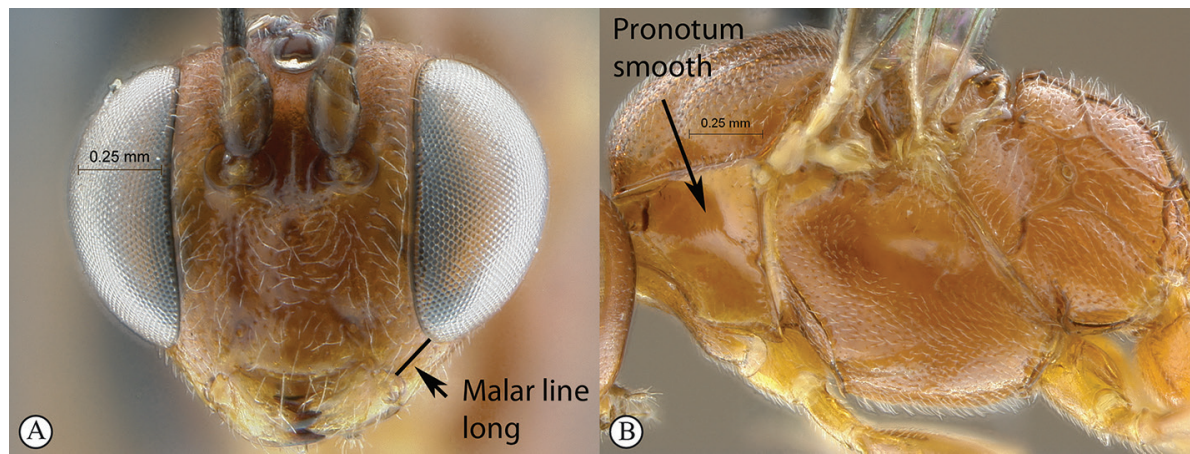

31. Malar line rather long $(M L>0.5)(A)$; pronotum almost entirely smooth with some punctures postero-dorsally (B); ovipositor moderately short $(\mathrm{OT}<1.6)$; entire body without obvious dark markings except sometimes some infuscate markings around scutellum and on basal tergites; Southern Africa

P. san sp. nov.

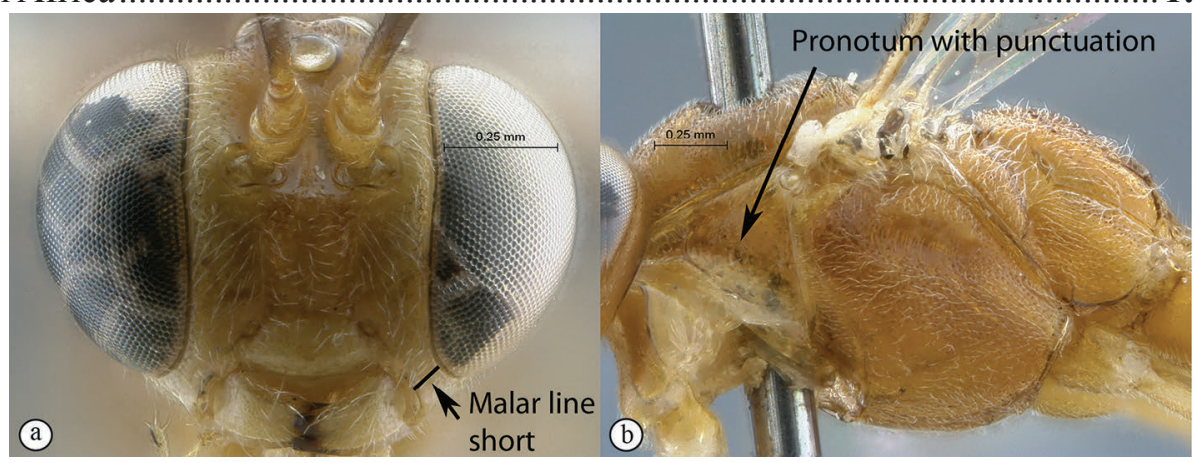

- Malar line short $(\mathrm{ML}<0.5)(\mathrm{a})$; pronotum more extensively punctate $(\mathrm{b})$; ovipositor usually longer $(\mathrm{OT}>1.5)$; colour various, often with large brown to black dorsal markings 


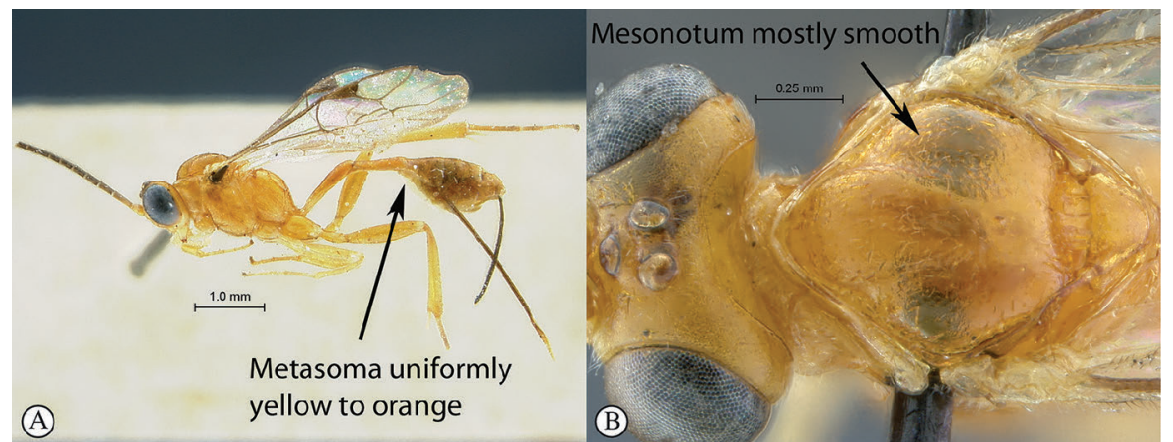

32. Metasoma uniformly yellow to orange (A); mesonotum almost smooth, only scutellum and apex of mesoscutum weakly punctate (B); antenna with more than 30 flagellomeres; Madagascar....

P. kelikely Rousse, Villemant \& Seyrig, 2013

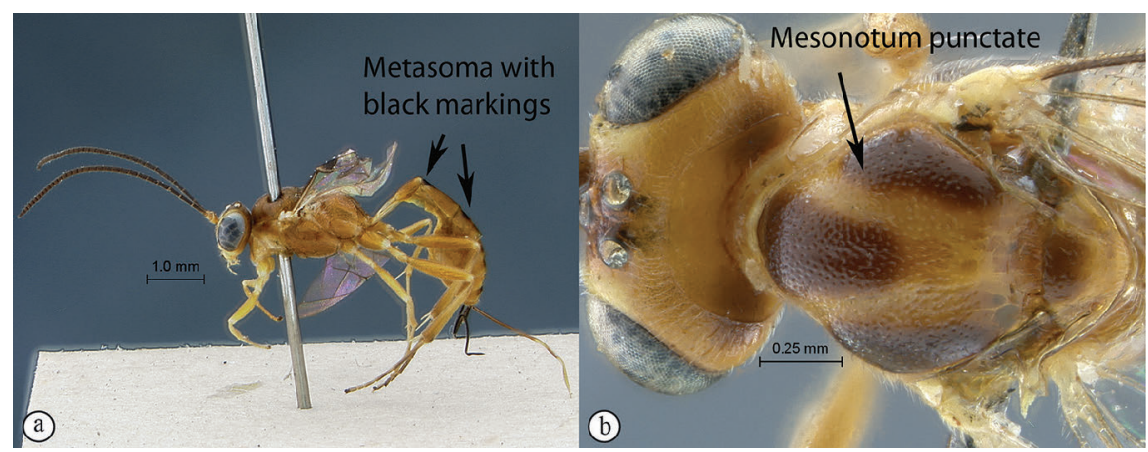

- Metasoma with at least basal tergites distinctly black maculated (a); entire mesonotum distinctly punctate (b); antenna with at most 30 flagellomeres

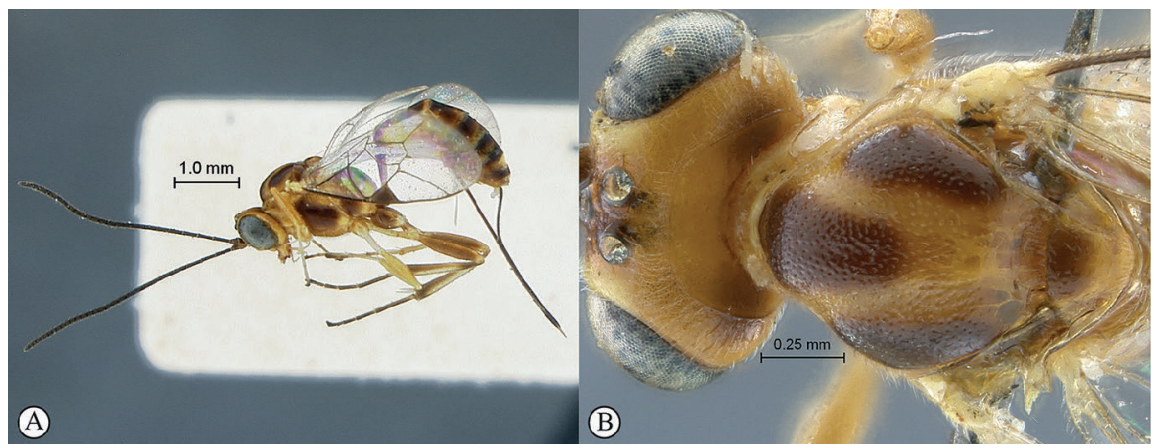

33. Dark markings of body strongly extended: all metasomal tergites largely black maculated (A), mesosoma with dark testaceous markings dorsally and laterally (A, B); Madagascar..

P. moramora Rousse, Villemant \& Seyrig, 2013

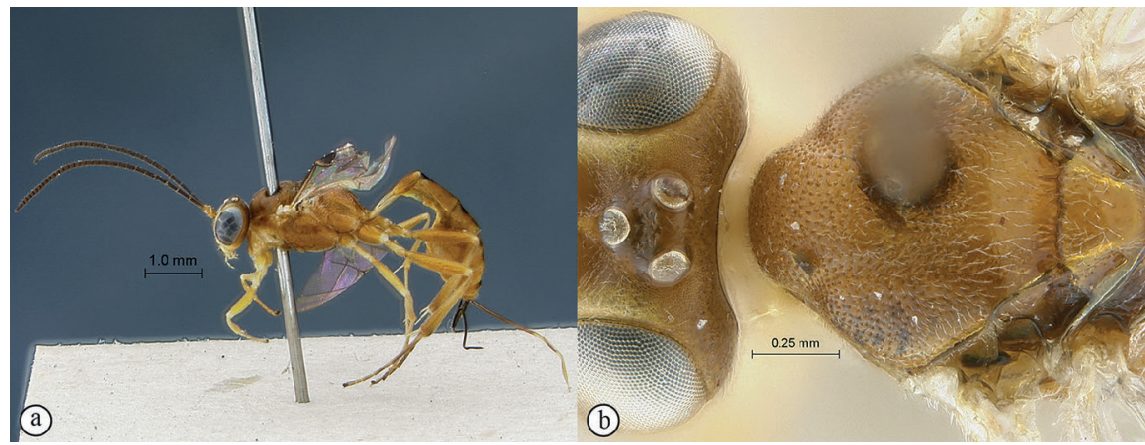

- Body lighter, with only basal tergites partially dark (a); mesosoma uniformly pale (a, b), but sometimes with infuscate markings around scutellum; Southern Africa. P. venda sp. nov. 


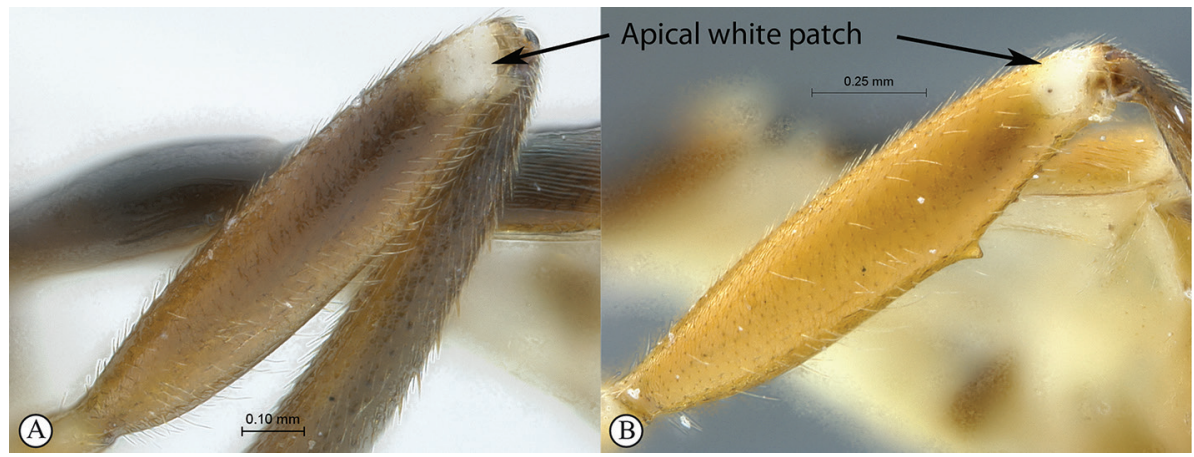

34. Hind femur, and often other femora, with an obvious apical white patch (A, B); tropical mainland Africa 35
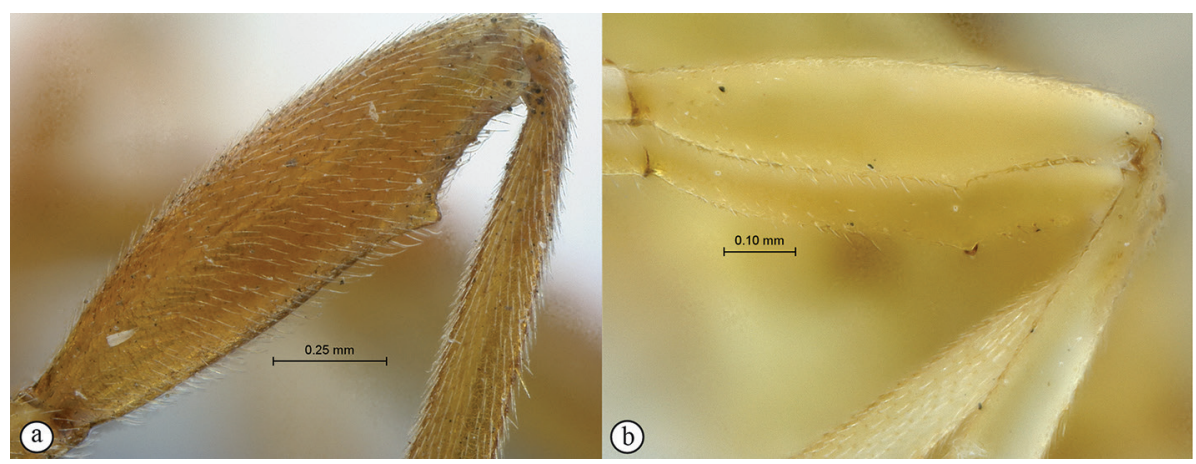

- Femora without distinct apical white patches, though often lighter apically $(\mathrm{a}, \mathrm{b})$

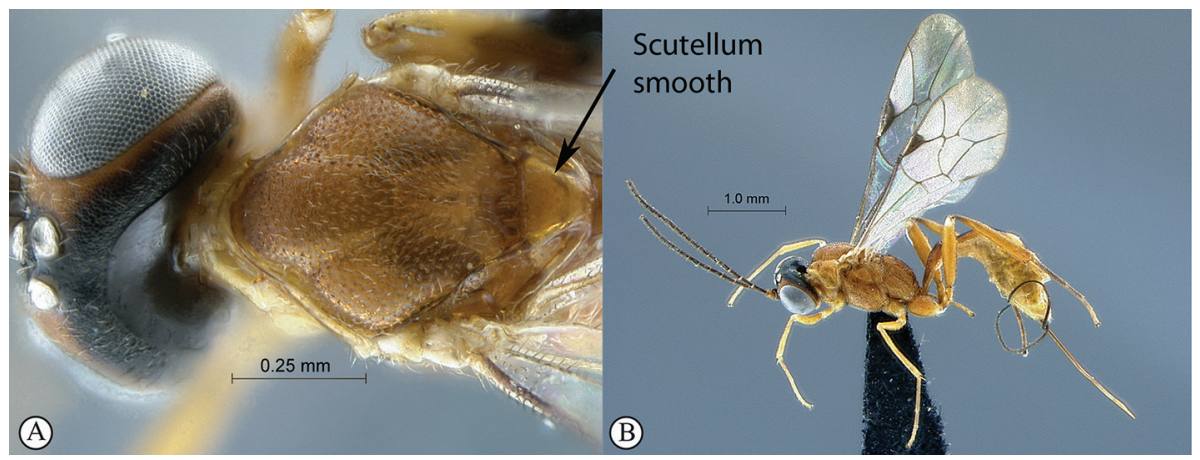

35. Scutellum smooth (A)

P. mboum sp. nov.

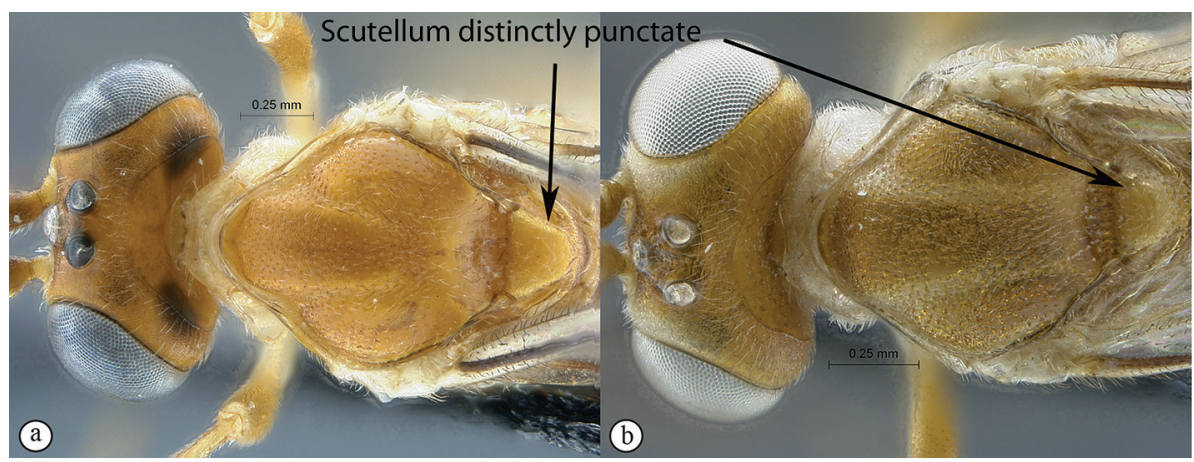

- Scutellum distinctly punctate $(a, b)$ 


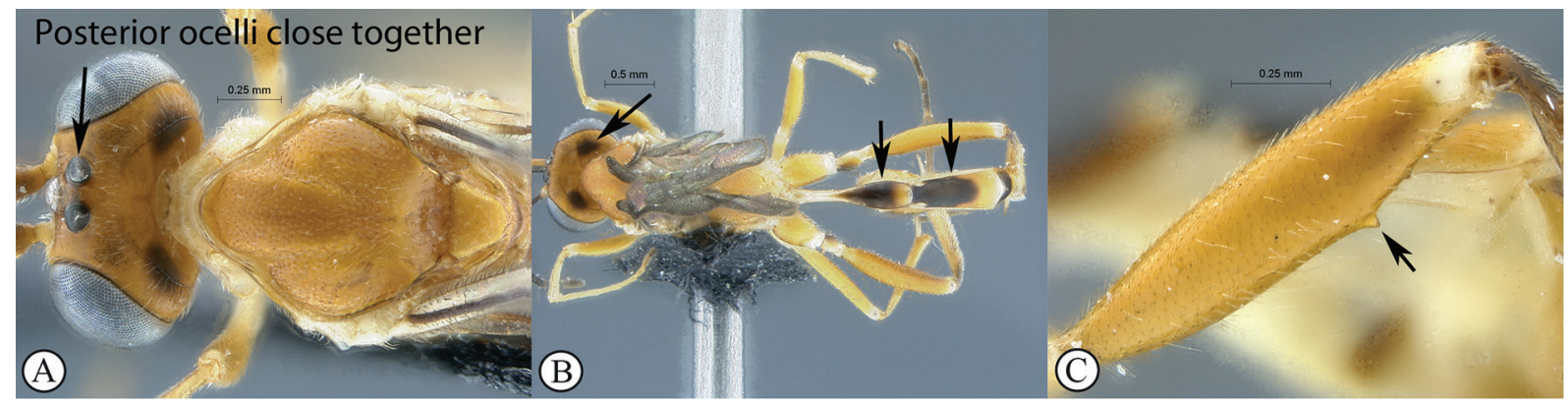

36. Ocelli enlarged, posterior ocelli close together $(\mathrm{POL}<0.8)(\mathrm{A})$; tergites $1-3$ at least half black, and occiput black-maculated in female (B); femoral tooth moderate (C); widespread in tropical Africa P. masai sp. nov.

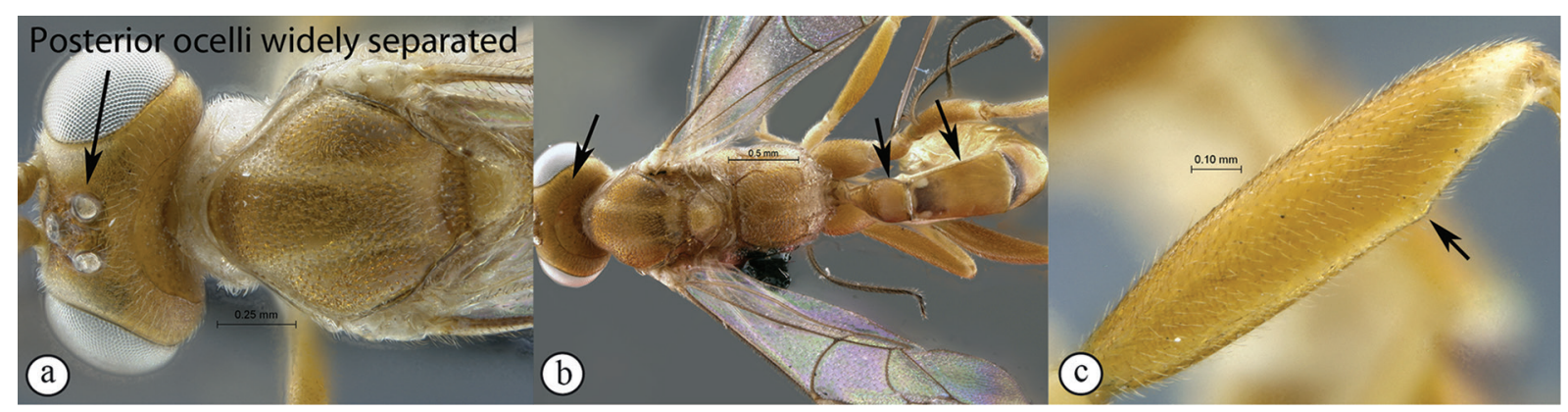

- Ocelli not enlarged, posterior ocelli more widely separated (POL $>0.8)$ (a); tergites $1-3$ mostly yellow, at most basally blackened, and occiput not black-maculated (b); femoral tooth strongly reduced (c); Western Africa

P. wolof sp. nov.

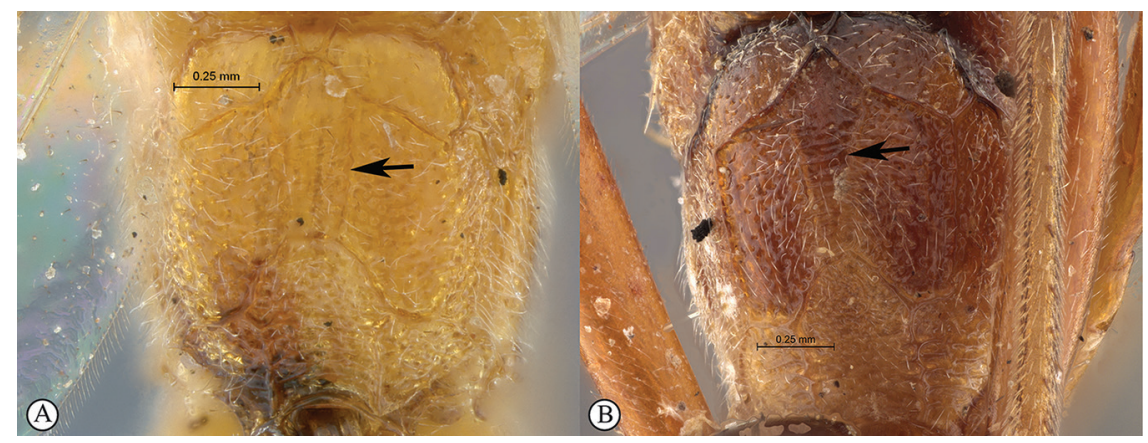

37. Area superomedia not defined postero-laterally (A, B); large wasps ( $\mathrm{F}>6 \mathrm{~mm})$; ovipositor long $(\mathrm{OT}>1.7)$ 38

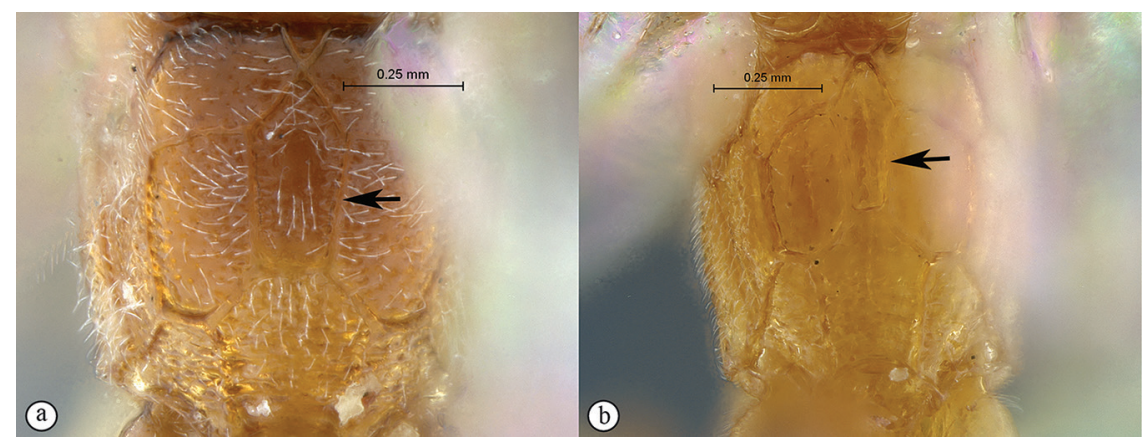

- Area superomedia most often fully delimited (a), though sometimes weakly so in P. keyka (b) but then specimens very small $(\mathrm{F}<4.5 \mathrm{~mm})$; otherwise small to moderately large wasps $(\mathrm{F}<5.5 \mathrm{~mm})$; ovipositor variable 


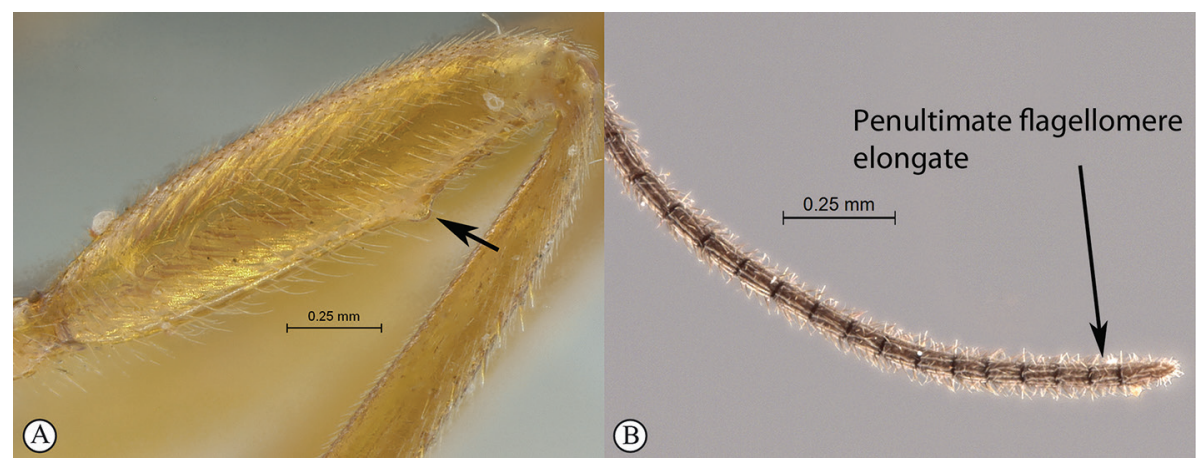

38. Female femoral tooth moderate in size (A); antenna with more than 35 flagellomeres, penultimate flagellomere elongate (B); Madagascar.....

P. patator Rousse, Villemant \& Seyrig, 2013

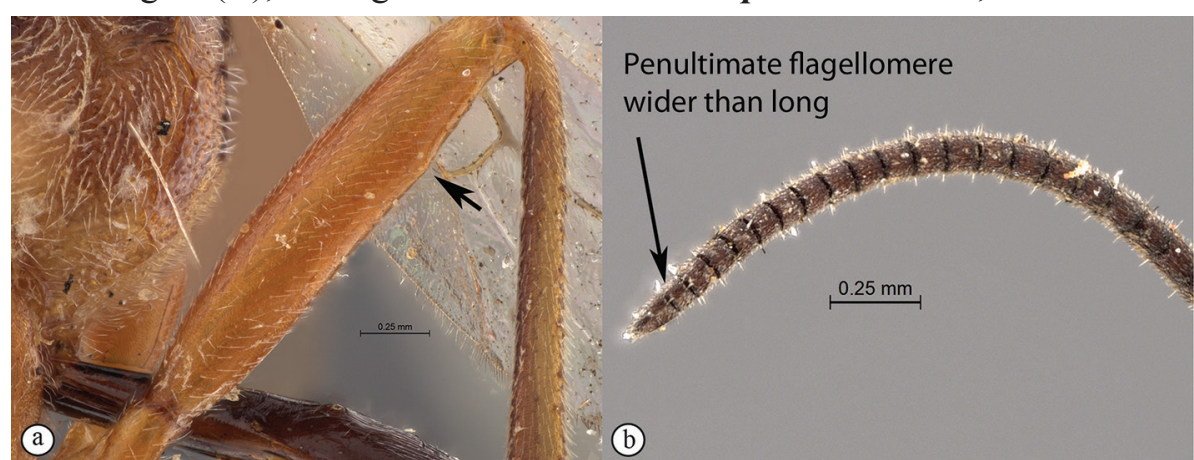

- Female femoral tooth reduced to a subapical protuberance followed by small denticles (a); antenna with fewer than 35 flagellomeres, penultimate flagellomere transverse (b); Namibia

... Perero sp. nov (in part)

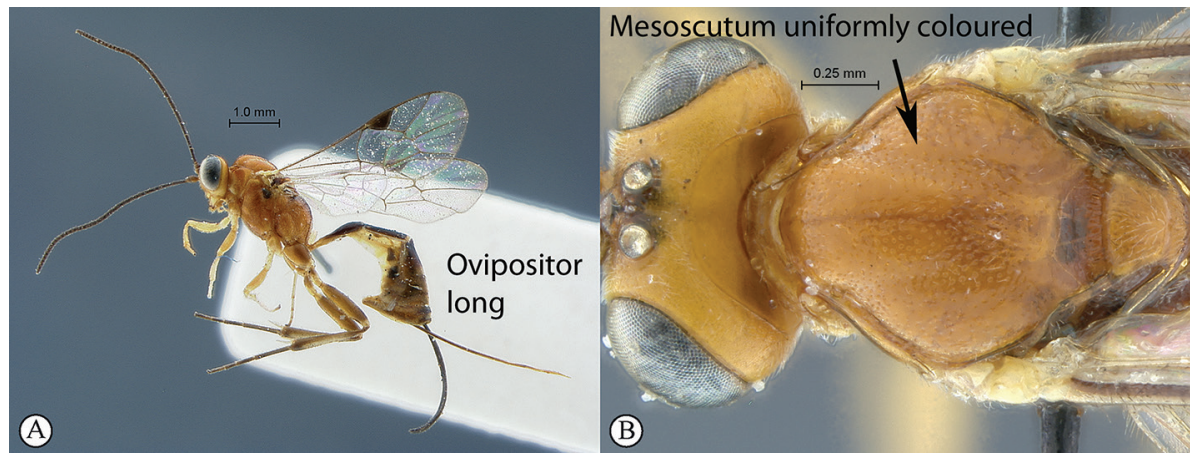

39. Ovipositor long $(\mathrm{OT}>1.7)(\mathrm{A})$; notauli concolourous with remainder of mesoscutum (B); Madagascar.

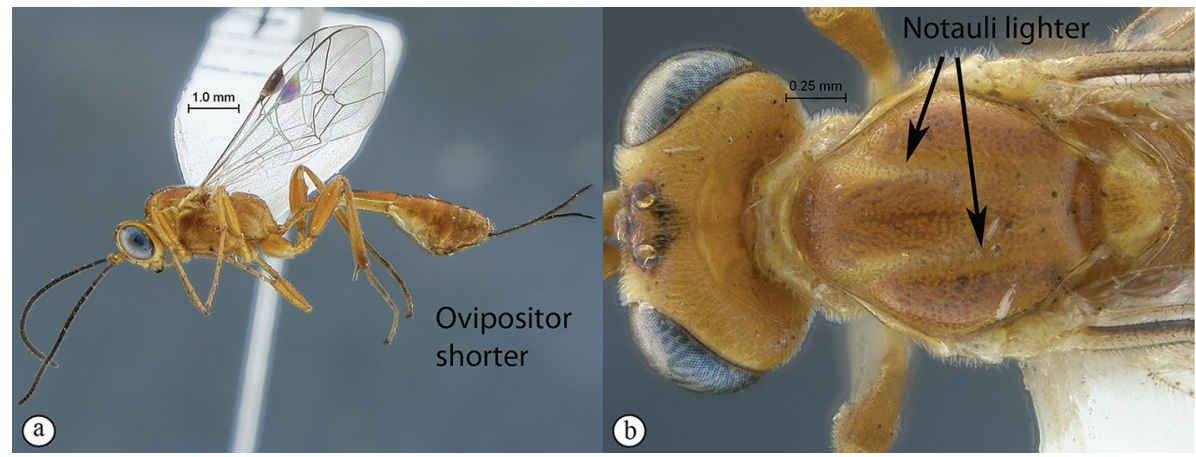

- Ovipositor shorter $(\mathrm{OT}<1.7)$ (a); notauli often distinctly lighter than remainder of mesoscutum (b) ....41 


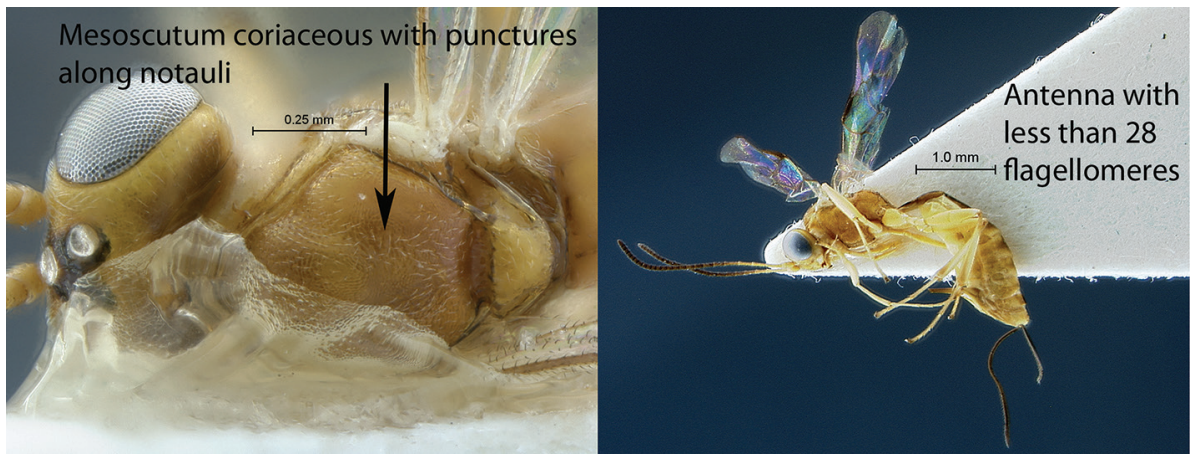

40. Mesoscutum coriaceous with punctures along notauli lines $(A)$; small species $(\mathrm{F}<3.2)(\mathrm{B})$; antenna with less than 28 flagellomeres (B) P. keyka Rousse, Villemant \& Seyrig, 2013

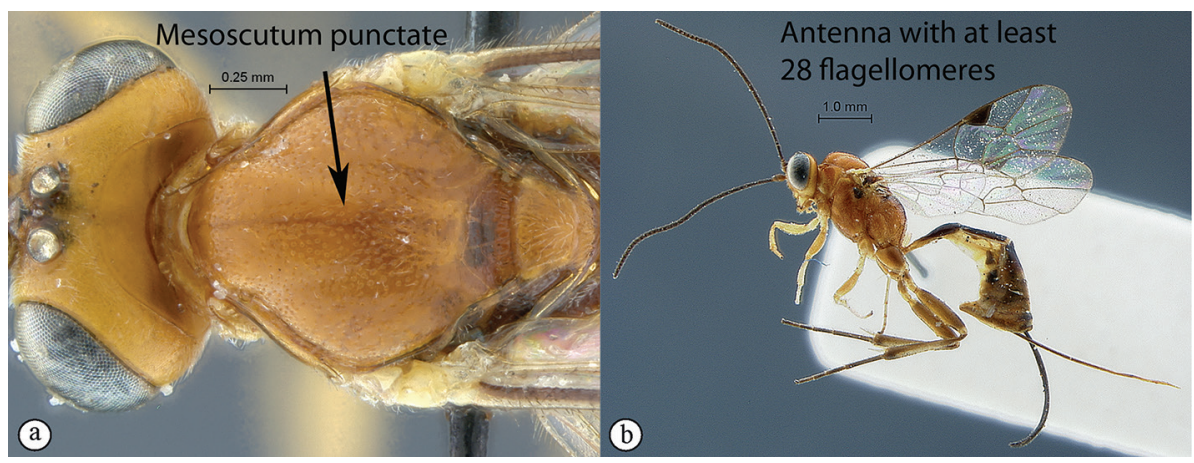

- Mesoscutum distinctly punctate (a) (coriaceous in male); larger species ( $\mathrm{F}>3.2)$ (b); antenna with at least 28 flagellomeres (b)...... P. roberti Rousse, Villemant \& Seyrig, 2013

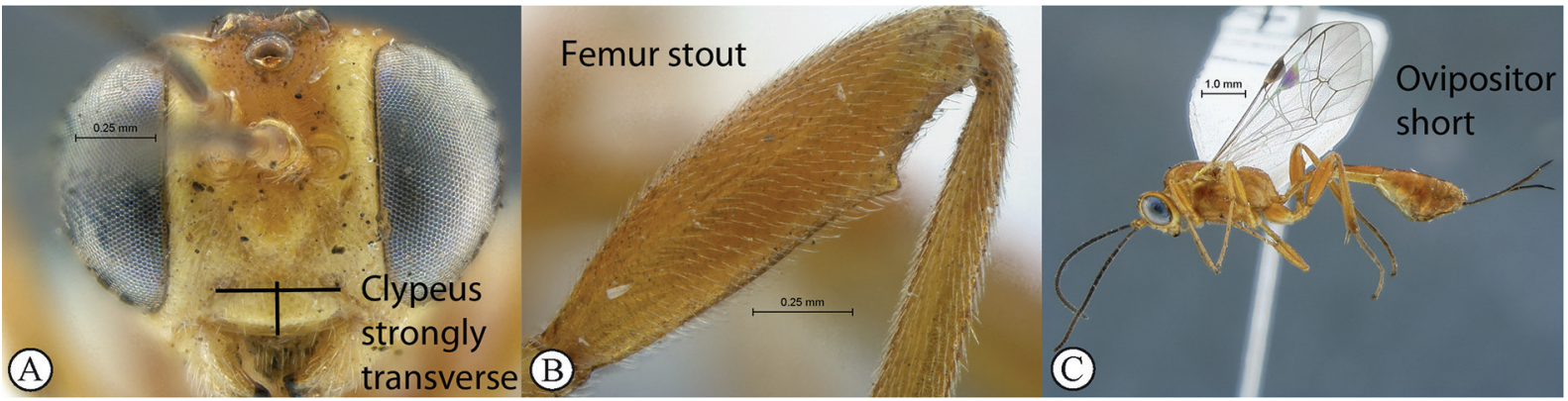

41. Clypeus strongly transverse ( $\mathrm{CT}>2.4)$ (A); female femur unusually stout (B); ovipositor short (OT $\leq 1.3)(\mathrm{C})$; body without dark markings $(\mathrm{C})$; Eastern Africa. P. bullis Fitton, 1994

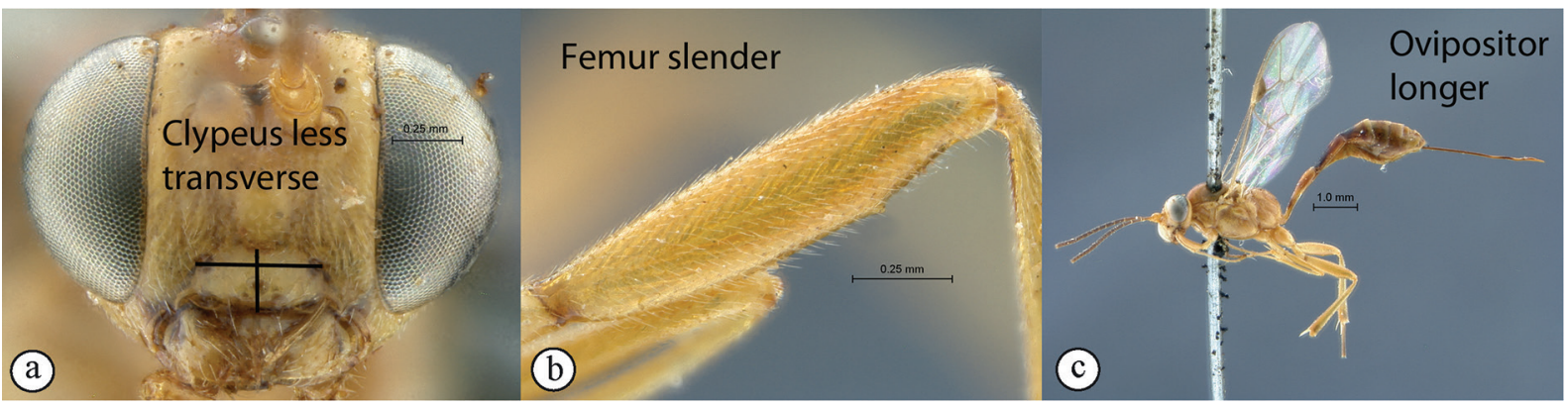

- Clypeus less transverse $(\mathrm{CT}<2.4)$ (a); female femur more slender (b); ovipositor longer $(\mathrm{OT} \geq 1.3)$ (c); body most often with dark dorsal markings (c)

P. pallidus Kriechbaumer, 1884 

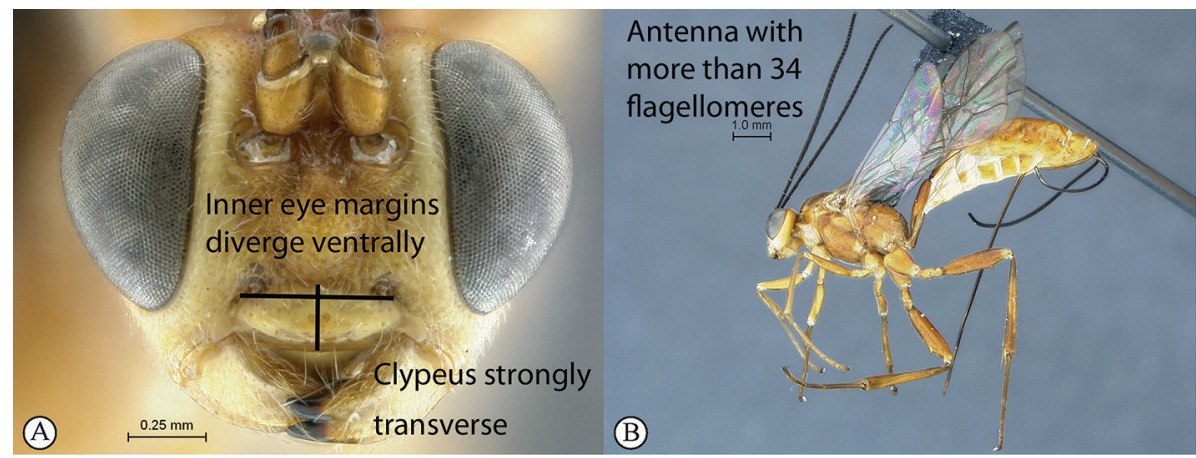

42. Clypeus strongly transverse (CT > 2.4) (A); inner margins of eyes distinctly diverging ventrally (A); antenna with more than 34 flagellomeres (B); Central Africa

P. babinga sp. nov.

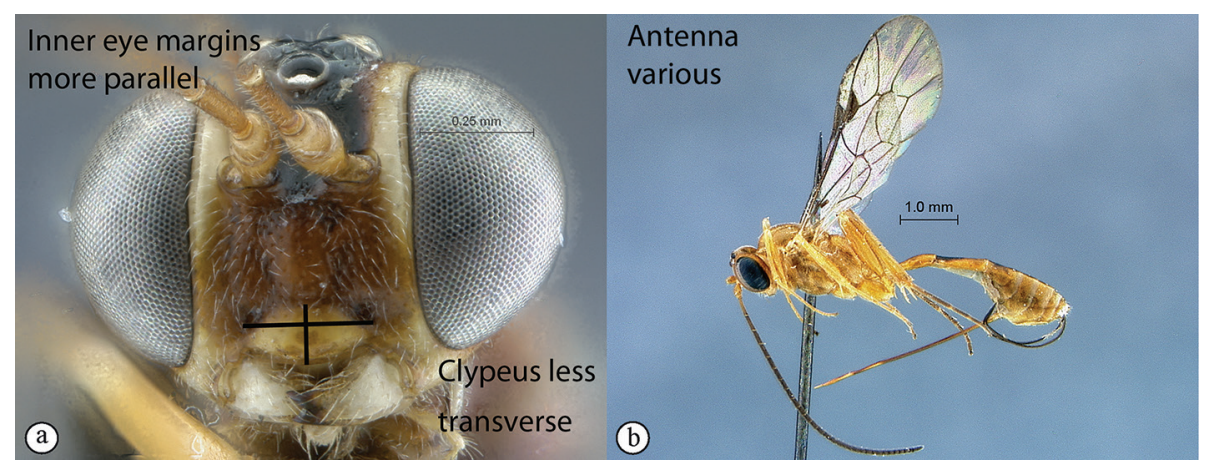

- Clypeus less transverse $(\mathrm{CT}<2.4)(\mathrm{a})$; inner margins of eyes at most slightly diverging ventrally (a); antenna various (b) 43

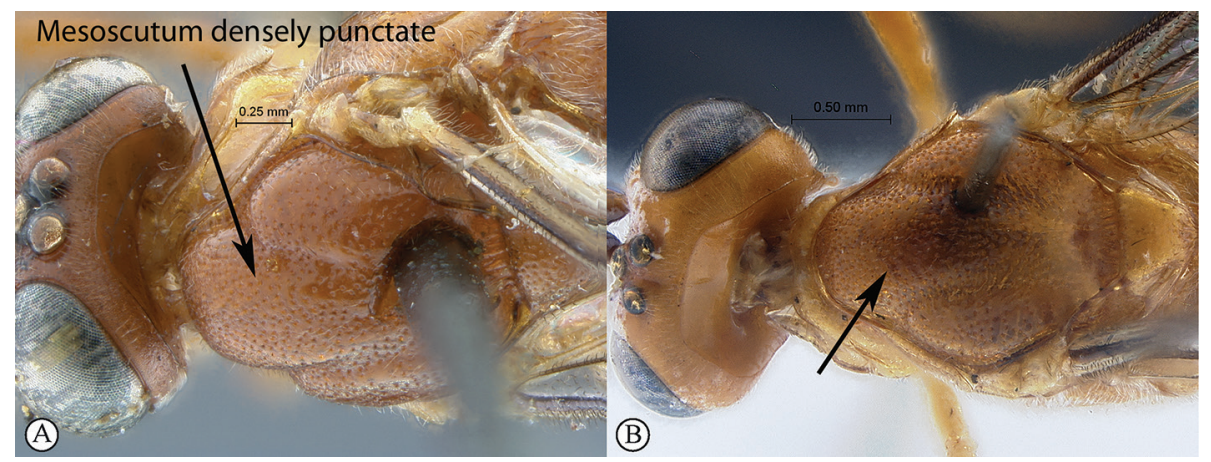

43. Mesoscutum, and often scutellum, densely punctate over entire surface (A, B)....

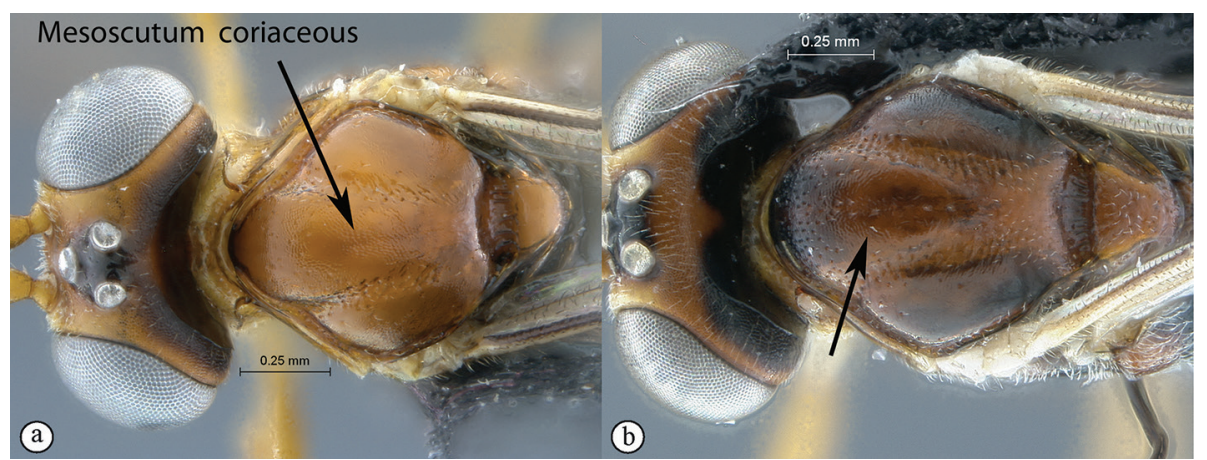

- Mesoscutum largely to entirely coriaceous, scutellum often quite smooth $(\mathrm{a}, \mathrm{b})$ 


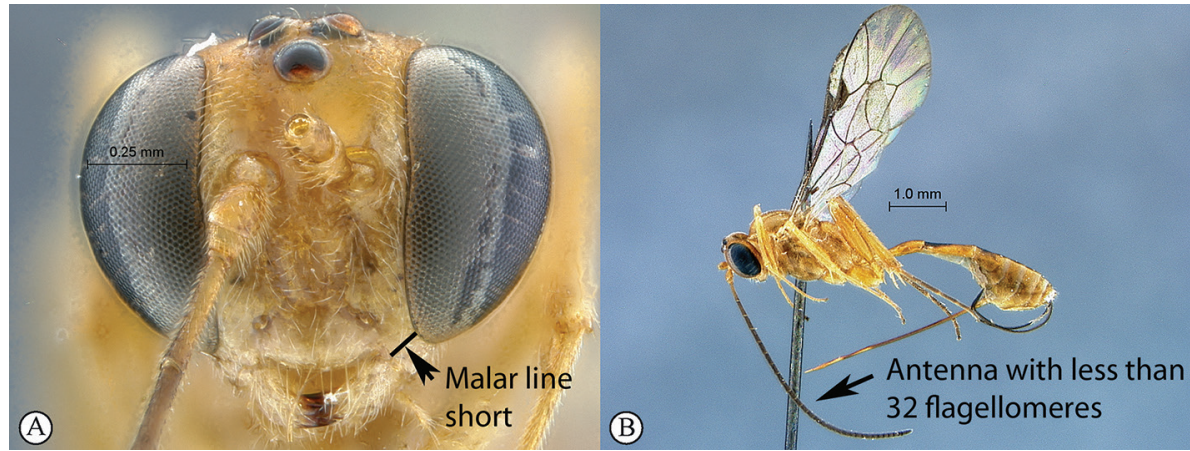

44. Malar line moderately short (ML < 0.6) (A); antenna with fewer than 32 flagellomeres (B); size moderate $(\mathrm{F}<5.0)(\mathrm{B})$; Western Africa .

P. yoccolo sp. nov.

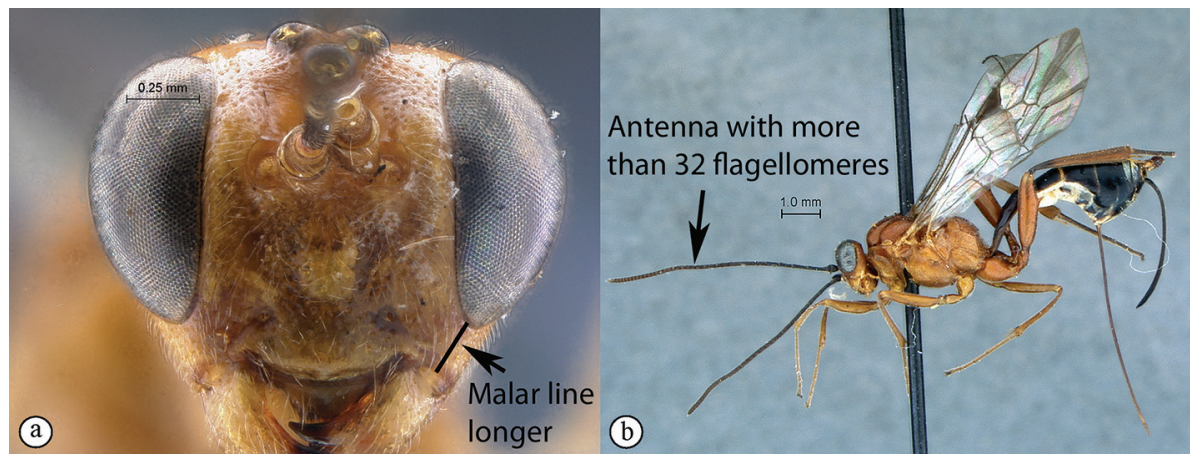

- Malar line moderately long (ML > 0.6) (a); antenna with more than 32 flagellomeres (b); large $(\mathrm{F}>5.0)(\mathrm{b})$; South Africa and Madagascar.....

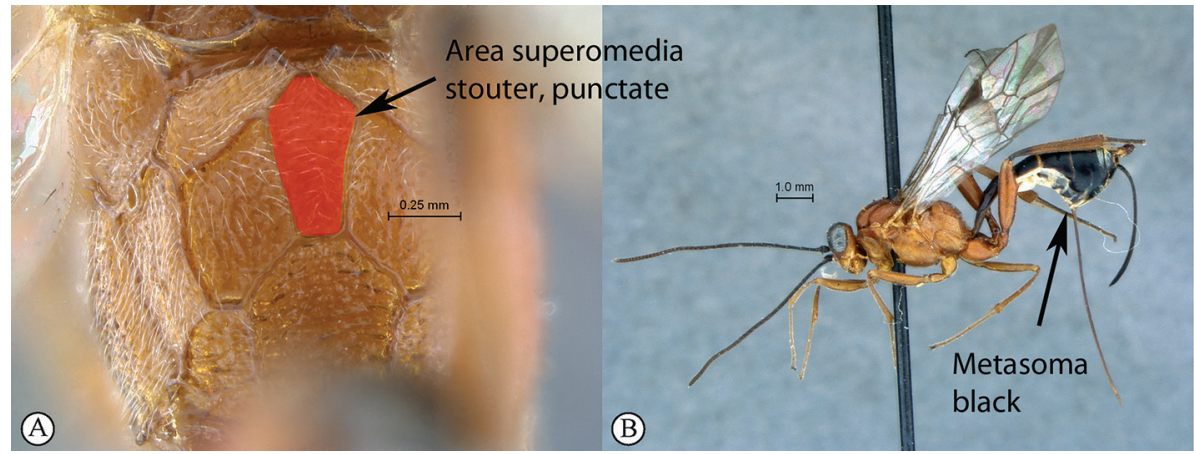

45. Area superomedia stouter (ASM < 1.8) and punctate (A); metasoma black (B); Madagascar ...........

P. veloma Rousse, Villemant \& Seyrig, 2013

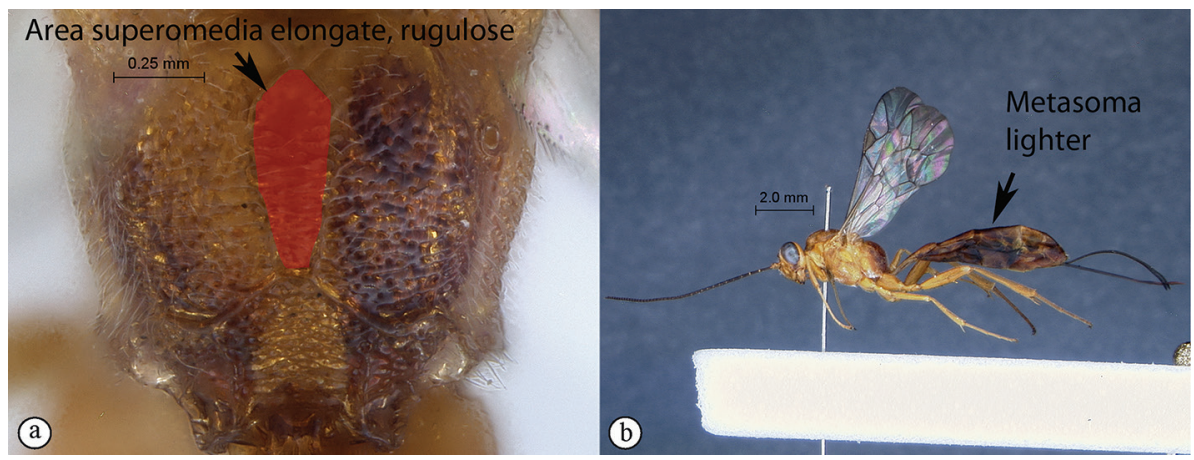

- Area superomedia elongate (ASM > 2.0) and transversely rugulose (a); metasoma lighter (b); South Africa P. afrikaner sp. nov. 

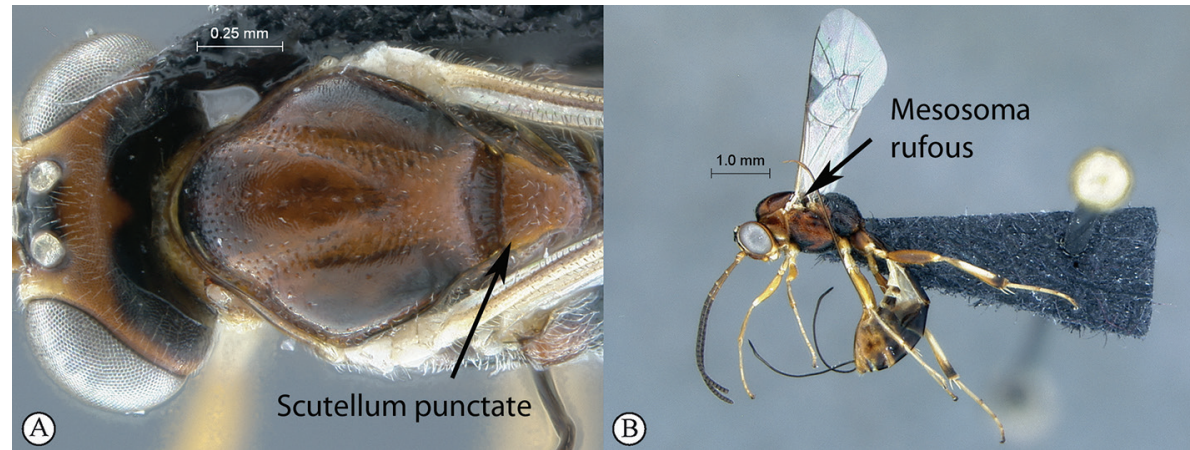

46. Scutellum punctate (A); antenna with less than 27 flagellomeres; mesosoma rufous, ventrally and posteriorly black (B); tropical Africa.

P. bemba sp. nov.

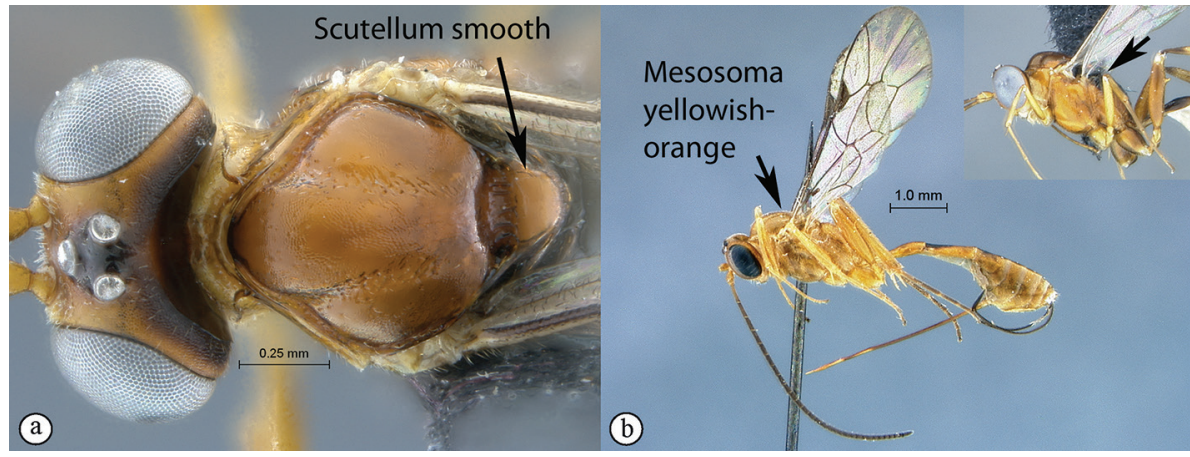

- Scutellum smooth (a); antenna with more than 27 flagellomeres; mesosoma usually uniformly yellow to orange (b), postero-dorsally black in P. swahili (b, inset)

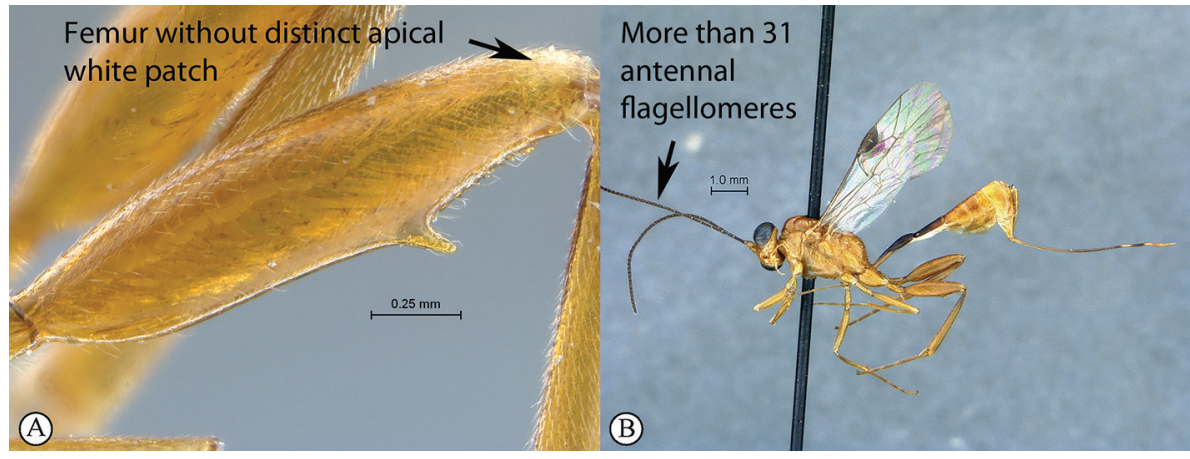

47. Femora and trochanters without obvious apical white patches (A); antenna with more than 31 flagellomeres (B); Madagascar P. yago Rousse, Villemant \& Seyrig, 2013

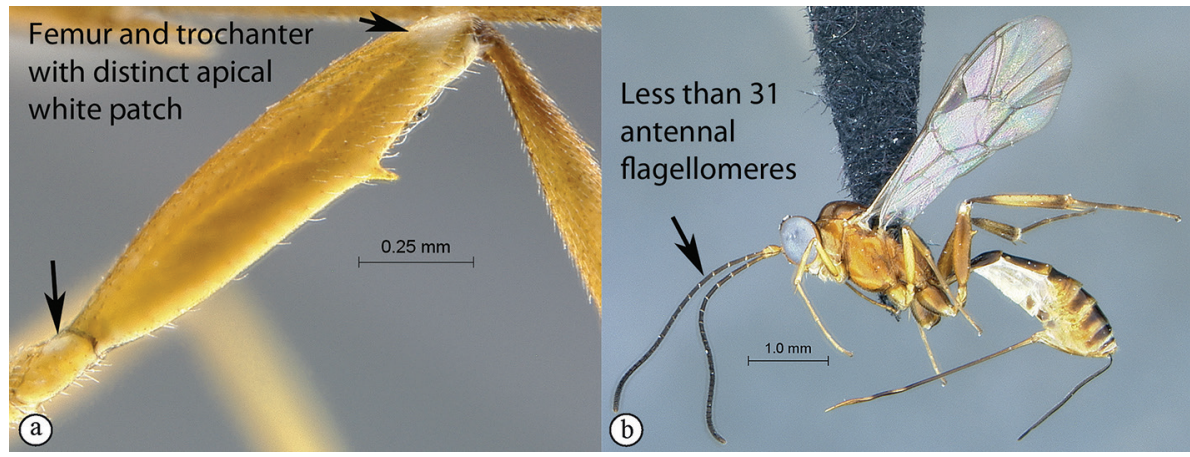

- Femora and trochanters with obvious apical white patches (a); antenna with fewer than 31 flagellomeres (b); Eastern Africa 


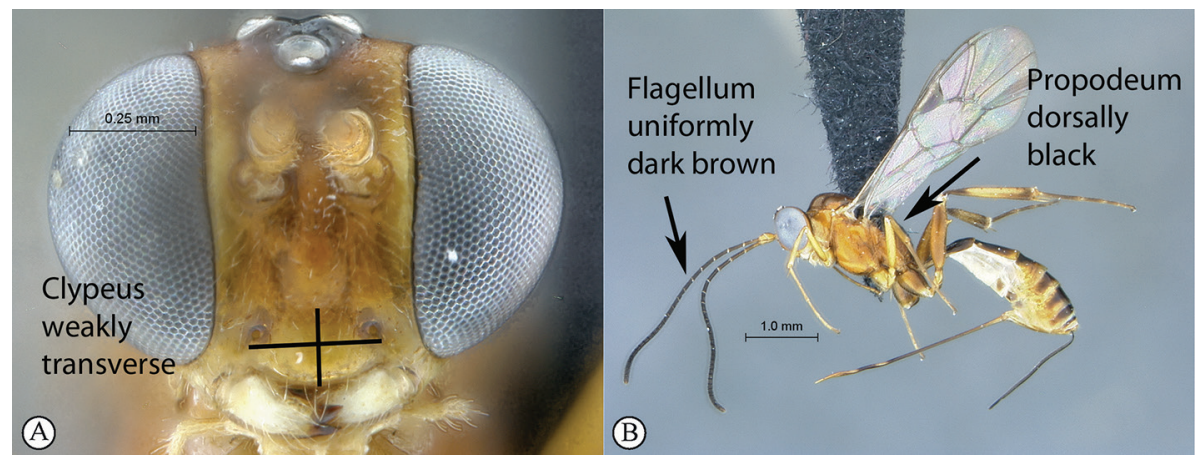

48. (47) Clypeus weakly transverse $(\mathrm{CT}<1.8)(\mathrm{A})$; flagellum uniformly dark brown $(\mathrm{B})$; propodeum dorsally black (B)

P. swahili sp. nov.

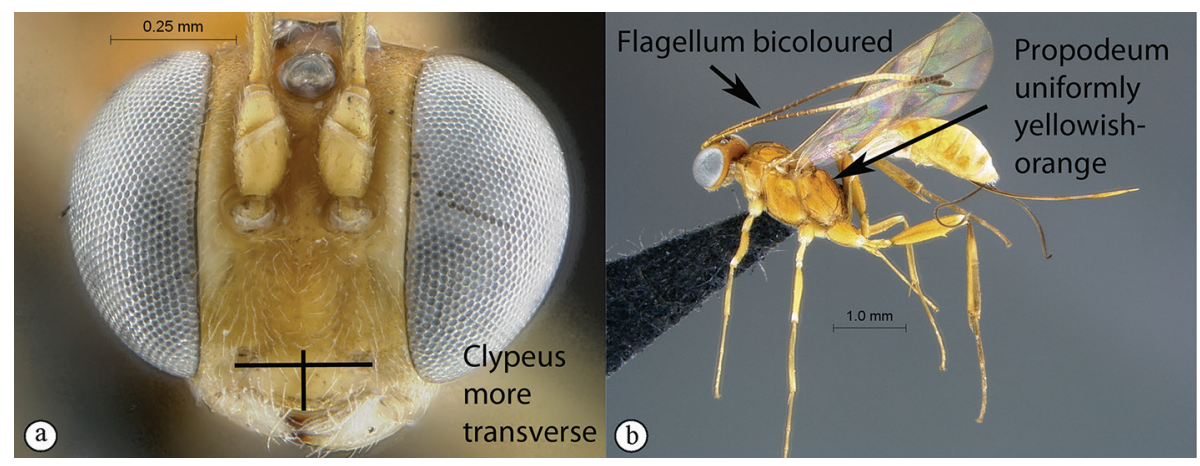

- Clypeus more transverse (CT > 1.8) (a); flagellum brown, basally distinctly lighter and sometimes with a long whitish segment in apical half (b); propodeum uniformly yellowish-orange (b).

P. yakoma sp. nov.

\section{Taxonomic descriptions}

Class Hexapoda Blainville, 1816

Order Hymenoptera Linnaeus, 1758

Suborder Apocrita Latreille, 1810

Superfamily Ichneumonoidea Latreille, 1802

Family Ichneumonidae Latreille, 1802

Subfamily Cremastinae Förster, 1869

Genus Pristomerus Curtis, 1836

Pristomeridia Ashmead, 1900: 100.

Pristocelus Szépligeti, 1905: 48.

Neopristomerus Viereck, 1912: 592.

Nesanomalon Morley, 1913: 56.

\section{Type species}

Ichneumon vulnerator Panzer, 1799.

Diagnosis (updated from Gauld 2000)

\section{Female}

Small to moderate sized species, fore wing length 2-8 mm; main background colour yellow to black; head with mandible not twisted, without obvious ventral flange, teeth subequal to upper tooth slightly 
longer than lower tooth; palpi formula 5:4; frons biconcave, sometimes with a mid-longitudinal ridge that may be strongly raised; occipital carina mid-dorsally complete to narrowly obsolescent, ventrally joining hypostomal carina at to distinctly above mandible base; antenna with flagellum finely setose; inner margins of eyes from slightly converging to distinctly diverging ventrally; mesosoma punctate with smooth or coriaceous parts to extensively punctate; notaulus weakly to strongly impressed; pronotum unspecialized with epomia usually discernible and quite short; scutellum flat to moderately convex, without lateral carina; epicnemial and postpectal carinae complete; propodeum with carination usually complete, sometimes longitudinal carinae partially obsolescent; tarsal claws unspecialized, pectinate; mid tibia with two apical spurs; hind femur often with a ventral subapical tooth, often followed by auxiliary denticles; fore wing with areolet open (vein 3 rs-m absent); pterostigma stout, usually as broad or broader than $1^{\text {st }}$ subdiscal cell; distal abscissa of $\mathrm{M}$ from virtually absent to complete to wing margin; abscissa of $\mathrm{M}$ between rs- $\mathrm{m}$ and $2 \mathrm{~m}$-cu usually as long to far longer than rs- $\mathrm{m}$, rarely distinctly shorter; hind wing with distal abscissae of Rs, M, Cu1 and 1A usually absent, almost invariably without a trace of the distal abscissa of $\mathrm{Cu} 1$ basally so that $\mathrm{Cu} \& \mathrm{cu}-\mathrm{a}$ is not broken but smoothly curved; metasoma with tergites 1-2 usually aciculate and following ones coriaceous or granulate; first segment moderately stout, ventral margins of tergite 1 widely separated so that sternite 1 is exposed for its full length, glymma distinct in front of spiracle; tergite 2 slender to moderately stout, slightly depressed, with welldefined thyridium subcircular to elongate, close to anterior margin, at most separated from it by its own maximum diameter; laterotergite membranous and folded up; ovipositor $0.8-3.2 \times$ as long as hind tibia, straight to slightly down-curved but sometimes evenly bi-curved, its apex usually weakly to strongly sinuous but sometimes straight.

\section{Male}

Ocelli usually strongly enlarged, inner margins of eyes sometimes distinctly more convergent, mesoscutum sometimes strongly smoother, area superomedia sometimes more slender, hind femur stouter and femoral tooth stronger, nearly always present; gonosquama apically rounded, without distal lobe. Otherwise similar to female.

\section{Differential diagnosis}

Pristomerus is usually an easily identifiable ichneumonid genus, mostly defined by the presence of thyridia close to the anterior margin of tergite 2 and the separation of the ventral margins of tergite 1 . Apart from a few exceptions, the apex of the ovipositor is also distinctly sinuous. This derived character is present in other ichneumonid and braconid subfamilies (Tersilochinae, Doryctinae, Braconinae...), and is probably an adaptation enabling the female to actively bend the ovipositor tip and thus to forage more efficiently within the host's hideaway (Quicke 1991). The only other cremastine genus with comparable features is the Neotropical Xiphosomella Szépligeti,1905, in which the thyridia are distinctly removed from the anterior margin of tergite 2, and the ovipositor tip is rarely sinuous. Some extra-limital Xiphosomella cannot, however, be unambiguously separated from Pristomerus (Gauld 2000). When present, the femoral tooth is also a reliable feature, though many Pristomerus females lack it. The only other cremastine genus in the Afrotropical region with a ventral tooth on the femur is the Malagasy genus Fafana: in the only known Fafana Rousse, Villemant \& Seyrig, 2011 species, the sculpture is almost entirely smooth, the distal abscissa of $\mathrm{Cu} 1$ reaches the hind wing margin and the ovipositor tip is straight.

\section{Phylogeny}

No comprehensive phylogenetic analysis of the subfamily Cremastinae has been published. The generic identification of Pristomerus is usually easy, but not one of the diagnostic morphological features may be unambiguously considered as a synapomorphy. The presence of thyridia (absent in most other cremastine genera), is considered as a plesiomorphic feature within Ichneumonidae (Gauld 1985). The sinuous ovipositor tip and the femoral tooth cannot be considered as derived characters, because they are not 
restricted to Pristomerus and are totally absent in some Pristomerus females. It is therefore impossible to ascertain whether the genus is monophyletic or not. Hence, Pristomerus is either a widespread and rather variable clade or part of a paraphyletic clade including Xiphosomella and other smaller cremastine genera.

\section{Distribution, species richness and ecology}

Including the three new synonyms and 31 descriptions in the present revision, the genus now comprises 140 species. This is a worldwide genus, most diversified in the tropics, which contain about two thirds of the currently known species. All known hosts are small lepidopterans (including several major pests) living in leaf rolls, tunnels, silk shelters or other concealed substrates. The biology of some widespread Pristomerus parasitizing agricultural pests has been documented: for example see Smith \& Johnson (1986) and Cave (1995) for P. spinator (Fabricius, 1804), or Rosenberg (1934) and Athanassov et al. (1997) for P. vulnerator (Panzer).

\section{Pristomerus afrikaner sp. nov. urn:1sid:zoobank.org:act:95885592-2369-423D-B533-BC4CB98EFCE4}

Fig. 1

\section{Diagnosis}

Large; head and mesosoma mostly yellow, metasoma mostly reddish-testaceous; face densely and shallowly punctate; inner margins of eyes barely diverging ventrally; clypeus transverse and mostly smooth; malar line long; remainder of head coriaceous; antenna long with 38 flagellomeres, penultimate flagellomere quadrate; mesosoma densely punctate to punctate-granulate except most of pronotum finely and sparsely punctate, ventral half of speculum smooth, and propodeum roughly transversely rugose medially; female femoral tooth long and narrow; ovipositor moderately long, apically strongly sinuous. Male with antenna shorter, with 33 flagellomeres, inner margins of eyes more diverging ventrally, ocelli enlarged, mesoscutum coriaceous, hind femur stouter and femoral tooth stronger.

\section{Differential diagnosis}

Large yellow to reddish-testaceous species, differentiated from all other Afrotropical species by the combination of the strong and narrow femoral tooth in the female, the blunt transverse rugosities on the propodeum, the long malar line, the long antenna and the extensively punctate mesonotum.

\section{Type material}

\section{Holotype}

SOUTH AFRICA: , "SOUTH AFRICA, 35-70 km W Pretoria Magaliesberg 31-xii-1994 A. Freidberg" (SANC).

Paratype

SOUTH AFRICA: $\hat{\jmath}$, same label data (SANC).

\section{Description}

Female (holotype)

B 11.9; A 6.1; F 6.2; CT 1.8; ML 0.7; POL 0.7; OOL 1.4; F1 1 1.0; ASM 2.3; OT 1.8; FFT 2.

CoLour. Head and mesosoma mostly yellow with frons and mesoscutum barely darker, and propodeum fading to reddish-testaceous; metasoma mostly reddish-testaceous; legs yellow; ovipositor sheath and flagellum dark brown; wings hyaline, venation yellowish. 
HEAD. Face very densely and shallowly punctate; inner margins of eyes slightly diverging ventrally; clypeus transverse, long, mostly smooth with some punctures along dorsal margin; malar line long; vertex and temple coriaceous; ocelli relatively small; occipital carina joining hypostomal carina above mandible base; antenna long with 38 flagellomeres, penultimate flagellomere quadrate.
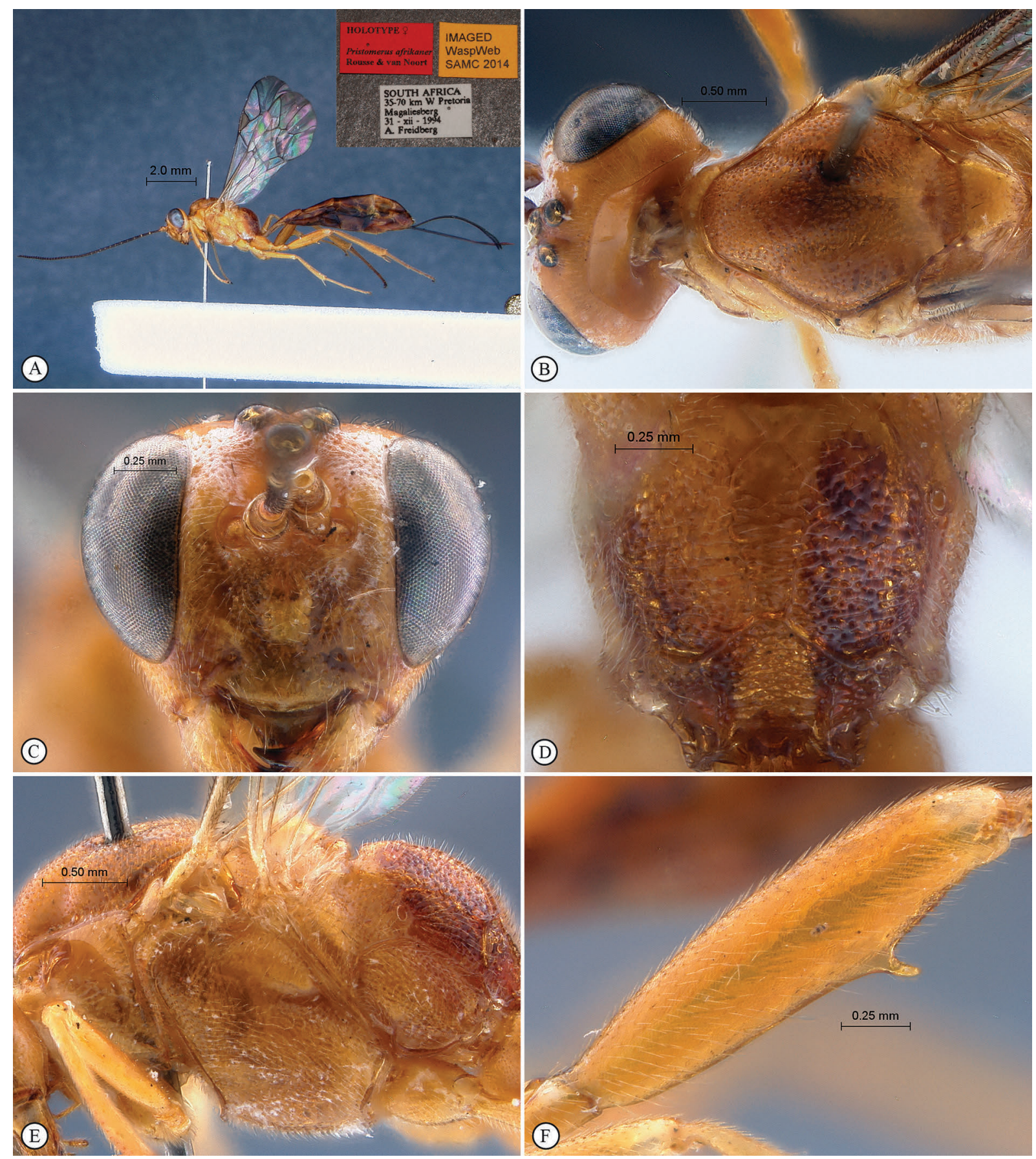

Fig. 1. Pristomerus afrikaner sp. nov. Holotype, . A. Habitus, lateral view (inset: data labels). B. Mesosoma, dorsal view. C. Head, anterior view. D. Propodeum, dorsal view. E. Mesosoma, lateral view. F. Hind tibia, lateral view. 
Mesosoma. Mesosoma moderately elongate; pronotum sparsely and finely punctate with anterior margin shallowly crenulate; mesopleuron and metapleuron densely punctate with a striate oblique furrow below speculum, speculum ventrally smooth; mesoscutum densely punctate-granulate, punctures confluent into fine transverse rugosities along notaulus; notaulus moderate; scutellum densely punctate; propodeum roughly and densely punctate, punctures confluent into blunt transverse rugosities medially, area superomedia long. Legs. Female femoral tooth long and narrow.

Metasoma. Tergite 2 and apex of tergite 1 aciculate, following tergites coriaceous; thyridium long elliptic, its main axis longitudinal; ovipositor moderately long, apically moderately sinuous.

Male (paratype)

B 11.2; A 5.8; F 6.3; POL 0.9; OOL 0.9. Inner margins of eyes more strongly diverging ventrally; antenna with 33 flagellomeres; ocelli enlarged; mesoscutum more shallowly sculptured, mostly coriaceous with punctures along rugose notaulus; hind femur and femoral tooth stouter; propodeum and metasoma barely lighter; otherwise similar to female.

\section{Distribution}

South Africa.

Pristomerus aka sp. nov. urn:1sid:zoobank.org:act:05D1309D-376B-4548-8ACE-375594C8B6B2

Fig. 2

\section{Diagnosis}

Small; mostly black with yellow markings on mouthparts, base of antenna and tergite 3 ; hind femur apically pale dotted; head coriaceous with sparse punctures on face; clypeus transverse; inner margins of eyes subparallel; malar line long; antenna short with 23 flagellomeres, penultimate flagellomere distinctly elongate; mesosoma laterally punctate with most of speculum and a dorsal area on pronotum smooth; mesoscutum coriaceous; scutellum coarsely punctate; propodeum rugose punctate; female femoral tooth moderate; ovipositor short, apically slightly sinuous. Male with ocelli strongly enlarged, lateral ocellus touching eye margin; inner margins of eyes moderately diverging ventrally; hind femur stouter, femoral tooth strong and stout; otherwise similar to female.

\section{Differential diagnosis}

Small and overall black species with legs lighter, differentiated from all other Afrotropical species by the combination of the coriaceous mesoscutum, the punctate scutellum, the short ovipositor and the antenna with few flagellomeres.

\section{Type material}

Holotype

UGANDA: + , "UGANDA, Kibale National Park, Kanyawara, Makerere University Biological Field Station, $1495 \mathrm{~m}, 0^{\circ} 33.960$ 'N 30²1.267'E, 2-12.viii.2008, S. van Noort, UG08-KF1-M01, Malaise trap, secondary mid-altitude rainforest, SAM-HYM-P047383" (SAMC).

Paratype

IVORY COAST: O̊, "Côte d’Ivoire: Divo 28.XI.1963 J. Decelle” (MRAC).

\section{Description}

Female (holotype)

B 3.5; A 2.6; F 2.6; CT 1.9; ML 0.6; POL 0.7; OOL 1.0; Fl $1_{n-1} 1.5$; ASM 2.2; OT 1.2; FFT 1. 
CoLour. Black; tergite 3 laterally yellowish-orange; scape, pedicel, mandible, palpi, fore and mid legs yellow; hind leg yellow with coxa black, femur brown but a pale apical spot and tarsus brown; wings hyaline, venation brown.

HEAD. Face coriaceous with sparse and shallow punctures; inner eye margins subparallel; clypeus transverse, sparsely punctate, convex in profile view; malar line long; frons, vertex and temple coriaceous; ocellar triangle moderate, equilateral; occipital carina joining ventrally hypostomal carina
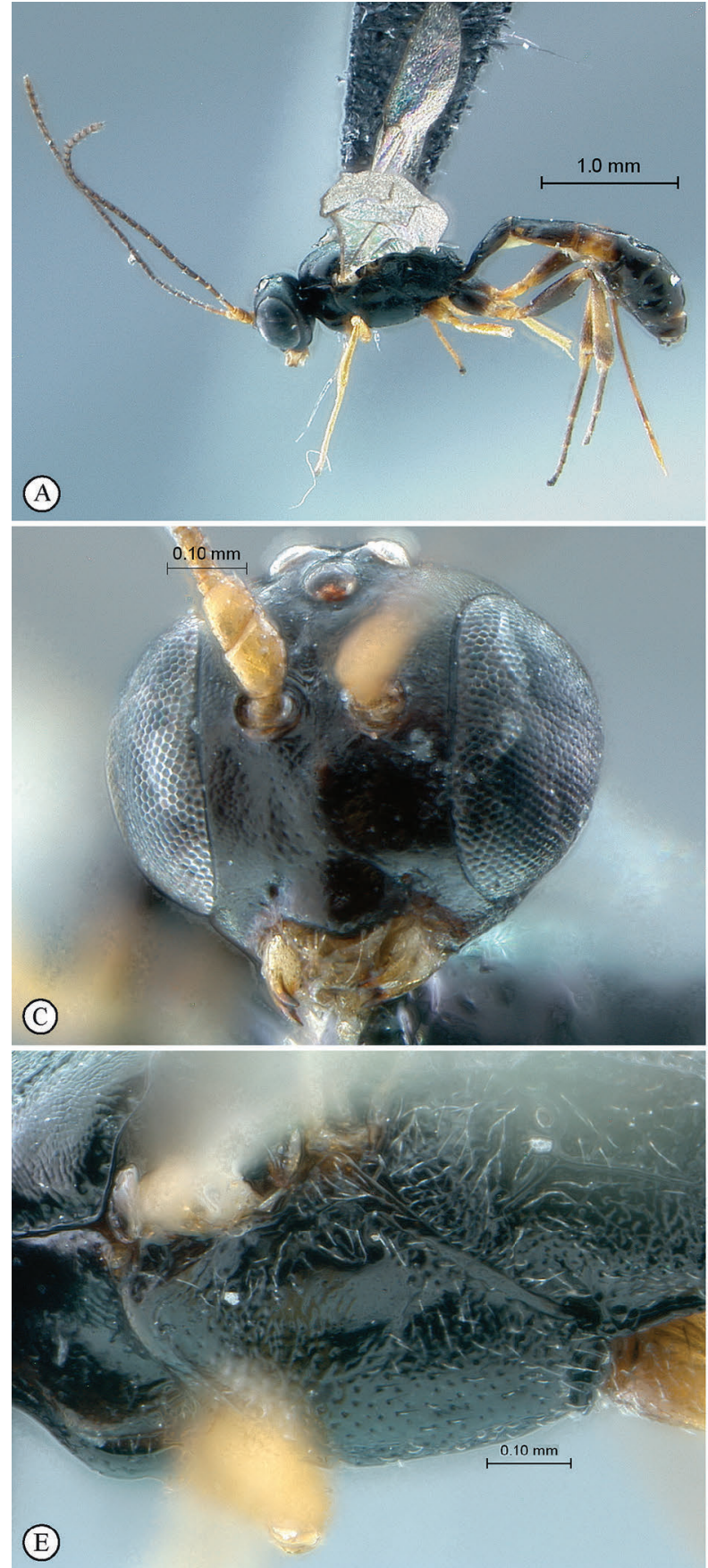
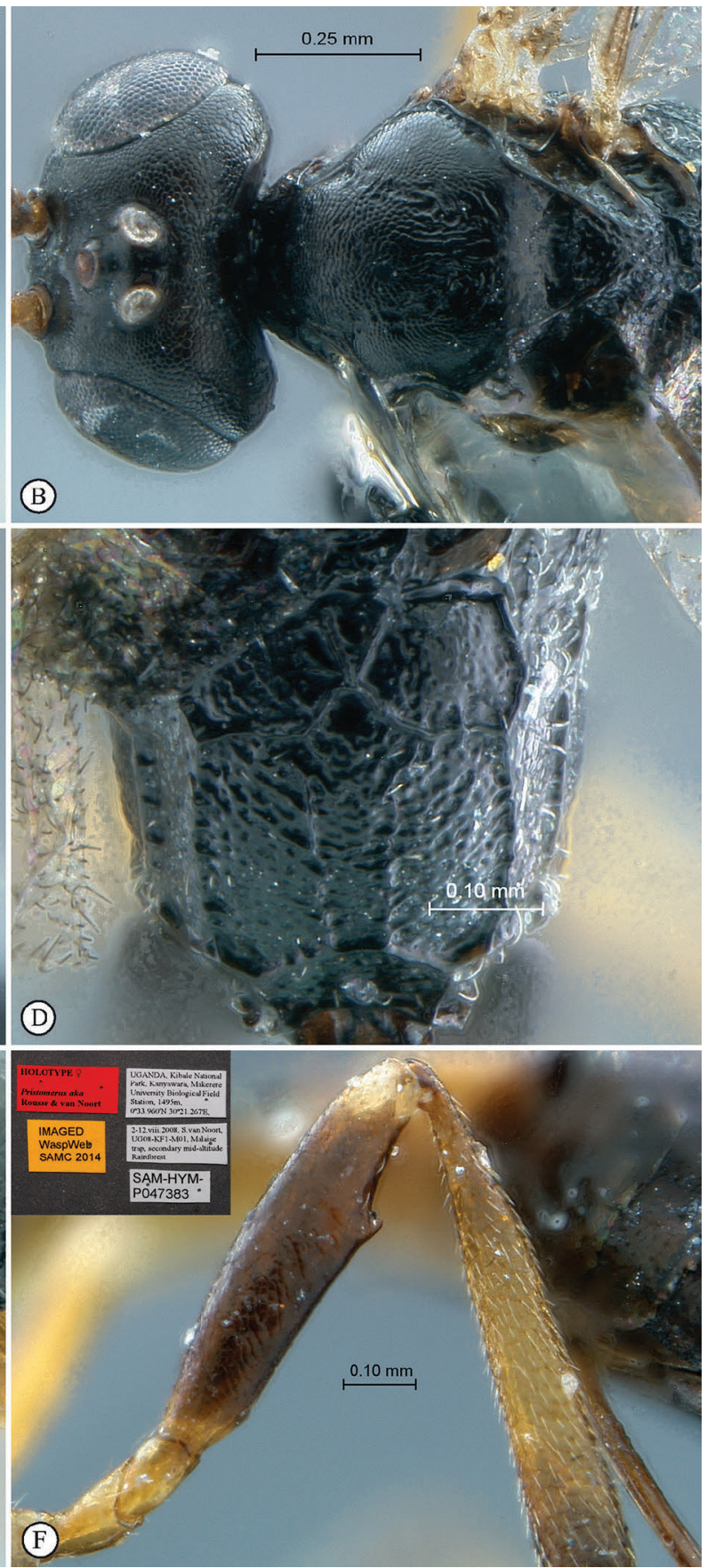

Fig. 2. Pristomerus aka sp. nov. Holotype, + . A. Habitus, lateral view. B. Head, mesosoma, dorsal view. C. Head, anterior view. D. Propodeum, dorsal view. E. Mesosoma, lateral view. F. hind tibia, lateral view (inset: data labels). 
above mandible base; antenna short, thin and slender with 23 flagellomeres, first flagellomere distinctly longer than second, penultimate flagellomere elongate.

Mesosoma. Elongate; pronotum moderately punctate with some ventral crenulations and a smoother postero-dorsal area; mesopleuron and metapleuron densely and deeply punctate, with a large oblique rugulose furrow below speculum, speculum mostly smooth; mesoscutum coriaceous, sculpture apically confluent into transverse rugosities; notaulus moderate; scutellum coarsely punctate; propodeum rugose punctate, area superomedia elongate and hardly delimited laterally beyond anterior transverse carina. Legs. Femoral tooth stout and short.

Metasoma. Tergite 2, apical half of tergite 1 and base of tergite 3 longitudinally aciculate; thyridium subelliptic, its main axis longitudinal; ovipositor short, apically slightly sinuous.

Male (paratype)

B 3.7; A 2.8; F 2.8; POL 0.3; OOL $<0.1$. Ocelli strongly enlarged, lateral ocellus touching eye margin; inner margins of eyes moderately diverging ventrally; flagellum with 25 flagellomeres; hind femur stouter, femoral tooth strong and stout; otherwise similar to female.

\section{Distribution}

Ivory Coast, Uganda.

Pristomerus albescens (Morley, 1917)

Fig. 3

Pristomeridia albescens Morley, 1917: 224.

Diagnosis (range of variation from Rousse et al. 2013)

Small; head transverse, pale yellow with frons, vertex, occiput and sometimes face orange, mesosoma pale yellow with large testaceous to black markings, notaulus and scutellum strongly lighter than remainder of mesonotum; metasoma orange with tergites 1-3 and a variable part of following dark brown to black; face densely and shallowly punctate; inner margins of eyes slightly converging ventrally; clypeus narrow and long, unusually convex, coriaceous; malar line short; antenna with 29-32 flagellomeres; upper head coriaceous; mesosoma moderately elongate, moderately to densely punctate, but upper pronotum and ventral half of speculum smoother; area superomedia with lateral margin sometimes evanescent beyond anterior transverse carina; female femoral tooth small, sometimes reduced to a small point but always distinct; ovipositor moderately short, apically straight. B 6.0-6.7; A 2.8-3.5; F 3.1-3.5; CT 1.5; ML 0.4; POL 1.0; OOL 1.1; $\mathrm{Fl}_{\mathrm{n}-1} 1.3$; ASM 1.9; OT 1.3; FFT 1. Male with ocelli, hind femur and femoral tooth enlarged. POL 0.7; OOL 0.3 .

\section{Differential diagnosis}

Small and mostly yellowish species with large black dorsal markings; differentiated from all other Afrotropical species by the combination of the straight ovipositor tip, the narrow clypeus and the converging inner margins of eyes.

\section{Material examined}

Lectotype

SOUTH AFRICA: §, “Mfongosi Zulu L. WE Jones April 1916 SAM-HYM-P001199” (SAMC).

\section{Paralectotypes}

SOUTH AFRICA:1 đ̂, 1 q , same label data SAM-HYM-P001199 and P001223 (SAMC). 


\section{Other material}

SOUTH AFRICA: 1 + , “Kwazulu-Natal, Richards Bay, site 4, 2840'S 32¹4'E, 14.xi.1991, M. Vogt, 5-8 year old Acacia karoo thicket, SAM-HYM-P046456" (SAMC).

TANZANIA: 2 우, "Tanzania, Mkomazi Game Reserve, Ibaya Camp, 3.58S 37.48E 25.xii.199529.i.1996, S. van Noort, Malaise trap, Acacia / Commiphora / Combretum bushland, SAM-HYMP015867” (SAMC); 1 ㅇ, same data, except: "29 Jan-11 Mar 1996, SAM-HYM-P015624” (SAMC);
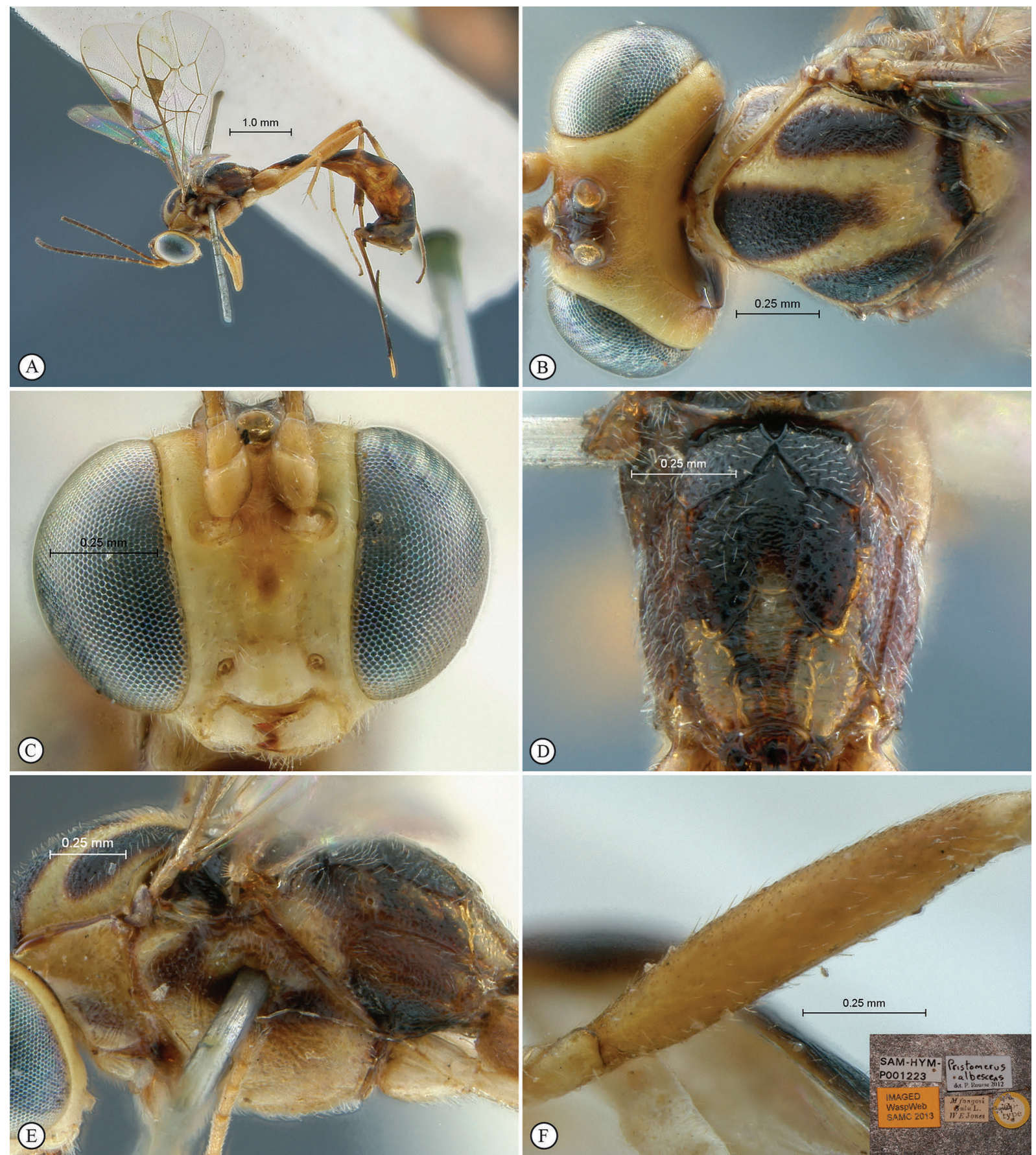

Fig. 3. Pristomerus albescens (Morley, 1917). Holotype,, . A. Habitus, lateral view. B. Head, mesosoma, dorsal view. C. Head, anterior view. D. Propodeum, dorsal view. E. Mesosoma, lateral view. F. Hind tibia, lateral view (inset: data labels). 
1 ㅇ, same data, except: "14 April-3 May 1996, SAM-HYM-P015573" (SAMC); 1 +, same data, except: "Ibaya Hill, 03 58.40S 37 47.13E, 15-30 April 1996, S. van Noort, Malaise trap, wet montane forest margin bordering Setaria/Panicum grass, SAM-HYM-P015173" (SAMC); 1 , same locality, “Kikolo plot, $4^{\circ} 08.72^{\prime}$ S 3801.37’E, 16 April-2 May 1996, S. van Noort, Commiphora woodland, Malaise trap, SAM-HYM-P016193" (SAMC).

\section{Distribution}

South Africa, Madagascar, Tanzania (Rousse et al. 2013).

Pristomerus babinga sp. nov. urn:lsid:zoobank.org:act:D84F4F33-A53F-44CF-A6CB-88E4E1F87C43

Fig. 4

\section{Diagnosis}

Large; yellow to yellowish-orange overall, with frons darker than face and notaulus and scutellum distinctly lighter than remainder of mesonotum; anterior edge of pterostigma whitish; face densely punctate-granulate; inner margins of eyes diverging ventrally; clypeus strongly transverse, medially smooth; malar line moderately short; remainder of head coriaceous; antenna with 31-35 flagellomeres, penultimate flagellomere quadrate; mesosoma densely and evenly punctate, except pronotum dorsally and speculum ventrally; area superomedia elongate; female femoral tooth strong; ovipositor long, slightly sinuous apically. Male unknown.

\section{Differential diagnosis}

Large and mostly yellow to orange species; differentiated from all other Afrotropical species by the combination of the rather strong femoral tooth, the ventrally diverging inner margins of eyes, the strongly transverse clypeus, the numerous flagellomeres and the long ovipositor. The only other Afrotropical species with such a transverse clypeus is $P$. bullis, in which the femoral tooth and the ovipositor are shorter.

\section{Type material}

\section{Holotype}

CENTRAL AFRICAN REPUBLIC: + , "Central African Republic, Préfecture Sangha-Mbaéré, Parc National de Dzanga-Ndoki, $38.6 \mathrm{~km} 173^{\circ} \mathrm{S}$ Lidjombo, $2^{\circ} 21.60^{\prime} \mathrm{N} 16^{\circ} 03.20^{\prime} \mathrm{E}, 350 \mathrm{~m}, 20-21 . v .2001$, S. van Noort, Malaise trap, CAR01-M160, lowland rainforest SAM-HYM-P047384” (SAMC).

\section{Paratype}

CENTRAL AFRICAN REPUBLIC: + , same label data except: "Réserve Spéciale de Forêt Dense de Dzangha-Sangha, $12.7 \mathrm{~km} 326^{\circ} \mathrm{NW}$ Bayanga, $3^{\circ} 00.27^{\prime} \mathrm{N} 16^{\circ} 11.55^{\prime} \mathrm{E}, 420 \mathrm{~m}, 10-11 . v .2001$, CAR01M78, Lowland Rainforest SAM-HYM-P047385" (SAMC).

\section{Description}

Female (2 specimens)

B 9.6-10.1; A 5.5-5.9; F: 6.2-6.4; CT 2.4-2.6; ML 0.5; POL 1.0; OOL 1.3; Fl ${ }_{\mathrm{n}-1} 1.0$; ASM 2.2; OT $1.9-2.1$; FFT 2.

CoLour. Head yellow with frons, vertex and occiput yellowish-orange; mesosoma, legs and metasoma yellowish-orange with scutellum and notaulus yellow; tergites 1-2 sometimes basally blackened; flagellum and ovipositor sheath black; wings hyaline, venation brown, anterior edge of pterostigma whitish. 
HEAD. Face densely punctate-granulate; inner margins of eyes diverging ventrally; clypeus strongly transverse, short, moderately punctate-granulate laterally, medially smooth; malar line moderately short; frons, vertex and temple coriaceous; occipital carina joining hypostomal carina at mandible base; antenna with 34 flagellomeres (both apices broken in holotype), penultimate flagellomere quadrate.
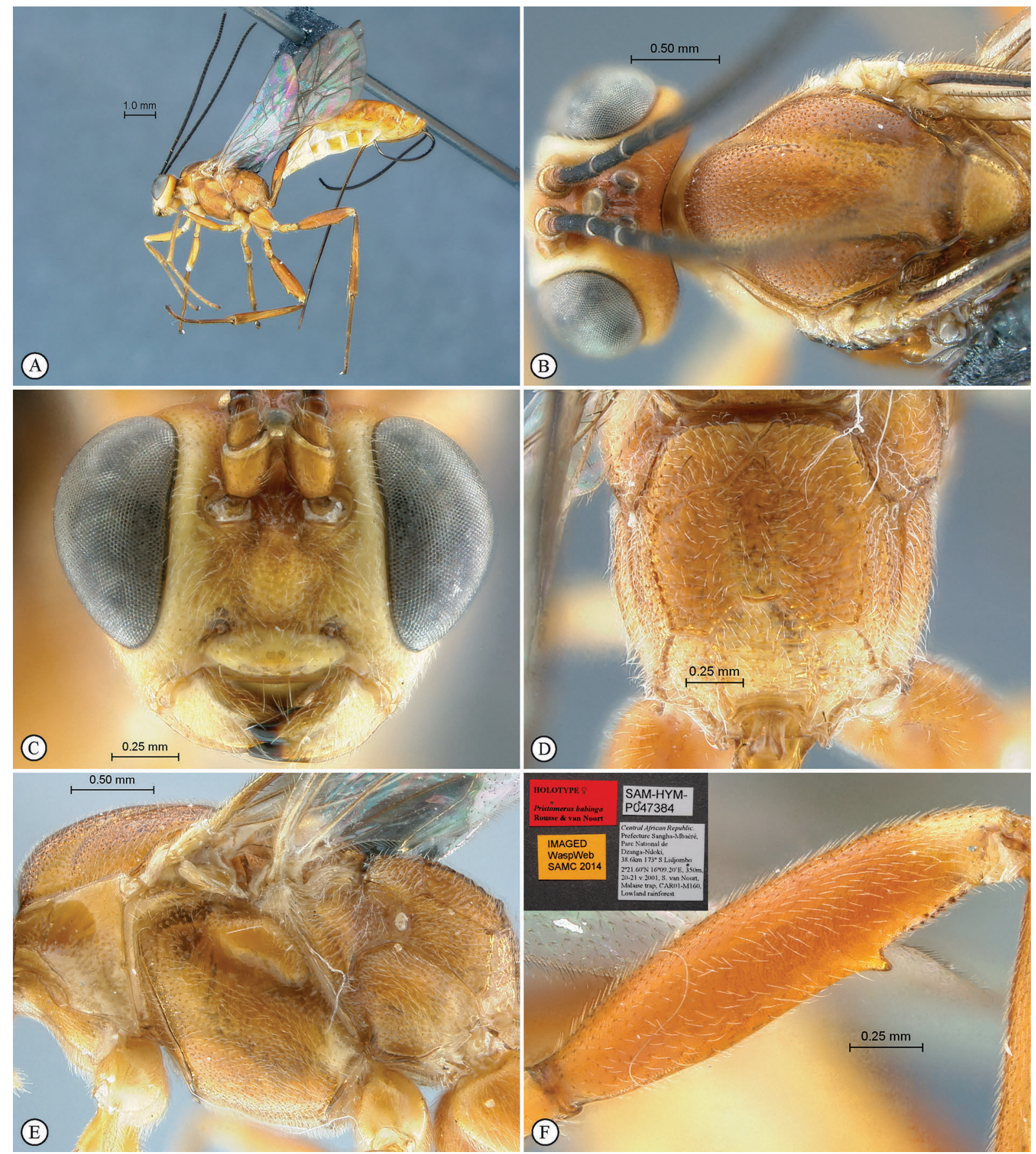

Fig. 4. Pristomerus babinga sp. nov. Holotype, +. A. Habitus, lateral view. B. Head, mesosoma, dorsal view. C. Head, anterior view. D. Propodeum, dorsal view. E. Mesosoma, lateral view. F. Hind tibia, lateral view (inset: data labels). 
Mesosoma. Moderately elongate; entire mesosoma densely and deeply punctate, except pronotum dorsally and ventral half of speculum smooth, mesopleuron with an oblique, shallowly striate furrow below speculum, and propodeum medially transversely striate; notaulus moderately deep; area superomedia sometimes not defined laterally. Legs. Femoral tooth about as high as basally wide, followed by a row of denticles.

Metasoma. Tergite 2, apical half of tergite 1 and base of tergite 3 longitudinally aciculate, following tergites coriaceous with sparse punctures; thyridium subcircular; ovipositor long, stout, weakly sinuous apically.

Male
Unknown.

Distribution

Central African Republic.

Pristomerus bemba sp. nov. urn:Isid:zoobank.org:act:C0EE1F41-9AEC-4873-BB1B-3775997F7966

Fig. 5

\section{Diagnosis}

Small; mostly testaceous interspersed with black, and with yellow parts on head; flagellum bicolour, dark brown with flagellomeres 1-3 testaceous; hind femur apically pale dotted; face densely punctate; clypeus strongly transverse, ventrally smooth; malar line moderately long; antenna with 24-26 flagellomeres, slightly widening toward apex, penultimate flagellomere quadrate; mesosoma moderately to densely punctate with pronotum almost entirely smooth, speculum ventrally smooth and mesoscutum coriaceous with most punctures located along notaulus; propodeum with area superomedia elongate; femoral tooth long and relatively narrow; ovipositor long, strongly sinuous apically. Male with inner margins of eyes moderately diverging ventrally, ocelli greatly enlarged, hind femur stouter, femoral tooth long and acute, followed by strong denticles.

\section{Differential diagnosis}

Small testaceous and black species with inner orbits lighter, pale yellow, and hind legs noticeably mottled; differentiated from all other Afrotropical species by the combination of this unique colour pattern, the largely coriaceous mesoscutum with scutellum punctate, the strong femoral tooth and the antenna with few flagellomeres.

\section{Type material}

\section{Holotype}

ZAMBIA: + , “Zambia, South Luangwa nr. Mfuwelabout $10 \mathrm{~km}$ E. Mfuwe Malinba village vicinities, 12.XII.2011, Gumovsky leg. SAM-HYM-P047391”(SAMC).

\section{Paratypes}

IVORY COAST: 1 ○े, "Lamto-RCI, 502 W 6¹3 N, 8.8-11.9.1985, Afrormosia laxiflora" (BMNH). KENYA: 1 ð̊, "Kenya, Lake Nakuru Hippo Point 16.xii.1970, A.E. Stubbs B.M. 1972-211” (BMNH).

SOUTH AFRICA: 1 q, "South Africa, Kranskloof SW of Buffelspoort Dam Magaliesberg, Tvl 16.iii.1993, S. Neser \& R. Urban, with tingids on Rothmannia capensis" (SANC); 1 đે, "Retief's Kloof Transvaal 5.9.1961 H. N. Empey" (SANC). 


\section{Description}

Female (2 specimens)

B 5.8-6.8; A 3.0-3.6; F 3.3-3.9; CT 2.1; ML 0.5; POL 0.8; OOL 0.7; $\mathrm{Fl}_{\mathrm{n}-1}$ 1.0; ASM 2.3; OT 2.0; FFT 2.

CoLour. Head testaceous with frons, inter-ocellar area and occiput black, orbits, clypeus and malar space yellow, and mandible and palpi pale yellow; antenna dark brown with scape, pedicel and flagellomeres

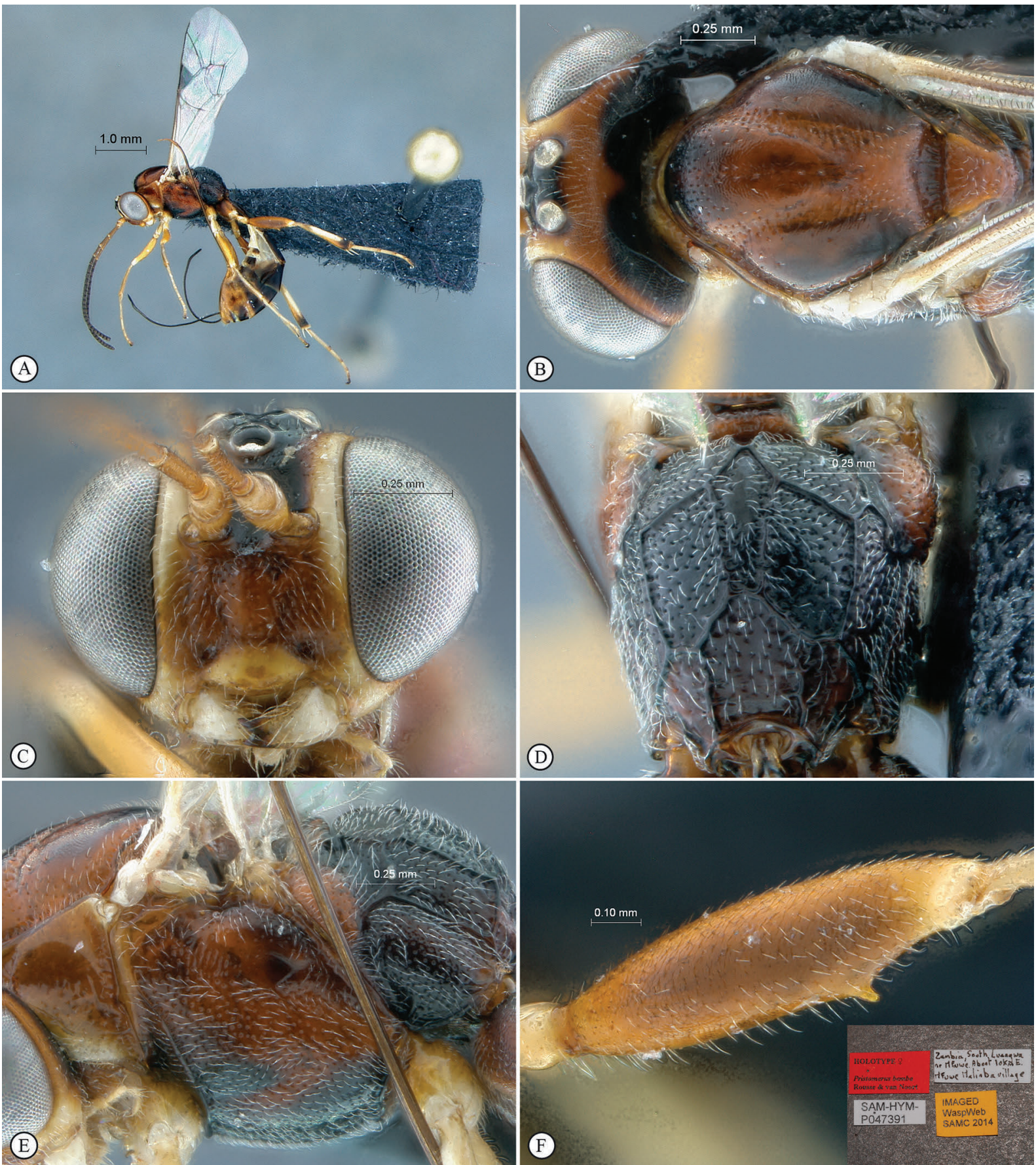

Fig. 5. Pristomerus bemba sp. nov. Holotype, +. A. Habitus, lateral view. B. Head, mesosoma, dorsal view. C. Head, anterior view. D. Propodeum, dorsal view. E. Mesosoma, lateral view. F. Hind tibia, lateral view (inset: data labels). 
1-3 testaceous; mesosoma mostly testaceous with tegula yellow, and propodeum, metapleuron and most of mesosternum black; tergites 1-3 black, following tergites black with apical half fading to orange; fore and mid legs yellow; hind leg testaceous with trochanter, trochantellus, tibia and tarsus yellow, but apex of tibia black and apex of femur whitish-dotted; wings hyaline, venation pale brown, pterostigma anteriorly paler.

HEAD. Face densely punctate, punctation sparser on median bulge; inner margins of eyes parallel; clypeus strongly transverse, almost smooth with some punctures dorsally; malar line rather short; frons, vertex and temple coriaceous; ocelli enlarged; occipital carina joining mandible base; antenna with 24-26 flagellomeres, slightly widening toward apex, penultimate flagellomere quadrate.

Mesosoma. Elongate; pronotum hardly sculptured, mostly smooth with some punctures ventrally; mesopleuron and metapleuron densely and deeply punctate, with a shallow striate furrow below speculum, speculum ventrally smooth; mesoscutum coriaceous with apical margin, notaulus, and base of median lobe densely punctate; scutellum moderately punctate; propodeum coarsely and deeply punctate, area superomedia elongate and centrally smoother. Legs. Femoral tooth long and narrow, without denticles behind.

Metasoma. Metasoma coriaceous with apex of tergite 1, entire tergite 2 and base of tergite 3 longitudinally aciculate; thyridium subcircular; ovipositor long, strongly sinuous apically.

Male (paratypes)

B 6.2-6.6; A 3.1-3.5; F 3.5-4.0; POL 0.7; OOL 0.1. Inner margins of eyes moderately diverging ventrally; antenna with 25-26 flagellomeres; ocelli enlarged, median ocellus nearly connected to eye; hind femur stouter, femoral tooth long and acute, followed by strong denticles; antenna slightly lighter orange with flagellomeres 1-3 yellow; otherwise similar to female.

\section{Biological record}

Unknown host on Afrormosia laxiflora (Fabaceae).

\section{Distribution}

Ivory Coast, Kenya, South Africa, Zambia.

Pristomerus bullis Fitton in Polaszek et al., 1994

Fig. 6

Pristomerus bullis Fitton in Polaszek et al., 1994: 83.

\section{Diagnosis}

Moderately sized; yellow to orange overall with base of tergite 2 infuscate, frons darker than face, and notaulus and scutellum lighter than remainder of mesonotum; face densely punctate; inner eye margins parallel; clypeus very strongly transverse, sparsely punctate with inter-punctures space smooth; malar line short; frons and vertex punctate-granulate, gena and temple coriaceous; occipital carina joining hypostomal carina shortly above mandible base; antenna with 26-32 flagellomeres, penultimate flagellomere shorter than wide; mesosoma strongly elongate, mostly very densely punctate but dorsal half of pronotum and ventral half of speculum smooth; propodeum with area superomedia narrow and elongate; hind femur rather stout; femoral tooth stout, about half as high as basally wide, followed by minute denticles; ovipositor rather short, apically moderately sinuous. B 7.3-8.3; A 3.5-4.0; F 4.0-4.7; CT 2.2-2.5; ML 0.3; POL 1.0; OOL 1.3; $\mathrm{Fl}_{\mathrm{n}-1}$ 0.7; ASM 2.8; OT 1.3; FFT 1. Male with inner margins of eyes diverging ventrally, ocelli, hind femur and femoral tooth enlarged, and mesoscutum strongly smoother; otherwise similar to female. POL 0.5; OOL 0.4. 


\section{Differential diagnosis}

Moderately sized and yellow to orange overall; differentiated from most other Afrotropical species by the very transverse clypeus. It is thus apparently closely related to $P$. babinga sp. nov. but $P$. bullis has a significantly shorter ovipositor.
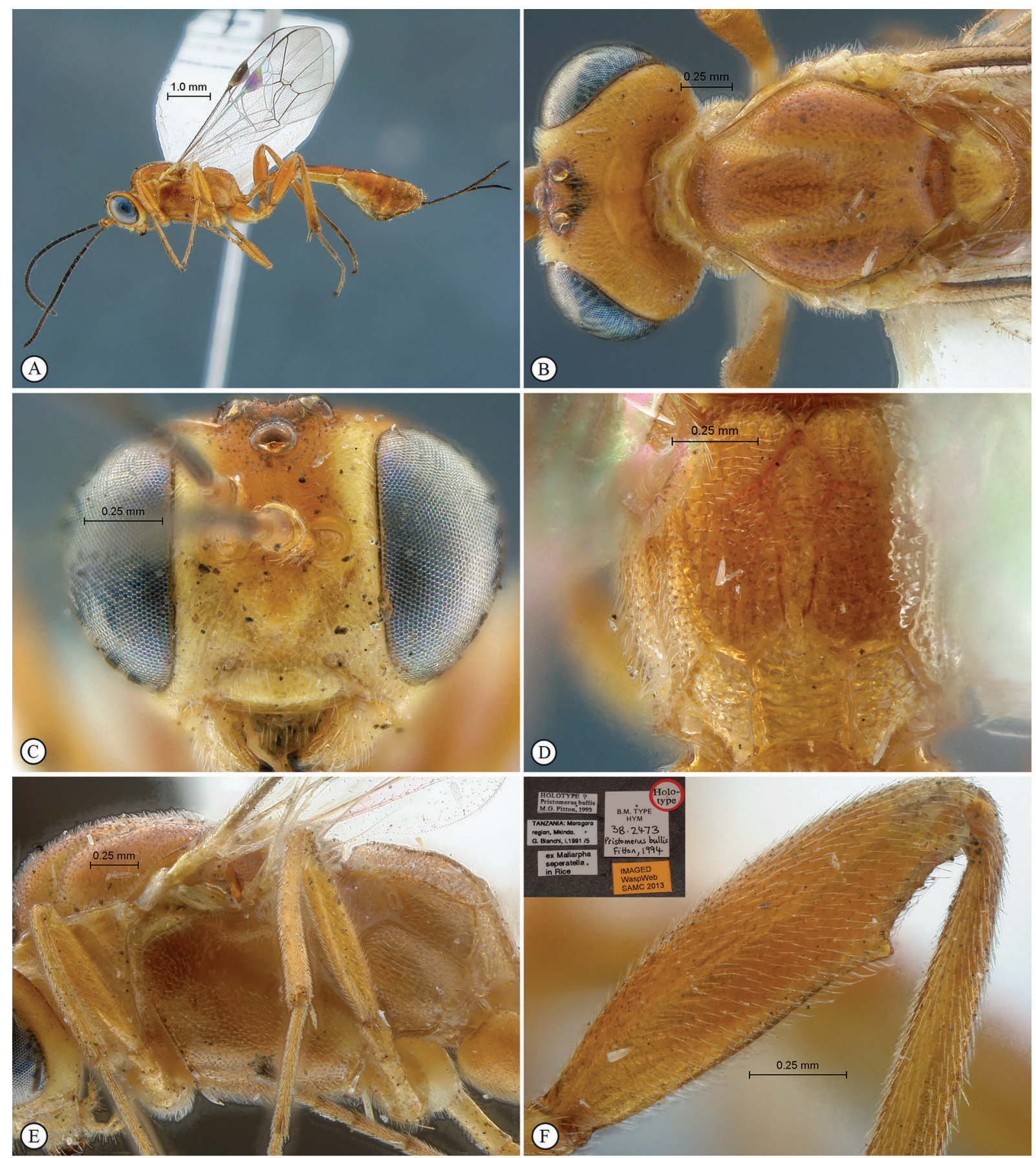

Fig. 6. Pristomerus bullis Fitton, 1994. Holotype, ․ A. Habitus, lateral view. B. Head, mesosoma, dorsal view. C. Head, anterior view. D. Propodeum, dorsal view. E. Mesosoma, lateral view. F. Hind tibia, lateral view (inset: data labels). 


\section{Material examined}

\section{Holotype}

TANZANIA: + " "TANZANIA: Morogoro region, Mkindo. G. Bianchi, i.1991 /5, 5.8, ex Maliarpha seperatella [sic] in Rice, B.M. Type Hym 3B.2473” (BMNH).

\section{Other material}

UGANDA: 1 \%, "Uganda, Kibale National Park, Kanyawara, Makerere University Biological Field Station, $1465 \mathrm{~m}, 0^{\circ} 35.442$ 'N 30²1.741'E, 10.viii.2008, S. van Noort, UG08-KF12-S03, Sweep, primary mid-altitude rainforest, near stream, SAM-HYM-P047402" (SAMC).

ZAMBIA: 10 , "Zambia, nr Mfuwe sweeping on the dried egg tree 09.XII.2011 Gumovsky; Mopane tree [Colophospermum mopane, Fabaceae] SAM-HYM-P049439” (SAMC).

\section{Host records}

Maliarpha separatella Ragonot, 1888 (Lepidoptera: Pyralidae).

\section{Distribution}

Tanzania. New records: Uganda, Zambia.

Pristomerus caris Fitton in Polaszek et al., 1994

Fig. 7

Pristomerus caris Fitton in Polaszek et al., 1994: 83.

Diagnosis (range of variation from Rousse et al. 2013)

Head very pale yellow with frons, inter-ocellar and occiput black, face often with a median infuscate to dark brown marking of variable extent; mesosoma and metasoma testaceous orange with tergites 1-2 or 1-3 blackened, mesosoma sometimes with black spots dorsally; face moderately and shallowly punctate; inner margins of eyes barely diverging ventrally; clypeus transverse, smooth; malar line moderately long; frons, vertex and temple coriaceous; occipital carina joining hypostomal carina at mandible base; antenna with 29-32 flagellomeres, penultimate flagellomere subquadrate; mesosoma elongate, densely punctate except pronotum and ventral half of speculum smooth, background sculpture on posterior mesoscutum somewhat transversely rugose; area superomedia narrow and elongate, usually about twice as long as wide but sometimes distinctly more elongate; female femoral tooth absent; ovipositor moderately long, strongly sinuous apically. B 4.1-7.2; A 3.0-5.3; F 3.3-4.7; CT 1.8; ML 0.6; POL 0.6; Fl ${ }_{n-1} 1.0$; OOL 0.9; ASM 1.9-2.7; OT 1.5-1.7; FFT 0. Male with eye margins more diverging ventrally, femoral tooth enlarged, ocelli usually enlarged (see comments); otherwise similar to female. B 3.8-7.2; A 2.9-5.1; F 3.5-4.2; POL 0.6; OOL 0.2-0.5.

\section{Differential diagnosis}

Rather small species from Madagascar, mostly yellowish to testaceous-orange with basal tergites blackened and whitish head, though dorsally and often medially darkened. Differentiated from most other Afrotropical species by the absence of the femoral tooth in females, the whitish face, the mostly yellowish-orange metasoma and the moderately long ovipositor. It is hence morphologically related to P. vahaza, which has a narrower clypeus, a more slender mesosoma and a rather flat scutellum, and to P. ranomafana, which is darker with a significantly longer ovipositor.

\section{Material examined}

Holotype

MADAGASCAR: + , "MADAGASCAR: Lac Alaotra, Stn Cala, 12.02.1988, ex Maliarpha separatella LB4-, B.M. Type Hym 3B.2472" (BMNH). 


\section{Host records}

Maliarpha separatella Ragonot (Lepidoptera: Pyralidae).

\section{Distribution}

\section{Madagascar.}
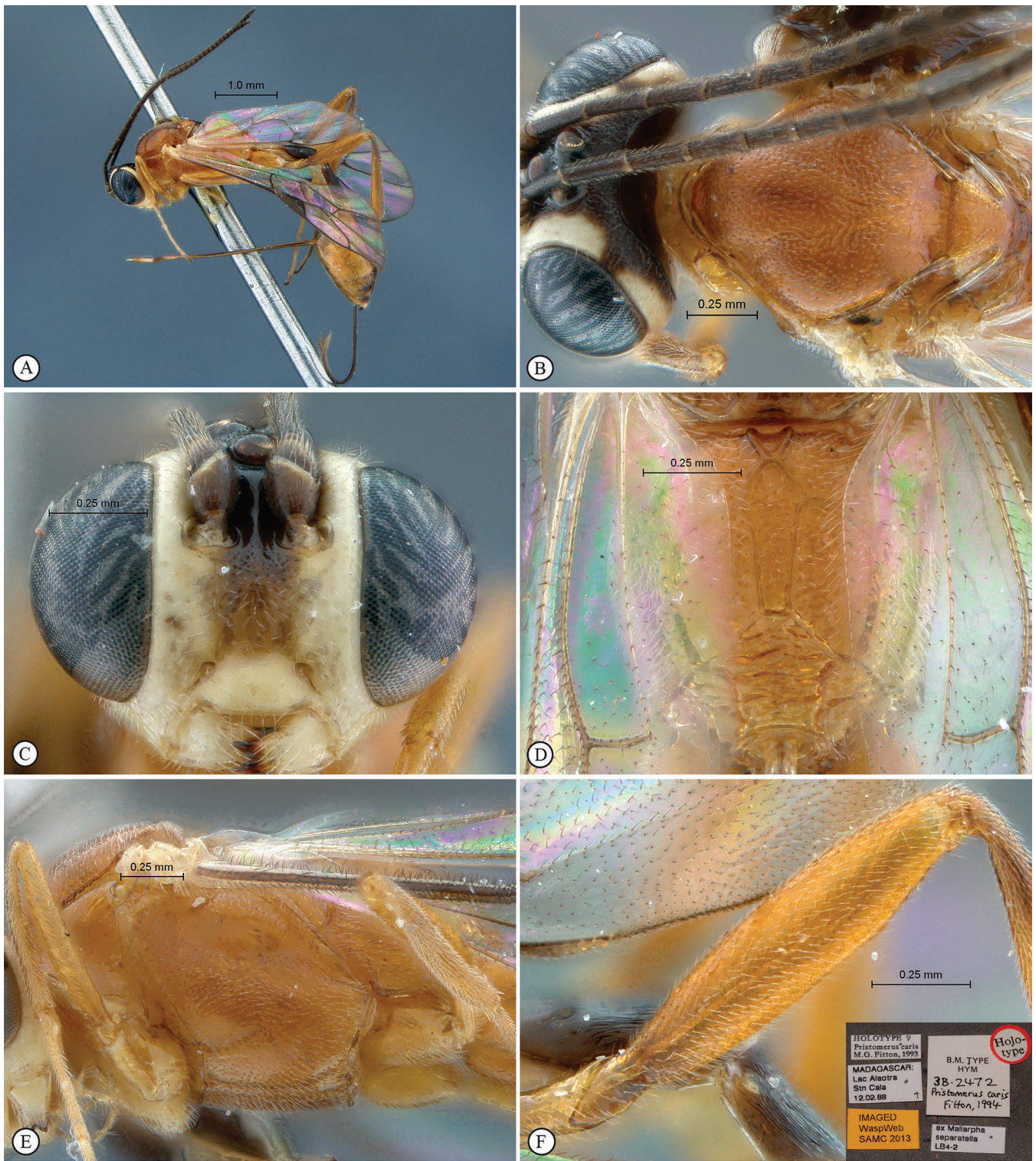

Fig. 7. Pristomerus caris Fitton, 1994. Holotype, + . A. Habitus, lateral view. B. Head, mesosoma, dorsal view. C. Head, anterior view. D. Propodeum, dorsal view. E. Mesosoma, lateral view. F. Hind tibia, lateral view (inset: data labels). 
Comments (from Rousse et al. 2013)

The large series of specimens available in the MNHN collection shows considerable variation with respect to the original description of $P$. caris. The propodeum carination is highly variable, the area basalis being petiolate to truncate, and the area superomedia greatly varies in elongation. Colour also varies from lighter specimens with reduced brownish markings to darker ones with larger black spots on face, vertex, mesoscutum and propodeum. We furthermore observed two male groups with differently sized ocelli. Such variability is, however, not correlated with any other morphological or geographical difference. These specimens might represent a species complex whose study needs more comprehensive molecular and morphometric investigations.

\section{Pristomerus dikidiki sp. nov. urn:1sid:zoobank.org:act:93406C5D-7EE2-4A1E-9F84-0F50CB9BD95B}

Fig. 8

\section{Diagnosis}

Large; mostly black with legs mostly testaceous and trochanters and apex of femora pale dotted; anterior edge of pterostigma whitish; face densely punctate, clypeus almost totally punctate, sculpture smoother on remainder of head; clypeus transverse; malar line moderately short; inner margins of eyes parallel; antenna with 38 flagellomeres, penultimate flagellomere quadrate; mesosoma densely and deeply punctate with a smoother dorsal area on pronotum, ventral half of speculum smooth; area superomedia rather stout, weakly carinate laterally; female femoral tooth very strong; ovipositor moderately long, strongly sinuous. Male unknown.

\section{Differential diagnosis}

Large and mostly black species, differentiated from most other Afrotropical species by the combination of the colour pattern, the strong femoral tooth and the extensively punctate mesonotum. It is morphologically closely related to P. nzakara sp. nov., whose ovipositor is distinctly stouter with a straight apex.

\section{Type material}

\section{Holotype}

DEMOCRATIC REPUBLIC OF THE CONGO: + , "Yangambi (Stan.), XII-1958, P. Dessart" (MRAC).

\section{Description}

Female (holotype)

B 12.1; A 6.2; F 7.7; CT 1.9; ML 0.4; POL 0.8; OOL 1.6; F1 1 1.0; ASM 1.7; OT 1.7; FFT 2.

Colour. Head black with frontal orbit orange, mandible and palpi yellow; mesosoma black; metasoma black with apical and lateral margins of tergites 3 and following testaceous-orange; fore and mid legs testaceous, hind leg mostly dark brown; trochanters and apex of femora pale dotted; wings apically infuscate, venation pale brown, anterior edge of pterostigma whitish.

HEAD. Face deeply and densely punctate, mid-longitudinally weakly bulging; inner margins of eyes parallel; clypeus transverse, entirely punctate; malar line short; frons finely and densely punctate with a weak mid-longitudinal ridge from upper face to median ocellus; vertex and temple coriaceous; occipital carina joining hypostomal carina distinctly above mandible base; antenna with 38 flagellomeres, penultimate flagellomere quadrate.

Mesosoma. Moderately elongate; pronotum sparsely punctate with anterior margin crenulate and a dorsal smoother area; mesopleuron and metapleuron deeply and very densely punctate, with a striate oblique furrow below speculum, speculum ventrally smooth; mesoscutum densely punctate-granulate, punctures apically confluent into transverse rugosities, notaulus moderate and rugose; scutellum densely punctate- 
granulate, apically striate; propodeum deeply punctate-rugose, carination thick, area superomedia rather stout, centrally smoother and hardly delimited laterally. Legs. Femoral tooth long and acute, higher than basally wide.

Meталома. Tergite 2 and apical half of tergite 1 longitudinally aciculate, following tergites coriaceous; thyridium elliptic with main axis longitudinal; ovipositor moderately long and apically strongly sinuous.
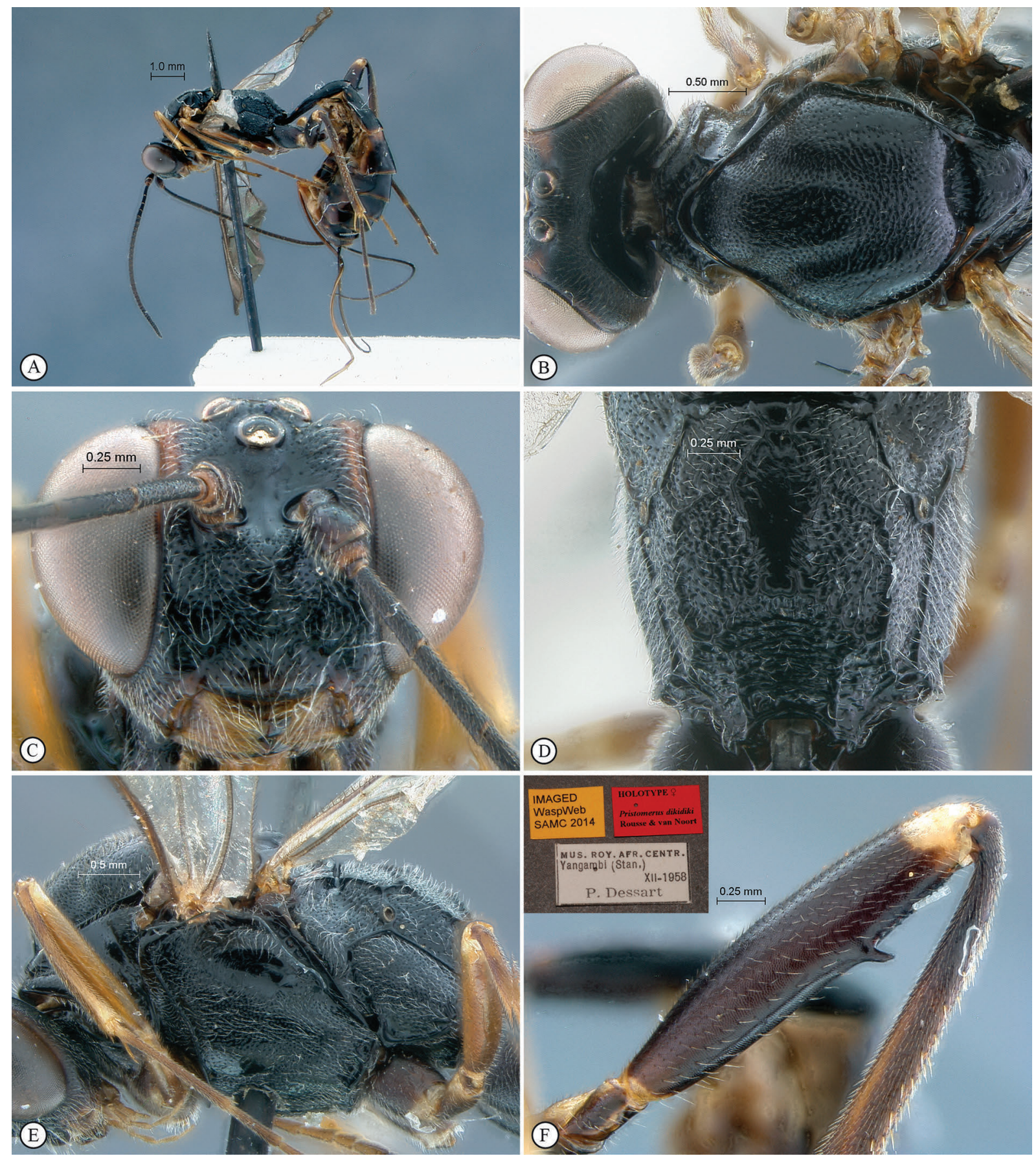

Fig. 8. Pristomerus dikidiki sp. nov. Holotype, $\uparrow$. A. Habitus, lateral view. B. Head, mesosoma, dorsal view. C. Head, anterior view. D. Propodeum, dorsal view. E. Mesosoma, lateral view. F. Hind tibia, lateral view (inset: data labels). 


\section{Male}

Unknown.

\section{Distribution}

Democratic Republic of the Congo.
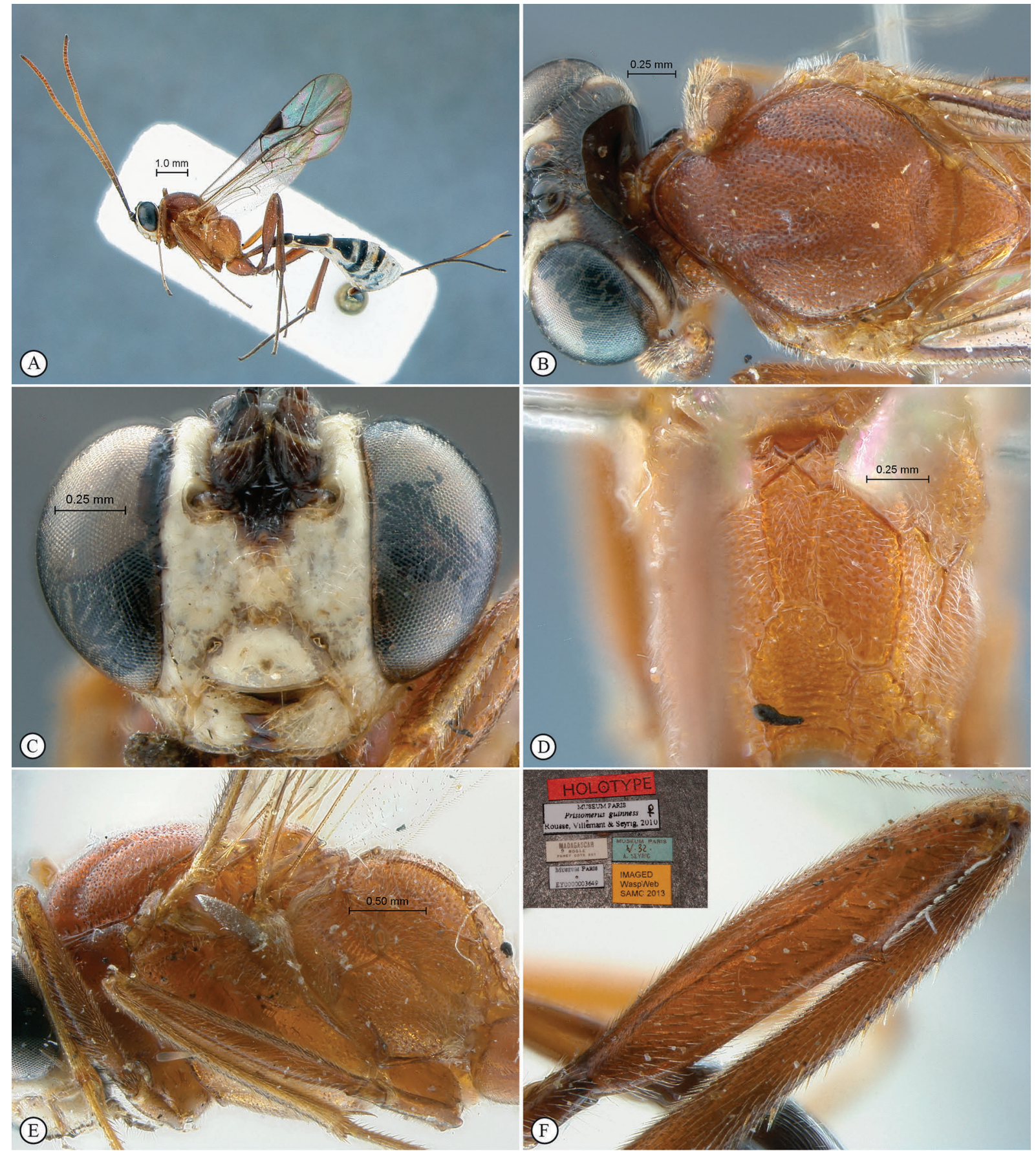

Fig. 9. Pristomerus guinness Rousse, Villemant \& Seyrig, 2013. Holotype, $q$. A. Habitus, lateral view. B. Head, mesosoma, dorsal view. C. Head, anterior view. D. Propodeum, dorsal view. E. Mesosoma, lateral view. F. Hind tibia, lateral view (inset: data labels). 
Pristomerus guinness Rousse, Villemant \& Seyrig, 2013

Fig. 9

Diagnosis (range of variation from Rousse et al. 2013)

Head whitish yellow with frons, inter-ocellar area and occiput black; mesosoma testaceous-orange; metasoma black with apical margin of tergites $2-7$ white; antenna basally black, fading to pale testaceous, then apically darker; face densely and shallowly punctate; inner margins of eyes subparallel; clypeus transverse, sparsely punctate; malar line long; occipital carina joining hypostomal carina shortly above mandible base; antenna long with 35-36 flagellomeres, penultimate flagellomere quadrate; mesosoma elongate, very densely punctate-granulate except pronotum centrally and speculum ventrally smoother, and mesoscutum mid-posteriorly transversely rugose; area superomedia elongate; female femoral tooth about as long as basally wide; ovipositor moderately long, weakly sinuous apically. B 6.2-9.2; A 4.76.9; F 4.9-7.1; CT 1.8; ML 0.7; POL 0.7; OOL 0.4; $\mathrm{Fl}_{\mathrm{n}-1}$ 1.0; ASM 2.5; OT 1.4-1.5; FFT 1-2. Male with ocelli and femoral tooth enlarged, posterior ocellus almost touching eyes dorsally; otherwise similar to female. OOL 0.1; POL 0.4.

\section{Differential diagnosis}

Rather large Madagascan species, differentiated from all other Afrotropical species by the atypical colour pattern: head mostly white, mesosoma testaceous orange and metasoma mostly black with apical margins of tergites white. The only other Afrotropical species with a somewhat similar colour pattern is P. zulu sp. nov., whose face is medially reddish-testaceous and the malar line is distinctly shorter.

\section{Material examined}

\section{Holotype}

MADAGASCAR: , "MADAGASCAR, Rogez, foret côte est, V. 32, EY 0000003649” (MNHN).

\section{Distribution}

Madagascar.

Pristomerus hansoni Rousse, Villemant \& Seyrig, 2013

Fig. 10

Diagnosis (range of variation from Rousse et al. 2013)

Head whitish yellow with frons, inter-ocellar area and occiput black; remainder of body orange; face mostly smooth with some shallow punctures laterally; inner margins of eyes subparallel; clypeus transverse, quite smooth; malar line moderately long; frons, vertex and temple coriaceous; occipital carina joining hypostomal carina at mandible base; antenna with 33-39 flagellomeres, penultimate flagellomere slightly elongate; mesosoma elongate; pronotum quite smooth; mesopleuron and metapleuron moderately and shallowly punctate with ventral half of speculum smooth; mesoscutum moderately punctate-granulate; punctation on scutellum sparser, inter-punctures spaces smooth; area superomedia elongate; female femoral tooth absent; ovipositor very long, apically strongly sinuous. B 7.6-9.2; A 5.0-6.4; F 4.7-6.7; CT 1.9; ML 0.6; POL 0.6; OOL $0.9 ; \mathrm{Fl}_{\mathrm{n}-1} 1.2 ;$ ASM 2.3; OT 2.8-3.2; FFT 0. Male with mesosoma smoother, ocelli and femoral tooth enlarged; otherwise similar to female. POL 0.3 ; OOL 0.2 .

\section{Differential diagnosis}

White faced species from Madagascar, chiefly characterized by the very long ovipositor, much longer than in any other Afrotropical species of Pristomerus. 


\section{Material examined}

Holotype

MADAGASCAR: +, "MADAGASCAR, Rogez, forêt côte est, XII.30, EY 0000003620” (MNHN).

\section{Distribution}

\section{Madagascar.}
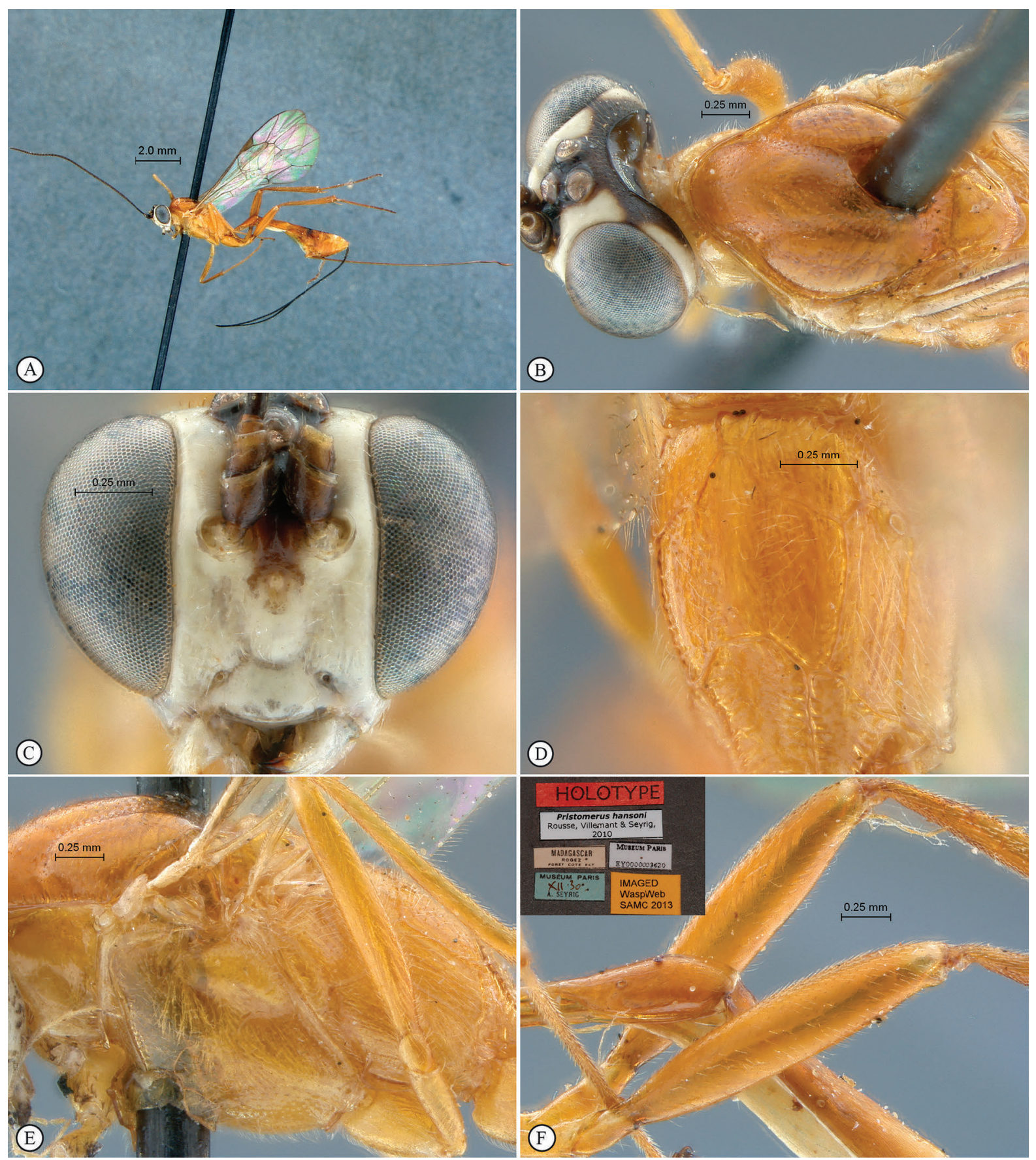

Fig. 10. Pristomerus hansoni Rousse, Villemant \& Seyrig, 2013. Holotype, $\uparrow$. A. Habitus, lateral view. B. Head, mesosoma, dorsal view. C. Head, anterior view. D. Propodeum, dorsal view. E. Mesosoma, lateral view. F. Hind tibia, lateral view (inset: data labels). 


\section{Pristomerus herero sp. nov. urn:1sid:zoobank.org:act:A7126D35-043A-429F-B1CB-9F13C3D0FAA4}

Fig. 11

\section{Diagnosis}

Large; mottled yellow to reddish-orange with numerous variable black markings on entire body; face deeply and densely punctate, punctation slightly sparser on clypeus; clypeus weakly transverse; malar line long; remainder of head coriaceous except inter-ocellar area deeply and densely punctate; antenna with 31-33 flagellomeres, penultimate flagellomere shorter than wide; mesosoma coarsely and densely punctate but pronotum mid-dorsally and speculum ventrally smooth; area superomedia elongate and not carinate postero-laterally; female femoral tooth strongly reduced, reduced to a subapical point followed by denticles; ovipositor very long, its apex sinuous. Male with mesosoma more shallowly punctate, inner margins of eyes distinctly diverging ventrally, ocelli enlarged, femur and femoral tooth strongly stouter, and area superomedia fully carinate.

\section{Differential diagnosis}

Large and mostly yellow and reddish-orange; differentiated from all other Afrotropical species by the combination of the coarse punctation on face and mesosoma, the near absence of the femoral tooth in the female and the very long ovipositor. Probably related to P. roberti in Madagascar, which is, however, far smaller with a stronger femoral tooth and a fully delimited area superomedia in both sexes.

\section{Type material}

\section{Holotype}

NAMIBIA: + , “Kaoko Otavi S. W. A. Mus. exp. Mar. 1926, SAM-HYM-P001203” (SAMC).

\section{Paratypes}

NAMIBIA: 1 +, $2 \hat{\jmath}$, same label data (SAMC).

\section{Description}

Female (2 specimens)

B 9.8-10.2; A 6.3-6.9; F 7.9-8.2; CT 1.6; ML 0.7; POL 1.0; OOL 1.3; $\mathrm{Fl}_{\mathrm{n}-1} 0.8$; ASM 2.3; OT 2.3; FFT 1.

CoLour. Background colour mottled yellow and reddish-orange with face brown and variable black markings (sometimes strongly reduced) on: frons, ocellar area, occiput, anterior margin of mesosternum and mesopleuron, ventral margin of metapleuron, axillar trough, metanotum and basal margin of propodeum, and basal half of tergites 1-3; legs yellowish orange, hind tibia somewhat darker and hind tarsus strongly infuscate; flagellum and ovipositor sheath strongly infuscate; wings hyaline, venation brown.

HEAD. Face very densely and deeply punctate, punctation slightly sparser on median bulge; inner margins of eyes weakly diverging ventrally; clypeus weakly transverse, long, punctation sparser and shallower than on face; malar line long; frons, vertex and temple coriaceous except inter-ocellar area deeply and densely punctate; occipital carina joining hypostomal carina at mandible base; antenna with 32-33 flagellomeres, rather thick, penultimate flagellomere shorter than wide.

Mesosoma. Entire mesosoma unusually deeply and densely punctate, except pronotum mid-dorsally and speculum ventrally smooth; notaulus moderate; propodeum coarsely transversely punctate-rugose medially; area superomedia fairly elongate and not delimited postero-laterally. Legs. Femoral tooth hardly distinct, reduced to a weak subapical point, followed by some denticles. 
Metasoma. Tergite 2 and apical half of tergite 1 coarsely aciculate, following tergites coriaceous; thyridium subcircular; ovipositor very long and apically slightly sinuous.

Male (paratype)

B 8.8-9.9; A 6.0-6.4; F 7.3-7.9; POL 0.8; OOL 0.7. Inner margins of eyes distinctly diverging ventrally; ocelli and hind femur enlarged; femoral tooth long and acute, followed by strong denticles; mesosoma
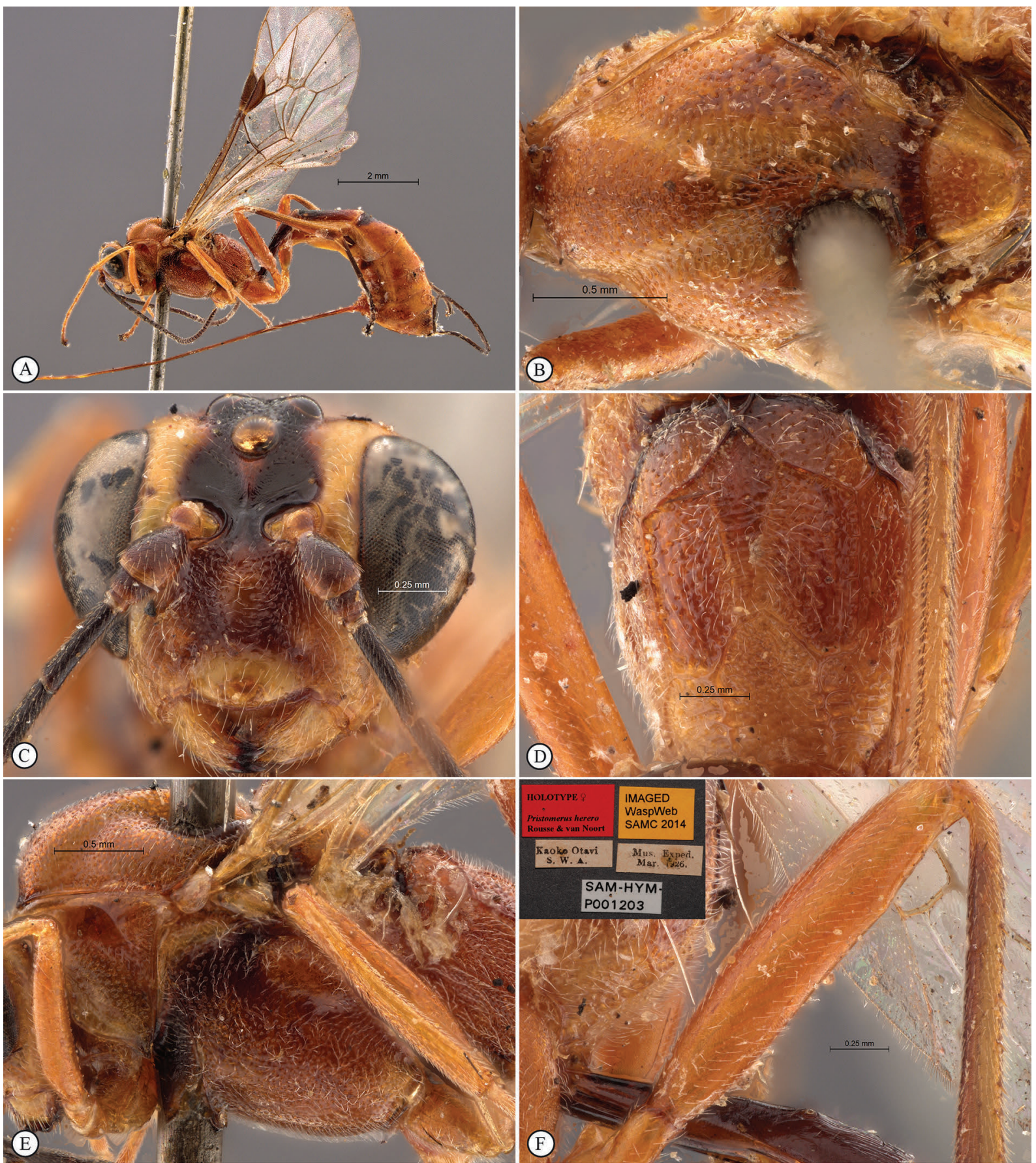

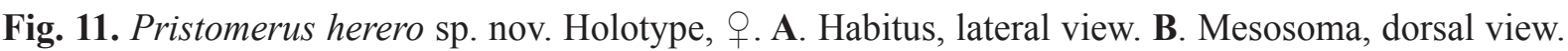
C. Head, anterior view. D. Propodeum, dorsal view. E. Mesosoma, lateral view. F. Hind tibia, lateral view (inset: data labels). 
more shallowly punctate, lateral lobes of mesoscutum largely coriaceous; area superomedia fully carinate; otherwise similar to female.

\title{
Distribution
}

Namibia.

\author{
Pristomerus hutu sp. nov. \\ urn:1sid:zoobank.org:act:8EE623B7-247F-4A4F-8F79-AEC68BB95B75
}

Fig. 12

\section{Diagnosis}

Most of body ventrally and laterally mostly pale yellow to yellowish-orange, dorsally nearly entirely black; face except orbits dark brown; fore and mid legs yellowish-orange, hind legs mostly dark brown to black, femora and trochanters apically white-dotted; anterior edge of pterostigma whitish; face laterally densely punctate, clypeus and middle of face sparsely and finely punctate; clypeus weakly transverse, convex in profile; malar line short; remainder of head coriaceous; antenna with 28-31 flagellomeres; mesosoma moderately to densely punctate but pronotum almost entirely smooth, speculum ventrally smooth, and area superomedia usually transversely striate; area superomedia elongate, usually hardly delimited laterally beyond anterior transverse carina; female femoral tooth weak but distinct; ovipositor moderately long, apically moderately sinuous. Male with ocelli and hind femur enlarged, femoral tooth long and acute, otherwise similar to female.

\section{Differential diagnosis}

Moderately sized, ventrally yellow to orange and dorsally black. Differentiated from all other Afrotropical Pristomerus species by the combination of the light facial orbits, the always black scutellum, the very short malar line, and the weak though distinct female femoral tooth.

\section{Type material}

\section{Holotype}

UGANDA: + , "UGANDA, Kibale National Park, Kanyawara, Makerere University Biological field station, $1505 \mathrm{~m}, 0^{\circ} 33.859^{\prime} \mathrm{N} 30^{\circ} 21.630^{\prime} \mathrm{E}, 31$.vii-3.viii.2005, S van Noort, UG05-M07, Malaise trap, primary mid-altitude rainforest, SAM-HYM-P047386" (SAMC).

\section{Paratypes}

UGANDA: 2 우, same label data except: “1495 m, 0³3.996’N 30²1.262’E, 5-12.viii.2005, UG05M15, secondary mid-altitude Rainforest, SAM-HYM-P047387" (SAMC); 1 \&, same label data except: "3-5.vii.2005, UG05-M12, SAM-HYM-P047398" (SAMC); 1 ㅇ, same label data except: "12-185. viii.2005, UG05-M19, SAM-HYM-P047399" (SAMC); 1 †, same label data except: " $0{ }^{\circ} 33.871$ 'N 30²1.355'E, 12-26.viii.2008, UG08-KF2-M12, secondary mid-altitude Rainforest, SAM-HYMP047388" (SAMC); 1 + , same label data except: “1505 m, 0³3.823’N 30²1.490’E, 2-12.viii.2008, UG08-KF3-M03, primary mid-altitude Rainforest, SAM-HYM-P047400” (SAMC); 2 우, 1 o,, "Uganda, Rwenzori Mts, nr. Nyakalengija village, along Mubuku river. 1640 m 12.III.2013 A. Gumovsky; agricultural landscape with cultivated plants + some ruderal plants, SAM-HYM-P047389" (SAMC).

CENTRAL AFRICAN REPUBLIC: 1 \&, "Central African Republic, Préfecture Sangha-Mbaéré, Parc

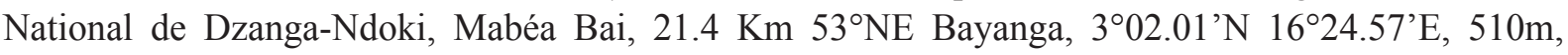
6-7.v.2001, S. van Noort, Malaise trap, CAR01-M58, Lowland Rainforest, marsh clearing, SAMHYM-P047390" (SAMC). 


\section{Description}

Female (10 specimens)

B 6.5-7.2; A 4.1-4.5; F: 4.0-4.4; CT 1.6; ML 0.3; POL 0.5; OOL 0.9; $\mathrm{Fl}_{\mathrm{n}-1}$ 1.3; ASM 2.3; OT 1.5-1.8; FFT 1.

CoLour. Background colour of head yellowish-orange with face often medially dark brown, mandible, malar space, clypeus and frontal orbit sometimes pale yellow, and frons, inter-ocellar area, and occiput
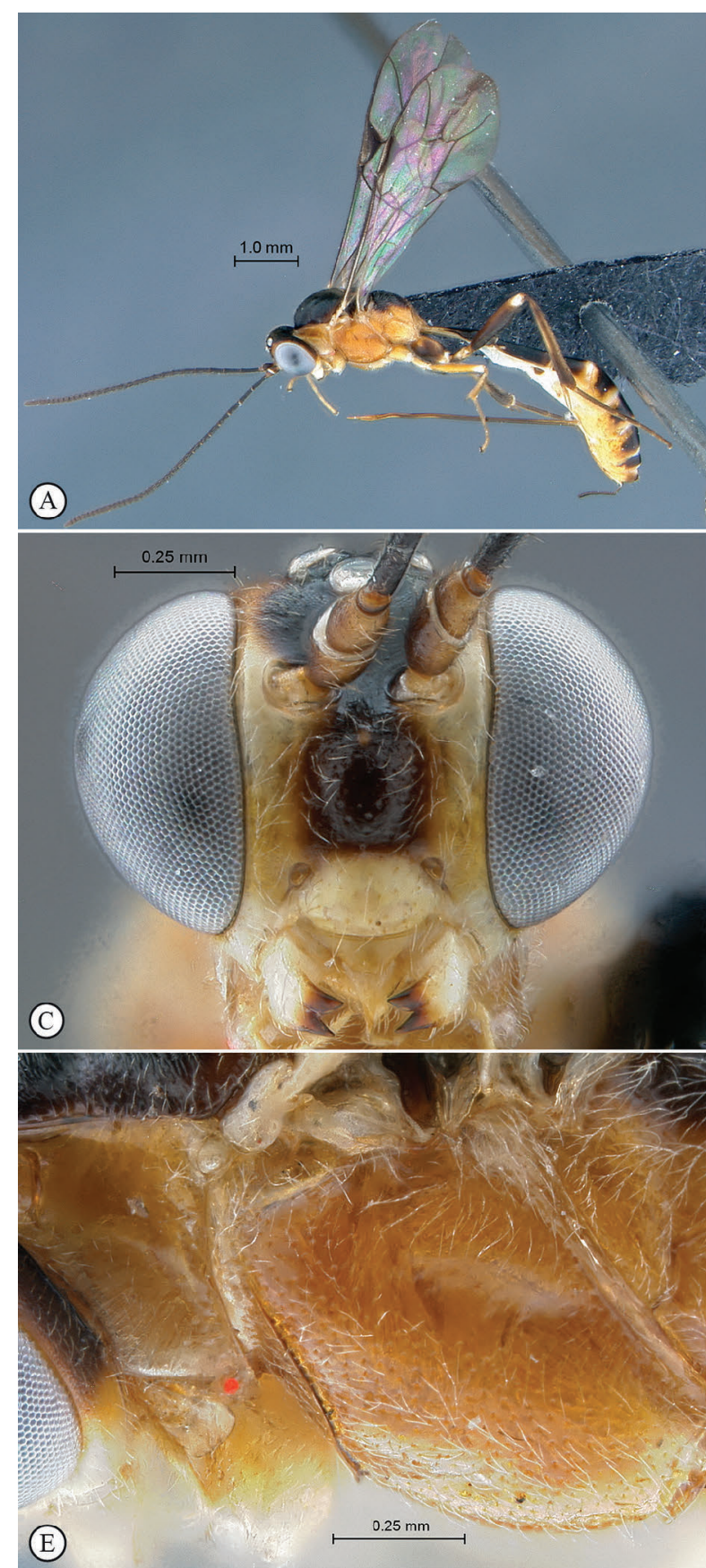
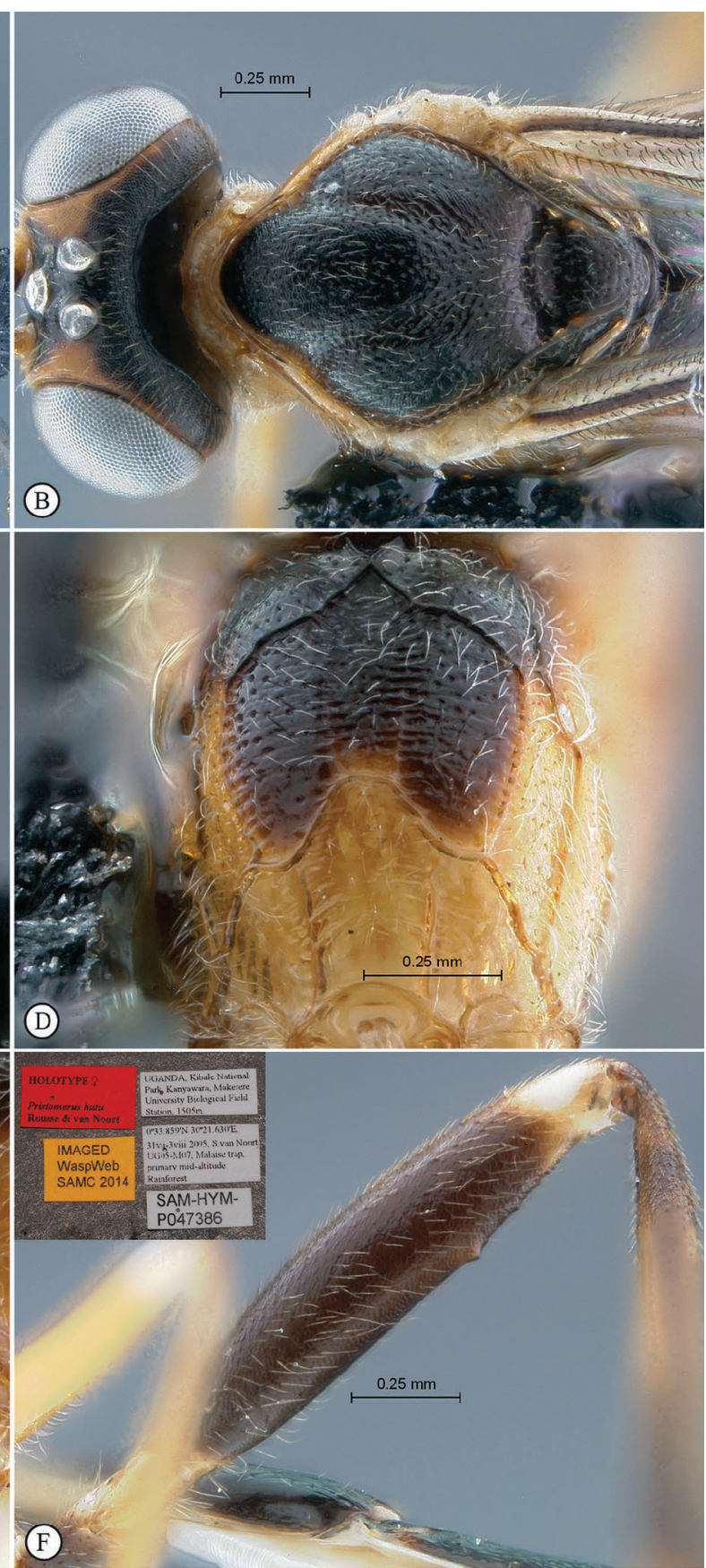

Fig. 12. Pristomerus hutu sp. nov. Holotype, ․ . A. Habitus, lateral view. B. Head, mesosoma, dorsal view. C. Head, anterior view. D. Propodeum, dorsal view. E. Mesosoma, lateral view. F. Hind tibia, lateral view (inset: data labels). 
black; background colour of mesosoma orange, dorsally entirely black except sometimes notaulus and lateral margin of mesoscutum, metanotum and a variable basal part of propodeum; tergites 1-2 nearly entirely black, following tergites pale yellow to orange with a large median black spot of variable extent; fore and mid legs yellowish-orange, hind leg mostly dark brown to black, all trochanters and femora apically white; wings hyaline, venation brown, pterostigma more or less whitish anteriorly.

HEAD. Face moderately densely and deeply punctate, punctation sparser and finer on median bulge; inner margins of eyes weakly converging ventrally; clypeus barely transverse, long, distinctly convex in profile view, shallowly and sparsely punctate; malar line very short; frons, vertex and temple coriaceous; occipital carina joining hypostomal carina shortly above mandible base; antenna with 28-32 flagellomeres, penultimate flagellomere slightly elongate.

Mesosoma. Moderately elongate; pronotum almost smooth; mesopleuron moderately punctate with an oblique shallowly striate furrow below speculum, ventral half of speculum smooth; metapleuron moderately and shallowly punctate-granulate; mesoscutum coarsely and densely punctate-granulate, apical half with punctures confluent into transverse rugosities, notaulus moderate; scutellum densely and evenly punctate, its posterior vertical face longitudinally striate; propodeum moderately punctate, area superomedia elongate, usually hardly delimited laterally beyond anterior transverse carina and often transversely striate. Legs. Femoral tooth weak but always distinct, followed by minute denticles.

Metasoma. Tergite 2, apical half of tergite 1 and basal half of tergite 3 longitudinally aciculate, following tergites coriaceous; thyridium elliptic and more or less wide, its main axis longitudinal; ovipositor moderately long, its apical third moderately sinuous.

Male (paratype)

B 6.8; A 4.4; F: 4.2; POL 0.5; OOL 0.6. Ocelli and hind femur enlarged; femoral tooth long and acute, followed by strong denticles; otherwise similar to female.

\section{Distribution}

Central African Republic, Uganda.

$$
\begin{aligned}
& \text { Pristomerus kagga sp. nov. } \\
& \text { urn:1sid:zoobank.org:act:2EF10C4A-F4E5-4F5D-8247-DA8F06876E80 }
\end{aligned}
$$

Fig. 13

\section{Diagnosis}

Moderately sized; background colour rufo-testaceous with black markings of variable extent; face densely punctate-granulate, punctation sparser on clypeus and on remainder of head; inner margins of eyes subparallel; malar line very long; ocelli reduced; antenna with 25-28 flagellomeres, penultimate one slightly transverse; entire mesosoma densely, deeply and evenly punctate but pronotum and speculum mostly smooth; propodeum with area superomedia elongate, weakly delimited laterally; female femoral tooth very strong, followed by strong denticles; ovipositor moderately short, its apex moderately sinuous.

\section{Differential diagnosis}

Moderately sized species with a characteristic colour pattern, rufo-testaceous with large black markings; differentiated from all other Afrotropical species by the combination of the very long malar line and the strong femoral tooth in females. The reduced ocelli and the dense punctation over the entire mesosoma are also helpful for identification. 


\section{Etymology}

Kagga is old Norse for a keg or casket and is taken from the name of the type locality.

\section{Type material}

\section{Holotype}

SOUTH AFRICA: + , "South Africa, Western Cape, Cederberg, Kagga Kamma Nature Reserve, 3245.382’S 19³4.045'E, 1065m, 19 July 2014, S. van Noort, Sweep, Swartruggens Quartzite Fynbos, KAG14-FYN1-S01, SAM-HYM-P048057” (SAMC).
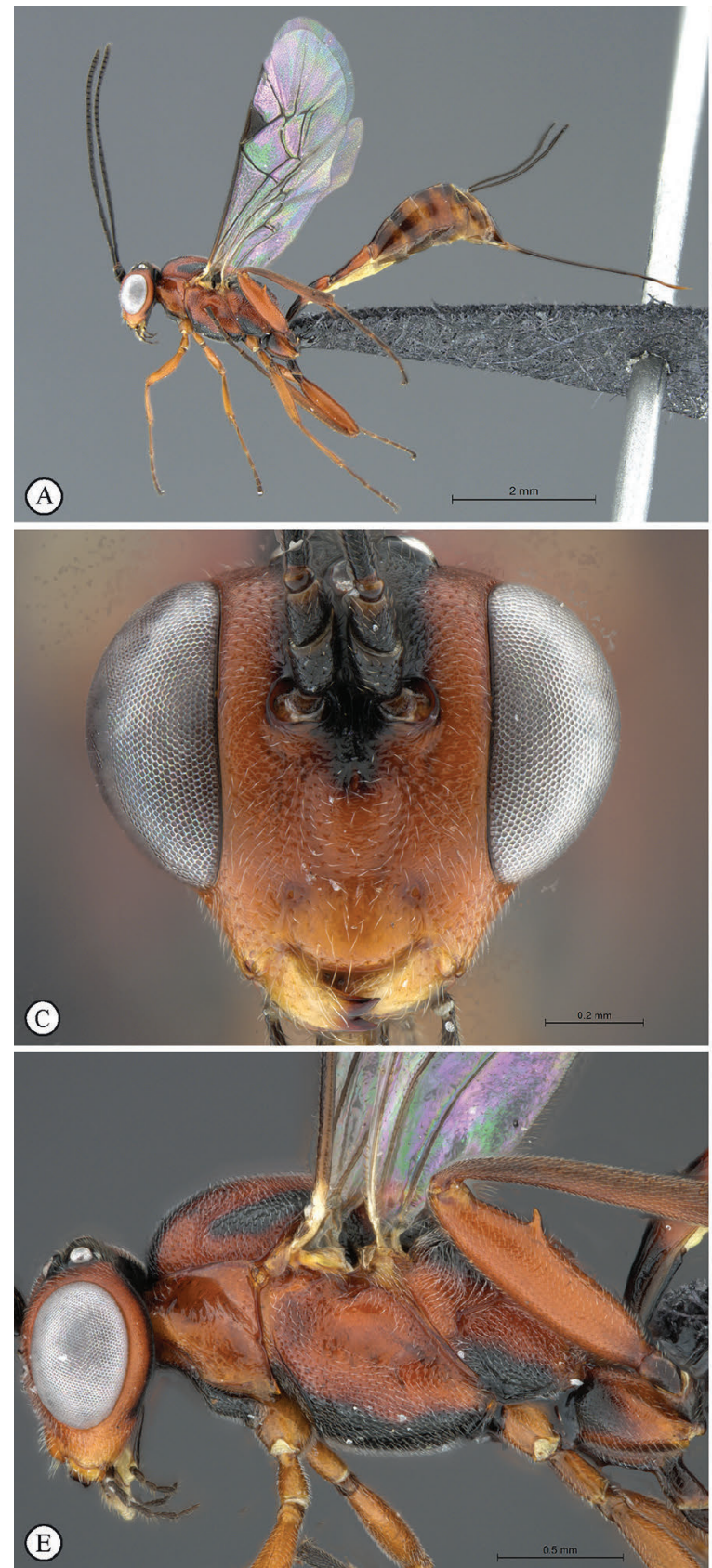
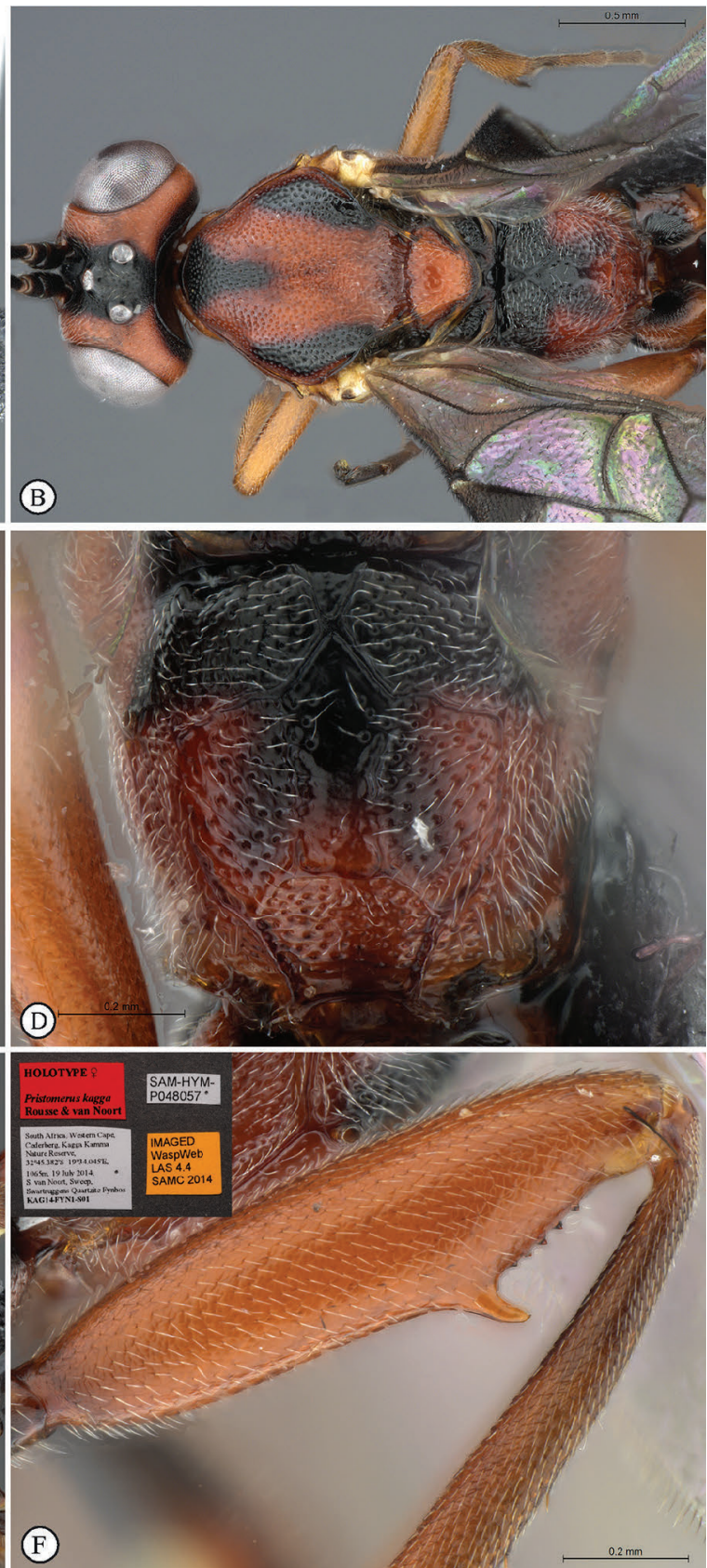

Fig. 13. Pristomerus kagga sp. nov. Holotype, ๆ. A. Habitus, lateral view. B. Head, mesosoma, dorsal view. C. Head, anterior view. D. Propodeum, dorsal view. E. Mesosoma, lateral view. F. Hind tibia, lateral view (inset: data labels). 
Paratypes

SOUTH AFRICA: 2 우, same label data except: "SAM-HYM-P048056 and SAM-HYM-P048058" (SAMC).

\section{Description}

Female (3 specimens)

B 4.9-5.8; A 2.7-3.1; F 3.6-4.2; CT 1.5; ML 1.1; POL 2.1; OOL 1.5; Fl $\mathrm{n}_{1-1}$ 0.9; ASM 2.0; OT 1.2-1.3; FFT 2.

CoLour. Background colour rufo-testaceous with black markings of variable extent on: frons, inter-ocellar area (marking sometimes extending to frons and occiput), occiput, mesoscutal lobes (sometimes only notaulus rufo-testaceous), sometimes scuto-scutellar groove and base of scutellum, propodeum (basally to entirely), mesopleuron and metapleuron almost entirely rufo-testaceous to black with only speculum area rufo-testaceous, entire mesosoma ventrally, basal half of tergite 1 only to metasoma almost entirely black, hind coxa more or less entirely, flagellum and ovipositor sheath; wings hyaline, venation dark brown.

HEAD. Face densely punctate-granulate, punctation sparser on median bulge; inner margins of eyes subparallel; clypeus barely transverse, long, shallowly and sparsely punctate; malar line very long; frons, vertex and temple sparsely to densely punctate-granulate; antenna with 25-28 flagellomeres, penultimate flagellomere shorter than wide.

Mesosoma. Moderately elongate; pronotum almost smooth with some sparse punctures along dorsal, posterior and ventral margins; mesopleuron and metapleuron densely, deeply and evenly punctate, speculum smooth except some punctures dorsally; mesoscutum and scutellum densely, deeply and evenly punctate, apical third of mesoscutum with punctures somewhat confluent into weak transverse rugosities, notaulus relatively strong; propodeum densely, deeply and evenly punctate with area superomedia smoother centrally, area superomedia elongate, weakly delimited laterally beyond anterior transverse carina. Legs. Femoral tooth very strong, obviously higher than basally wide, followed by strong denticles.

Metasoma. Tergite 2 and apical half of tergite 1 longitudinally aciculate, following tergites coriaceous; thyridium large and subcircular; ovipositor moderately short, straight, moderately sinuous apically.

\section{Male \\ Unknown.}

\section{Distribution}

South Africa (Western Cape).

Pristomerus kelikely Rousse, Villemant \& Seyrig, 2013

Fig. 14

Diagnosis (updated from Rousse et al. 2013)

Small; yellow to yellowish-orange overall; face moderately to densely punctate; inner margins of eyes slightly converging ventrally; clypeus strongly transverse, sparsely and shallowly punctate; malar line short; remainder of head coriaceous; occipital carina joining hypostomal carina at mandible base; antenna with 29-32 flagellomeres, penultimate flagellomere longer than wide; mesosoma elongate, moderately to densely punctate but pronotum almost entirely and ventral half of speculum smooth, and mesonotum apically shallowly punctate; female femoral tooth absent; ovipositor moderately long, apically weakly sinuous. B 3.2-4.6; A 2.8-4.0; F 3.2-4.3; CT 2.0; ML 0.4; POL 0.8; OOL 1.2; Fl ${ }_{\mathrm{n}-1} 1.2$; ASM 2.1; OT 1.6-1.8; FFT 0. Male with ocelli not enlarged, hind femur and femoral tooth stouter, and area superomedia sometimes more slender. POL 0.9; OOL 1.1. 


\section{Differential diagnosis}

Small and entirely yellow to yellowish orange species; differentiated from most other Afrotropical species by the absence of the femoral tooth in females, the short malar line, the strongly transverse clypeus and the rather long ovipositor. It is closely related to P. moramora and $P$. venda sp. nov., from which it may be differentiated by the colour and antennal length characters given in the key (see comments below). It is also structurally very similar to $P$. sara sp. nov.; however, this species exhibits white-marked femora and tibiae, a colour pattern that appears to have ecological relevance (see general discussion).
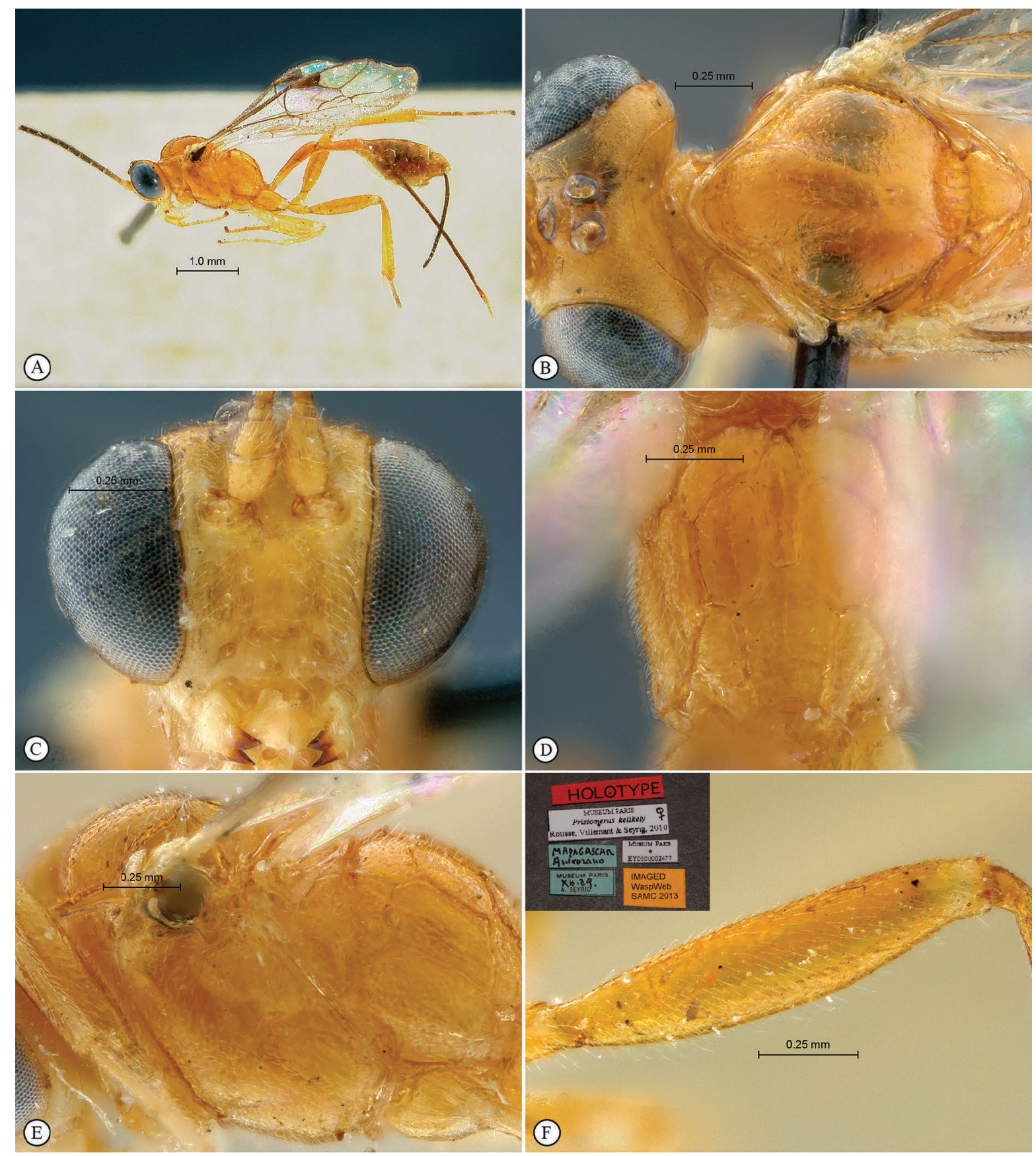

Fig. 14. Pristomerus kelikely Rousse, Villemant \& Seyrig, 2013. Holotype, $q$. A. Habitus, lateral view. B. Head, mesosoma, dorsal view. C. Head, anterior view. D. Propodeum, dorsal view. E. Mesosoma, lateral view. F. Hind tibia, lateral view (inset: data labels). 


\section{Material examined}

Holotype

MADAGASCAR: ๆ, "MADAGASCAR, Anivorano XII 1929, EY 0000002477” (MNHN).

\section{Other material}

TANZANIA: 3 우, “Tanzania, Mkomazi Game Reserve, Ibaya Camp, 3.58S 37.48E 25.xii.199529.i.1996, S. van Noort, Malaise trap, Acacia / Commiphora / Combretum bushland, SAM-HYMP048059" (SAMC); 1 + , same locality, "Kikolo plot, 0408.72'S 3801.37’E, 16 April-2 May 1996, S. van Noort, Commiphora woodland, Malaise trap, SAM-HYM-P016192” (SAMC).

\section{Distribution}

Madagascar. New record: Tanzania.

\section{Comments}

The three species $P$. kelikely, $P$. moramora and $P$. venda can only be keyed by rather weak though constant differentiating features. Pristomerus moramora is mostly separated from the other two by the extensive dark colouration of the mesosoma and metasoma. Furthermore, the males of $P$. kelikely and $P$. moramora have ocelli that are not enlarged, which is very unusual in Pristomerus and separate both from $P$. venda. However, several specimens in the SAMC and MNHN collections could not unambiguously be assigned to one of these three species: this species-complex needs further examination before being fully resolved.

Pristomerus keyka Rousse, Villemant \& Seyrig, 2013

Fig. 15

Diagnosis (updated from Rousse et al. 2013)

Small; pale yellow to testaceous orange with very variable dark markings on inter-ocellar area, around scutellum and on metasoma; flagellum dark brown, basally yellow; face shallowly punctate; inner margins of eyes subparallel; clypeus smooth, strongly transverse; malar line moderately long; occipital carina joining hypostomal carina shortly above mandible base; antenna short with 23-27 flagellomeres, penultimate flagellomere subquadrate; mesosoma moderately elongate, laterally densely and shallowly punctate-granulate including most of speculum but pronotum dorsally smooth, mesoscutum coriaceous with some punctures along notaulus, scutellum almost smooth; propodeum with area superomedia often weakly delimited laterally beyond anterior transverse carina; female femoral tooth small, followed by minute denticles; ovipositor long, its apex weakly sinuous. B 4.5-4.9; A 2.3-2.5; F 2.4-2.8; CT 2.2; ML 0.6; POL 1.0; OOL 1.3; Fl $l_{\mathrm{n}-1} 1.1$; ASM 1.8; OT 1.8-2.0; FFT 1. Male with inner margins of eyes diverging ventrally, ocelli strongly enlarged, hind femur and femoral tooth stouter, scutellum quite smooth. POL 0.6; OOL 0.3.

\section{Differential diagnosis}

Small and mostly yellowish with variable dark dorsal markings; differentiated from all other Afrotropical species by the combination of the short antenna (basally yellow fading to dark brown), the mesoscutum coriaceous with only few punctures along the notaulus, the strongly transverse clypeus and the short female femoral tooth.

\section{Material examined}

\section{Holotype}

MADAGASCAR: + , “MADAGASCAR, Mahajanga Province, Parc Nat Namoraka, 162' $28^{\circ}, 45^{\circ} 20^{\prime} \mathrm{E}$, November 2002 colls Fisher, Griswold et al., in tropical dry forest, California Academy of Sciences" (CASC). 


\section{Paratype}

MADAGASCAR: + , same label data, EY 0000002493 (MNHN).

\section{Other material}

DEMOCRATIC REPUBLIC OF THE CONGO: 1 q, "Elisabethville [Lubumbashi] (A la lumière [attracted to light]) I. 1960 Ch. Seydel" (MRAC); 1 đ̊, "South Africa c. $25 \mathrm{~km} \mathrm{~W}$ Pretoria along R-514 11-1-1995 K. W. R. Zwart" (SANC).
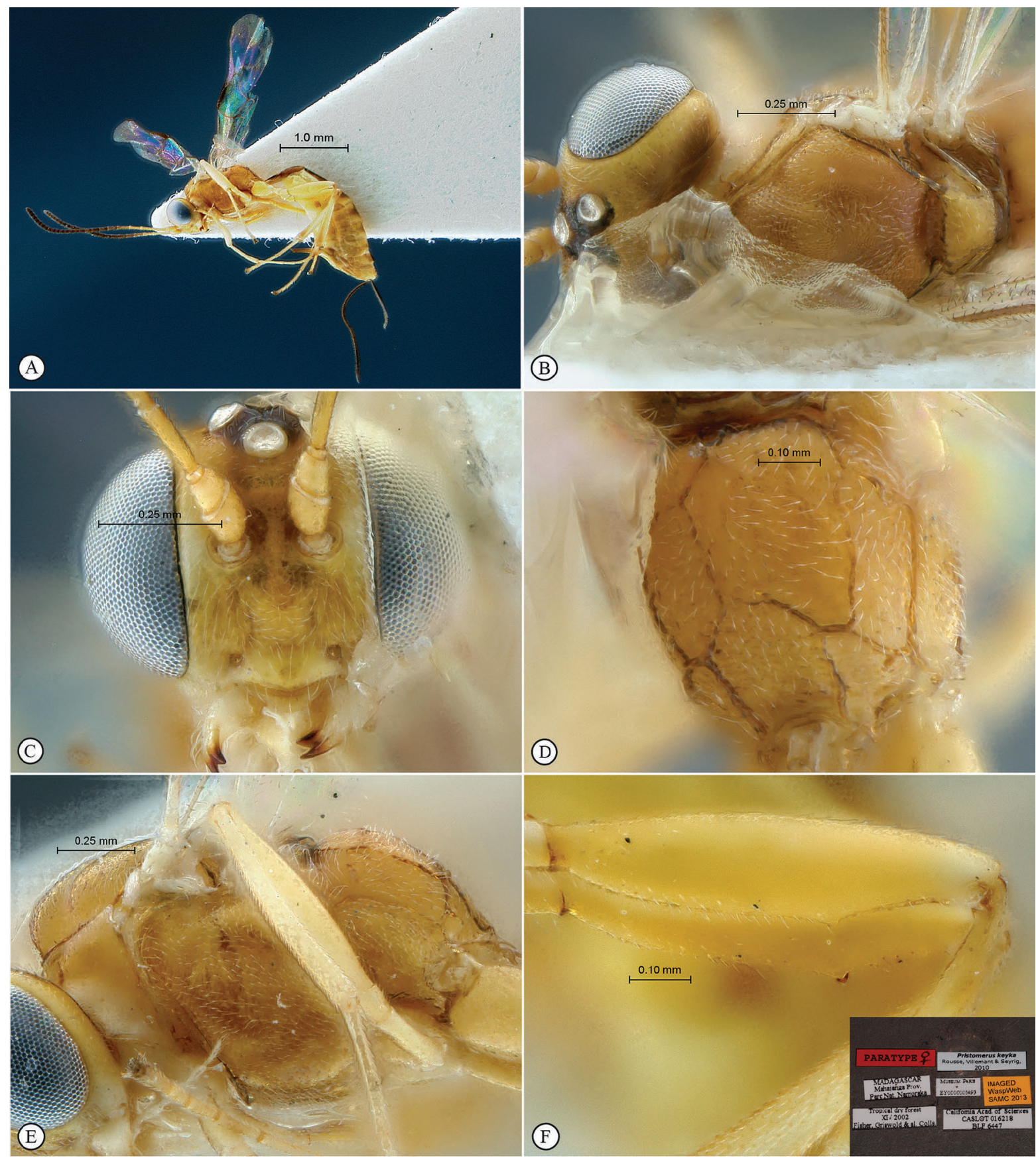

Fig. 15. Pristomerus keyka Rousse, Villemant \& Seyrig, 2013. Paratype, + . A. Habitus, lateral view. B. Head, mesosoma, dorsal view. C. Head, anterior view. D. Propodeum, dorsal view. E. Mesosoma, lateral view. F. Hind tibia, lateral view (inset: data labels). 


\section{Distribution}

Madagascar. New records: Democratic Republic of the Congo, South Africa.

Pristomerus khoikhoi sp. nov. urn:1sid:zoobank.org:act:C10B9AAB-BA87-4421-81A6-DE6331803CF9

Fig. 16

\section{Diagnosis}

Small; mostly black with legs mostly yellowish-orange; face moderately punctate; clypeus transverse, ventrally smooth; remainder of head coriaceous to finely granulate; inner margins of eyes subparallel; malar line very long; antenna short and slender with 19-25 flagellomeres, penultimate flagellomere strongly elongate; mesosoma laterally moderately to densely punctate with speculum ventrally smooth, mesoscutum coriaceous with notaulus punctate, scutellum smooth; female femoral tooth small; ovipositor moderately long, strongly sinuous apically. Male with ocelli weakly enlarged, hind femur swollen and femoral tooth stronger.

\section{Differential diagnosis}

Small and mostly black, apparently restricted to the south of South Africa. Differentiated from all other species of Pristomerus by the combination of the coriaceous mesoscutum, the smooth scutellum, the short antenna and the very long malar line.

\section{Type material}

\section{Holotype}

SOUTH AFRICA: + , “SOUTH AFRICA, Western Cape, Rocherpan Nature Reserve, $32^{\circ} 36.802^{\prime}$ S 18¹8.150'S, 9 m, 29 September 2012, P. Rousse, Sweep, West Coast Strandveld RP12-STR1-S16, SAM-HYM-P047392" (SAMC).

\section{Paratypes}

SOUTH AFRICA: $1 \hat{\jmath}$, same label data (SAMC); 1 $\hat{\partial}$, same label data except: "28 September 2012 RP12STR1-S04 SAM-HYM-P047393" (SAMC); 1 , "South Africa, W. Cape, Koeberg Nature Reserve, 3337.622’S 18²4.259'S, 20 Mar-17 April 1998, S van Noort, Malaise trap, KO97-M30, West Coast Stranveld SAM-HYM-P047394" (SAMC); 1 9, same label data except: "3-31 October 1997, KO97-M12

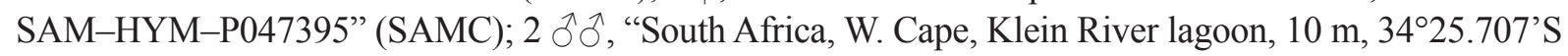
19²1.494'S, 16 May 1998, S. van Noort, Sweep, WB97-S68, South Coast Strandveld, Leucodendrum

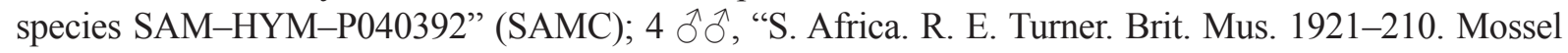
Bay, Cape Province. April 1921" (BMNH); 1 ô, same label data except: "1921-248, May. 1921" (BMNH);

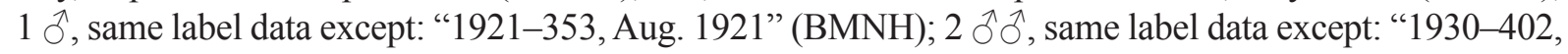
vi-vii. 1930" (BMNH); 1 q, "Hendrik Verwoerd Dam 12.3.69 L. C. Starke, ACP 5727" (SANC); 1 q, "South Africa, C. P. Fort Beaufort, 32.46S 26.38E. 01.xii.1983 GL Prinsloo NC Grobbelaar" (SANC).

\section{Other material}

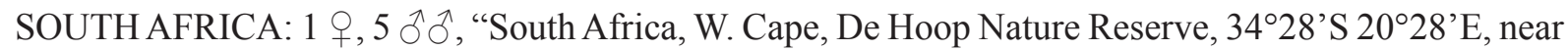
Koppie Alleen, 40 m alt., 28 September 1995, S. van Noort, Sweep, Strandveld including Sideroxylon inerma SAM-HYM-P047161" (SAMC); 1 q, "Knersvlakte, Namaqualand, Mus. exped., Oct. 1950, SAM-HYM-P001201" (SAMC).

\section{Description}

Female ( 5 specimens)

B 3.5-4.2; A 1.9-2.3; F 2.5-3.1; CT 1.8; ML 0.9; POL 1.6; OOL 1.3; Fl 1 1.5; ASM 2.3; OT 1.6-1.8; FFT 1. 
CoLour. Mostly black with lighter yellowish-orange and pale yellow parts; yellowish-orange: clypeus, scape, pedicel, fore and mid legs; pale yellow: mandible, tegula and metasomal sternites; metasoma sometimes dark testaceous from tergite 3 ; hind leg testaceous with coxa black and tibia medially pale yellow; wings hyaline, venation brown.

HEAD. Face mid-longitudinally bulging, moderately punctate; clypeus transverse, dorsally sparsely punctate and ventrally smooth, its ventral margin strongly and evenly convex; malar line very long;

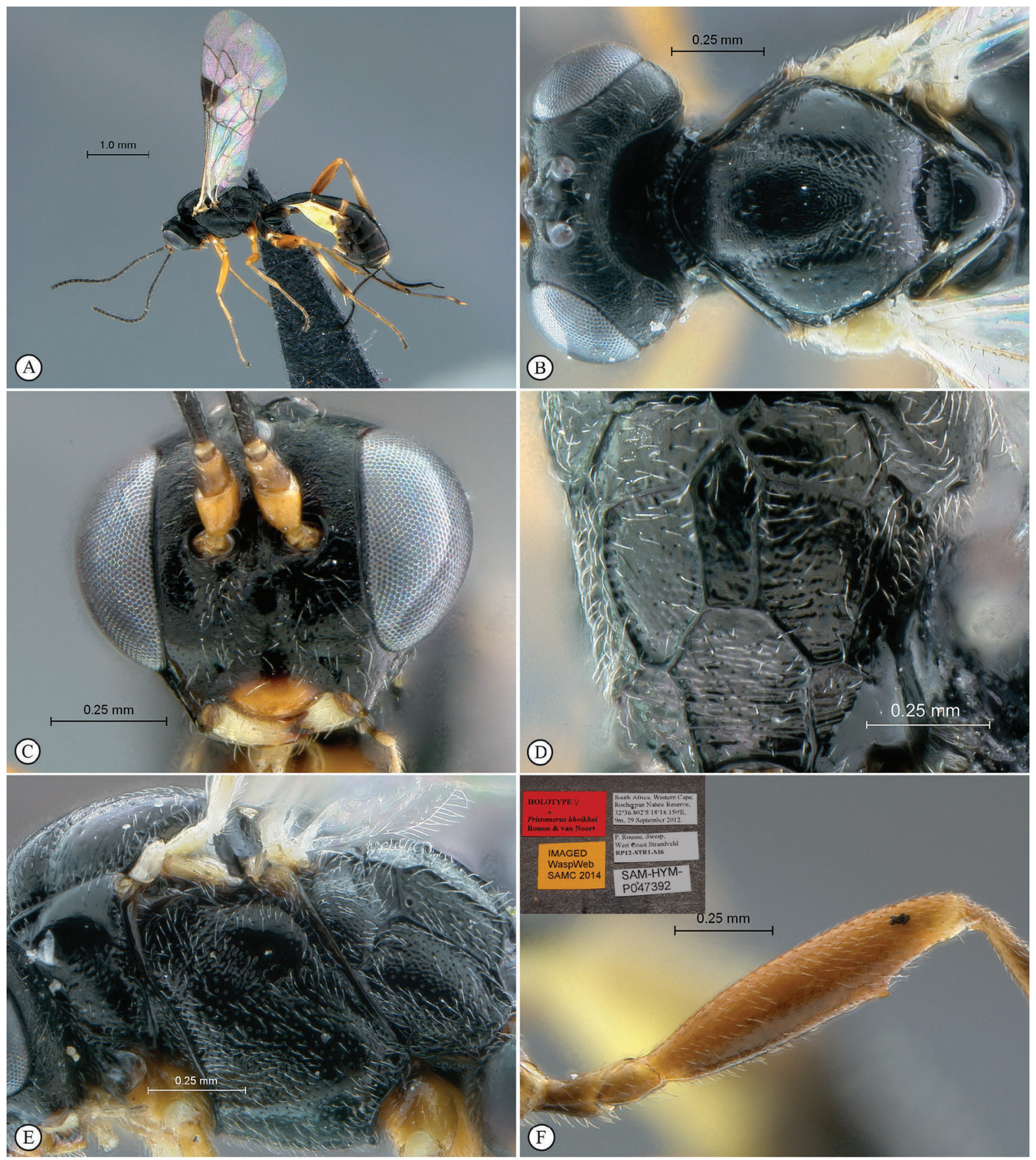

Fig. 16. Pristomerus khoikhoi sp. nov. Holotype, ․ A. Habitus, lateral view. B. Head, mesosoma, dorsal view. C. Head, anterior view. D. Propodeum, dorsal view. E. Mesosoma, lateral view. F. Hind tibia, lateral view (inset: data labels). 
frons finely coriaceous; vertex and temple coriaceous; occipital carina joining hypostomal carina near mandible base; ocelli reduced; antenna short and slender with 22-25 flagellomeres, penultimate flagellomere distinctly elongate.

Mesosoma. Moderately elongate; pronotum bluntly longitudinally crenulate, postero-dorsally smoother; mesopleuron and metapleuron moderately to densely punctate, punctation coarser on metapleuron, with a shallow oblique and coarsely striate furrow below speculum, speculum ventrally smooth; mesoscutum coriaceous with some punctures on median lobe and along notaulus, punctures fused into transverse rugosities apically; notaulus moderately deep; scutellum nearly smooth; propodeum shallowly rugose punctate, area petiolaris transversely strigose; area superomedia elongate. Wings. Pterostigma unusually enlarged, its anterior transverse margin $1.5 \times$ longer than its maximal mid-longitudinal length. Legs. Femoral tooth small.

Metasoma. Tergite 2 and apex of tergite longitudinally aciculate, following tergites coriaceous; thyridium subelliptic, oblique; ovipositor moderately long, strongly sinuous apically.

Male (12 specimens)

B 4.4-4.6; A 2.1-2.4; L 3.3-3.5; POL 1.4; OOL 1.1. Ocelli weakly enlarged; femur swollen, femoral tooth stronger; otherwise similar to female.

\section{Distribution}

South Africa.

Pristomerus kuku sp. nov. urn:1sid:zoobank.org:act:96D377D7-D0FE-45AC-A263-A8027D1983A9

Fig. 17

\section{Diagnosis}

Moderately large; mostly black with fore and mid legs and metasoma from tergite 3 yellowish-orange; trochanters and femora apically white-dotted; pterostigma anteriorly white; face coarsely and densely punctate, sculpture sparser and smoother on remainder of head; malar line moderately long; frons with a strong median protuberance; antenna with 35 flagellomeres; mesosoma densely and coarsely sculptured, punctate to rugose-punctate, including pronotum and almost entire speculum; female femoral tooth nearly absent; ovipositor short, weakly sinuous apically. Male with ocelli slightly enlarged, femoral tooth strong, tergites 3 and following medially black; otherwise similar to female.

\section{Differential diagnosis}

Large black species, differentiated from all other Afrotropical Pristomerus by the absence of a femoral tooth in females, the short ovipositor and the strong protuberance on the frons. It is related to P. yangere sp. nov., which lacks the frontal protuberance and has a distinctly longer ovipositor.

\section{Type material}

\section{Holotype}

CENTRAL AFRICAN REPUBLIC: ${ }^{+}$, "Central African Republic, Préfecture Sangha-Mbaéré, Parc

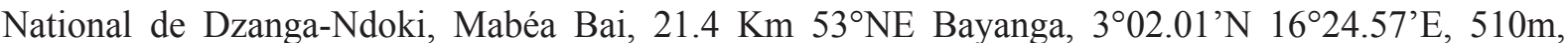
6-7.v.2001, S van Noort, Malaise trap, CAR01-M01, Lowland Rainforest, marsh clearing, SAMHYM-P047401" (SAMC).

\section{Paratype}

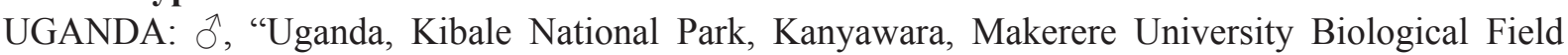
Station, $1465 \mathrm{~m}, 0^{\circ} 35.442$ 'N 30²1.741'E, 10.viii.2008, S. van Noort, UG08-KF12-S03, Sweep, primary mid-altitude rainforest, near stream, SAM-HYM-P047402” (SAMC). 


\section{Description}

Female (holotype)

B 9.3; A 6.1; F 6.2; CT 1.7; ML 0.6; POL 0.8; OOL 0.9; Fl $\mathrm{n}_{\mathrm{n}-1}$ 1.2; ASM 1.7; OT 1.2; FFT 0-1.

Colour. Mostly black with metasoma orange from tergite 3 and pale yellow parts on head: a thin margin along frontal orbit, malar space, mandible and palpi; legs testaceous-brown but hind femur black and
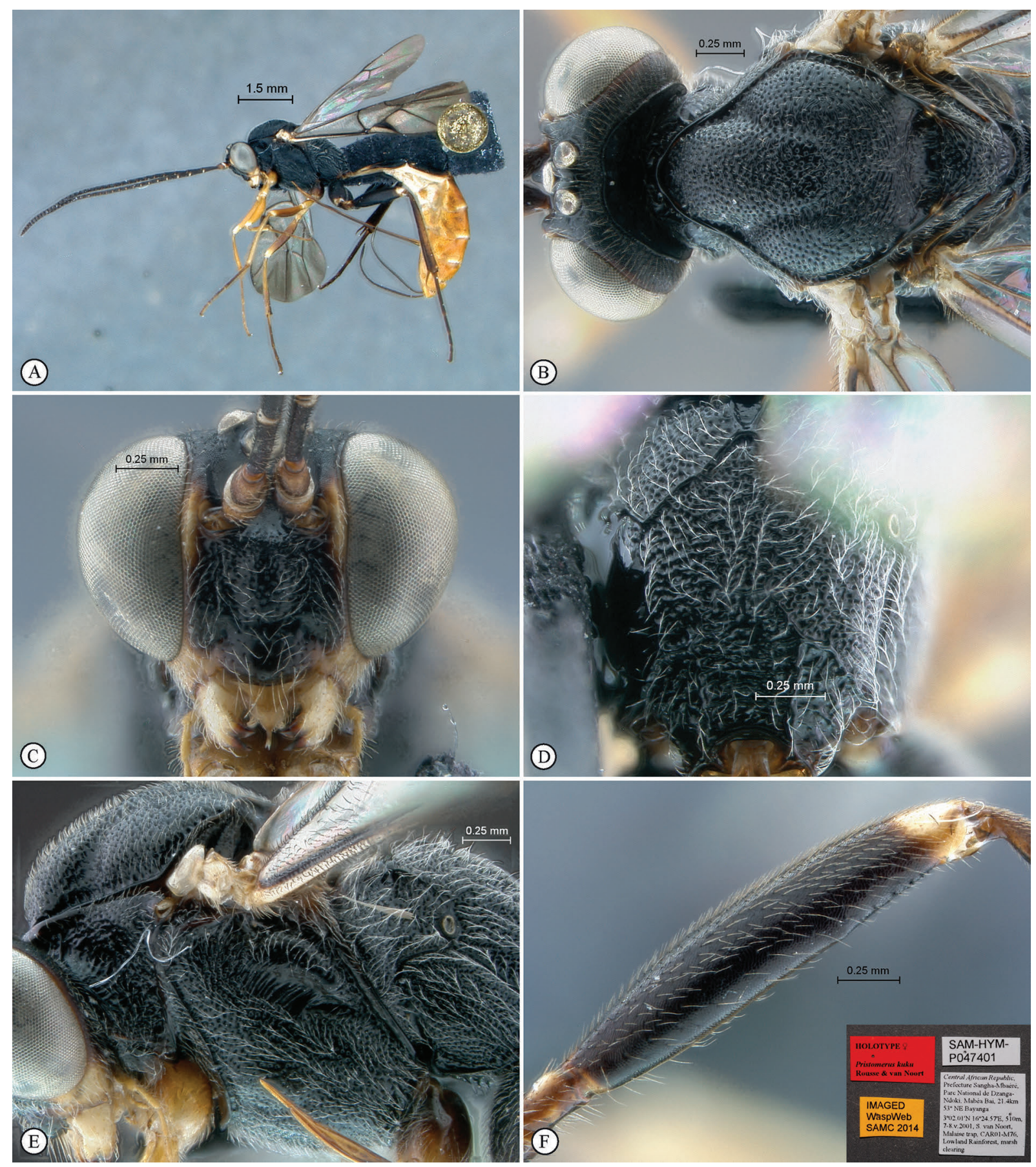

Fig. 17. Pristomerus kuku sp. nov. Holotype, q. A. Habitus, lateral view. B. Head, mesosoma, dorsal view. C. Head, anterior view. D. Propodeum, dorsal view. E. Mesosoma, lateral view. F. Hind tibia, lateral view (inset: data labels). 
all trochanters and femora apically white-dotted; wings slightly infuscate, venation brown, pterostigma anteriorly white.

HEAD. Face mid-longitudinally bulging, coarsely punctate, punctures somewhat confluent into transverse rugosities; clypeus transverse, more sparsely punctate, distinctly convex in profile view, its ventral margin strongly convex; malar line moderately long; frons finely and densely punctate with a strong median protuberance: laterally compressed, about triangular, its tip rounded, about as high as basally wide; vertex and temple coriaceous; occipital carina joining hypostomal carina distinctly above mandible base; antenna with 35 flagellomeres, penultimate one slightly elongate.

Mesosoma. Mesosoma elongate; entire pronotum, mesopleuron and metapleuron densely and deeply punctate, with a deep oblique striate furrow below speculum, speculum almost entirely punctate; mesonotum similarly punctate with punctures on apex of mesoscutum confluent into coarse transverse rugosities; notaulus strongly impressed; posterior vertical face of scutellum longitudinally striate; propodeum coarsely rugose punctate, carination thick, area superomedia not carinate laterally beyond anterior transverse carina. Legs. Femoral tooth nearly absent, reduced to a weak subapical protuberance followed by minute denticles.

Metasoma. Tergite 2 and apical half of tergite 1 longitudinally aciculate, following tergites coriaceous; thyridium subelliptic and wide with main axis longitudinal; ovipositor relatively short, slightly downcurved, apically slightly swollen and weakly sinuous.

Male (paratype)

B 9.1; A 6.0; F 5.5; POL 0.5; OOL 0.6. Ocelli slightly enlarged; frontal protuberance present but distinctly smaller than basally wide; area superomedia fully carinate and slightly more elongate; femur swollen, femoral tooth and following denticles strong; tergite 3 and following medially black; otherwise similar to female.

\title{
Distribution
}

Central African Republic, Uganda.

\author{
Pristomerus masai sp. nov. \\ urn:1sid:zoobank.org:act:83828FAA-D200-4813-B23C-BC1045C173F8
}

Fig. 18

\section{Diagnosis}

Moderate size; yellowish-orange overall with variable dorsal black spots; femora and trochanters apically white-dotted; pterostigma anteriorly white; face densely and shallowly punctate-granulate; clypeus transverse and smooth; remainder of head coriaceous; malar line short; antenna long with 3033 flagellomeres; mesosoma densely punctate to punctate-reticulate with pronotum and ventral half of speculum nearly smooth; female femoral tooth moderate, followed by a row of minute denticles; ovipositor moderately long, apically weakly sinuous. Male with ocelli enlarged, inner margins of eyes slightly diverging ventrally, femur and femoral tooth stouter with femoral tooth long and acute, area superomedia much more slender, and lateral black marking on occiput absent.

\section{Differential diagnosis}

Moderately sized species from tropical mainland Africa; differentiated from all other Afrotropical species by the combination of the black dorsal markings (including most of the occiput in females), the rather enlarged ocelli with an unusually reduced POL, the short malar line, the small female femoral tooth, the long and narrow thyridium and the long ovipositor. It is apparently very closely related to 
other undescribed species (see comments) and to $P$. wolof sp. nov., from which it is separated by the size of the ocelli and femoral tooth as given in the key.

\section{Type material}

\section{Holotype}

KENYA: + , “KENYA, Tsavo Safari Lodge, Athi River, 518 m, 2³8.529’S 38²1.984’E, 19.vii.2008, S. van Noort, UG08-KEN-S02, Sweep, savanna woodland, SAM-HYM-P047403" (SAMC).
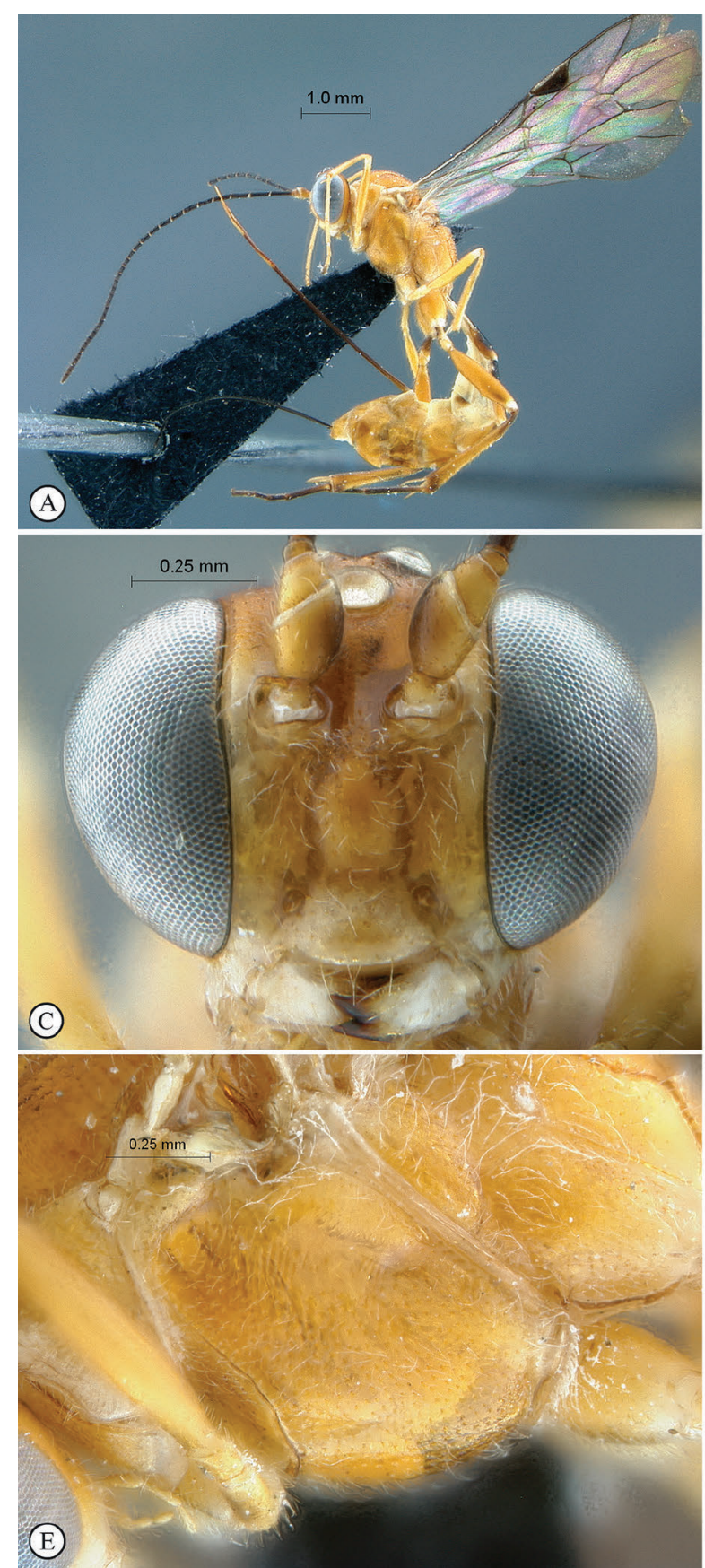
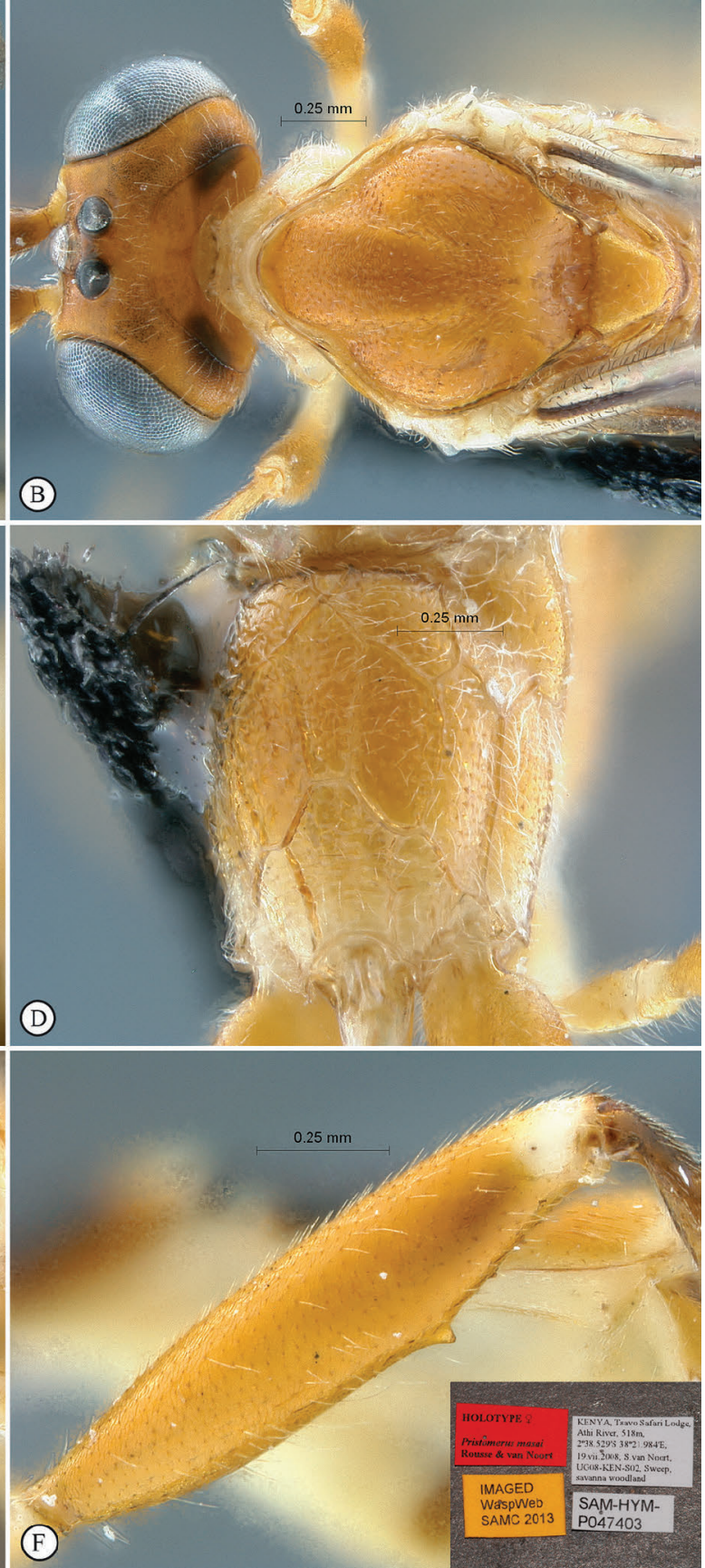

Fig. 18. Pristomerus masai sp. nov. Holotype, + . A. Habitus, lateral view. B. Head, mesosoma, dorsal view. C. Head, anterior view. D. Propodeum, dorsal view. E. Mesosoma, lateral view. F. Hind tibia, lateral view (inset: data labels). 
Paratypes

DEMOCRATIC REPUBLIC OF THE CONGO: 1 q, “Congo Belge, P.N.G. Miss. H. De Saeger II/eb/9, 13.III.1952 H. De Saeger. 3254" (MRAC).

GUINEA-BISSAU: 1 đ, "reg. Bafalà 5 km W Bijne 2.xi.92 M. Söderlund scr. sweep, undergrowth in forest and glades partly grazed by sheeps, 12h30-15h00, SAM-HYM-P049447" (SAMC).

IVORY COAST: 1 đ̊, "Lamto-RCI, 502 W 6¹3 N, 20.9-4.X.1985, Parkinsonia esculaenta" (BMNH).

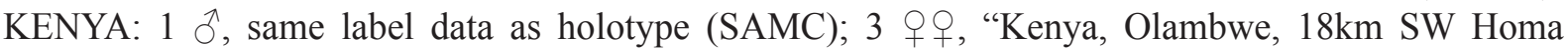
Bay, 1257 m, 0`38.580'S 34²0.403'E, 26.vii.2008, S. van Noort, UG08-KEN-S08, Sweep, riparian woodland, SAM-HYM-P047404" (SAMC).

\section{Material excluded from type series}

GABON: 1 + "Prov. Ogooué-Maritime, Réserve de la Moukalaba-Dougoua, 12.2km 305NW Doussala, $2^{\circ} 17.00^{\prime}$ S $10^{\circ} 29.83^{\prime}$ E, 110m, 27.ii.2000, S. van Noort, Sweep, GA00-S15, Lowland Rainforest, elephant path, SAM-HYM-P041661" (SAMC).

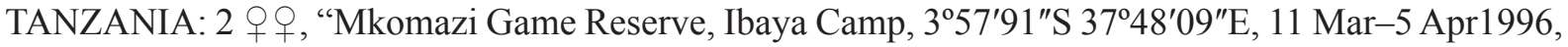
S. van Noort, Malaise trap, Acacia-Commiphora-Combretum bushland, SAM-HYM-P015658"

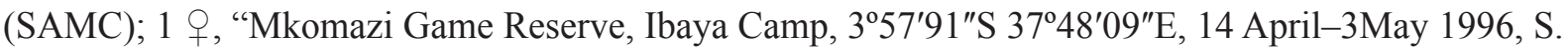
van Noort, Malaise trap, Acacia-Commiphora-Combretum bushland, SAM-HYM-P015665" (SAMC); 3 우, “Mkomazi Game Reserve, Kisima Plot, 406'06"S 3805'58"E, 25 Nov-8Dec 1995, S. van Noort, Malaise trap, Acacia-Commiphora bushland, SAM-HYM-P016461" (SAMC); 2 o SAM-HYM-P016463 (SAMC).

\section{Description}

Female (5 specimens)

B 6.4-7.4; A 4.8-5.4; F 4.2-4.9; CT 1.7; ML 0.4; POL 0.5; OOL 1.0; $\mathrm{Fl}_{\mathrm{n}-1}$ 1.2; ASM 1.8-2.1; OT 1.9-2.0; FFT 1.

CoLour. Yellowish-orange overall with mandible and frontal orbit pale yellow, and black markings: a large lateral spot on occiput, tergites 1-3 but a variable apical part, and basal half of tergite 1; following tergites sometimes also black maculated; flagellum and ovipositor sheath black; trochanters and femora apically white-dotted, hind tibia basally and apically infuscate, hind tarsus infuscate; wings hyaline, venation brown, pterostigma anteriorly white.

HEAD. Face densely and very shallowly punctate; inner margins of eyes subparallel; clypeus transverse and moderately convex, almost smooth; malar line short; frons, vertex and temple coriaceous; ocellar triangle small, equilateral, post ocellar line noticeably short; occipital carina joining hypostomal carina distinctly above mandible base; antenna with 31-32 flagellomeres, penultimate flagellomere slightly elongate.

Mesosoma. Moderately elongate; pronotum nearly smooth, weakly sculptured anteriorly; mesopleuron and metapleuron densely punctate with a shallow oblique and transversely strigose furrow below speculum, speculum ventrally smooth; mesoscutum finely and densely punctate-granulate, punctures confluent along notaulus line into fine transverse rugosities, notaulus relatively deep; scutellum densely punctate, its posterior vertical face longitudinally striate; propodeum densely punctate, mid-apically transversely strigose, area superomedia moderately elongate but elongation variable. Legs. Femoral tooth moderate, followed by a row of minute denticles.

Metasoma. Apical half of tergite 1, tergite 2 and base of tergite 3 longitudinally aciculate, following tergites coriaceous; thyridium elongate, elliptic, its main axis longitudinal; ovipositor moderately long, apically weakly to moderately sinuous. 
Male (3 specimens)

B 6.7-7.1; A 5.0-5.5; POL 0.6; OOL 0.5. Ocelli enlarged; antenna with 28-33 flagellomeres; inner margins of eyes slightly diverging ventrally; femur swollen, femoral tooth stronger, long and acute; area superomedia much more slender, lateral black marking on occiput absent; otherwise similar to female.

\section{Distribution}

Democratic Republic of the Congo, Guinea-Bissau, Ivory Coast, Kenya.

\section{Comments}

Nine morphologically related specimens in the SAMC collection (listed under material examined as excluded from type series), from Tanzania and Gabon, could not be definitively associated with P. masai sp. nov., but their morphological differences are also not strong enough to warrant description of a distinct species. Pristomerus masai sp. nov. is probably included within a widespread tropical species-complex; resolution of species delimitation within this complex requires thorough examination using molecular and morphometric tools.

\section{Pristomerus mbaka sp. nov. urn:lsid:zoobank.org:act:943E40C0-B8F2-4AB1-BE51-10F875C98FE1}

Fig. 19

\section{Diagnosis}

Rather small; mostly black with scutellum and apical half of metasoma testaceous-brown; trochanters and apex of femora white-dotted; anterior edge of pterostigma whitish; face moderately punctate; inner margins of eyes barely converging ventrally; clypeus moderately transverse, sparsely punctate; tentorial pits reduced; malar line very short; remainder of head coriaceous; antenna with 28 flagellomeres, penultimate flagellomere elongate; mesosoma moderately to densely punctate-granulate, including entire speculum and almost entire pronotum, except scutellum coriaceous, mesoscutum transversely rugose along notaulus, and propodeum coarsely rugose-punctate; female femoral tooth small; ovipositor very short, apically straight and hardly swollen. Male with inner margins of eyes strongly diverging ventrally, ocelli greatly enlarged, hind femur stouter, femoral tooth long and acute, mesoscutum mostly coriaceous with punctures along notaulus, and area superomedia more slender.

\section{Differential diagnosis}

Moderately small and mostly black; differentiated from all other Afrotropical species by the very short and entirely straight ovipositor. Also characterized by the very short malar line, the coriaceous scutellum and the entirely punctate speculum.

\section{Type material}

\section{Holotype}

CENTRAL AFRICAN REPUBLIC: ㅇ, "Central African Republic, Préfecture Sangha-Mbaéré, Réserve Spéciale de Forêt dense de Dzanga-Sangha, $12.7 \mathrm{~km} 326^{\circ} \mathrm{NW}$ Bayanga, $3^{\circ} 00.27^{\circ} \mathrm{N} 16^{\circ} 11.55^{\prime} \mathrm{E}, 420 \mathrm{~m}$, 12.v.2001, S. van Noort, Sweep, CAR01-S120, Lowland Rainforest, SAM-HYM-P047405” (SAMC).

Paratype

IVORY COAST: §, "Lamto-RCI 502W. 6¹3N, 19.5-19.6.84, Cynometra megalophylla" (BMNH).

\section{Description}

Female (holotype)

B 5.2; A 4.0; F 4.1; CT 1.7; ML 0.3; POL 0.7; OOL 0.7; Fl 1 1.2 ASM 2.2; OT 0.8; FFT 1. 
Colour. Head black with clypeus, scape and frontal orbit testaceous-orange, and mandible, palpi, malar space and pedicel yellow; flagellum testaceous; mesosoma black; tergite 1 black, metasoma fading to testaceous-brown from tergite 2; legs yellow with hind coxa and hind femur testaceous-brown, and trochanters and apex of femora with a more or less defined white spot; wings hyaline, venation brown, anterior edge of pterostigma whitish.
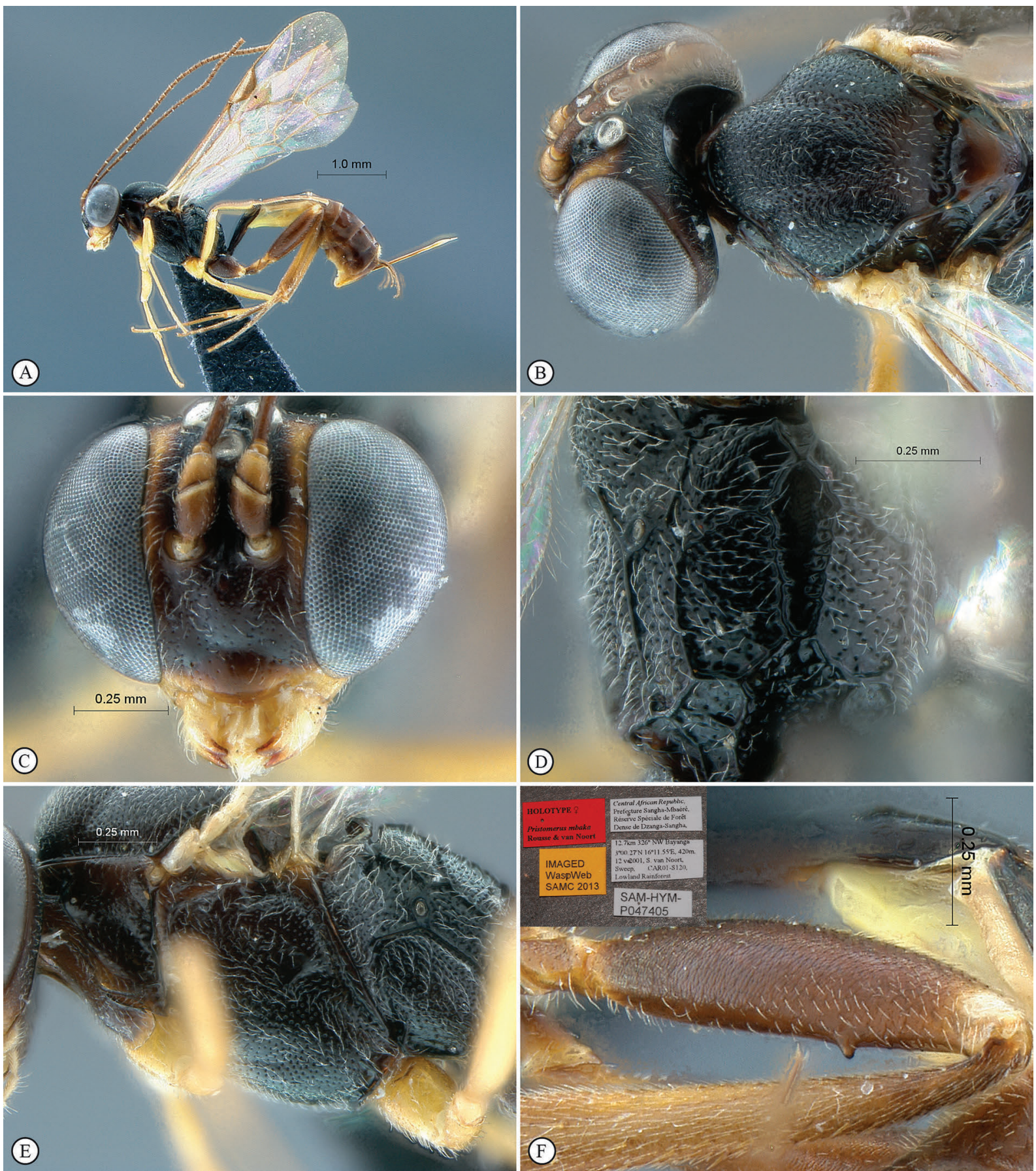

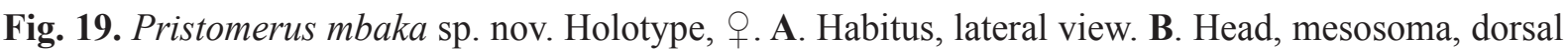
view. C. Head, anterior view. D. Propodeum, dorsal view. E. Mesosoma, lateral view. F. Hind tibia, lateral view (inset: data labels). 
HEAD. Face moderately and finely punctate; inner margins of eyes barely converging ventrally; clypeus moderately transverse, convex in profile view, finely and sparsely punctate; tentorial pits reduced, hardly distinct; malar line very short; frons, vertex and temple coriaceous; occipital carina joining hypostomal carina near mandible base; ocelli enlarged; antenna with 28 flagellomeres, penultimate flagellomere elongate.

Mesosoma. Elongate; pronotum moderately punctate, hardly smoother postero-dorsally; mesopleuron and metapleuron densely and evenly punctate, with an oblique striate furrow below speculum, speculum entirely punctate; mesoscutum densely punctate-granulate, punctures confluent into transverse rugosities along notaulus; notaulus moderate; scutellum nearly smooth, shallowly coriaceous without punctures; propodeum coarsely punctate rugose but area superomedia centrally smoother; area superomedia elongate. Legs. Femoral tooth small.

Metasoma. Tergite 2 and apical half of tergite 1 longitudinally aciculate, tergite 3 and following coriaceous; thyridium subelliptic, its main axis longitudinal; ovipositor unusually short, its apex straight and hardly swollen.

Male (paratype)

B 5.5; A 4.3; F 4.4; POL 0.4; OOL 0.2. Inner margin of eyes strongly diverging ventrally; antennae broken; ocelli greatly enlarged; hind femur stouter; femoral tooth long and acute, followed by strong denticles; mesoscutum smoother, coriaceous with some punctures along notaulus; area superomedia more slender; hind femur distinctly lighter, yellowish orange, but apical pale spot present; otherwise similar to female.

\section{Distribution}

Central African Republic, Ivory Coast.

\section{Pristomerus mbama sp. nov. urn:1sid:zoobank.org:act:5584F15B-A339-44E9-827F-5ECF671EBD94}

Fig. 20

\section{Diagnosis}

Moderately small; mostly black with metasoma mostly yellowish-orange from tergite 3; apex of femora pale dotted; face densely punctate, sculpture smoother on remainder of head; inner margins of eyes subparallel; clypeus transverse; malar line very short; antenna with 30 flagellomeres; mesosoma mostly coarsely punctate, including scutellum and entire speculum, pronotum hardly smoother postero-dorsally; propodeum with carination thick, area basalis petiolate; ovipositor moderately long, apically strongly sinuous. Male unknown.

\section{Differential diagnosis}

Moderately small and mostly black; differentiated from all other Pristomerus species by the combination of the very short malar line, the entirely punctate speculum and almost entirely sculptured pronotum, and the very weak female femoral tooth. It appears closely related to P. mbaka sp. nov. in which the scutellum is impunctate and the ovipositor is significantly shorter, apically straight.

\section{Type material}

\section{Holotype}

GABON: ㅇ, “GABON, Prov. Ogooué-Maritime, Réserve de la Moukalaba-Dougoua, $12.2 \mathrm{~km} 305^{\circ} \mathrm{NW}$ Doussala, $2^{\circ} 17.00^{\prime} \mathrm{S} 10^{\circ} 29.83^{\prime} \mathrm{E}, 110 \mathrm{~m}, 28.1 i .2000$, S. van Noort, Sweep, GA00-S18, Lowland Rainforest, forest margin along road, SAM-HYM-P041662" (SAMC). 


\section{Description}

Female (holotype)

B 6.0; A 3.6; F: 4.1; CT 1.8; ML 0.3; POL 0.5; OOL 0.8; Fl ${ }_{\mathrm{n}-1}$ 1.1; ASM 2.1; OT 1.6; FFT 1.

Colour. Head black with mandible, palpi, clypeus, malar space and frontal orbits yellow to yellowishorange; mesosoma black; tergites 1-2 black, following tergites mostly yellowish-orange and centrally
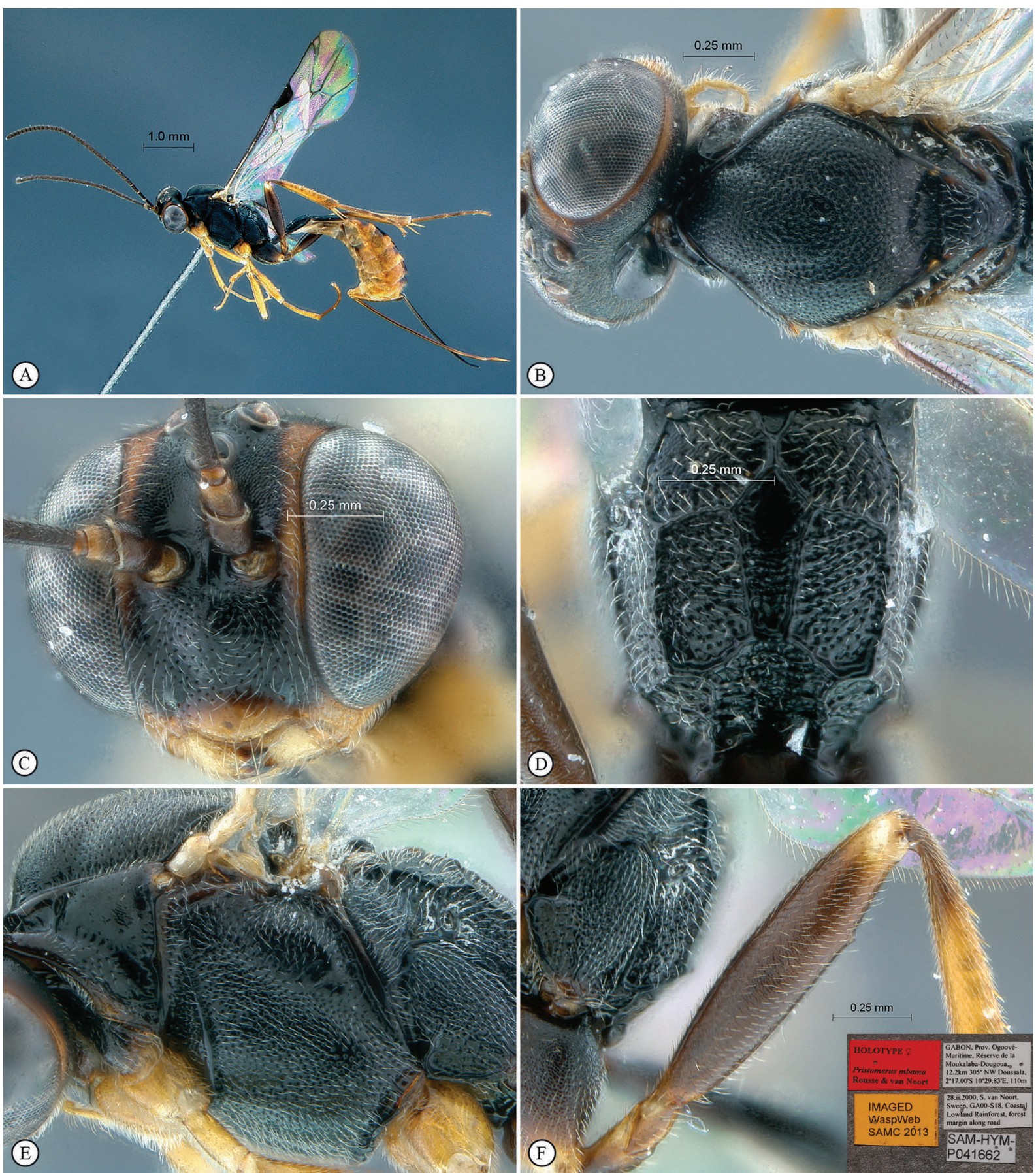

Fig. 20. Pristomerus mbama sp. nov. Holotype, ․ A. Habitus, lateral view. B. Head, mesosoma, dorsal view. C. Head, anterior view. D. Propodeum, dorsal view. E. Mesosoma, lateral view. F. Hind tibia, lateral view (inset: data labels). 
blackened; legs yellowish-orange with hind coxa black and hind femur testaceous-brown; all femora apically white dotted; wings hyaline, slightly infuscate apically, venation brown with pterostigma somewhat paler anteriorly.

HEAD. Face densely and deeply punctate, medially bulging; inner margins of eyes subparallel; clypeus transverse, mostly smooth but dorsal margin punctate, convex in profile view; malar line very short; frons and vertex finely and closely punctate-granulate; temple and occiput coriaceous; frons midlongitudinally weakly bulging; occipital carina joining hypostomal carina above mandible base; antenna with 30 flagellomeres, penultimate flagellomere barely elongate.

Mesosoma. Elongate; pronotum entirely sculptured, moderately punctate, anteriorly crenulate and posteriorly coriaceous; mesopleuron and metapleuron evenly, densely and deeply punctate with an oblique striate groove below speculum, speculum entirely punctate; mesoscutum densely and finely punctategranulate, punctures confluent into oblique rugosities along notaulus; notaulus moderate; scutellum densely punctate; propodeum densely punctate-granulate with area superomedia centrally smoother and area petiolaris transversely strigose; carination thick, area basalis petiolate, area superomedia elongate. Legs. Femoral tooth very weak though distinct.

Metasoma. Tergite 2 and apical half of tergite 1 longitudinally aciculate, following tergites coriaceous; thyridium subelliptic, its main axis longitudinal; ovipositor moderately long, strongly sinuous apically.

\section{Male \\ Unknown.}

\section{Distribution}

Gabon.

Pristomerus mboum sp. nov. urn:1sid:zoobank.org:act:F0F10028-D908-4AF6-8300-C54074B182B2

Fig. 21

\section{Diagnosis}

Small; yellow to yellowish-orange with dorsal black markings on head and metasoma; femora and trochanters apically white-dotted; anterior edge of pterostigma whitish; face densely punctate; clypeus smooth, moderately transverse; malar line very short; remainder of head coriaceous; mesosoma densely punctate to punctate-granulate, with speculum ventrally, most of pronotum and scutellum quite smooth; area superomedia long and narrow, hardly carinate laterally; femoral tooth small; ovipositor moderately short, apically strongly sinuous. Male unknown.

\section{Differential diagnosis}

Small, mostly yellowish-orange; differentiated from all other Afrotropical Pristomerus by the combination of the quite smooth scutellum, the short malar line, the small female femoral tooth and the rather enlarged ocelli. The apical white dot on the femora and the black occiput are also reliable identification cues, making P. mboum sp. nov. morphologically close to P. masai sp. nov. and related species.

\section{Type material}

\section{Holotype}

CENTRAL AFRICAN REPUBLIC: ㅇ, "Central African Republic, Préfecture Sangha-Mbaéré, Parc

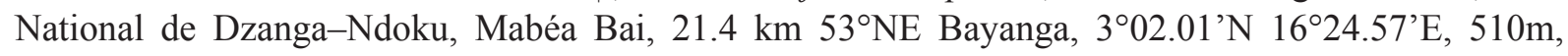
6-7.v.2001, S van Noort, sweep, CAR01-S94, lowland rainforest, marsh clearing SAM-HYMP047406" (SAMC). 
Other material? (see comments)

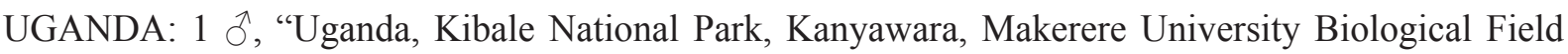
Station, $1465 \mathrm{~m}, 0^{\circ} 35.442^{\prime} \mathrm{N} 30^{\circ} 21.741$ 'E, 10.viii.2008, S. van Noort, UG08-KF12-S03, Sweep, primary mid-altitude rainforest, near stream, SAM-HYM-P049448" (SAMC).
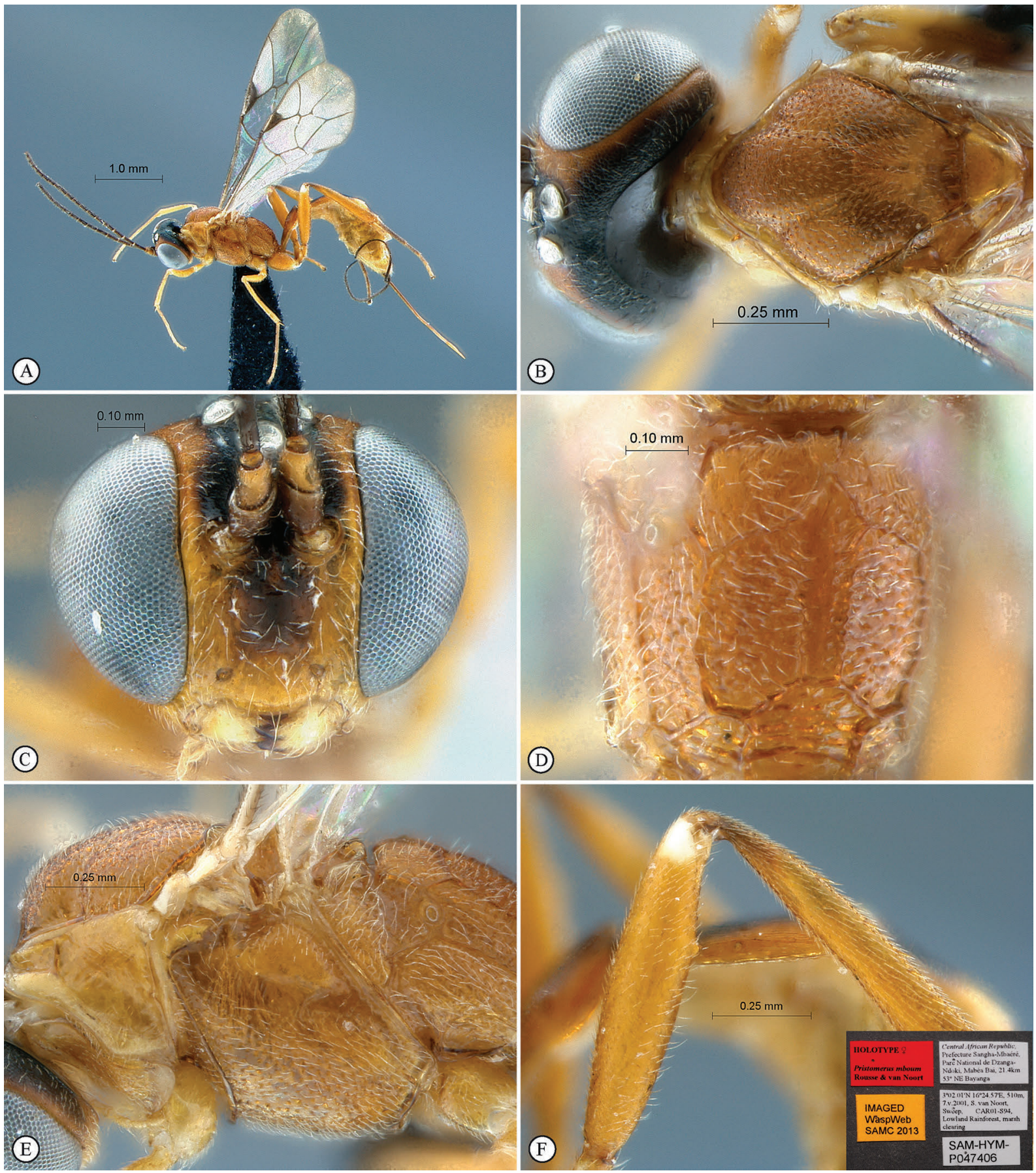

Fig. 21. Pristomerus mboum sp. nov. Holotype, ․ A. Habitus, lateral view. B. Head, mesosoma, dorsal view. C. Head, anterior view. D. Propodeum, dorsal view. E. Mesosoma, lateral view. F. Hind tibia, lateral view (inset: data labels). 


\section{Description}

Female (holotype)

B 4.4; A n/a; F 3.3; CT 1.7; ML 0.3; POL 0.5; OOL 0.8; Fl n-1 $_{\text {na }}$; ASM 2.4; OT 1.5; FFT 1.

CoLour. Yellow to yellowish-orange overall, with face fading to dark brown medially and numerous black markings: frons, inter-ocellar area, occiput, tergite 2 medially and a basal spot on following tergites; femora and trochanters apically white-dotted; wings slightly infuscate apically, venation pale brown, anterior edge of pterostigma whitish.

HEAD. Face moderately densely and deeply punctate; inner margins of eyes subparallel; clypeus moderately transverse, almost smooth; frons, vertex and temple coriaceous; malar line very short; ocelli enlarged; occipital carina joining hypostomal carina distinctly above mandible base; both antennae broken.

Mesosoma. Moderately elongate; pronotum smooth, shallowly strigose anteriorly; mesopleuron and metapleuron densely punctate, with an oblique striate furrow below speculum, ventral half of speculum smooth; mesoscutum densely punctate-granulate, punctures confluent apically; notaulus moderate; scutellum quite smooth; propodeum densely punctate-granulate, medially transversely strigose, area superomedia long and narrow, weakly delimited laterally beyond anterior transverse carina. Legs. Femoral tooth small, followed by minute denticles.

Metasoma. Apical half of tergite 1, tergite 2 and base of tergite 3 longitudinally aciculate; following tergites coriaceous; thyridium elliptic, its main axis longitudinal; ovipositor moderately short, its apical third sinuous.

\section{Male}

Not known with certainty (see comments).

\section{Distribution}

Central African Republic, Uganda (?).

\section{Comments}

The probable male from Uganda shares the colour pattern and the quite smooth scutellum and pronotum. It was, however, not included as a paratype because its head is missing and it therefore could not be unambiguously determined.

Pristomerus melissa Rousse, Villemant \& Seyrig, 2013

Fig. 22

\section{Diagnosis}

Moderate size; head dark brown to black with clypeus, mandible, malar space and palpi pale yellow; remainder of body mostly yellow to yellowish-orange with black markings on tergite 1 and apical half of tergite 2; face densely and evenly punctate-granulate; inner margins of eyes subparallel; clypeus strongly transverse, shallowly and sparsely punctate; malar line moderately long; remainder of head coriaceous; occipital carina joining hypostomal carina slightly above mandible base; antenna with 35 flagellomeres, penultimate flagellomere elongate; mesosoma distinctly elongate; entirely densely punctate to punctate-granulate, with most of pronotum and ventral half of speculum smooth; area superomedia elongate and laterally not delimited beyond anterior transverse carina; female femoral tooth small; ovipositor short, slightly sinuous apically. B 6.6; A 5.3; F 5.1; CT 2.2; ML 0.6; POL 0.8; OOL 0.8; $\mathrm{Fl}_{\mathrm{n}-1}$ 1.1; ASM 2.3; OT 1.0; FFT 1. Male unknown. 


\section{Differential diagnosis}

Mostly yellowish orange with upper head black; differentiated from all other Pristomerus species by the combination of the colour pattern (entire face black and entire mesosoma yellowish-orange), the numerous flagellomeres, the area superomedia hardly delimited postero-laterally, and the short ovipositor.
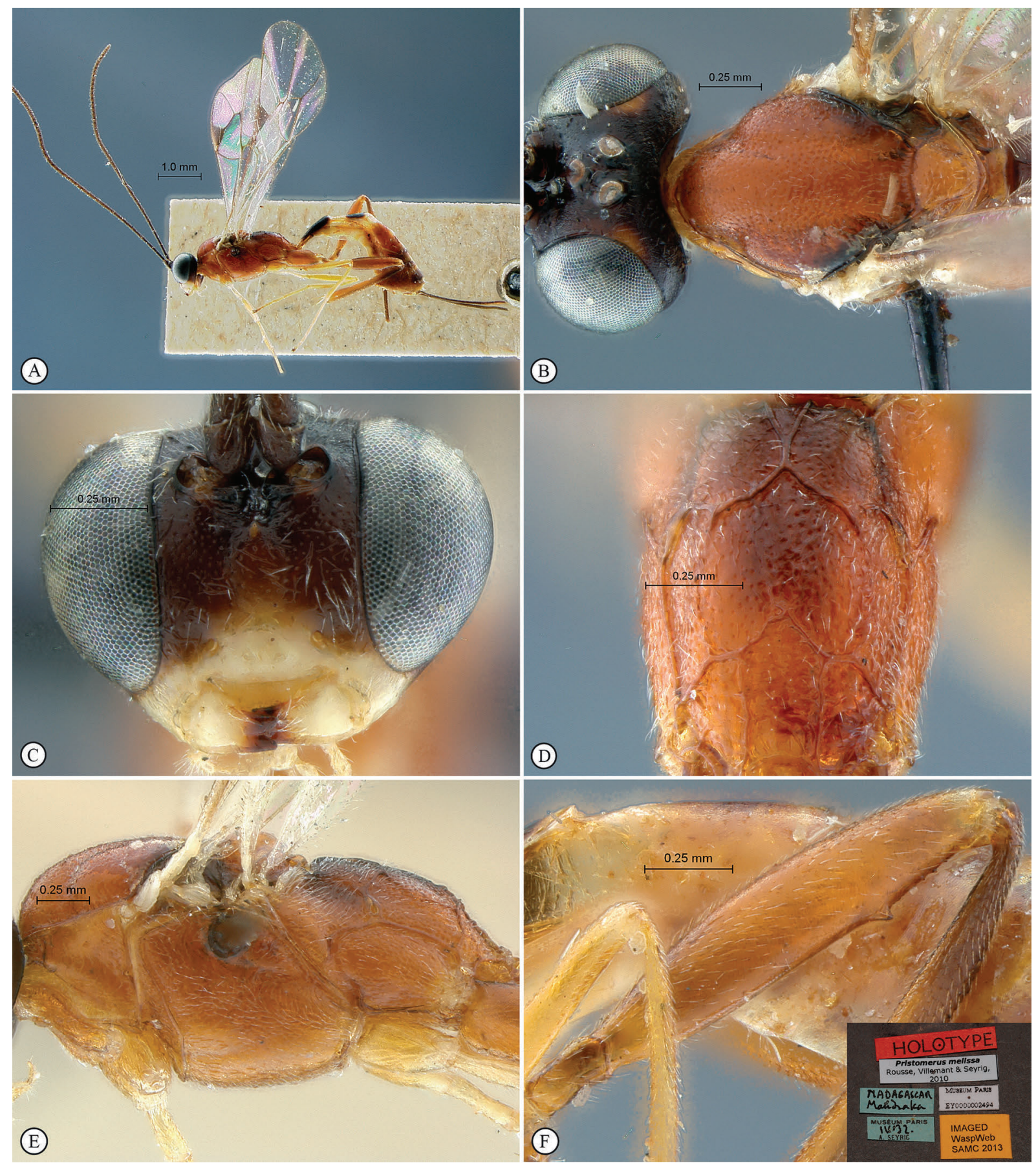

Fig. 22. Pristomerus melissa Rousse, Villemant \& Seyrig, 2013. Holotype,, . A. Habitus, lateral view. B. Head, mesosoma, dorsal view. C. Head, anterior view. D. Propodeum, dorsal view. E. Mesosoma, lateral view. F. Hind tibia, lateral view (inset: data labels). 


\section{Material examined}

\section{Holotype}

MADAGASCAR: ㅇ, “MADAGASCAR, Mandraka forest, IV.32, EY 0000002494” (MNHN).

\section{Distribution}

\section{Madagascar.}
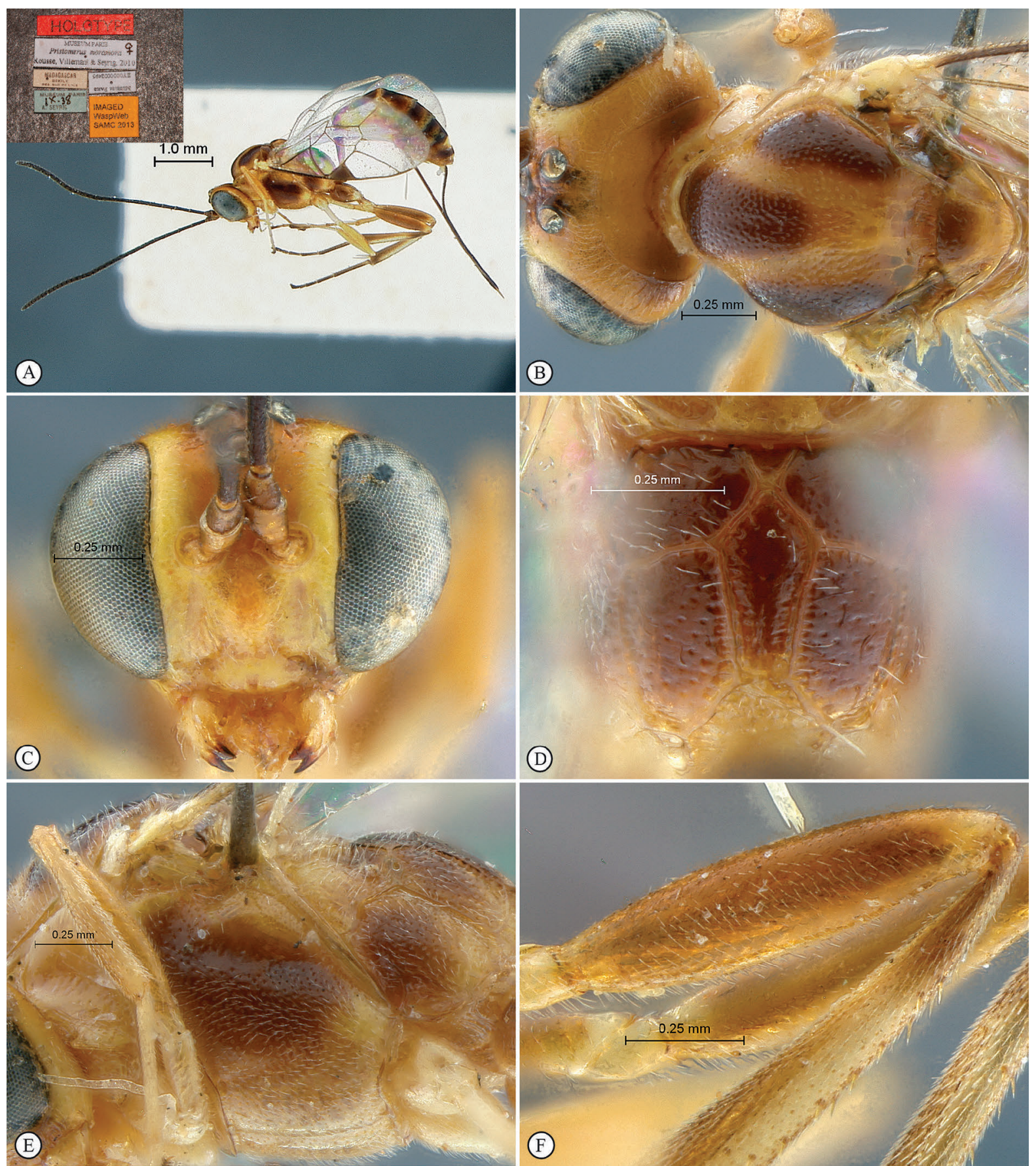

Fig. 23. Pristomerus moramora Rousse, Villemant \& Seyrig, 2013. Holotype, + . A. Habitus, lateral view (inset: data labels). B. Head, mesosoma, dorsal view. C. Head, anterior view. D. Propodeum, dorsal view. E. Mesosoma, lateral view. F. Hind tibia, lateral view. 
Pristomerus moramora Rousse, Villemant \& Seyrig, 2013

Fig. 23

Diagnosis (ranges from Rousse et al. 2013)

Small to moderately small; background colour yellowish-orange with dark testaceous to black markings of variable extent on mesosoma and metasoma, frons darker than face, and notaulus and scutellum most often lighter than remainder of mesonotum; face moderately to densely punctate; inner margins of eyes weakly converging ventrally; clypeus transverse, shallowly and sparsely punctate; malar line very short; remainder of head sparsely punctate-granulate to coriaceous; occipital carina joining hypostomal carina distinctly above mandible base; antenna with 27-29 flagellomeres, penultimate flagellomere quadrate; mesosoma elongate, densely, deeply and evenly punctate except pronotum almost entirely smooth and speculum ventrally smooth; area superomedia relatively stout to elongate; female femoral tooth absent; ovipositor long, weakly sinuous apically. B 3.5-4.3; A 2.4-3.2; F 2.8-3.5; CT 2.0; ML 0.3; POL 1.0; OOL 1.2; $\mathrm{Fl}_{\mathrm{n}-1} 1.0 ;$ ASM 1.7-2.5; OT 1.7-1.8; FFT 0 . Male with ocelli hardly enlarged, hind femur and femoral tooth stouter, otherwise similar to female. B 3.4-4.5; A 2.2-3.2; F 2.5-3.5; POL 1.0; OOL 1.0.

\title{
Differential diagnosis
}

Small species from Madagascar; differentiated from most other Afrotropical species by the absence of the femoral tooth in females, the very short malar line, the strongly transverse clypeus and the long ovipositor. It is closely related to $P$. kelikely and $P$. venda sp. nov., from which it may differentiated by the colour and antenna length characters given in the key (see comments on P. kelikely).

\section{Material examined \\ Holotype}

MADAGASCAR: + , "MADAGASCAR, Bekily [Ampandrandava], reg. sud de l'île, IX 1938, EY 0000002495” (MNHN).

\section{Distribution}

Madagascar.

\author{
Pristomerus nzakara sp. nov. \\ urn:1sid:zoobank.org:act:719C9EFB-B4A0-4848-8B83-217E77DD93B6
}

Fig. 24

\section{Diagnosis}

Large; black with lighter parts on head and metasoma fading to yellowish-orange from tergite 3; trochanters and apex of femora pale dotted; pterostigma anteriorly white; face moderately punctate, sculpture smoother on remainder of head; clypeus transverse; malar line moderately short; inner margins of eyes parallel; antenna with 36 flagellomeres, penultimate flagellomere quadrate; mesosoma densely and deeply punctate with a large smooth dorsal area on pronotum, ventral half of speculum and apical half of lateral lobe on mesoscutum almost smooth; notaulus noticeably deep and rugose; area superomedia stout, hardly carinate laterally; female femoral tooth very strong; ovipositor moderately long, exceptionally stout and entirely straight. Male unknown.

\section{Differential diagnosis}

Large, black species from tropical mainland Africa; chiefly differentiated from all other Afrotropical Pristomerus species by the very stout and apically straight ovipositor, also characterized by the long antenna, the deep and rugose notaulus, and the posteriorly smooth lateral mesoscutal lobe.

\section{Type material}

\section{Holotype}

CENTRAL AFRICAN REPUBLIC: $q$, "CENTRAL AFRICAN REPUBLIC, Préfecture SanghaMbaéré, Parc National de Dzanga-Ndoki, Mabéa Bai, 21.4km 53NE Bayanga, $3^{\circ} 02.01^{\prime} \mathrm{N} 16^{\circ} 24.57^{\prime} \mathrm{E}$, 510m, 1-2.v.2001, S. van Noort, Malaise trap, CAR01-M01, Lowland Rainforest, marsh clearing, SAM-HYM-P047407" (SAMC). 


\section{Description}

Female (holotype)

B 9.2; A 6.0; F 6.3; CT 1.8; ML 0.5; POL 0.8; OOL 0.9; Fl 1 1.1 1.0 ASM 1.5; OT 1.7; FFT 2.

CoLour. Head black with frontal orbit testaceous, mandible, palpi and malar space yellow; mesosoma black; metasoma black with tergite 3 and following fading laterally to testaceous-orange; fore and mid legs yellowish-orange, hind leg mostly black, with tibia and tarsus strongly infuscate; trochanters and apex of femora white dotted; wings apically infuscate, venation pale brown, pterostigma anteriorly white.

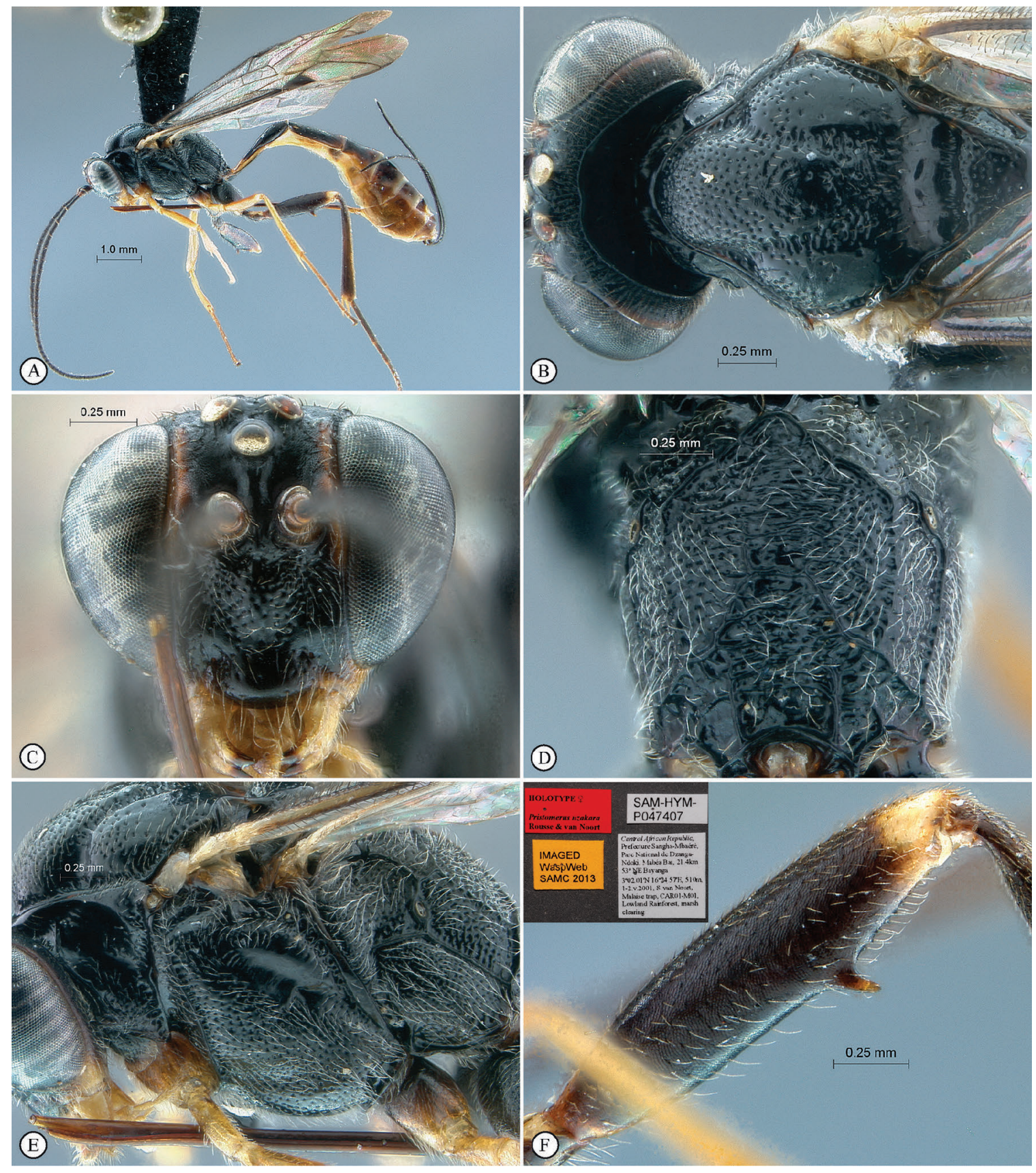

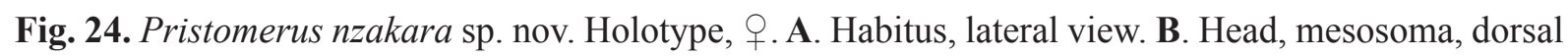
view. C. Head, anterior view. D. Propodeum, dorsal view. E. Mesosoma, lateral view. F. Hind tibia, lateral view (inset: data labels). 
HEAD. Face deeply and moderately punctate, mid-longitudinally bulging; inner margins of eyes parallel; clypeus transverse, smooth with some punctures dorsally, distinctly convex in profile view; malar line moderately short; frons finely and densely punctate with a weak mid-longitudinal ridge from upper face to median ocellus; vertex and temple coriaceous; occipital carina joining hypostomal carina distinctly above mandible base; antenna with 36 flagellomeres, penultimate flagellomere quadrate.

Mesosoma. Barely elongate; pronotum sparsely punctate with ventral margin strigose and largely smooth dorsally; mesopleuron and metapleuron densely, evenly and deeply punctate, with a weakly striate oblique furrow below speculum, speculum ventrally smooth; mesoscutum densely punctate but apical half of lateral lobe nearly smooth, notaulus deep and rugose; scutellum densely punctate; propodeum deeply punctate-rugose, carination thick, area superomedia stout, hardly delimited laterally. Legs. Femoral tooth strong and acute, higher than basally wide.

Meталома. Tergite 2 and apical half of tergite 1 longitudinally aciculate, following tergites coriaceous; thyridium elliptic with main axis longitudinal; ovipositor moderately long, stout, entirely straight.

\section{Male \\ Unknown.}

\section{Distribution}

Central African Republic.

Pristomerus pallidus (Kriechbaumer in Magretti, 1884)

Fig. 25

Cremastus pallidus Kriechbaumer in Magretti, 1884: 243.

Pristomerus africator Aubert \& Shaumar, 1978: 18. Syn. nov.

Pristomerus cunctator Tosquinet, 1896: 422. Syn. nov.

Pristomerus luteolus Tosquinet, 1896: 421. Syn. nov.

\section{Diagnosis}

Moderately small to moderately sized; yellow to reddish overall with variable dark markings on first tergites and often around scutellum, dark markings sometimes also present on propodeum and apical tergites; frons darker than face, mesosoma varying from almost uniformly yellowish to strikingly mottled yellowish and reddish, with notaulus and scutellum almost always lighter than remainder of mesonotum; face densely punctate; inner margins of eyes barely diverging ventrally; clypeus strongly transverse, densely but very shallowly punctate; malar line moderately long to long; remainder of head coriaceous to punctategranulate; occipital carina joining hypostomal carina shortly above mandible base; antenna long with 28-35 flagellomeres, penultimate flagellomere subquadrate; mesosoma moderately elongate and very densely punctate but pronotum dorsally and ventral half of speculum smooth; propodeum with area superomedia moderately stout to elongate; female femoral tooth moderate to very small, sometimes reduced to a barely distinct subapical tubercle; ovipositor moderately short, its apex strongly sinuous. B 7.4-12.1; A 4.7-6.8; F 4.2-6.4; CT 1.7-2.4; ML 0.6-0.7; POL 0.9; OOL 1.1; Fl 1 1.1; ASM 1.8-2.3; OT 1.3-1.6; FFT 1. Male with inner margins of eyes more strongly diverging ventrally, mesoscutum most often weakly sculptured, mostly coriaceous with dense punctation on anterior edge of median mesoscutal lobe, punctation occasionally more extended; ocelli strongly enlarged, hind femur and femoral tooth stouter. POL 0.6; OOL 0.2.

\section{Differential diagnosis}

Mostly yellow to yellowish-orange with notaulus and scutellum most often usually distinctly lighter than remainder of mesoscutum; otherwise differentiated from all other Afrotropical species by the combination of the rather long malar line, the strongly transverse clypeus, the somewhat reduced ocellus, the weak female femoral tooth and the rather short ovipositor. Confusion may occur with P. moramora, 
P. kelikely or $P$. venda sp. nov., these three species having a shorter malar line and no trace of a femoral tooth in females; P. pallidus may also be confused with $P$. bullis in which the clypeus is significantly more transverse and the ovipositor shorter.

\section{Material examined}

\section{Holotype}

ETHIOPIA: $q$ of $C$. pallidus, "Coll. P. Magretti, Kor Arvian, [in Homran area (Townes \& Townes 1973)], Afr. Orle, 9.3.1883” (MCSN).
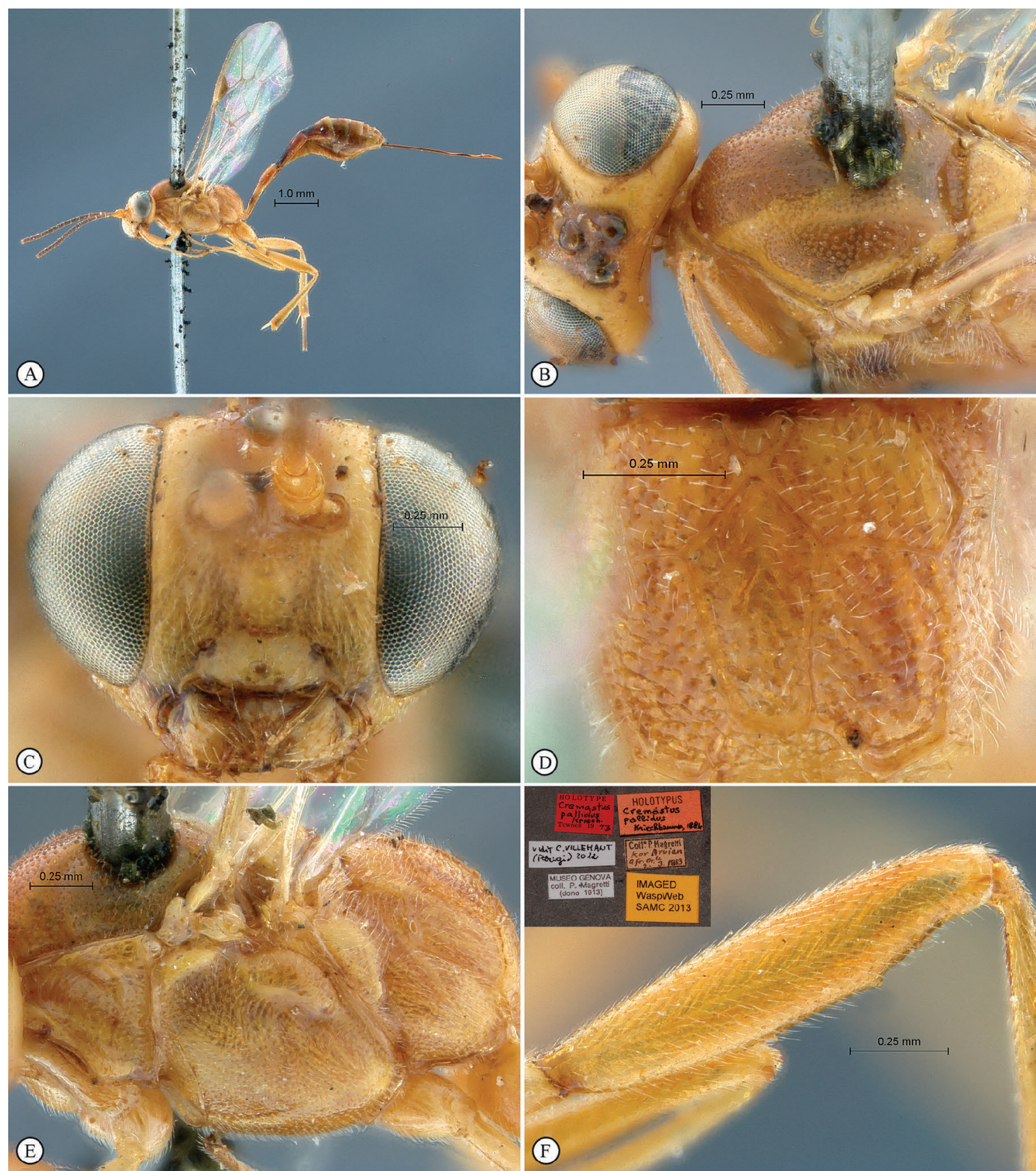

Fig. 25. Pristomerus pallidus (Kriechbaumer, 1884). Holotype, + . A. Habitus, lateral view. B. Head, mesosoma, dorsal view. C. Head, anterior view. D. Propodeum, dorsal view. E. Mesosoma, lateral view. F. Hind tibia, lateral view (inset: data labels). 


\section{Other material}

BENIN: “1 +, Bénin: Cotonou, ex Plutella xylostella sur Brassica, 13.vi.1999 E. Goudegnon” (CBGP). CAMEROON: 1 ô, "21328 tube H-0009 Cameroun Guider, ex Helicoverpa armigera sur Gossypium hirsutum, ix/x 2008 Patrick Prudent” (CBGP).

DEMOCRATIC REPUBLIC OF THE CONGO: 1 , 1 ๙ , “Congo Belge, P. N. G. Miss. H. De Saeger II/gc/8, 30-iv-1952 H. De Saeger. 3402" (MRAC); 1 q, same label data except: "II/fd/17, 7-v-1952 H. De Saeger. 3431" (MRAC); 1 + , same label data except: "II/gd/4, 23-viii-1952 H. De Saeger. 3972" (MRAC).

GAMBIA: 1 $\lambda$, [Holotype of $P$. luteolus]: "Gambie Mocquerys [date of collection not reported]" (ISNB). IVORY COAST: 1 O , [Paratype of $P$. africator]: "Côte d'Ivoire 28.1.1977 e. 1. de Maliarpha separatel [sic] Bouake-Côte d'Ivoire sur riz" (MZLS); 1 ð,, "Bouaké R.C.I. 21.II.1977 LDR rec., 490” (CBGP); 1 ${ }^{\lambda}$, same locality, "4.3.77 A. Pollet rec. coll. $\mathrm{n}^{\circ} \mathrm{a}$, ex larva Maliarpha separatella riz, 557" (CBGP); 1 o, "Lamto-RCI $5^{\circ} 02 \mathrm{~W} .6^{\circ} 13 \mathrm{~N}, 2.5$ à4.6.84, Teramnus buettneri"; 1 đo, same locality, 22.4 à17.6.85 Tephrosia bracteolata" (BMNH); 2 우, 2 $\widehat{\jmath}$, same locality "22.03 à17.4.85, Crotalaria goveensis";

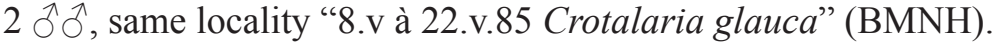

MOZAMBIQUE: 1 , [Lectotype of P. cunctator]: "Delagoa-Bai [collection date not reported], 26283" (MNK).

NAMIBIA: 1 q, "South West Africa Okahandja, 21.57S 16.54E, 11.1978 S. J. v. Tonder" (SANC);

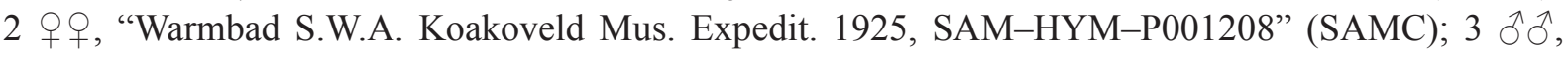
"Zesfontein S.W.A. Mus. Expedit. 1925, SAM-HYM-P001206" (SAMC).

SENEGAL: 1 , [Paralectotype of $P$. cunctator] "Senegal Buq. [date and locality of collection not reported], 11229" (MNK); 1 + , "Darou Sourang, Senegal, 24.IX.1976 Vercambre, 1049, sur larve de

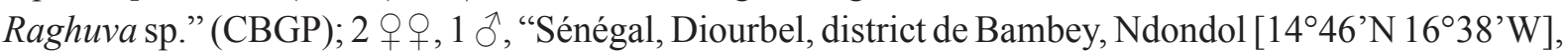
ex épi mil avec chenille Rhaguva albipunctella [ex millet ears with $R$. albipunctella caterpillars] 44-xi000 and 1-H23-000" (CBGP).

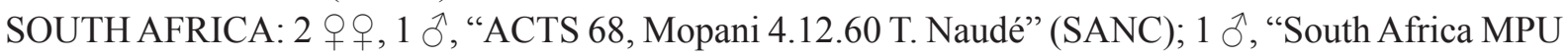
Loskop Res Stn Moitse West nr Marble Hall 6.iv.2004 D Mamogobo, ex larvae of bollworm on cotton" (SANC); 1 đૈ, "South Africa, Tvl, Brits 2.i.1987 P.J. Guest, ACB 304 nr 3" (SANC); 1 ㅇ, same label data except: "6.i.1986ACB $302 \mathrm{nr1"}$ (SANC).

SUDAN: 1 , "Khartoum, H. W. Bedford, 28.7.31, bred out from Laphygma exigua, Ent. coll. C10438" (BMNH).

TANZANIA: 1 q, "Mkomazi Game Reserve, Ibaya Camp, 3.58S 37.48E 10-25 Dec 1995, S. van Noort, Malaise trap, Acacia / Commiphora / Combretum bushland, SAM-HYM-P015675" (SAMC).

\section{Host records}

Maliarpha separatella Ragonot (Lepidoptera: Pyralidae) on Oryza sativa L. (Poacaeae); unidentified lycaenid cocoons on Crotalaria sp. (Fabaceae). New records: Plutella xylostella (L., 1758) (Lepidoptera: Plutellidae) on Brassica sp.; Helicoverpa armigera Hübner, 1827 (Lepidoptera: Noctuidae) on Gossypium hirsutum L. (Malvaceae); Heliocheilus albipunctella (de Joannis, 1925) (Lepidoptera: Noctuidae); Spodoptera exigua ((Hübner, 1808) (Lepidoptera: Noctuidae); unknown hosts on Crotalaria glauca Willd., C. goveensis Guill. \& Perr., Teramnus buettneri (Harms) Baker f. and Tephrosia bracteolata Guill. \& Perr. (Fabaceae).

\section{Distribution}

Egypt (?, see comments), Ethiopia, Gambia, Ivory Coast, Italy, Madagascar, Mozambique, Senegal, Sierra Leone. New records: Benin, Cameroon, Democratic Republic of the Congo, Namibia, South Africa, Sudan, Tanzania. 


\section{Comments}

Pristomerus pallidus is distributed throughout the whole Afrotropical region and is very common in collections. It exhibits a noticeable intra-specific variation in the size of the femoral tooth in the female, although the tooth is always distinct and shorter than wide. The extent of the dorsal dark markings and the intensity of the reddish markings on the mesosoma are also variable. Finally, some males from Western Africa also have a mostly punctate mesoscutum. The holotype of $P$. africator (from Ivory Coast) is in the private collection of Jacques F. Aubert and was not available for examination. According to Horstmann (1990), the record from Egypt is doubtful. We could not examine this specimen, but we consider the record as probable because of the species' wide distribution.
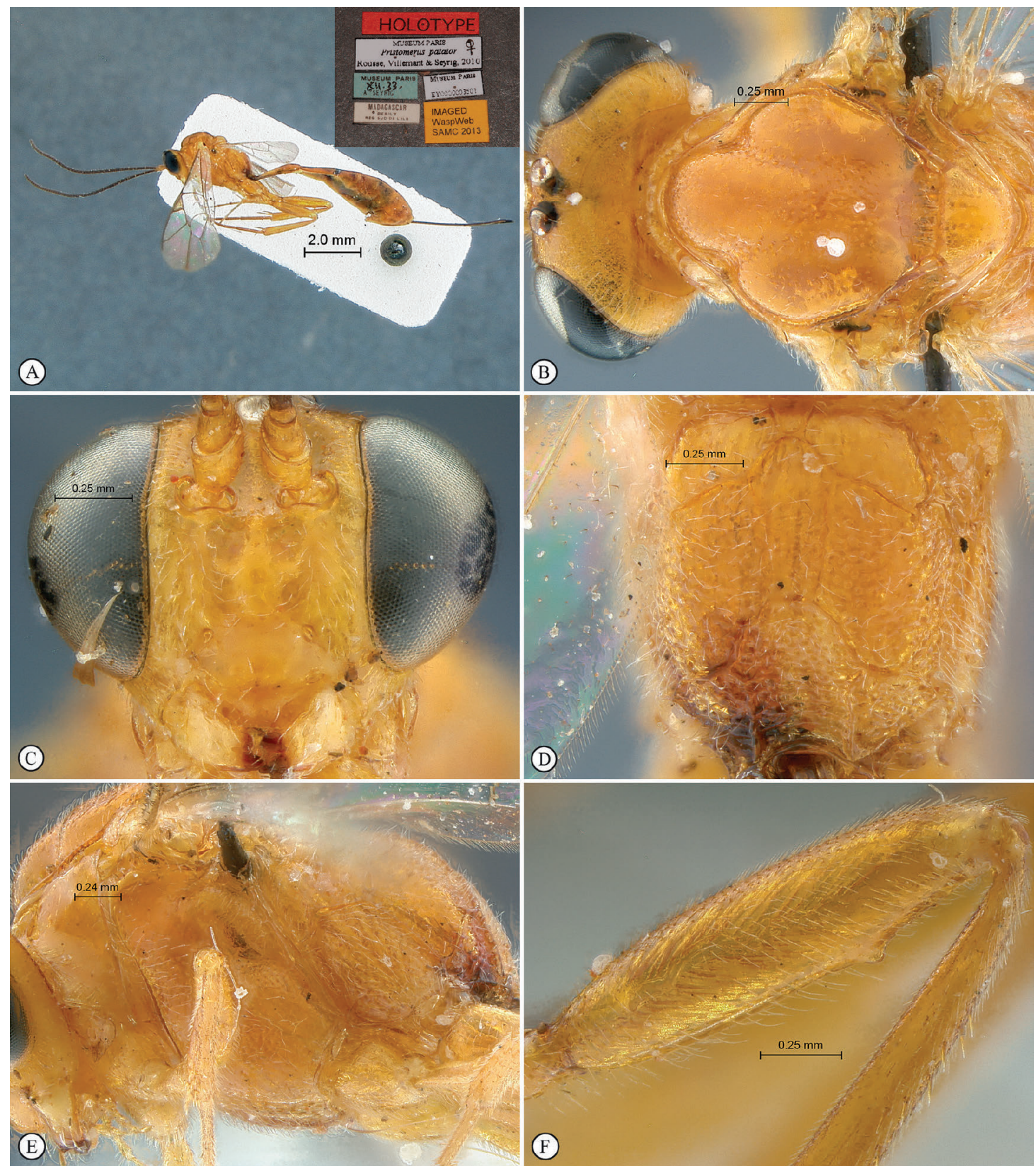

Fig. 26. Pristomerus patator Rousse, Villemant \& Seyrig, 2013. Holotype, + . A. Habitus, lateral view (inset: data labels). B. Head, mesosoma, dorsal view. C. Head, anterior view. D. Propodeum, dorsal view. E. Mesosoma, lateral view. F. Hind tibia, lateral view. 
Pristomerus patator Rousse, Villemant \& Seyrig, 2013

Fig. 26

Diagnosis (range of variation from Rousse et al. 2013)

Background colour yellowish-orange with some median dark spots on metasomal tergites; face densely punctate; inner margins of eyes subparallel; clypeus transverse, very sparsely punctate, inter-puncture spaces smooth; malar line long; remainder of head coriaceous; occipital carina joining hypostomal carina shortly above mandible base; antenna very long with more than 37-38 flagellomeres, penultimate flagellomere elongate; mesosoma moderately elongate, moderately to densely punctate, but pronotum and speculum almost entirely smooth and scutellum distinctly more sparsely punctate than mesoscutum; area superomedia weakly delimited laterally beyond anterior transverse carina; female femoral tooth small, followed by some minute denticles; ovipositor long, slightly sinuous apically. B 7.8-10.1; A 5.36.9; F 5.9-7.5; CT 1.8; ML 0.7; POL 0.7; OOL 1.1; Fl ${ }_{n-1}$ 1.2; ASM 2.0; OT 1.8-1.9; FFT 1. Male with inner margins of eyes diverging ventrally, and ocelli, hind femur and femoral tooth enlarged. B 8.9-9.8; A 5.8-7.1; F 6.3-6.7: POL 0.6; OOL 0.4.

\title{
Differential diagnosis
}

Large yellowish-orange species from Madagascar; differentiated from all other Pristomerus species in the region by the combination of the large size, the antenna with numerous flagellomeres, the long malar line, the largely smooth speculum, the punctation on the scutellum, which is often distinctly sparser than on the mesoscutum, the area superomedia hardly delimited postero-laterally, the small female femoral tooth and the long ovipositor.

\section{Material examined}

\section{Holotype}

q “MADAGASCAR, Bekily [Ampandrandava], reg. sud de l'île, XII.33, EY 0000003501” (MNHN).

\section{Distribution}

Madagascar.

\author{
Pristomerus protea sp. nov. \\ urn:1sid:zoobank.org:act:1C2445B9-50D4-4C69-991D-8289D0F03DB3
}

Fig. 27

\section{Diagnosis}

Small; head and mesosoma black, metasoma mostly testaceous-brown with tergites 1-2 black; face and clypeus deeply and sparsely to densely punctate without granulate background sculpture; clypeus transverse; malar line very long; upper head punctate-granulate; ocelli exceptionally reduced; antenna with 26 flagellomeres, penultimate one shorter than wide; mesosoma entirely deeply and densely punctate except speculum ventrally smooth; propodeum with area superomedia shorter than wide and not laterally defined beyond anterior transverse carina; female femoral tooth absent; ovipositor moderately short, evenly up-curved and apically down-curved. Male unknown.

\section{Differential diagnosis}

Small and mostly black, highly atypical among Pristomerus because of the exceptionally reduced ocelli, the fore wing venation with the abscissa of $\mathrm{M}$ between rs-m and $2 \mathrm{~m}$-cu very short, and the ovipositor shape, evenly curved without the usual sinuous apex of most Pristomerus. It is only close to P. restio sp. nov., in which the face is lighter and more roughly punctate, and the area superomedia more slender. 


\section{Etymology}

Refers to one of the most emblematic flowers of the Cape Floral Kingdom. Noun in apposition.

\section{Type material}

\section{Holotype}

SOUTH AFRICA: 9 , “SOUTH AFRICA, W. Cape, Koeberg Nature Reserve, 33³7.622’S 18²4.259’E, 31 October 1997, S. van Noort, sweep, KO97-S22, West Coast Strandveld, SAM-HYM-P039304” (SAMC).
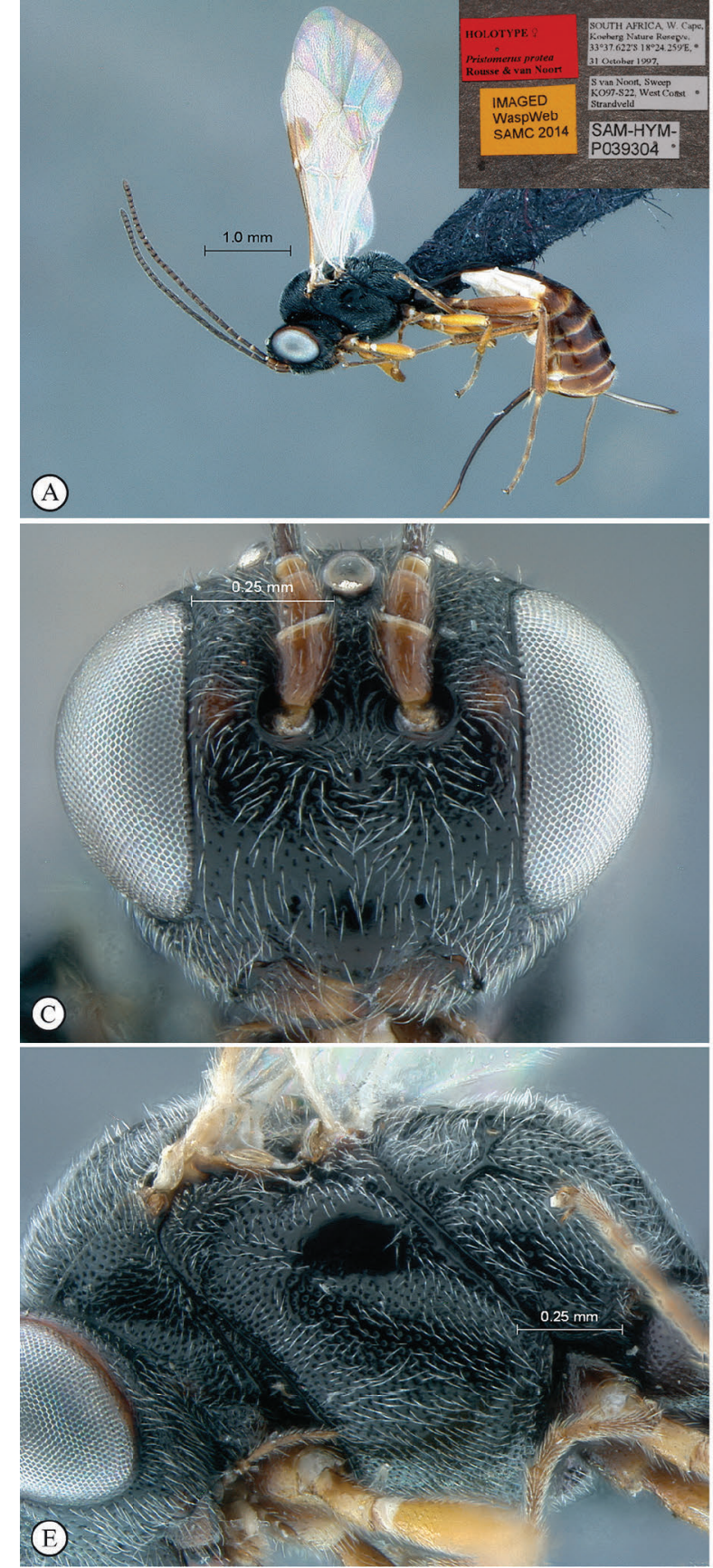
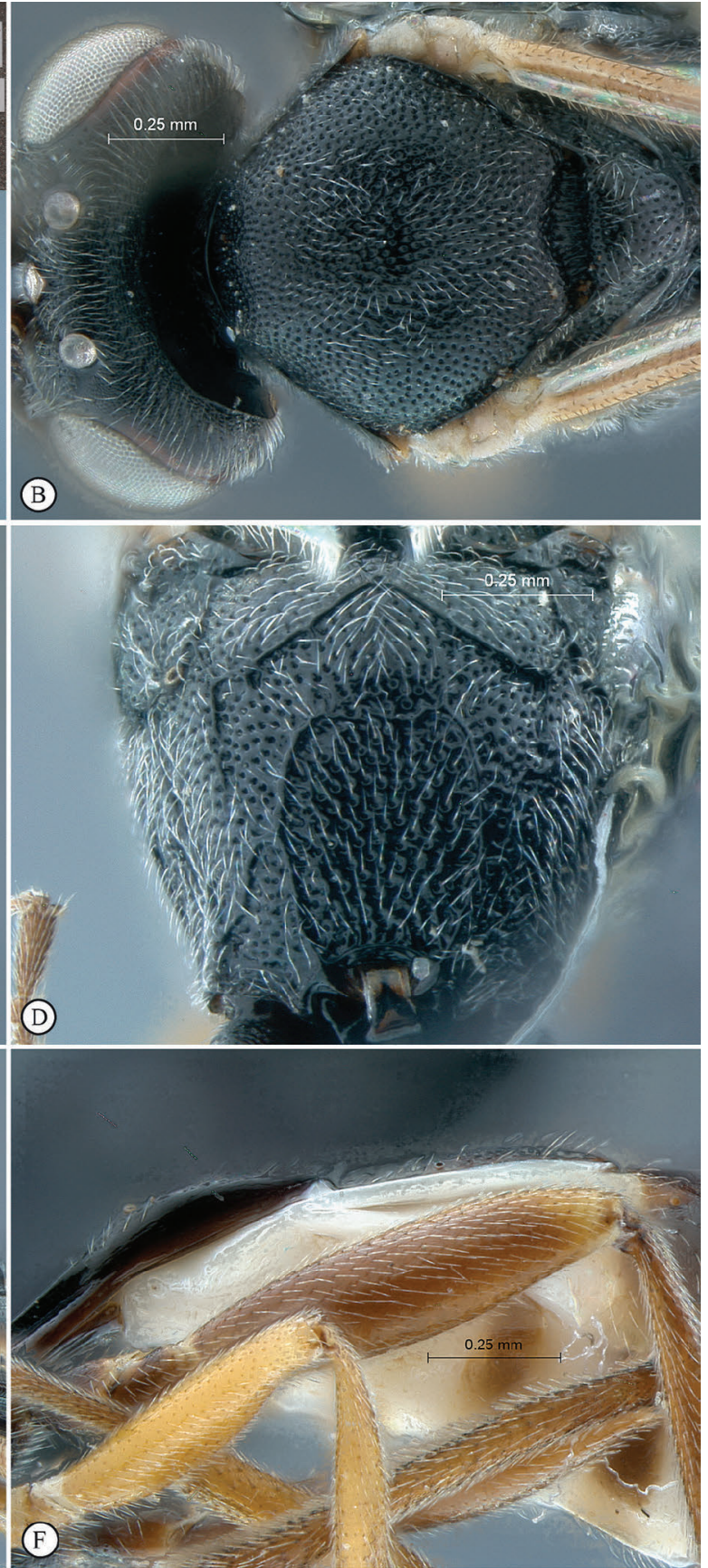

Fig. 27. Pristomerus protea sp. nov. Holotype, + . A. Habitus, lateral view (inset: data labels). B. Head, mesosoma, dorsal view. C. Head, anterior view. D. Propodeum, dorsal view. E. Mesosoma, lateral view. F. Hind tibia, lateral view. 


\section{Description}

Female (holotype)

B 5.2; A 2.9; F 3.3; CT 1.7; ML 0.9; POL 2.3; OOL 1.2; Fl ${ }_{\mathrm{n}-1}$ 0.9; ASM 0.8; OT 1.3; FFT 0.

Colour. Head and mesosoma black with mandible and a thin margin along posterior orbit yellowishtestaceous; metasoma testaceous-brown with tergites 1-2 mostly black and posterior margins of tergites yellow; antenna blackish; fore and mid legs yellow; hind leg testaceous with coxa and trochanter black; wings hyaline, venation pale yellowish with pterostigma basally whitish.

HEAD. Face deeply and densely punctate, inter-punctures spaces quite smooth; inner margins of eyes subparallel; clypeus transverse and sparsely punctate, ventral margin rather strongly convex; malar line very long; frons, vertex and temple sparsely punctate-granulate; ocelli strongly reduced, posterior ocelli remote from each other; occipital carina joining hypostomal carina distinctly above mandible base; antenna with 26 flagellomeres, flagellomere 1 distinctly longer than flagellomere 2, penultimate flagellomere slightly shorter than wide.

Mesosoma. Mesosoma stout; entirely deeply and very densely punctate except ventral half of speculum smooth; area superomedia short, subquadrate, laterally not delimited beyond anterior transverse carina. Wings. Fore wing with $2 \mathrm{~m}$-cu subopposite $2 \mathrm{rs}-\mathrm{m}$, both separated by less than their own width. Legs. Female femoral tooth absent.

Metasoma. Metasoma coriaceous with tergite 2 and apical half of tergite 1 aciculate; thyridium small and subcircular; ovipositor moderately short, stout, basally evenly up-curved with apical third downcurved, apex slightly swollen and not sinuous.

\section{Male \\ Unknown. \\ Distribution}

South Africa.

\section{Comments}

The affiliation of this species (and P. restio sp. nov.) to the genus Pristomerus is uncertain. Without associated males, however, we refrain from describing a new genus and keep them as extra-limital Pristomerus.

Pristomerus ranomafana Rousse, Villemant \& Seyrig, 2013

Fig. 28

\section{Diagnosis}

Moderate size; head whitish yellow with middle of face, frons, inter-ocellar and occiput black; mesosoma and metasoma reddish-testaceous with black markings on mesonotum and propodeum, tergites 1-3 black, and following tergites medially dark brown; face moderately punctate-granulate; inner margins of eyes subparallel; clypeus transverse, sparsely and shallowly punctate; malar line long; antenna with 31 flagellomeres, penultimate flagellomere quadrate; mesosoma densely punctate except pronotum shallowly sculptured, speculum ventrally smooth, and notaulus somewhat rugose; area superomedia elongate; female femoral tooth absent; ovipositor very long, apically strongly sinuous. B 7.2; A 4.4; F 4.9; CT 1.7; ML 0.7; POL 0.6; OOL 1.2; $\mathrm{Fl}_{\mathrm{n}-1}$ 1.0; ASM 2.0; OT 2.2; FFT 0. Male unknown.

\section{Differential diagnosis}

Moderately sized species from Madagascar, mostly reddish-testaceous with basal tergites black, and head mostly white, posteriorly and mid-longitudinally black. Differentiated from most of other Afrotropical species by the absence of a femoral tooth in the female, the white orbits, and the very long ovipositor. 
Morphologically related to $P$. vahaza, whose clypeus is narrower and mesosoma more slender, and to $P$. caris, whose ovipositor is significantly shorter.

\section{Material examined}

\section{Holotype}

MADAGASCAR: + , “MADAGASCAR, Province Fianarantsoa, Parc Nat. Ranomafana, $21^{\circ} 15.05$ 'S, 4724.43'E, Mixed tropical forest (radio tower) -1130 m, 14-21 / I / 2002, Irwin \& Harin'Hala colls, California Acad of Sciences, Malaise trap MA-02-09B-12" (CASC).
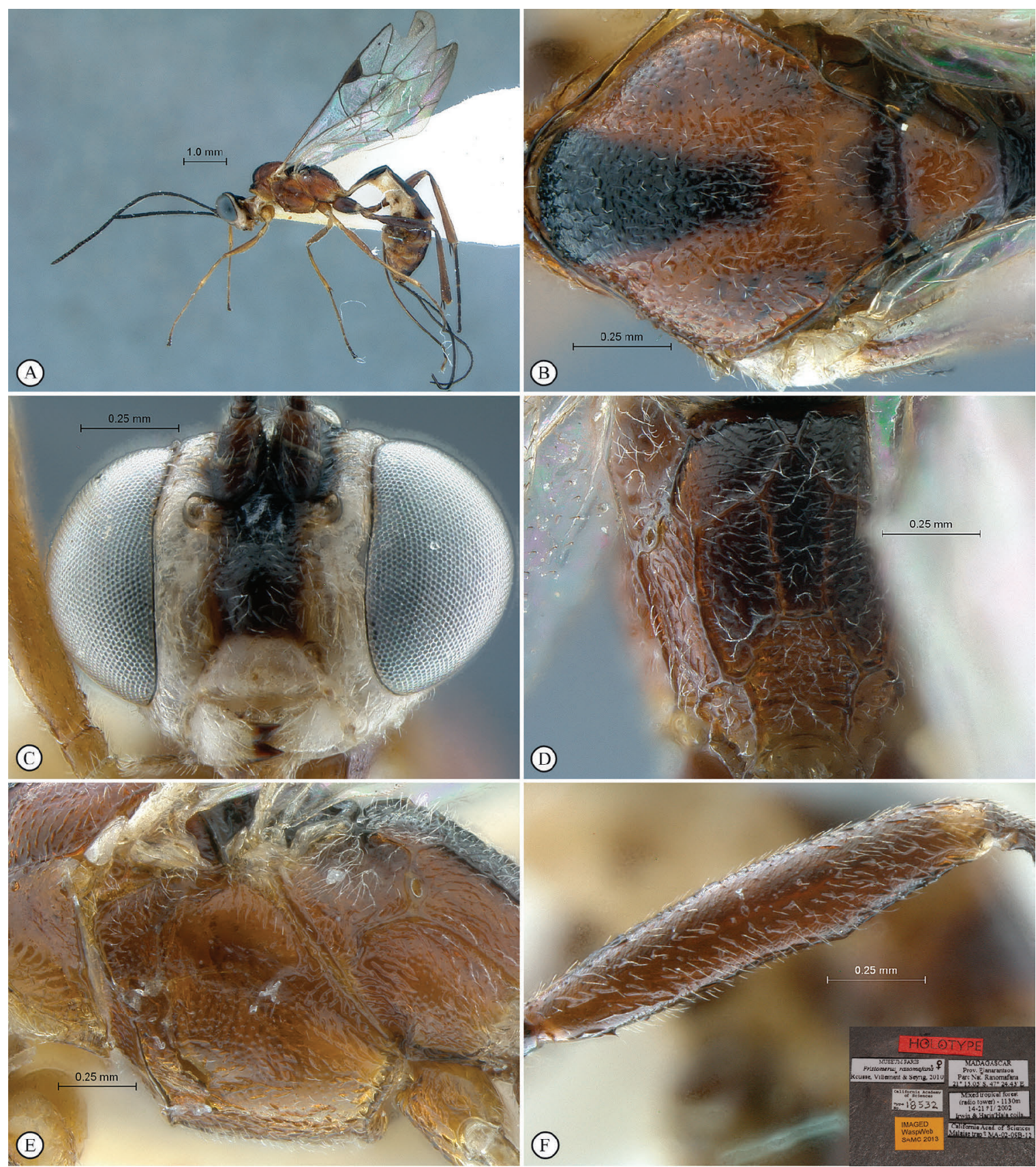

Fig. 28. Pristomerus ranomafana Rousse, Villemant \& Seyrig, 2013. Holotype, ․ . A. Habitus, lateral view. B. Mesosoma, dorsal view. C. Head, anterior view. D. Propodeum, dorsal view. E. Mesosoma, lateral view. F. Hind tibia, lateral view (inset: data labels). 


\title{
Distribution
}

Madagascar.

\author{
Pristomerus restio sp. nov. \\ urn:1sid:zoobank.org:act:1FD99527-2A70-4236-8FCD-F8F0C031AB7F
}

Fig. 29

\section{Diagnosis}

Small; head yellowish, medially, dorsally and posteriorly black; mesosoma mostly black with legs yellowish; metasoma mostly testaceous-brown; head densely and finely punctate-granulate, dorsally coriaceous; clypeus transverse; malar line long; ocelli reduced, widely separated; antenna with 28 flagellomeres, penultimate one distinctly elongate; entire mesosoma densely and finely rugose punctate, except pronotum centrally smoother; area superomedia stout and area petiolaris concave; fore wing with $2 \mathrm{~m}$-cu weakly apical to $2 \mathrm{rs}-\mathrm{m}$; female femoral tooth absent; ovipositor moderately short, evenly up-curved, apically swollen and down-curved but not sinuous. Male unknown.

\section{Differential diagnosis}

See P. protea sp. nov.

\section{Etymology}

Refers to another one of the most emblematic flowers of the Cape Floral Kingdom. Noun in apposition.

\section{Type material}

\section{Holotype}

SOUTH AFRICA: 9 , “SOUTH AFRICA, W. Cape, Koeberg Nature Reserve, 3337.622’S 18²4.259’E, 20 Mar-17 April 1998, S. van Noort, Malaise trap, KO98-M29 , West Coast Strandveld, SAM-HYMP047408" (SAMC).

\section{Description}

Female (holotype)

B 3.9; A 2.8; F: 2.8; CT 1.7; ML 0.8; POL 2.1; OOL 1.5; Fl ${ }_{\mathrm{n}-1}$ 1.3; ASM 1.5; OT 1.4; FFT 0.

Colour. Head yellowish with frons, vertex and occiput black; mesosoma black with pronotum largely yellowish; metasoma testaceous-brown with tergites 1-2 blackened; antenna basally yellowish, fading to testaceous from flagellomere 3-4; legs yellow with hind coxa darker brown; wings hyaline, venation pale yellowish with pterostigma basally whitish.

HEAD. Face and clypeus finely and very densely punctate-granulate; inner margins of eyes weakly convergent ventrally; clypeus transverse; malar line long; frons, vertex and temple deeply coriaceous; ocelli strongly reduced, subcircular, remote from each other; occipital carina joining hypostomal carina distinctly above mandible base; antenna thin with 28 flagellomeres, penultimate one distinctly elongate.

Mesosoma. Mesosoma moderately stout; entire mesosoma finely and very densely punctate-granulate, including entire speculum, except pronotum centrally smoother and somewhat crenulate anteroventrally; notaulus weak; area superomedia shortly elongate, fully delimited, area petiolaris concave and transversely strigose. Wings. Fore wing with 2m-cu unusually close to 2rs-m, 2rs-m twice as long as section of $\mathrm{M}$ between 2rs-m and 2m-cu. Legs. Female femoral tooth absent.

Metasoma. Tergite 2 and apical half of tergite 1 aciculate, following tergites coriaceous; thyridium small, subcircular; ovipositor moderately short, evenly up-curved, apically swollen and slightly downcurved but not sinuous. 


\section{Male \\ Unknown.}

\section{Distribution}

South Africa.

\section{Comments}

See P. protea sp. nov.
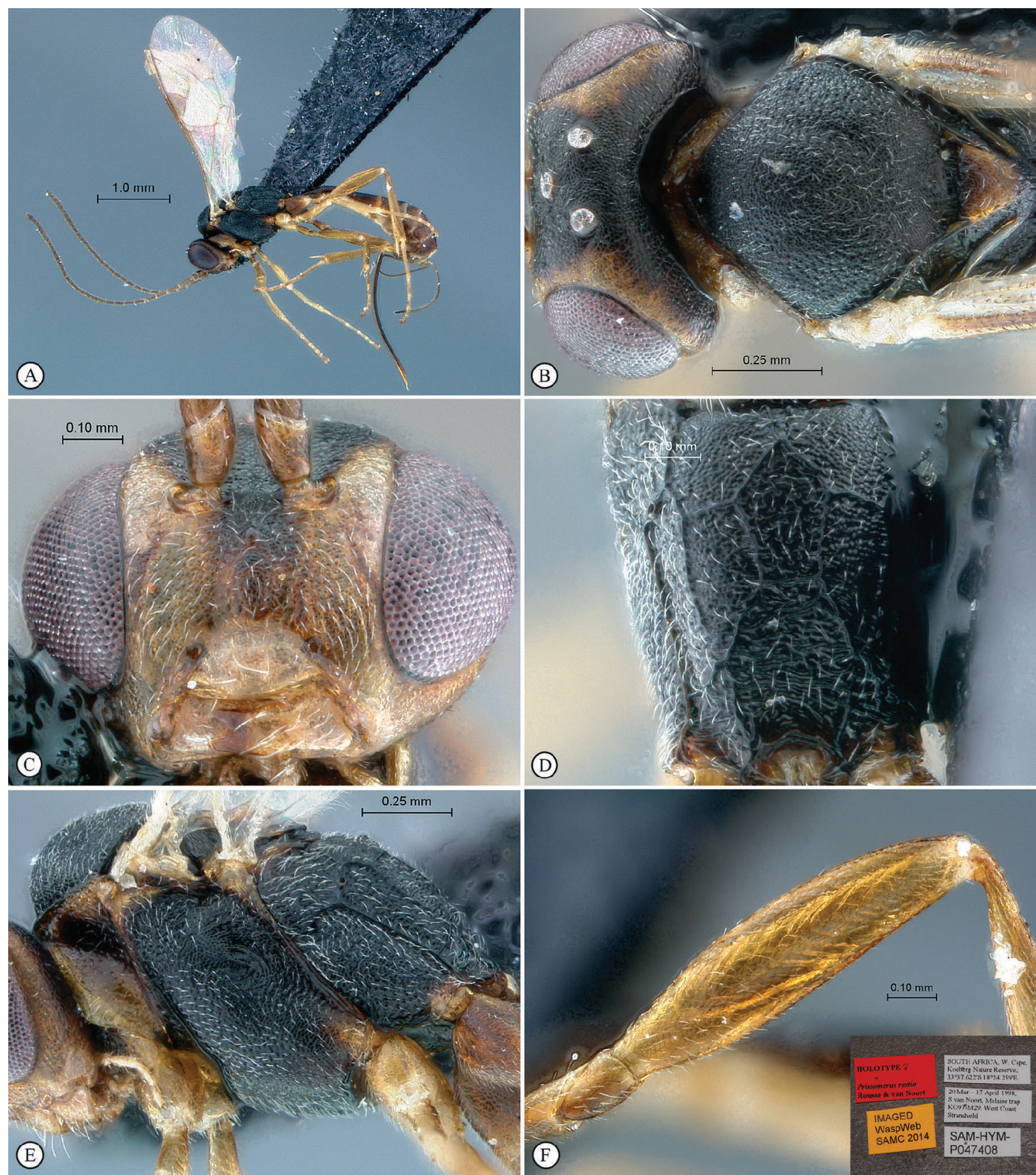

Fig. 29. Pristomerus restio sp. nov. Holotype, . . A. Habitus, lateral view. B. Head, mesosoma, dorsal view. C. Head, anterior view. D. Propodeum, dorsal view. E. Mesosoma, lateral view. F. Hind tibia, lateral view (inset: data labels). 
Pristomerus rivier Rousse \& Villemant, 2012

Fig. 30

Diagnosis (updated from Rousse \& Villemant 2012)

Moderately small; head black with clypeus, mandible, palpi and base of antenna yellow; mesosoma varying from mostly testaceous with base of propodeum black to mostly black with pronotum yellowish and mesonotum partly testaceous; metasoma basally black fading to testaceous from tergite 3, except base of tergite 1 yellow;
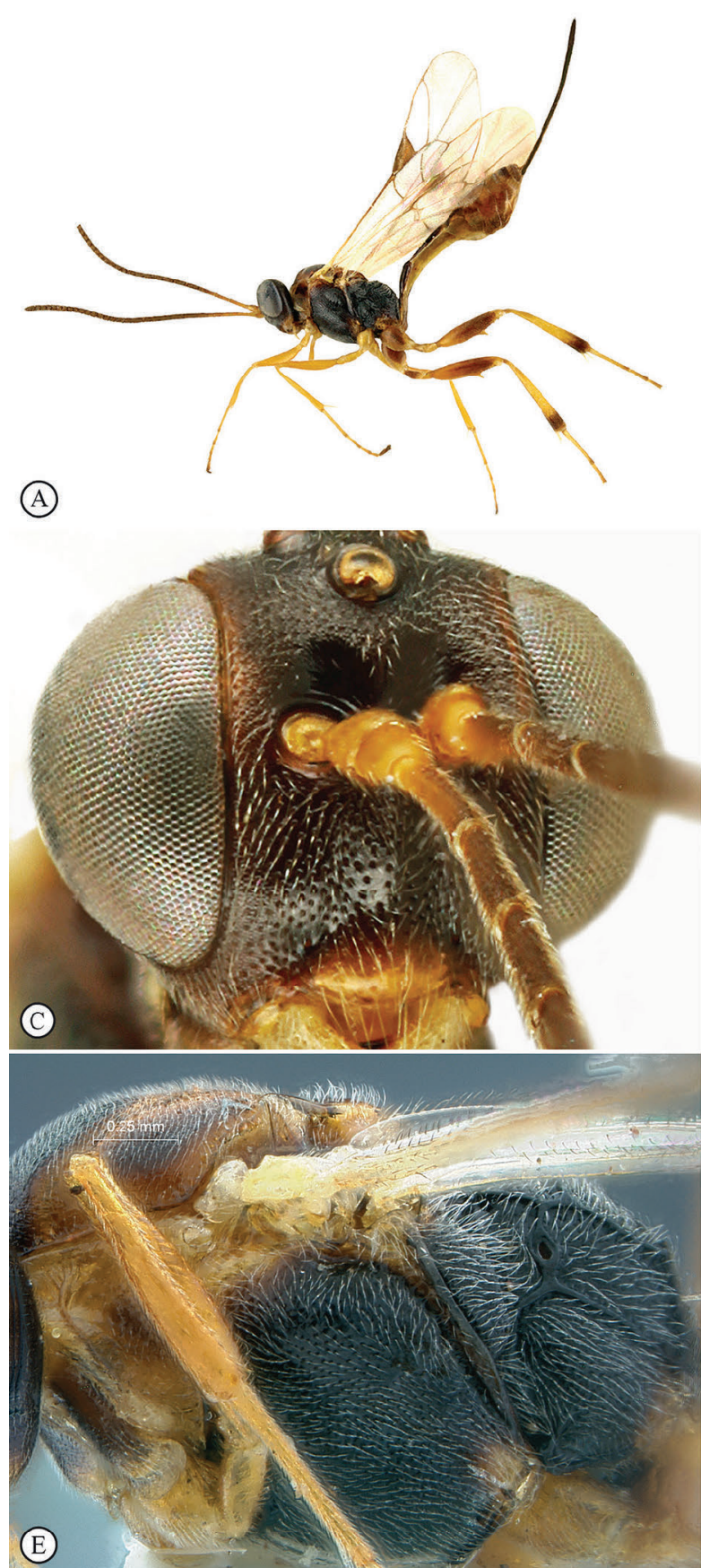
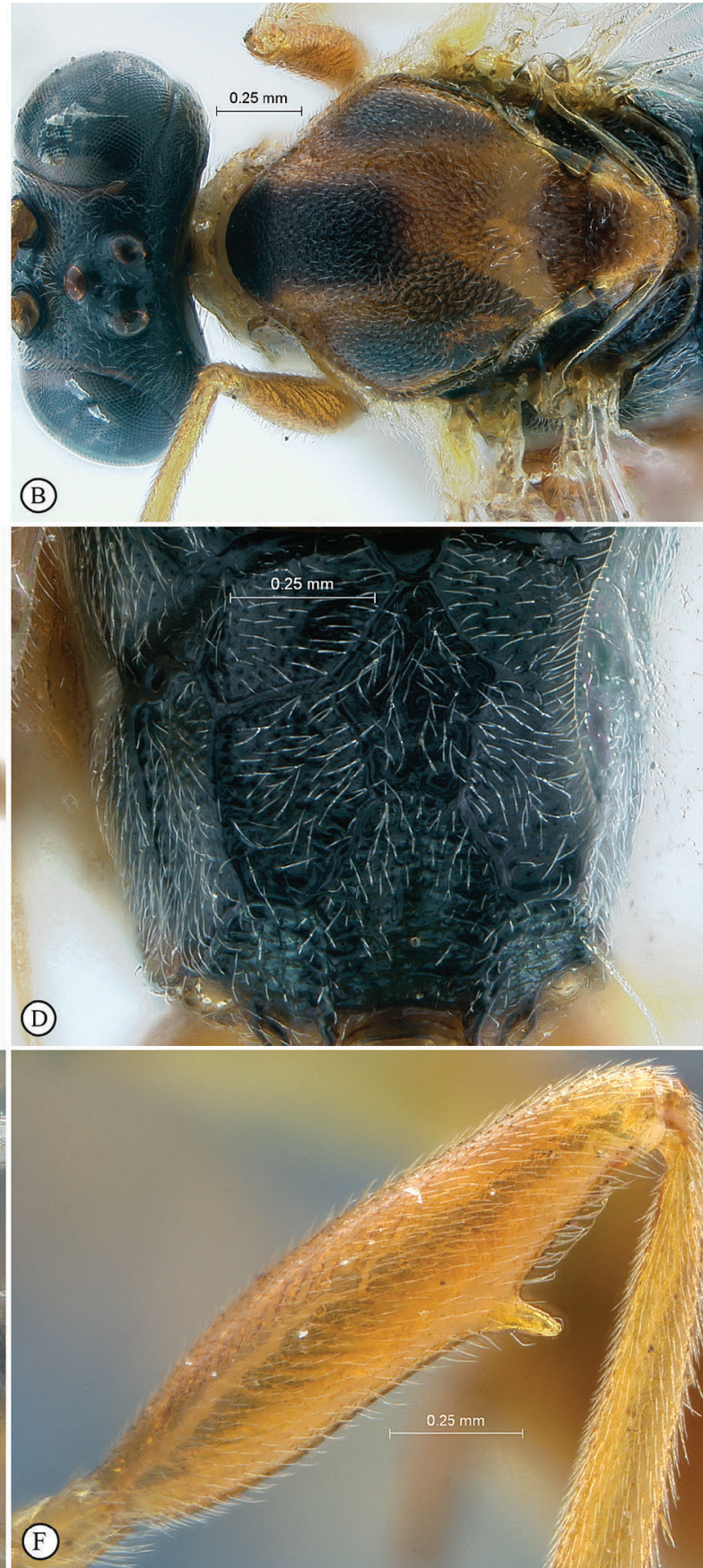

Fig. 30. Pristomerus rivier Rousse \& Villemant, 2012. Holotype, ㅇ. A. Habitus, lateral view. B. Head, mesosoma, dorsal view. C. Head, anterior view. D. Propodeum, dorsal view. E. Mesosoma, lateral view. F. Hind tibia, lateral view. 
legs mostly yellowish-orange with hind coxa and hind femur testaceous-brown and hind tibia apically dark; face densely punctate and hairy; clypeus transverse, sparsely punctate, distinctly convex in profile; malar line long; remainder of head coriaceous; occipital carina joining hypostomal carina at mandible base; antenna with 24-30 flagellomeres, penultimate flagellomere subquadrate; mesosoma moderately stout, entirely densely punctate, including whole pronotum, speculum and scutellum; area superomedia short and stout; female femoral tooth strong; ovipositor moderately long, apically sinuous. B 5.1-6.3; A 3.4-4.5; F 3.8-4.6; CT 1.9; ML 0.7; POL 1.0; OOL 1.1; $\mathrm{Fl}_{\mathrm{n}-1} 1.0 ;$ ASM 1.4; OT 1.8-2.0; FFT 2. Male with inner margins of eyes distinctly diverging ventrally, ocelli, hind femur and femoral tooth enlarged, and area superomedia more slender. POL $0.9 ;$ OOL 0.2 .

\section{Differential diagnosis}

Moderately small, black and testaceous species from Réunion Island; differentiated from all other Afrotropical species by the combination of the black orbits, the partially testaceous mesoscutum, the entirely punctate speculum, the stout area superomedia in the female and the strong female femoral tooth.

\section{Material examined}

Holotype

FRANCE: ㅇ, "La Réunion, Petit St Pierre, sur Litchi sinensis, 19/06/1996, Cirad 14373 RQ 3220, Quilici S. leg., EY 0000003897” (MNHN).

\section{Other material}

FRANCE: 1 ๆ, 1 ơ, "Réunion, Quatorzième, verger de café, iv.2012, ex. Prophantis smaragdina SAMHYM-P049438" (SAMC); 4 우, "Réunion, les Colimaçons, alt. 800m, 22.03.2013, ex. P. smaragdina, coll. David Muru" (personal collection D. Muru).

\section{Host records}

Plutella xylostella (Lepidoptera: Plutellidae) on cabbage (Brassica oleracea L.). New record: Prophantis smaragdina Butler, 1875 (Lepidoptera: Pyralidae) on coffee (Coffea arabica L.).

\section{Distribution}

Réunion island.

Pristomerus roberti Rousse, Villemant \& Seyrig, 2013

Fig. 31

Diagnosis (range of variation from Rousse et al. 2013)

Moderately small; yellow to yellowish-orange overall with tergites 1-3 variously blackened; frons, face and clypeus moderately densely punctate-granulate, remainder of head coriaceous; inner margins of eyes subparallel; clypeus strongly transverse; malar line long; occipital carina joining hypostomal carina shortly above mandible base; antenna with 28-32 flagellomeres, penultimate flagellomere subquadrate; mesosoma moderately elongate and densely punctate but pronotum dorsally and ventral half of speculum smooth; female femoral tooth small, followed by minute denticles; ovipositor long, its apex distinctly sinuous. B 7.0-8.4; A 3.8-4.6; F 3.6-4.3; CT 2.1; ML 0.7; POL 0.9; OOL 1.2; $\mathrm{Fl}_{\mathrm{n}-1} 1.1$; ASM 2.0; OT 1.8-2.1; FFT 1. Male with mesoscutum weakly sculptured, mostly coriaceous, inner margins of eyes distinctly diverging ventrally, ocelli enlarged, femur and femoral tooth strongly stouter. POL 0.6; OOL 0.4.

\section{Differential diagnosis}

Rather small, overall yellow to yellowish orange with metasoma basally black; differentiated from all other Afrotropical species by the combination of the rather strongly transverse clypeus, the long malar line, the small female femoral tooth and the markedly long ovipositor. Morphologically close to other Pristomerus 
species in Madagascar: P. kelikely and related species, which have a shorter malar line and no femoral tooth in the female; $P$. patator, which is distinctly larger with longer antennae and an incompletely carinate area superomedia; and the widespread P. pallidus, which has a shorter ovipositor and nearly always a differently coloured mesosoma with the notaulus and the scutellum paler than the remainder of the mesonotum. Pristomerus roberti is otherwise probably closely related to P. herero sp. nov. (see differential diagnosis of P. herero sp. nov.).
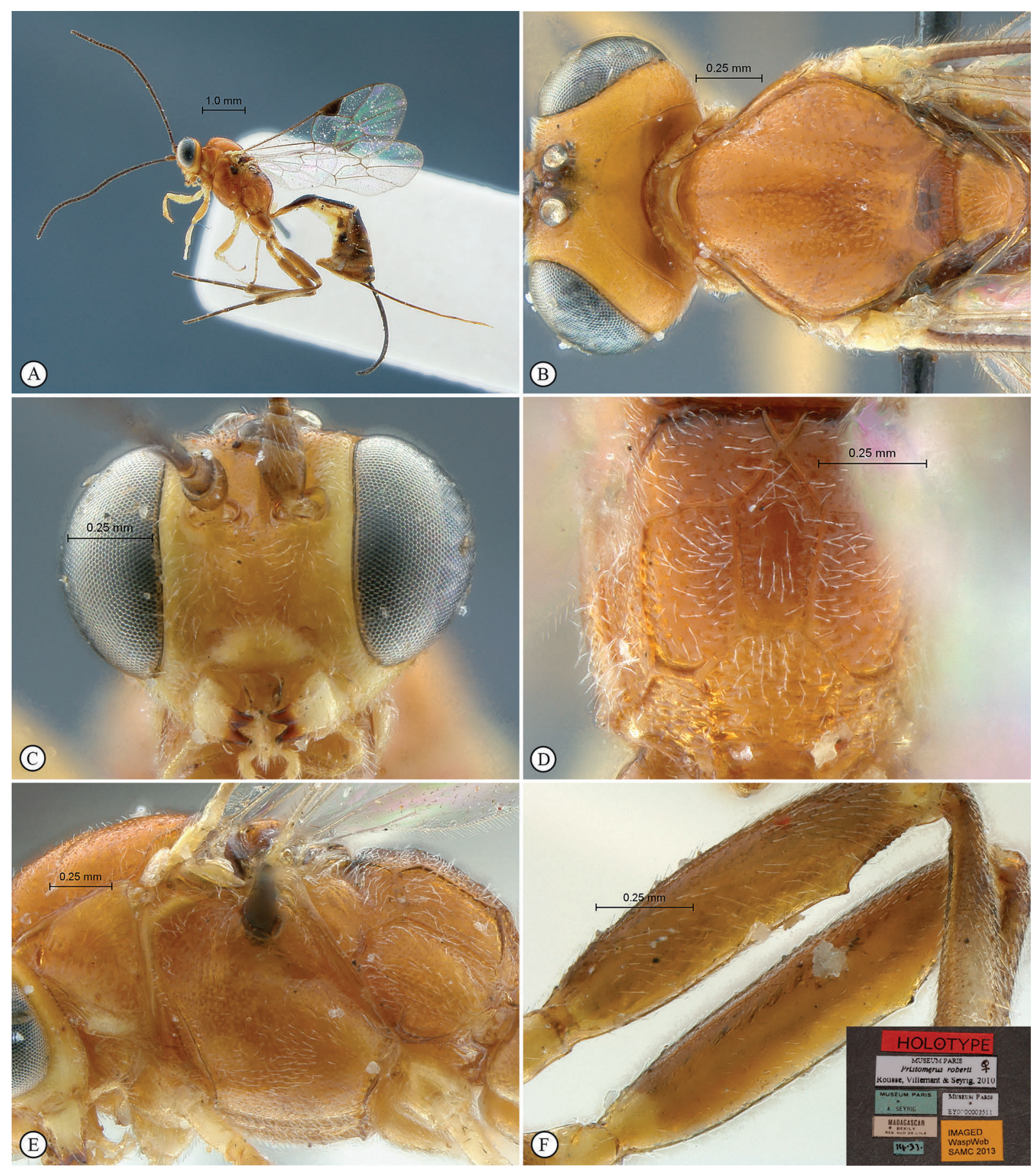

Fig. 31. Pristomerus roberti Rousse, Villemant \& Seyrig, 2013. Holotype,, . A. Habitus, lateral view. B. Head, mesosoma, dorsal view. C. Head, anterior view. D. Propodeum, dorsal view. E. Mesosoma, lateral view. F. Hind tibia, lateral view (inset: data labels). 


\section{Material examined}

Holotype

MADAGASCAR: +, "MADAGASCAR, Bekily [Ampandrandava], reg. sud de l'île, III. 33, EY 0000003511” (MNHN).

\section{Distribution}

\section{Madagascar.}
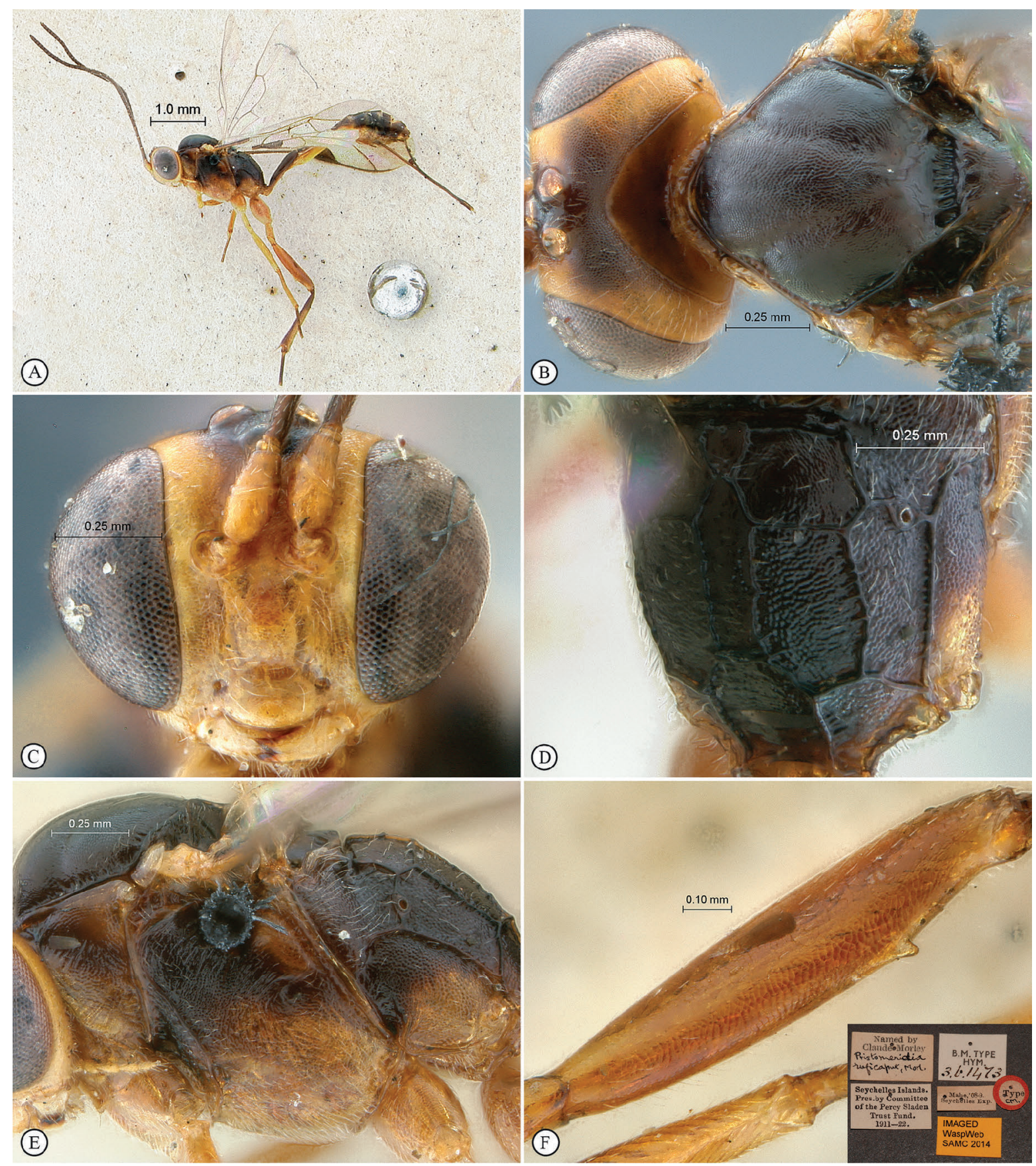

Fig. 32. Pristomerus ruficaput (Morley, 1912). Holotype, †. A. Habitus, lateral view. B. Head, mesosoma, dorsal view. C. Head, anterior view. D. Propodeum, dorsal view. E. Mesosoma, lateral view. F. Hind tibia, lateral view (inset: data labels). 
Pristomerus ruficaput (Morley, 1912)

Fig. 32

Pristomeridia ruficaput Morley, 1912: 176.

\section{Diagnosis}

Moderately small; head mostly yellowish-orange with vertex, frons and occiput dark brown to black; mesosoma dorsally black and ventrally yellowish-orange; metasoma mostly dark brown to black; head granulate to coriaceous with some isolated punctures; inner margins of eyes slightly convergent ventrally; clypeus transverse, long; malar line moderately short; occipital carina joining hypostomal carina strongly above mandible base; antenna with 31 flagellomeres, penultimate flagellomere slightly elongate; mesosoma moderately elongate, entirely coriaceous but ventral half of speculum smooth; area superomedia elongate; apical half of metasomal tergite 1 finely punctate-reticulate, tergite 2 aciculopunctate, following tergites coriaceous; female femoral tooth strong, slightly higher than basally wide, followed by a row of denticles; ovipositor short and straight, apically slightly sinuous. B 5.7; A 3.5; F 3.8; CT 1.7; ML 0.5; POL 1.0; OOL 1.3; $\mathrm{Fl}_{\mathrm{n}-1} 1.2$; ASM 2.2; OT 1.3; FFT 2.

\section{Differential diagnosis}

Rather small, yellowish-orange and black species from the Seychelles Islands; readily differentiated from all other Afrotropical species by the colour pattern with the mesosoma dorsally black and ventrally yellowish-orange, the coriaceous mesoscutum, the strong femoral tooth and the short ovipositor.

\section{Material examined}

\section{Holotype}

SEYCHELLES: + , "Mahe, 08-9. SEYCHELLES Exp. Seychelles Islands. Pres. by Committee of the Percy Sladen Trust Fund. 1911-22, HYM-3.G.1473" (BMNH).

\section{Distribution}

Seychelles.

Pristomerus san sp. nov. urn:1sid:zoobank.org:act:8ECF1D02-AFCA-4063-BEAF-6D479B1EB6F5

Fig. 33

\section{Diagnosis}

Rather small; yellowish-orange overall, with basal tergites sometimes variously infuscate; face and clypeus densely and deeply punctate but clypeus apically smoother, remainder of head coriaceous; clypeus transverse; malar line long; antenna short with 26-28 flagellomeres, penultimate flagellomere subquadrate; mesosoma entirely densely, deeply and evenly punctate, except almost entire pronotum and ventral half of speculum smooth; female femoral tooth absent; ovipositor moderately short, apically sinuous. Male with ocelli, hind femur and femoral tooth enlarged, inner margins of eyes diverging ventrally, and area superomedia more slender; otherwise similar to female.

\section{Differential diagnosis}

Moderately sized and yellowish orange with no defined dorsal dark markings; differentiated from all other Afrotropical species by the combination of the long malar line, the almost smooth pronotum, the deep and dense punctation, the absence of a femoral tooth in females and the rather short ovipositor. Morphologically close to P. moramora and related species which are also present in Southern Africa, but the longer malar line, the smooth pronotum and the deep dense punctation of $P$. san sp. nov. are reliable identification cues. 


\section{Type material}

\section{Holotype}

SOUTH AFRICA: + , "South Africa, Western Cape, Gamkaberg Nature Reserve, 3339.570'S 2153.957’E, 328 m, 31 July-10 Sept 2009, S. van Noort, Malaise Trap, Gamka Thicket, GB09-SUC3M17, SAM-HYM-P047410" (SAMC).
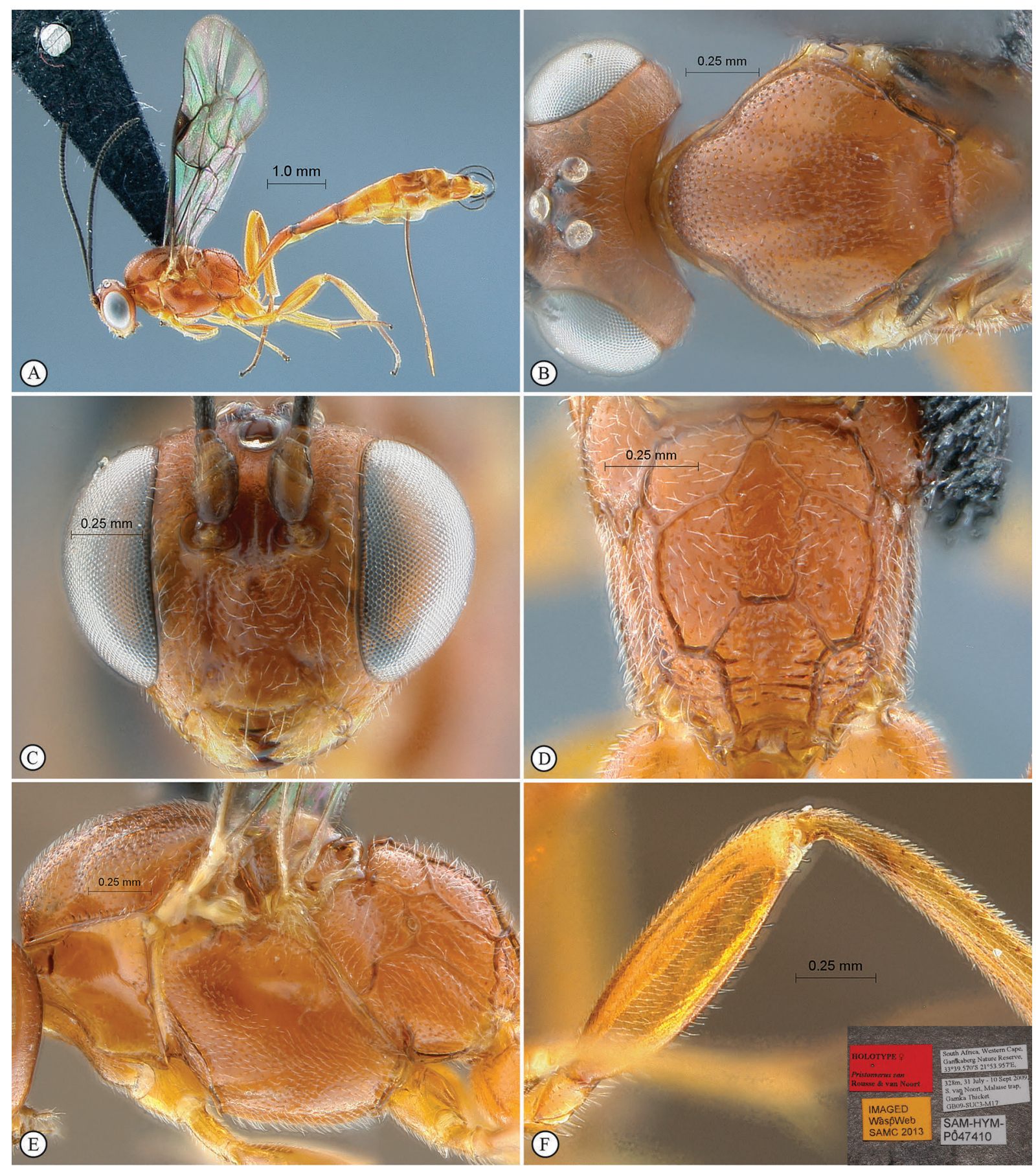

Fig. 33. Pristomerus san sp. nov. Holotype, ${ }$. A. Habitus, lateral view. B. Head, mesosoma, dorsal view. C. Head, anterior view. D. Propodeum, dorsal view. E. Mesosoma, lateral view. F. Hind tibia, lateral view (inset: data labels). 


\section{Paratypes}

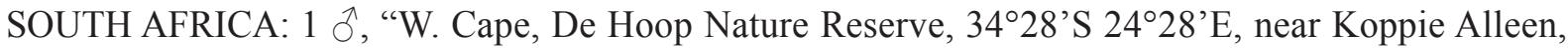
40m alt., 28 September 1995, S. van Noort, Sweep, Strandveld including Sideroxylon inerma, SAMHYM-P047156" (SAMC); 1 O’, same label data except: "SAM-HYM-P047158" (SAMC); 2 우, “South Africa, Eastern Cape, Pearston, Plains of Camdeboo Game Reserve, 32³2.033'S 25⒕267'E, 969m, 22 Feb-9 April 2010, S. van Noort, Malaise trap, Camdeboo Escarpment Thicket, PCD09ACA1-M03 (SAM-HYM-P049440)" (SAMC); 1 +, "South Africa, W. Cape, Walker Bay Nature Reserve, 34²7.414'S 19²1.393'E, 4 Oct-1 Nov 1997, S van Noort, Malaise trap, WB97-M12, South Coast Strandveld, 57m altitude, SAM-HYM-P049441" (SAMC); 1 \%, "South Africa Western

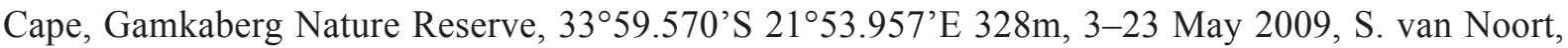
Malaise trap, Gamka Thicket, GB09-SUC3-M08, SAM-HYM-P049442" (SAMC); 1 q, "South Africa Northern Cape, Nieuwoudtville National Botanical Gardens, $797 \mathrm{~m}, 31^{\circ} 24.841^{\prime} \mathrm{S} 19^{\circ} 09.551$ 'E, 14 Feb-17 March 2008, S. van Noort, Malaise trap, Nieuwoudtville Dolerite Koppie Renosterveld, GL07-KOP2-M21, SAM-HYM-P049443" (SAMC); 1 , "Durban, C. v.d. Merwe, Sept. 1920, SAM-HYM-P001214" (SAMC); 1 +, "Mfongozi, Zululand, W.E. Jones, Apr--May 1931, SAMHYM-P001215" (SAMC); 1 + , "M'fongosi zulu L. W.E. Jones Jan. 1917, Cremastus testaceous + iii.1918 SAM-HYM-P001216" (SAMC); 1 을 Pretoria. Nov. 1942-Jan. 1943 H. K. Munro Ac. P. 4753" (SANC); 6 우, "South Africa TVL Roodeplant dam, nr Pretoria 24.41S 28.18E 16.ix.1986 J. S. Donaldson" (SANC).

\section{Other material}

SOUTH AFRICA: 9 $\widehat{\partial} \widehat{\partial}$, "Resolution, Grahamstown Miss Walton Jan.-April 1928, SAM-HYMP001212" (SAMC); same label data, SAM-HYM-P001213 (SAMC); 1 +, 1 ¡ै, "Beaufort West: dist. S.A-M. 2.58, SAM-HYM-P001217” (SAMC).

\section{Description}

Female (18 specimens)

B 6.2-7.5; A 3.3-3.9; F 3.9-4.5; CT 1.7; ML 0.7; POL 1.0; OOL 1.2; $\mathrm{Fl}_{\mathrm{n}-1}$ 1.1; ASM 1.9; OT 1.3-1.5; FFT 0.

CoLour. Yellowish-orange to orange overall with legs, mandible and clypeus somewhat paler, with sometimes reduced infuscate markings around scutellum and on basal tergites; flagellum and ovipositor sheath dark brown; wings hyaline, venation pale brown.

HEAD. Face moderately, deeply and evenly punctate; inner margins of eyes parallel; clypeus transverse, long, deeply punctate, apically smoother; malar line long; frons, vertex and temple coriaceous; frons with a moderate mid-longitudinal ridge; occipital carina joining hypostomal carina at mandible base; antenna with 26-28 flagellomeres, penultimate flagellomere subquadrate.

Mesosoma. Pronotum mostly smooth, shallowly crenulate anteriorly and with some punctures along posterior and dorsal margins; mesopleuron and metapleuron densely, deeply and evenly punctate, with a shallowly striate oblique furrow below speculum, speculum ventrally smooth; mesoscutum densely punctate-granulate, punctures somewhat confluent along notaulus; notaulus moderate; scutellum densely punctate; propodeum densely and deeply punctate with carination strong, punctation smoother in area superomedia, and area petiolaris transversely striate. Legs. Female femoral tooth absent.

Metasoma. Tergite 2 and apex of tergite 1 aciculate, following tergites coriaceous; thyridium subelliptic and longitudinal; ovipositor moderately short, apically sinuous. 
Male (2 specimens)

B 6.8-8.0; A 3.5-4.2; F 4.2-4.9; POL 0.6; OOL 0.5. Ocelli, hind femur and femoral tooth enlarged; inner margins of eyes diverging ventrally; area superomedia more slender; antenna with 28-29 flagellomeres; otherwise similar to female.

\section{Distribution}

South Africa.

\section{Comments}

The specimen SAM-HYM-P001216, labeled "Cremastus testaceous", was misidentified as Trathala concolor (Szépligeti, 1905) in Morley (1926).

Pristomerus sara sp. nov.

urn:1sid:zoobank.org:act:E44A1907-1177-4176-8613-65A640BBDD52

Fig. 34

\section{Diagnosis}

Small; yellow to yellowish-orange with dorsal dark markings; trochanters and apices of femora pale dotted; face and frons densely and superficially punctate; clypeus strongly transverse, almost smooth; malar line moderately short; occipital carina joining hypostomal carina shortly above mandible base; antenna with 29 flagellomeres, penultimate flagellomere distinctly elongate; mesosoma moderately and rather shallowly punctate, except most of pronotum coriaceous, and speculum ventrally smooth; area superomedia elongate; female femoral tooth absent; ovipositor moderately long, apically strongly sinuous. Male unknown.

\section{Differential diagnosis}

Small and mostly yellowish-orange species, differentiated from most other Afrotropical species by the combination of the strongly transverse clypeus, the rather short malar line, the shallow sculpture of face and pronotum, the absence of a femoral tooth in females and the rather long ovipositor. Morphologically, it is therefore very close to P. kelikely, from which it differs only by having the apices of the femora and the anterior half of the pterostigma strikingly white (see general discussion). Pristomerus sara sp. nov. seems also closely related to $P$. wolof sp. nov. (see differential diagnosis of $P$. wolof $\mathrm{sp}$. nov.).

\section{Type material}

\section{Holotype}

CENTRAL AFRICAN REPUBLIC: + , "Central African Republic, Préfecture Sangha-Mbaéré, Parc National de Dzanga-Ndoki, Mabéa Bai, 21.4 Km 53²NE Bayanga, $3^{\circ} 02.01^{\prime} \mathrm{N} 16^{\circ} 24.57^{\prime} \mathrm{E}, 510 \mathrm{~m}$, 6-7.v.2001, S van Noort, Malaise Trap, CAR01-M58, Lowland Rainforest, marsh clearing, SAMHYM-P047409" (SAMC).

\section{Paratype}

CENTRAL AFRICAN REPUBLIC: ${ }^{+}$, same label data.

\section{Description}

Female ( 2 specimens)

B 5.2-5.6; A 3.5-3.7; F 3.2-3.4; CT 2.1; ML 0.5; POL 0.5; OOL 1.1; Fl 1 1.1 ASM 2.5; OT 1.5-1.7; FFT 0.

Colour. Yellowish-orange overall, with mandible, clypeus and frontal orbit pale yellow, notaulus and scutellum slightly lighter than remainder of mesonotum, tergites 1-2 antero-medially black, and 
following tergites variably centrally infuscate; flagellum testaceous; all trochanters and femora apically white-dotted; wings hyaline, venation brown, pterostigma anteriorly white.

HEAD. Face densely and superficially punctate; inner margins of eyes parallel; clypeus strongly transverse, smooth; malar line rather short; frons and vertex sparsely superficially punctate, temple
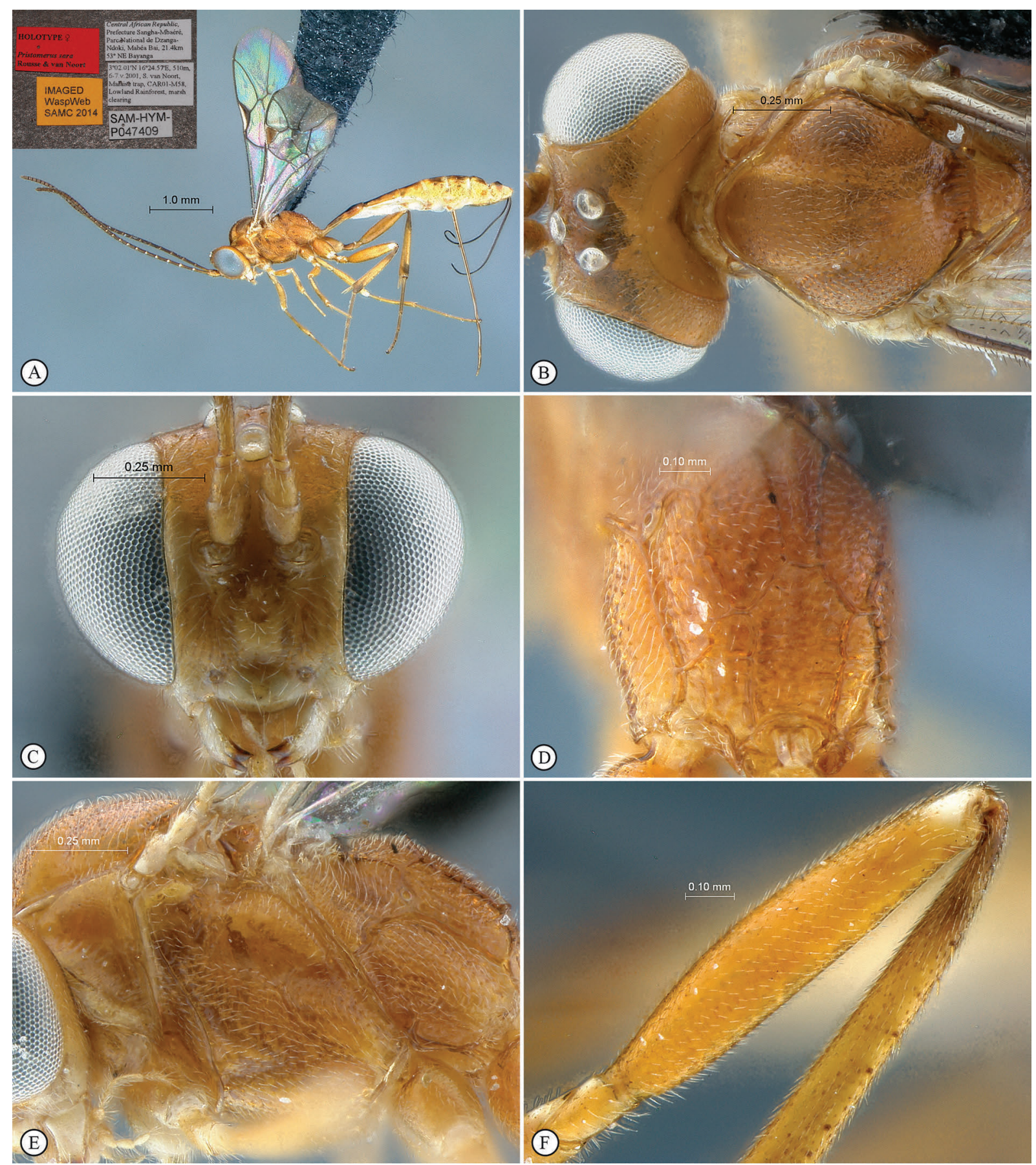

Fig. 34. Pristomerus sara sp. nov. Holotype, + . A. Habitus, lateral view (inset: data labels). B. Head, mesosoma, dorsal view. C. Head, anterior view. D. Propodeum, dorsal view. E. Mesosoma, lateral view. F. Hind tibia, lateral view. 
coriaceous; antenna with 28-29 flagellomeres, penultimate flagellomere elongate; occipital carina joining hypostomal carina above mandible base.

Mesosoma. Mesosoma moderately elongate; pronotum weakly sculptured, mostly alutaceous and anteroventrally weakly crenulate; mesopleuron and metapleuron densely and rather shallowly punctate with an oblique shallowly striate furrow below speculum, speculum ventrally smoother; mesonotum densely and shallowly punctate-granulate, punctures somewhat confluent along notaulus line; scutellum densely punctate; propodeum densely punctate-granulate, area petiolaris transversely strigose, area superomedia elongate. Legs. Femoral tooth absent.

Metasoma. Tergite 2 and apical half of tergite 1 longitudinally aciculate, following tergites coriaceous; thyridium elliptic and wide, its main axis longitudinal; ovipositor moderately long, basal half straight, apically strongly sinuous.

\section{Male \\ Unknown.}

\section{Distribution}

Central African Republic.

\section{Comments}

This species is mostly differentiated from P. kelikely by the colour pattern, the femora being apically white-dotted and the anterior half of the pterostigma being white. We consider this pattern to be a significant ecological indicator (see general discussion).

\section{Pristomerus sotho $\mathrm{sp}$. nov. urn:1sid:zoobank.org:act:D7109E59-7B2D-4F89-9E55-347D23E52A40}

Fig. 35

\section{Diagnosis}

Moderately large; mostly reddish-orange with entire head, mesosoma ventrally and tergites 1-2 black; face and clypeus densely punctate with unusually dense silver hairs; clypeus transverse; malar line long; mesosoma densely and evenly punctate, with pronotum centrally coriaceous and speculum ventrally smoother; femoral tooth strong; ovipositor short, apically moderately sinuous. Male unknown.

\section{Differential diagnosis}

Moderately sized, black and reddish-orange species; readily differentiated from every other Afrotropical species by the unique colour pattern, with most of the head and mesosoma ventrally black, the remainder of the mesosoma being reddish-orange; also characteristic because of the combination of the densely hairy face and mandibles, the short ovipositor, the strong female femoral tooth and the punctate scutellum.

\section{Type material}

\section{Holotype}

SOUTH AFRICA: + , "SA KZN [Kwazulu-Natal] Kamberg F57 29.3767º $29.67108^{\circ}$ E 1967m Forest Malaise 2 13-Jan-2006 III-UKZN MDTP 66029, SAM-HYM-P047100” (SAMC).

\section{Description}

Female (holotype)

B 1.3; A n/a; F 0.9; CT 1.7; ML 0.7; POL 0.8; OOL 1.0; Fl $1_{n-1}$ n/a; ASM 2.2; OT 1.2; FFT 2. 
CoLour. Head including antenna black with clypeus reddish-orange and mandible yellow; mesosoma dorsally reddish-orange, ventrally black; metasoma with tergites 1-2 black, following tergites reddishorange, medially blackened; legs orange with base and apex of hind tibia and hind femur blackened; wings hyaline, venation brown.
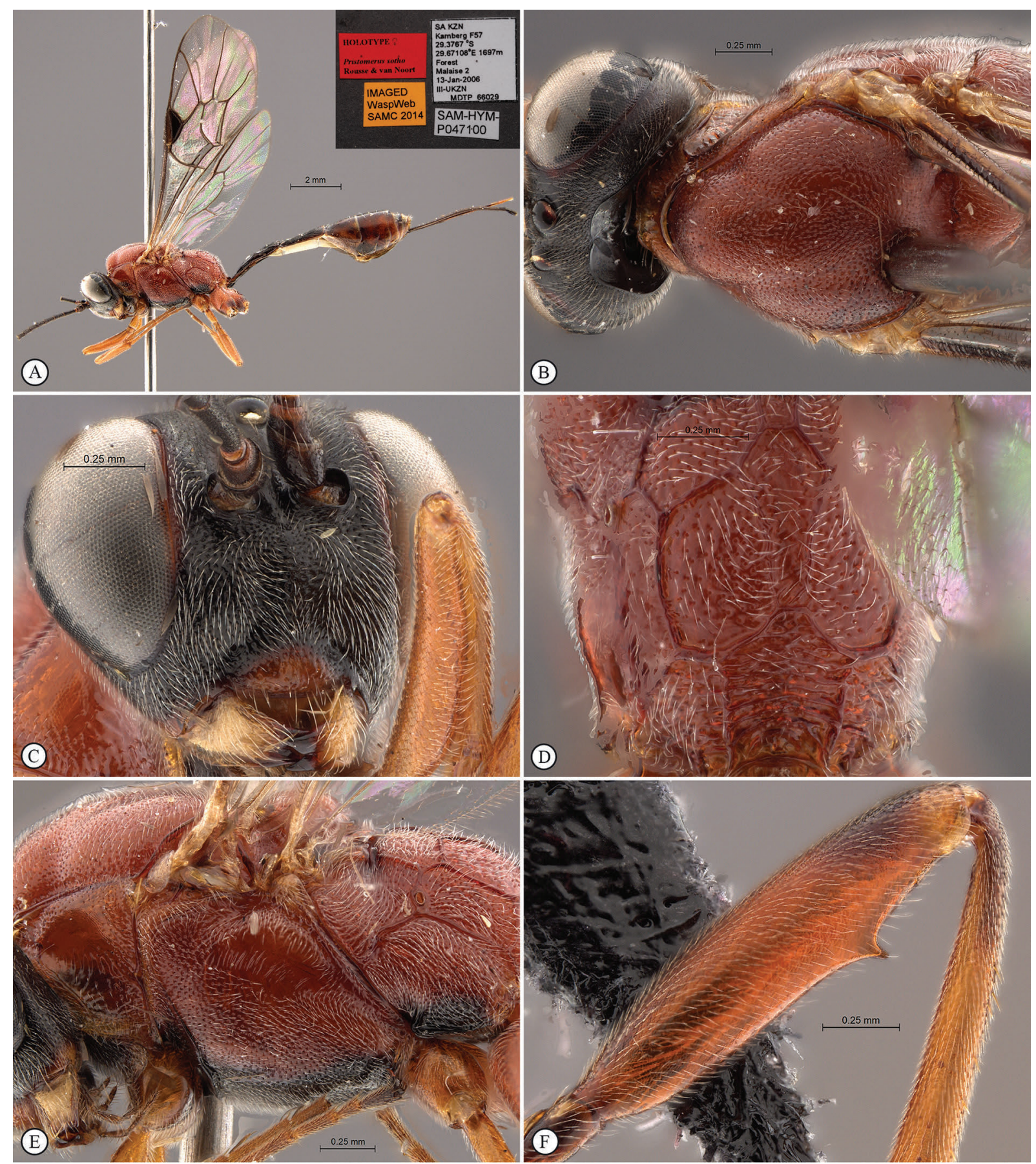

Fig. 35. Pristomerus sotho sp. nov. Holotype, q. A. Habitus, lateral view (inset: data labels). B. Head, mesosoma, dorsal view. C. Head, anterior view. D. Propodeum, dorsal view. E. Mesosoma, lateral view. F. Hind tibia, lateral view. 
HEAD. Face and clypeus densely punctate with very dense silver hairs obscuring most of sculpture; mandible also unusually hairy; inner margins of eyes parallel; clypeus transverse, punctation ventrally smoother; malar line long; frons and vertex sparsely punctate-granulate; temple coarsely coriaceous; occipital carina joining hypostomal carina distinctly above mandible base; both antennae broken.

Mesosoma. Mesosoma moderately elongate; pronotum entirely sculptured, moderately densely punctate with a median coriaceous area; mesopleuron and metapleuron densely, deeply and evenly punctate, with an oblique striate furrow below speculum, ventral half of speculum smoother; mesoscutum densely and evenly punctate; notaulus moderate; scutellum densely punctate; propodeum densely and roughly punctate, punctures sometimes confluent into rugosities, area superomedia elongate, area petiolaris transversely strigose. Legs. Femoral tooth strong and apically lamellar, followed by a row of hardly distinct denticles.

Metasoma. Tergite 2, apical half of tergite 1 and base of tergite 3 aciculate; following tergites coriaceous; thyridium sub-circular; ovipositor short, apically moderately sinuous.

\title{
Male
}

Unknown.

\section{Distribution}

South Africa.

\author{
Pristomerus swahili sp. nov. \\ urn:1sid:zoobank.org:act:B90C65C9-093B-40C9-9660-A53CF0A4CCB7
}

Fig. 36

\section{Diagnosis}

Moderate size; yellow to yellowish-orange with numerous dorsal black markings; trochanters and femora apically white-dotted, anterior edge of pterostigma whitish; face densely and shallowly punctate, sculpture smoother on remainder of head; clypeus weakly transverse, long; malar line short; antenna with 27-29 flagellomeres; mesosoma laterally moderately to densely and finely punctate with almost entire pronotum and ventral half of speculum smooth; mesoscutum alutaceous with punctures along notaulus line; scutellum quite smooth; propodeum mostly densely punctate; femoral tooth strong; ovipositor moderately short, apically moderately sinuous. Male unknown.

\section{Differential diagnosis}

Moderately sized, mostly yellowish to orange with numerous black markings dorsally; differentiated from all other Pristomerus species in the Afrotropical region by the combination of the quite smooth scutellum, the almost entirely smooth pronotum, the mostly coriaceous mesoscutum and the strong female femoral tooth.

\section{Type material}

\section{Holotype}

KENYA: + , “KENYA, Tsavo Safari Lodge, Athi River, 518 m, 2³8.529’S 38²1.984’E, 19.vii.2008, S. van Noort, UG08-KEN-S02, Sweep, savanna woodland, SAM-HYM-P047411” (SAMC).

\section{Paratypes}

KENYA: 2 우, same label data; 1 + , “Kenya, Ruma National Park, 1250 m, 0³9.121'S 34ำ19.417’E, 26 July 2008, S. van Noort, UG08-KEN-S09, sweep, savanna woodland, SAM-HYM-P047412" (SAMC). 


\section{Description}

Female (4 specimens)

B 6.7-7.1; A 4.4 4.8; F 4.0-4.7; CT 1.6; ML 0.4; POL 0.9; OOL 1.0; Fl ${ }_{\mathrm{n}-1}$ 1.3; ASM 1.7; OT 1.4-1.6; FFT 2.

CoLour. Yellowish-orange to reddish-orange, with yellow and black markings; yellow to pale yellow: clypeus, mandible, facial orbits, lower gena, and sometimes pronotum, fore and mid legs; black: inter-
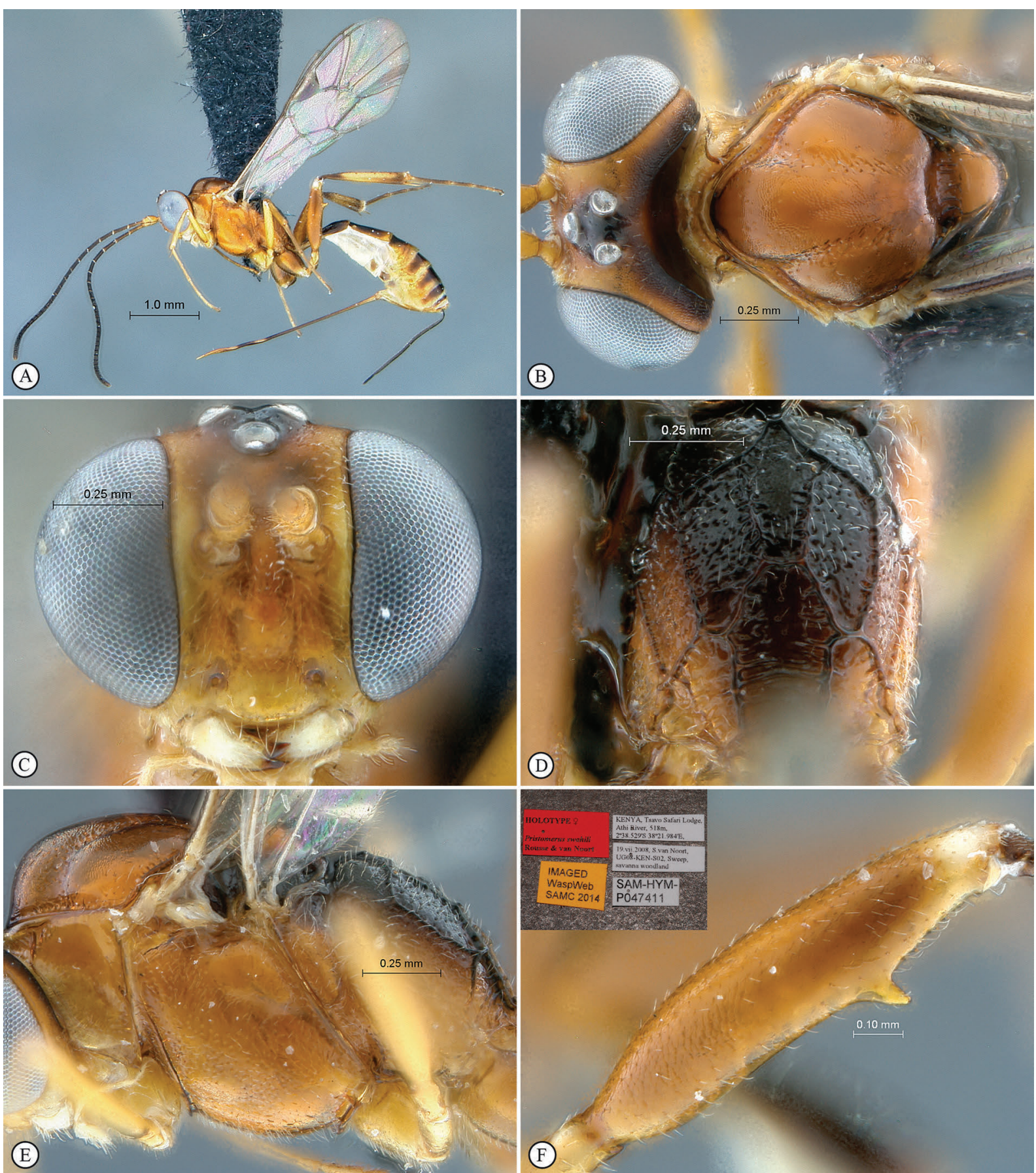

Fig. 36. Pristomerus swahili sp. nov. Holotype, ․ A. Habitus, lateral view. B. Head, mesosoma, dorsal view. C. Head, anterior view. D. Propodeum, dorsal view. E. Mesosoma, lateral view. F. Hind tibia, lateral view (inset: data labels). 
ocellar area, occiput more or less extensively, mesosoma postero-dorsally, most of tergites 1-2 and a large basal part of following tergites; base and apex of hind tibia strongly infuscate; trochanters and femora apically white-dotted; wings hyaline, venation brownish, anterior edge of pterostigma whitish.

HEAD. Face densely and shallowly punctate, punctation sparser on median bulge; inner margins of eyes barely converging ventrally; clypeus weakly transverse, long, nearly smooth with few punctures; malar line short; frons moderately and shallowly punctate; vertex and temple finely coriaceous; occipital carina joining hypostomal carina distinctly above mandible base; antenna with 27-29 flagellomeres.

Mesosoma. Pronotum nearly smooth with anterior margin weakly crenulate and some punctures along posterior and dorsal margins; mesopleuron moderately punctate, with an oblique striate furrow below speculum, ventral half of speculum smooth; punctation slightly denser and coarser on metapleuron; mesoscutum alutaceous, somewhat longitudinally rugose posteriorly, with punctures along notaulus; notaulus moderate; scutellum quite smooth; propodeum moderately and deeply punctate, area superomedia centrally smoother and relatively short, area petiolaris transversely strigose. Legs. Femoral tooth strong, higher than basally wide, followed by a row of denticles.

Metasoma. Tergite 2 and apical half of tergite 1 aciculate; following tergites coriaceous; thyridium subelliptic, its main axis longitudinal; ovipositor moderately short, apically moderately sinuous.

\section{Male \\ Unknown. \\ Distribution}

Kenya.

Pristomerus teke sp. nov. urn:Isid:zoobank.org:act:E5956D87-2231-4D49-B9C0-8D5BD00A8EA5

Fig. 37

\section{Diagnosis}

Moderately small; mostly black with lighteryellow to orange parts on head, legs and metasoma; trochanters and apex of femora white-dotted; face deeply and densely punctate; clypeus strongly transverse with punctation sparser ventrally; malar line moderately long; remainder of head coriaceous; ocelli unusually enlarged; antenna with 30 flagellomeres, penultimate one obviously elongate; mesosoma distinctly elongate, mostly deeply and densely punctate, except scutellum coriaceous, pronotum postero-dorsally and speculum ventrally smoother; scutellum quite flat; propodeum coarsely punctate to rugose with area superomedia strongly elongate; femoral tooth moderate; ovipositor short, slightly sinuous apically. Male unknown.

\section{Differential diagnosis}

Rather small and mostly black; readily differentiated among Afrotropical Pristomerus by the flat and coriaceous scutellum and the elongate penultimate flagellomere. Also characterized by the combination of the colour pattern, the elongate mesosoma, the moderate female femoral tooth, the short ovipositor, and the enlarged ocelli in females. It might be related to P. aka sp. nov., the latter having a mostly coriaceous mesoscutum, a punctate scutellum, and the ocelli not enlarged. Pristomerus teke sp. nov. is also strongly morphologically similar to P. mbaka sp. nov., the latter having a shorter and apically straight ovipositor, and not having the elongate mesosoma nor the flat scutellum of $P$. teke sp. nov.. 


\section{Type material}

\section{Holotype}

GABON: + , "GABON. Prov. Ogooué-Maritime, Réserve de la Moukalaba-Dougoua, $12.2 \mathrm{Km} 305^{\circ} \mathrm{NW}$ Doussala, $2^{\circ} 17.00^{\prime} \mathrm{S} 10^{\circ} 29.83^{\prime} \mathrm{E}, 110 \mathrm{~m}, 26.1 \mathrm{i} .2000$, S. van Noort, Sweep, GA00-S09, lowland rainforest, elephant path, SAM-HYM-P041663" (SAMC).
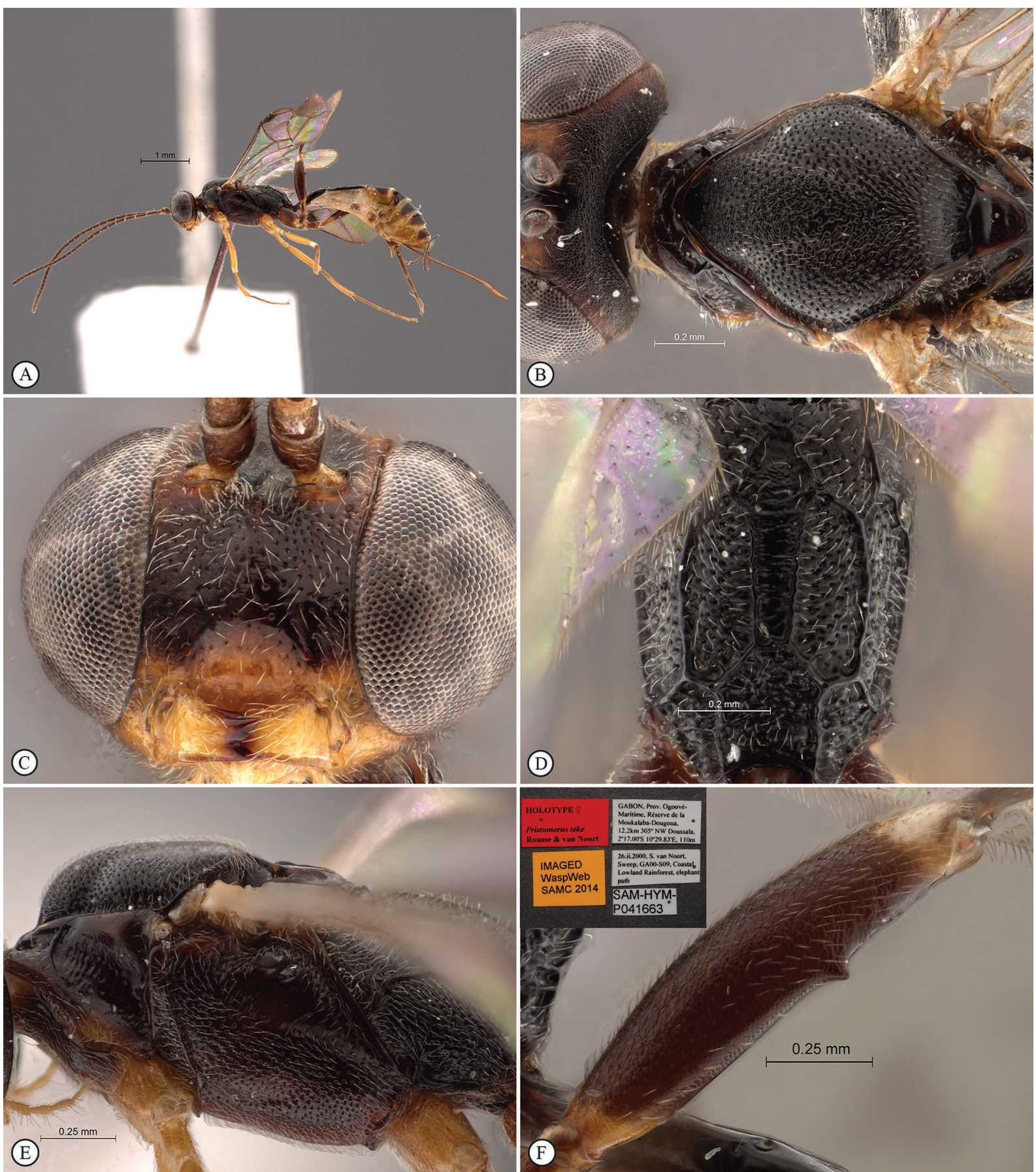

Fig. 37. Pristomerus teke sp. nov. Holotype, ․ A. Habitus, lateral view. B. Head, mesosoma, dorsal view. C. Head, anterior view. D. Propodeum, dorsal view. E. Mesosoma, lateral view. F. Hind tibia, lateral view (inset: data labels). 


\section{Description}

Female (holotype)

B 5.9; A 3.9; F 4.2; CT 2.1; ML 0.6; POL 0.4; OOL 0.6; Fl $\mathrm{n}_{\mathrm{n}-1}$ 1.5; ASM 2.5; OT 1.4; FFT 1.

CoLour. Head mostly black with clypeus, malar space, mandible, frontal and temporal orbits yellow to orange; mesosoma black with some lighter orange markings along anterior margin of pronotum and reddish glints on mesopleuron; metasomal tergites black with apical and lateral margins of tergites yellow from tergite 3; fore and mid legs yellow, hind leg darker brown, with apices of all femora and trochanters white-marked; wings hyaline, venation brown with anterior half of pterostigma slightly paler; flagellum and ovipositor sheath dark brown.

HEAD. Face deeply and densely punctate, weakly bulging mid-longitudinally; inner margins of eyes subparallel; punctation smoother on ventral half of clypeus; clypeus strongly transverse; malar line moderately long; frons, vertex and temple coriaceous; ocelli distinctly enlarged, strongly elliptic; occipital carina joining hypostomal carina ventrally shortly above mandible base; antenna with 30 flagellomeres, penultimate one distinctly elongate.

Mesosoma. Distinctly elongate; pronotum shallowly crenulate anteriorly, with a large smoother posterodorsal area; mesopleuron and metapleuron densely and deeply punctate with a coarsely striate oblique furrow below speculum, speculum ventrally smoother; mesoscutum densely punctate-granulate, punctures confluent along notaulus into fine transverse rugosities; scutellum coriaceous, quite flat; propodeum densely and coarsely punctate, medially transversally rugose, area superomedia long and narrow. Legs. Femoral tooth moderate.

Metasoma. Tergite 2, apical half of tergite 1 and base of tergite 3 longitudinally aciculate; thyridium elliptic, its main axis longitudinal; ovipositor short, slightly sinuous apically.

\section{Male}

Unknown.

\section{Distribution}

Gabon.

Pristomerus tutsi sp. nov. urn:1sid:zoobank.org:act:9F64294C-892B-499E-924E-840816D4939A

Fig. 38

\section{Diagnosis}

Moderately large; mostly black with lighter yellow to yellowish-orange markings on head and tergites 3-6; femora and trochanters apically white dotted; pterostigma anteriorly paler; face moderately punctate; inner margins of eyes subparallel; malar line moderately long; clypeus strongly transverse, sparsely and shallowly punctate; remainder of head coriaceous; antenna with 32 flagellomeres, penultimate flagellomere barely elongate; pronotum mostly smooth; mesopleuron and metapleuron moderately densely punctate with speculum largely smooth; mesoscutum roughly and densely punctate; punctation distinctly sparser on scutellum; area superomedia elongate; ovipositor long, apically sinuous. Male with inner margins of eyes diverging ventrally, ocelli and hind femur enlarged, femoral tooth long and narrow, mesoscutum mostly coriaceous with punctures along notaulus, area superomedia more slender, and metasoma darker with tergite 3 only partially yellowish-orange. 


\section{Differential diagnosis}

Moderately large and mostly black; differentiated from all other Afrotropical species by the combination of the mostly smooth pronotum, the coarsely punctate-granulate mesoscutum, the short post-ocellar line, the absence of a femoral tooth in females and the long ovipositor.
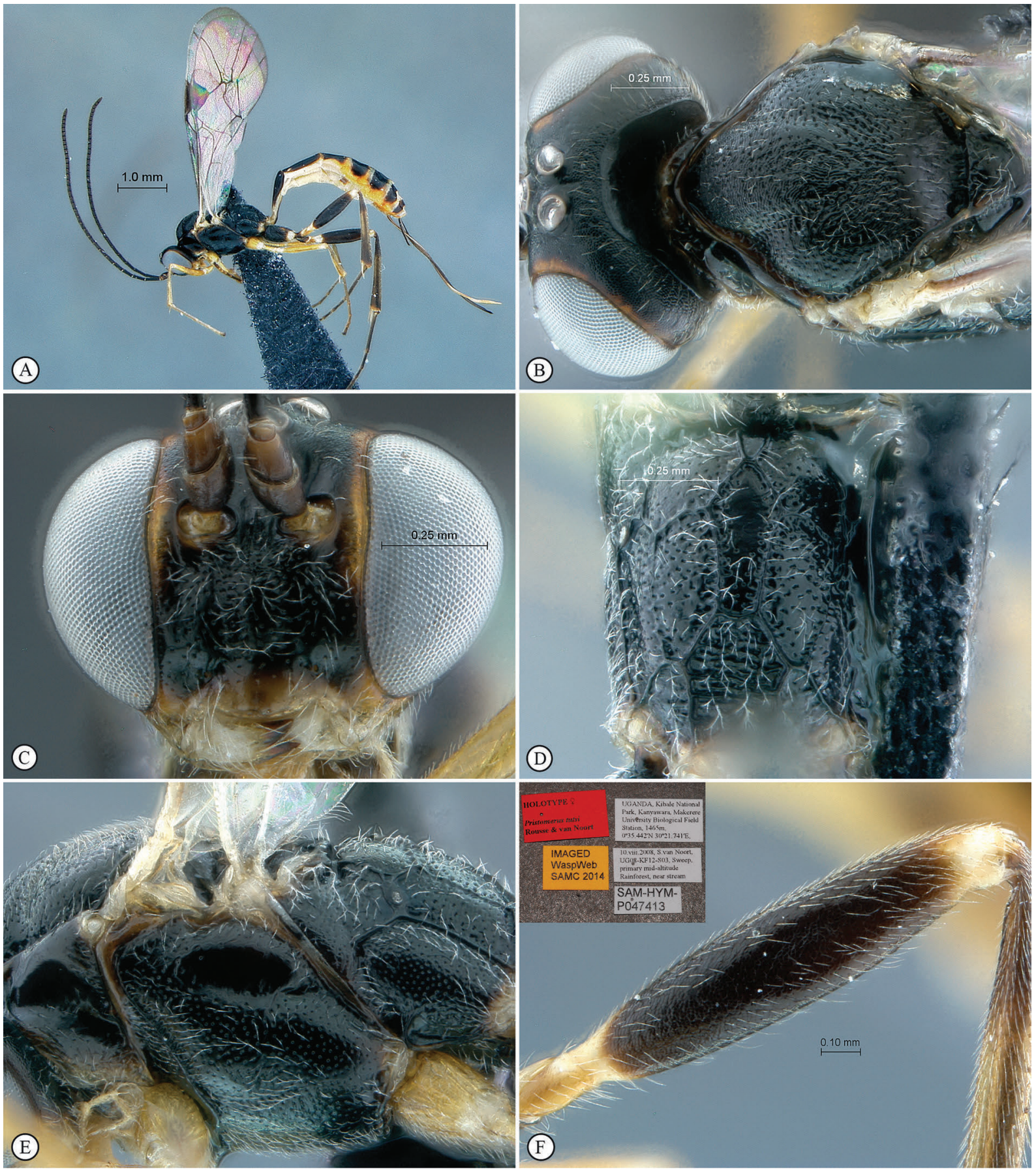

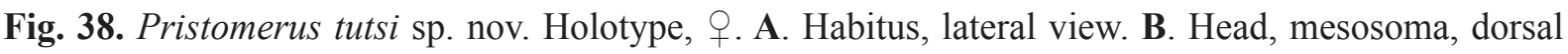
view. C. Head, anterior view. D. Propodeum, dorsal view. E. Mesosoma, lateral view. F. Hind tibia, lateral view (inset: data labels). 


\section{Type material}

\section{Holotype}

UGANDA: + , "UGANDA, Kibale National Park, Kanyawara, Makerere University Biological Field Station, $1465 \mathrm{~m}, 0^{\circ} 35.442^{\prime} \mathrm{N} 30^{\circ} 21.741^{\prime} \mathrm{E}$, 10.viii.2008, S. van Noort, UG08-KF12-S03, Sweep, primary mid-altitude rainforest, near stream, SAM-HYM-P047413" (SAMC).

\section{Paratypes}

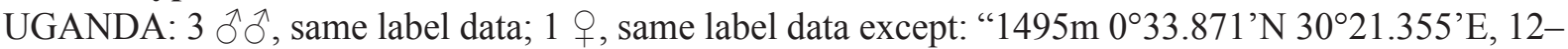
26.viii.2008, UG08-KF2-M12, Malaise trap, secondary mid-altitude rainforest, SAM-HYM-P047444" (SAMC); 1 9, "Uganda Rwenzori Mts nr. Kyanjuki village, wet forest nr. entrance NP 06.III.2013 A. Gumovsky SAM-HYM-P047414” (SAMC).

\section{Description}

Female (3 specimens)

B 7.0-8.1; A 4.9-5.2; F 4.8-5.4; CT 2.0; ML 0.6; POL 0.4; OOL 1.0; Fl ${ }_{\mathrm{n}-1} 1.1 ;$ ASM 2.2; OT 1.9-2.2; FFT 0.

CoLour. Head black with clypeus, malar space and frontal orbits yellowish-orange, and mandible and palpi pale yellow; mesosoma black; metasoma mostly black with base of tergite 1 pale yellow and tergites 3 and following apically and laterally yellowish-orange; fore and mid legs yellow to yellowishorange; hind leg mostly infuscate to black with trochantellus yellow to yellowish-orange and tibia medially lighter; all femora and coxae apically white dotted; wing hyaline, venation brown with anterior edge of pterostigma whitish.

HEAD. Face moderately punctate, punctation denser on median bulge; inner margins of eyes subparallel; clypeus strongly transverse, sparsely and shallowly punctate with punctation denser along dorsal margin; malar line moderately long; frons, vertex and temple coriaceous; occipital carina joining hypostomal carina shortly above mandible base; ocelli somewhat enlarged, posterior ones close to each other; antenna with 32 flagellomeres, penultimate flagellomere barely elongate.

Mesosoma. Elongate; pronotum mostly smooth with some punctures ventrally and posteriorly; mesopleuron and metapleuron moderately densely, deeply and evenly punctate with a shallowly sculptured oblique furrow below speculum, speculum mostly smooth with some dorsal punctures; mesoscutum densely and roughly punctate, inter-punctures areas finely rugose; notaulus moderate; scutellum with punctation distinctly sparser, inter-punctures areas smooth; propodeum densely punctate with area superomedia centrally smoother and area petiolaris transversely strigose; area superomedia elongate. Legs. Hind femur with femoral tooth absent.

Metasoma. Metasoma coriaceous with apex of tergite 1, entire tergite 2 and base of tergite 3 longitudinally aciculate; thyridium elliptic and long, its main axis longitudinal; ovipositor long, strongly sinuous apically.

\section{Male (paratypes)}

B 7.2-8.0; A 4.5-5.2; F 4.9-5.1; POL 0.4; OOL 0.5. Ocelli and hind femur enlarged; inner margins of eyes distinctly diverging ventrally; femoral tooth long and narrow; antenna with 27 flagellomeres; mesoscutum roughly coriaceous with punctures along notaulus; propodeum with area superomedia more slender; metasoma darker, with tergite 3 only partially yellowish-orange to quite dark; otherwise similar to female.

\section{Distribution}

Uganda. 
Pristomerus vahaza Rousse, Villemant \& Seyrig, 2013

Fig. 39

Diagnosis (range of variation from Rousse et al. 2013)

Moderately large to large; head distinctly transverse, whitish yellow with frons, inter-ocellar area and occiput black; remainder of body testaceous orange with tergites 1-3 medially blackened; face and
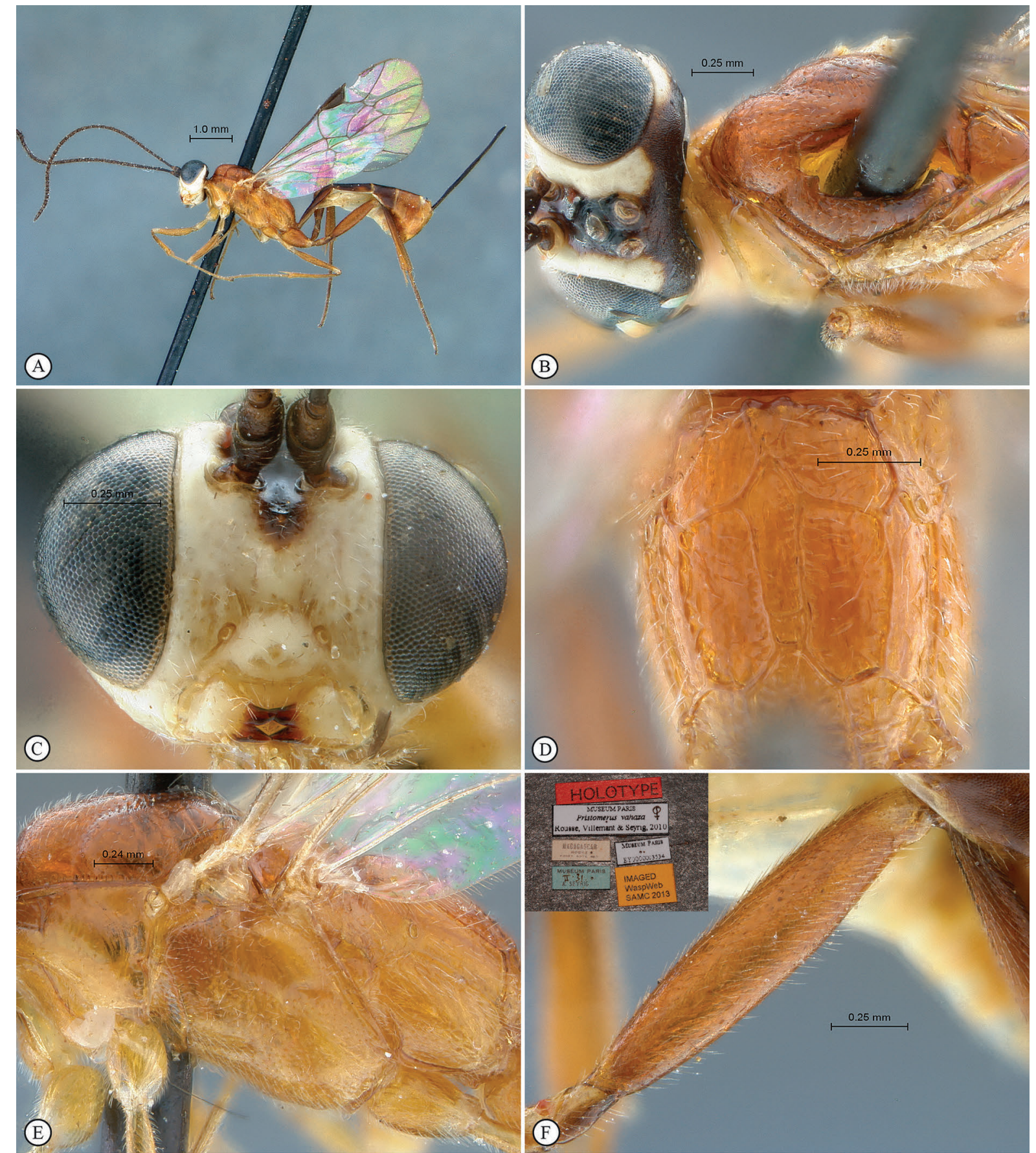

Fig. 39. Pristomerus vahaza Rousse, Villemant \& Seyrig, 2013. Holotype, . . A. Habitus, lateral view. B. Head, mesosoma, dorsal view. C. Head, anterior view. D. Propodeum, dorsal view. E. Mesosoma, lateral view. F. Hind tibia, lateral view (inset: data labels). 
frons moderately punctate-granulate; inner margins of eyes subparallel; clypeus weakly transverse, almost smooth; malar line short; remainder of head coriaceous; occipital carina joining hypostomal carina weakly above mandible base; antenna with 31-33 flagellomeres, penultimate flagellomere shortly elongate; mesosoma strongly elongate; pronotum almost quite smooth; mesopleuron and metapleuron moderately punctate with ventral half of speculum smooth; mesoscutum moderately punctate-granulate, inter-puncture spaces smoother on lateral lobes and finely transversely rugose along notaulus, scuto-scutellar groove hardly sculptured; scutellum sparsely punctate-granulate; area superomedia narrow and elongate; female femoral tooth absent; ovipositor moderately short, apically moderately sinuous. B 6.9-8.2; A 5.2-5.8; F 4.7-5.5; CT 1.5; ML 0.4; POL 0.4; OOL 1.3; $\mathrm{F}_{\mathrm{n}-1} 1.2$; ASM 2.4; OT 1.3-1.4; FFT 0. Male with inner margins of eyes diverging ventrally, ocelli and femoral tooth enlarged. POL 0.3 ; OOL 0.2 .

\section{Differential diagnosis}

Moderately large, mostly yellowish orange and white-faced; differentiated from all other species by the combination of the white orbits, the narrow clypeus, the transverse head, the absence of a femoral tooth and the short ovipositor. Pristomerus vahaza appears to be related to P. albescens with which it shares the unusually transverse head and narrow clypeus, but these species cannot be confused because $P$. albescens has an apically straight ovipositor, a strongly reduced but distinct femoral tooth and a distinctly darker head.

\section{Material examined}

\section{Holotype}

MADAGASCAR: + , "MADAGASCAR, Rogez, forêt côte est, II.31, EY0000003534” (MNHN).

\section{Distribution}

Madagascar.

Pristomerus veloma Rousse, Villemant \& Seyrig, 2013

Fig. 40

Diagnosis (range of variation from Rousse et al. 2013)

Large; head, mesosoma and legs reddish-orange; antenna, inter-ocellar area, metasoma and ovipositor sheath black; face moderately densely punctate-granulate; inner margins of eyes slightly diverging ventrally; clypeus transverse, dorsally moderately punctate and ventrally smooth; malar line long; occipital carina joining hypostomal carina shortly above mandible base; antenna long with 34-37 flagellomeres, penultimate flagellomere shorter than wide; mesosoma densely and deeply punctate but pronotum mid-dorsally and speculum ventrally smooth, and mesopleuron with an oblique striate furrow below speculum; area superomedia stout; female femoral tooth strong and acute, distinctly higher than basally wide, followed by distinct and sometimes merged denticles; ovipositor moderately long, apically weakly sinuous. B 7.1-9.1; A 5.0-6.3; F 5.9-7.5; CT 1.9; ML 0.7; POL 0.6; OOL 0.6; Fl 1 0.1 0 ; ASM 1.5; OT 1.7-1.9; FFT 2. Male: mesosoma smoother, ocelli and femoral tooth enlarged; B 7.1-8.5; A 5.0-6.0; F 5.9-7.2; POL 0.4; OOL 0.3.

\section{Differential diagnosis}

Large, reddish-orange with metasoma black; differentiated from all other Afrotropical Pristomerus species by the combination of that colour pattern, the distinctly diverging inner orbits in both sexes, the long antenna and the strong female femoral tooth. Pristomerus zulu sp. nov., in South Africa, shares a similar colour pattern, but is readily differentiated by its white and subparallel inner orbits. 


\section{Material examined}

\section{Holotype}

MADAGASCAR: ㅇ, "MADAGASCAR, Rogez, forêt côte est, XII. 30, EY 0000003545” (MNHN).

\section{Distribution}

\section{Madagascar.}
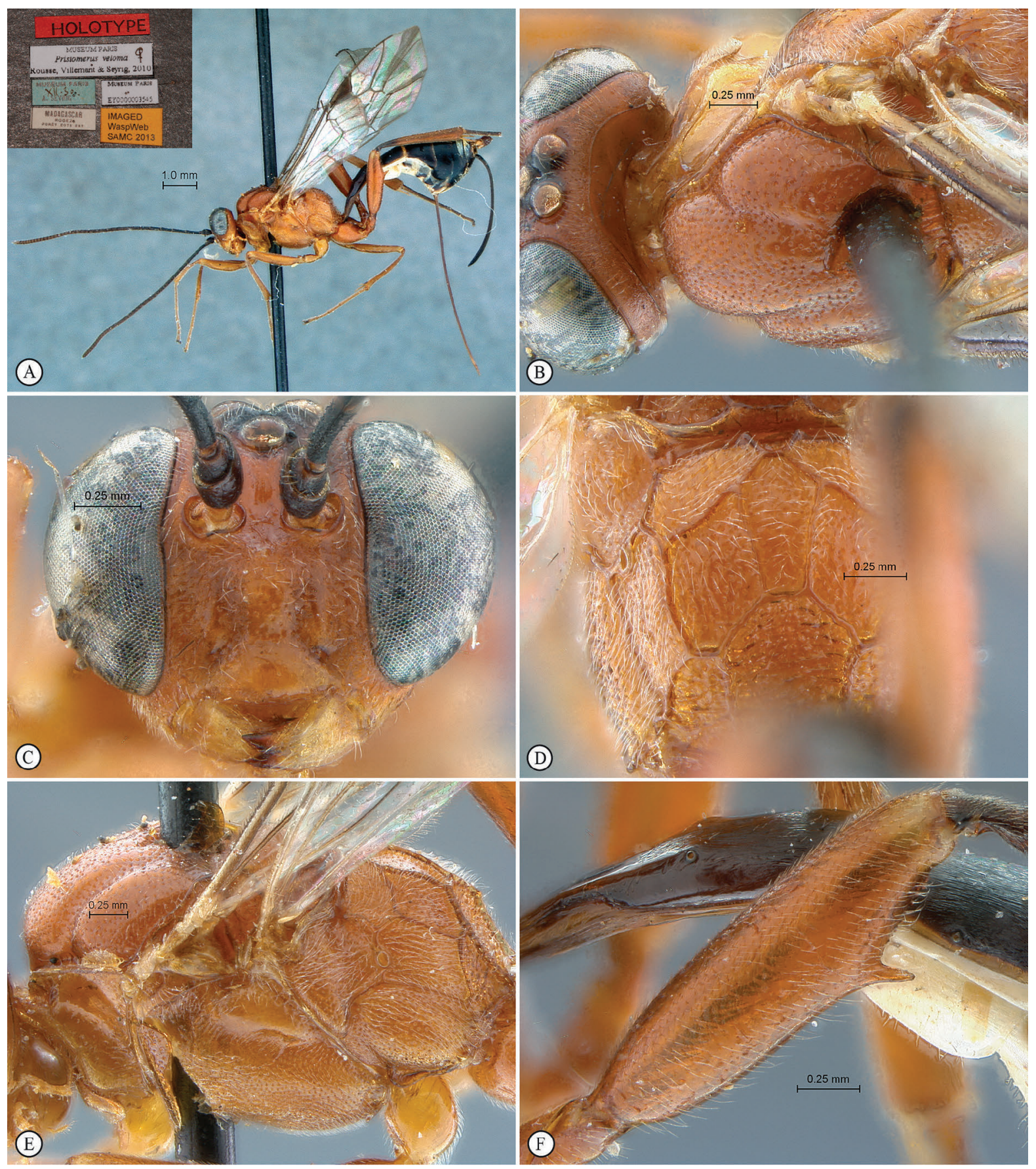

Fig. 40. Pristomerus veloma Rousse, Villemant \& Seyrig, 2013. Holotype, $q$. A. Habitus, lateral view (inset: data labels). B. Head, mesosoma, dorsal view. C. Head, anterior view. D. Propodeum, dorsal view. E. Mesosoma, lateral view. F. Hind tibia, lateral view. 


\section{Pristomerus venda sp. nov. urn:1sid:zoobank.org:act:3F426943-BF91-4A98-95B1-7B7778F96B02}

Fig. 41

\section{Diagnosis}

Moderately small; background colour yellow to testaceous with variable dark brown to black dorsal markings; head sparsely to moderately punctate; inner margins of eyes subparallel; clypeus strongly transverse; malar line short; antenna with 29-30 flagellomeres, penultimate flagellomere subquadrate; mesosoma moderately to densely punctate, pronotum hardly smoother postero-dorsally, and speculum ventrally smoother; propodeum with area superomedia sometimes weakly carinate postero-laterally; female femoral tooth absent; ovipositor moderately long, apically strongly sinuous. Male darker with ocelli, hind femur and femoral tooth strongly enlarged, inner margins of eyes strongly diverging ventrally, and area superomedia slightly more slender.

\section{Differential diagnosis}

Rather small and mostly yellowish-orange; differentiated from most other Afrotropical species by the combination of the absence of a femoral tooth in females, the short malar line, the strongly transverse clypeus and the rather long ovipositor. It is closely related to P. moramora and P. kelikely, from which it may be differentiated by the colour and antenna length characters given in the key (see comments).

\section{Type material}

\section{Holotype}

ZIMBABWE: q "Salisbury [Harare] S. Rhodesia Jan-March-1969 Nat. Museum S.R. coll. B.L. Mitchell, South African Museum ex National Museum Bulawayo 1981, ex Phthorimaea operculella SAM-HYM-P001224" (SAMC).

\section{Paratypes}

ZIMBABWE: 3 $\widehat{\jmath}, 1$, same label data.

\section{Description}

Female (2 specimens)

B 6.6-6.8; A 4.0; F 4.6-4.8; POL 0.9; OOL 1.1; CT 2.0; ML 0.4; F1 ${ }_{\mathrm{n}-1}$ 1.1; ASM 2.2; OT 1.7-1.8; FFT 0.

Colour. Head yellow with face testaceous, and frons, vertex, temples and occiput darker brown, frons sometimes with a mid-longitudinal yellow stripe; mesosoma yellowish-orange with pronotum paler and axillary troughs slightly infuscate; metasoma yellowish-orange with basal tergites variously dark marked; legs yellow to yellowish-orange; wings hyaline, venation brown; ovipositor sheath black.

HEAD. Face moderately and deeply punctate; inner margins of eyes subparallel; clypeus strongly transverse, moderately punctate and centrally smoother; malar line short; frons and vertex sparsely punctate, temple coriaceous; antenna with 29-30 flagellomeres, penultimate flagellomere subquadrate.

Mesosoma. Mesosoma moderately elongate; entire mesosoma densely punctate, except: pronotum posterodorsally very shallowly punctate, and speculum ventrally smoother; mesopleuron with an oblique striate furrow below speculum; punctures somewhat confluent along notaulus line; notaulus weak; punctation of scutellum distinctly sparser than on mesoscutum; posterior vertical side of scutellum longitudinally striate; area superomedia somewhat elongate, sometimes hardly carinate laterally. Legs. Femoral tooth absent.

Metasoma. Apical half of tergite 1, tergite 2 and base of tergite 3 longitudinally aciculate, following tergites coriaceous; thyridium elliptic and wide, its main axis longitudinal; ovipositor moderately long, its apical half strongly sinuous. 


\section{Male (paratypes)}

B 6.2-6.6; A 3.8-4.0; F 4.4-4.6; POL 0.5; OOL < 0.1. Darker with vertex and occiput centrally blackish, mesosoma dorsally brownish with scutellum yellow and axillary troughs black, hind femur sometimes dark brown, entire tergite 2 and apical half of tergite 1 dark brown; ocelli strongly enlarged, lateral ocellus nearly touching eye; area superomedia slightly more slender; femoral tooth long and acute, followed by a series of denticles; otherwise similar to female.
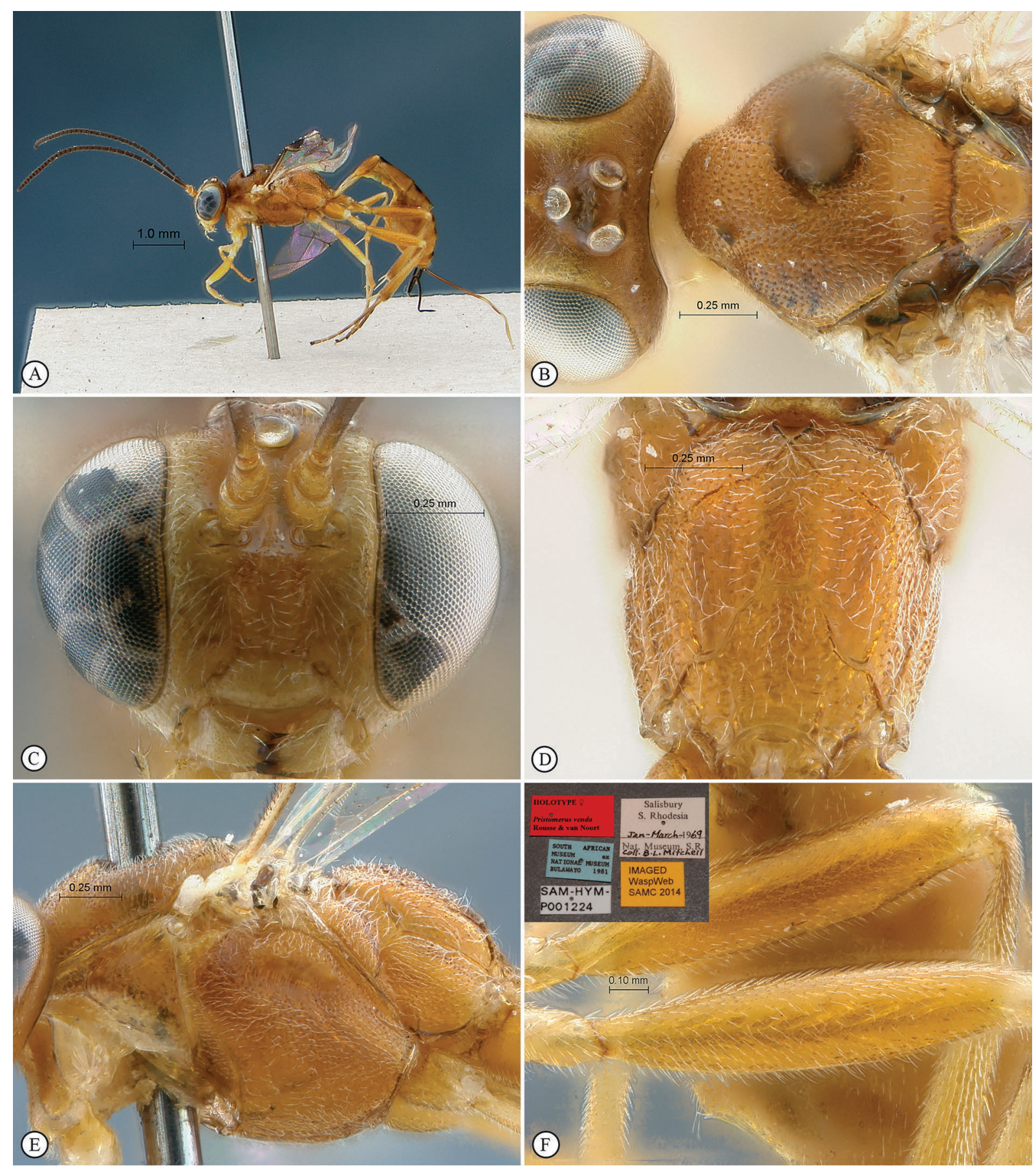

Fig. 41. Pristomerus venda sp. nov. Holotype, . . A. Habitus, lateral view. B. Head, mesosoma, dorsal view. C. Head, anterior view. D. Propodeum, dorsal view. E. Mesosoma, lateral view. F. Hind tibia, lateral view (inset: data labels). 


\section{Host records}

Reared from the potato tuber moth, Phthorimaea operculella (Zeller, 1873) (Lepidoptera: Gelechiidae).

\section{Distribution}

Zimbabwe.

\section{Comments}

Pristomerus venda sp. nov. females are likely to be very difficult to differentiate from some P. kelikely and P. moramora. However, we keep it as a separate species because it could be unambiguously associated with males. These males exhibit two of the usual features of sexual dimorphism in Pristomerus spp. which are absent in the males of $P$. kelikely and $P$. moramora (ventrally diverging eyes and enlarged ocelli). See $P$. kelikely for further comments about this species-complex.

\section{Pristomerus wolof sp. nov. \\ urn:lsid:zoobank.org:act:50B591FF-D0D9-429C-9644-4A3F8E5B8C12}

Fig. 42

\section{Diagnosis}

Small to moderately small; pale yellow to yellowish with base of tergites 2-3 black; femora and trochanters apically white-dotted; pterostigma anteriorly paler; face and clypeus moderately to densely punctate, remainder of head more finely sculptured; clypeus strongly transverse; inner margins of eyes subparallel; malar line moderately short; ocelli small; antenna long with 32-34 flagellomeres; mesosoma moderately elongate, densely punctate-granulate but upper pronotum and ventral half of speculum smooth; female femoral tooth barely distinct; ovipositor long, apically strongly sinuous. Male with ocelli and femoral tooth hardly enlarged, inner margins of eyes slightly diverging ventrally, area superomedia more slender, and mesoscutum sculpture smoother.

\section{Differential diagnosis}

Rather to fairly small, yellow to pale yellow overall; otherwise distinguished from all other Afrotropical species by the strongly transverse clypeus, the weak but distinct female femoral tooth and the long ovipositor. Pristomerus wolof sp. nov. is part of the P. masai sp. nov. species-complex (see comments for $P$. masai sp. nov.): the reduced femoral tooth and barely enlarged ocelli in both sexes differentiate P. wolof sp. nov. from P. masai sp. nov. It is also somewhat morphologically similar to P. sara sp. nov., whose ovipositor and malar line are shorter and whose femoral tooth is totally absent in the female.

\section{Type material}

\section{Holotype}

GUINEA-BISSAU: + , "Guinea-Bissau: Região Cacheu, 10 km W of São Domingos 31.x.1992 (17.4518.45), swampy grassland with bushes, palm trees and some hardwood trees at river-shore. Screensweep. leg. Michael Söderlund SAM-HYM-P047415” (SAMC).

\section{Paratype}

GUINEA-BISSAU: $\widehat{\jmath}$, same label data.

\section{Description}

Female (holotype)

B 6.5; A 4.2; F 3.5; CT 2.1; ML 0.5; POL 1.4; OOL 1.0; Fl $1_{\mathrm{n}-1} 1.2$; ASM 2.3; OT 2.2; FFT 1. 
Colour. Pale yellow to yellowish-orange, with scutellum and notaulus lighter than remainder of mesonotum; tergites 2-3 basally black; femora and trochanters apically white-dotted; wings hyaline; venation brown, anterior edge of pterostigma whitish.

HEAD. Face densely punctate-granulate, inner margins of eyes subparallel; clypeus strongly transverse, moderately punctate, convex in profile; malar line moderately short; frons finely punctate; vertex and temple coriaceous; antenna long with 34 flagellomeres, penultimate flagellomere slightly elongate.

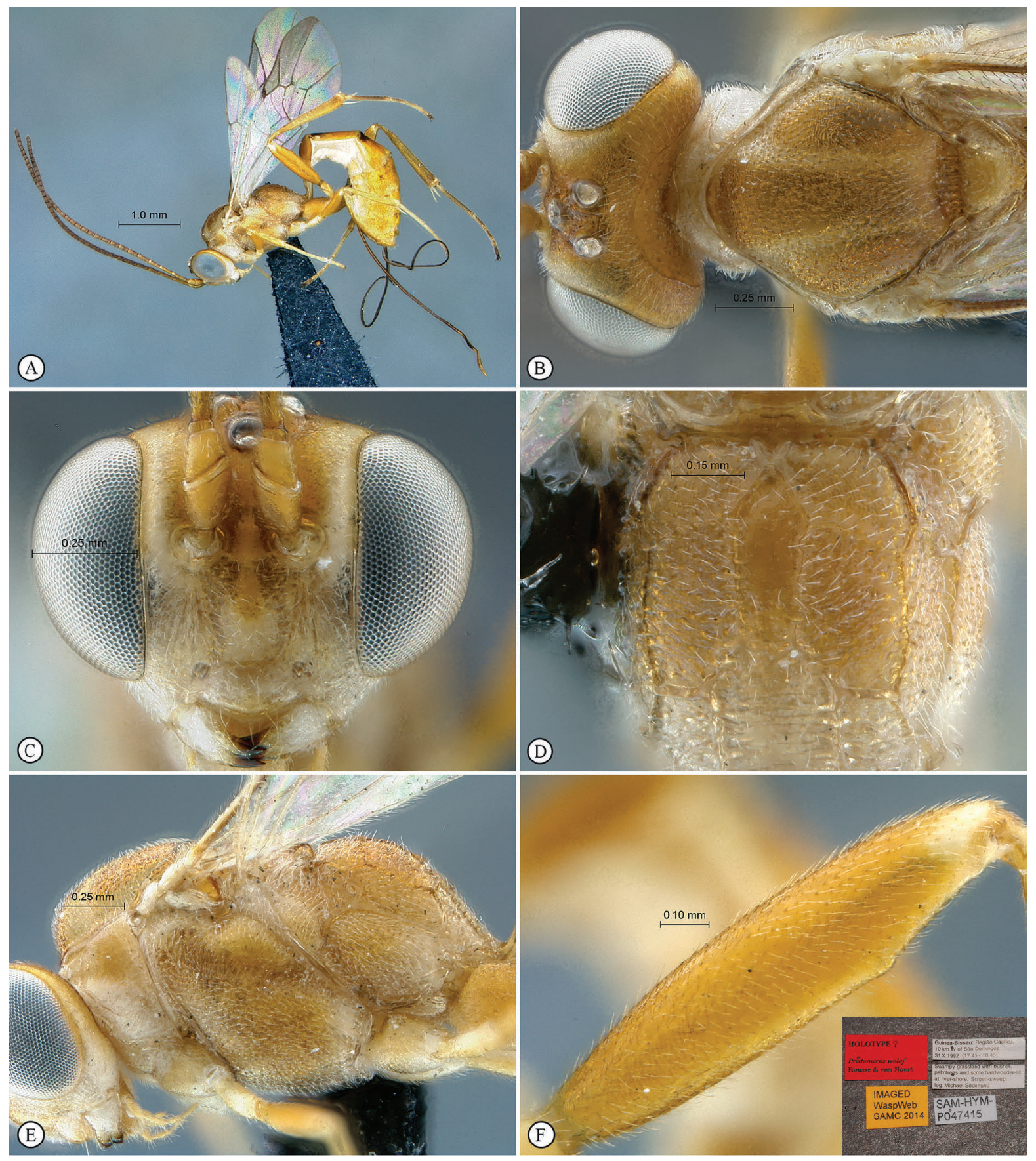

Fig. 42. Pristomerus wolof sp. nov. Holotype, $\uparrow$. A. Habitus, lateral view. B. Head, mesosoma, dorsal view. C. Head, anterior view. D. Propodeum, dorsal view. E. Mesosoma, lateral view. F. Hind tibia, lateral view (inset: data labels). 
Mesosoma. Moderately elongate; pronotum finely and shallowly punctate-granulate, postero-medially smoother, anterior margin crenulate; mesopleuron and metapleuron deeply and densely punctategranulate with a striate oblique furrow below speculum, speculum ventrally smooth; mesoscutum densely punctate-granulate, punctures confluent into fine transverse rugosities, notaulus hardly distinct; scutellum densely punctate; propodeum densely and shallowly punctate-granulate but area petiolaris transversely striate; area superomedia elongate. Legs. Femoral tooth distinct as a small subapical protuberance.

Metasoma. Apical half of tergite 1 and tergites 2-3 aciculate, following tergites coriaceous; thyridium elliptic and wide, its main axis longitudinal; ovipositor long, apically bent and strongly sinuous.

Male (paratype)

B 6.3; A 4.0; F 3.5; POL 0.7; OOL 1.3. Ocelli barely larger; femur barely swollen, femoral tooth slightly larger; antenna with 32 flagellomeres; inner margins of eyes slightly diverging ventrally; mesoscutum mostly granulate with punctures along notaulus; otherwise similar to female.

\section{Distribution}

Guinea-Bissau.

Pristomerus xhosa sp. nov. urn:1sid:zoobank.org:act:26B9F9AD-A183-4B2B-91B0-93C93F3C96F2

Fig. 43

\section{Diagnosis}

Moderately small; mottled overall, mostly yellow to reddish-testaceous with numerous large black areas; head densely and deeply punctate; clypeus long and rather narrow; malar line exceptionally long; ocelli unusually reduced; antenna long with 35-36 flagellomeres, penultimate flagellomere subquadrate; mesosoma deeply, densely and evenly punctate, but pronotum mid-dorsally and speculum ventrally smooth; female femoral tooth reduced to a subapical point, sometimes barely distinct; ovipositor moderately long, apically moderately sinuous. Male unknown.

\section{Differential diagnosis}

Moderately sized, mottled yellow, black and reddish-testaceous; unmistakably characterized by this unique colour pattern, the extremely long malar line, the strongly reduced ocelli and the long clypeus, all features making $P$. xhosa sp. nov. highly characteristic within Pristomerus. The only confusion might occur with $P$. kaggasp. nov. , from which it may otherwise be differentiated by the very weak femoral tooth in $P$. xhosa sp. nov. females.

\section{Type material}

\section{Holotype}

SOUTH AFRICA: + , "South Africa, Eastern Cape, Pearston, Plains of Camdeboo Game Reserve, 32³2.033'S 25⒕267’E, 969 m, 9 April-26 July 2010, S. van Noort, Malaise trap, Camdeboo Escarpment Thicket, PCD09-ACA1-M04, SAM-HYM-P047416" (SAMC).

\section{Paratypes}

SOUTH AFRICA: 1 , , same label data; 2 우, same label data except: "30.x.2009-22.ii.2010, PCD09ACA1-M02, SAM-HYM-P047416" (SAMC). 


\section{Description}

Female (3 specimens)

B 7.4-8.9; A 4.1-5.0; F 4.1-5.1; CT 1.4; ML 1.1; POL 1.5; OOL 1.6; Fl 1 1.1 1.0 ASM 2.2; OT 1.8-1.9; FFT 0-1.

Colour. Head mostly reddish with mandible, malar space and frontal orbits pale yellow, and black markings on mid-dorsal face, tentorial pit, frons, inter-ocellar area, occiput and antenna; mesosoma
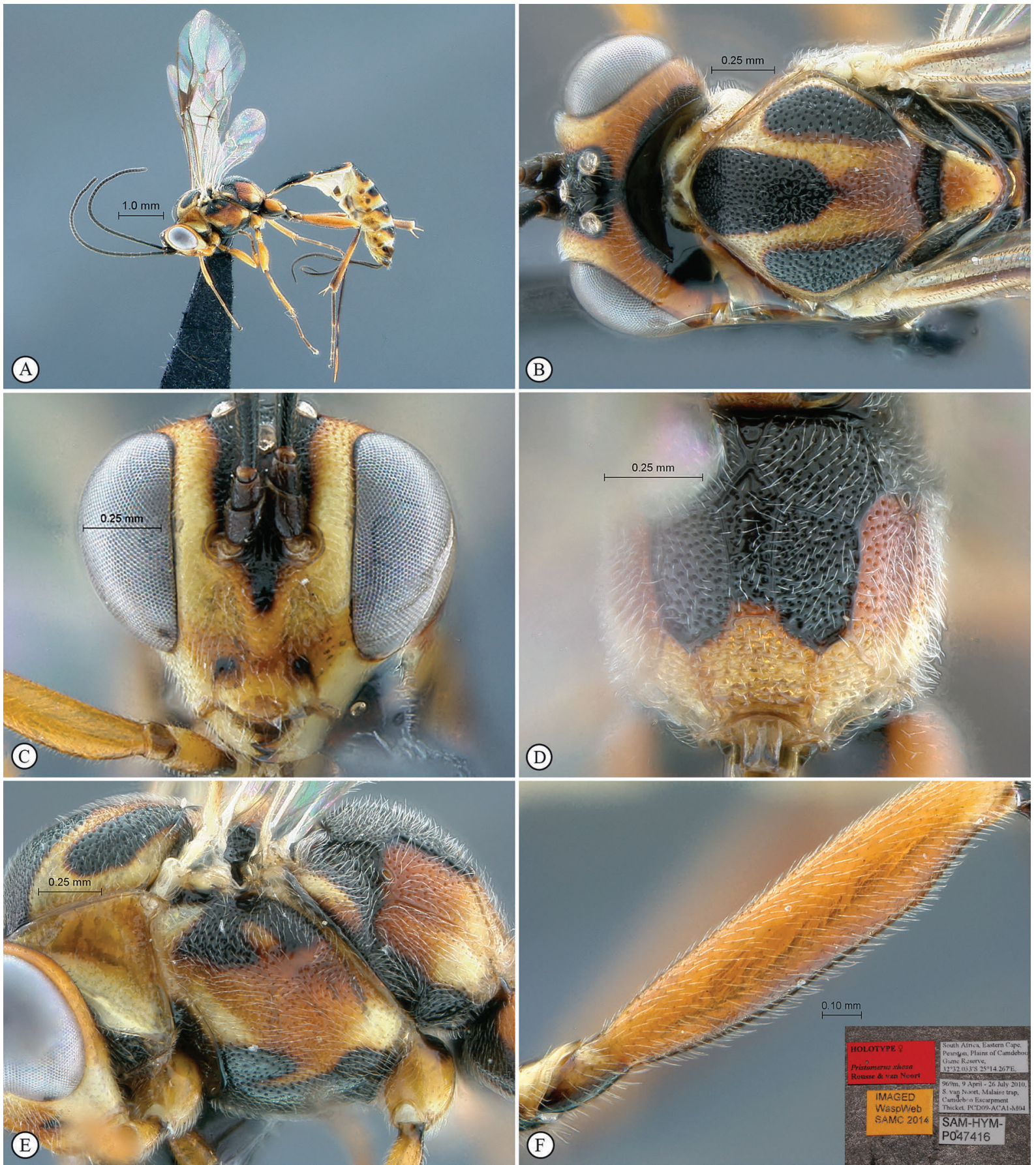

Fig. 43. Pristomerus xhosa sp. nov. Holotype, $q$. A. Habitus, lateral view. B. Head, mesosoma, dorsal view. C. Head, anterior view. D. Propodeum, dorsal view. E. Mesosoma, lateral view. F. Hind tibia, lateral view (inset: data labels). 
mottled: background colour yellow variously fading to reddish-testaceous, with numerous variable black markings on: mesoscutal lobes, scuto-scutellar groove, scutellar trough, metanotum, propodeum dorsally, mesopleuron dorsally, metapleuron anteriorly and most of mesosoma ventrally; metasomal tergites black with apical half reddish to yellow but tergite 1 basally yellow, and tergite 3 and following sometimes without black marking but one or two postero-lateral dark spots; fore and mid legs reddish with coxae and trochanters somewhat paler, hind leg reddish with black markings of variable extent: coxa ventrally, trochanter ventrally, femur ventrally, tibia basally and apically, and entire tarsus; wings hyaline, venation pale brown.

Head. Vertex, frons, face and clypeus uniformly densely and deeply punctate-granulate; temple and gena coriaceous; clypeus narrow and long, convex in profile; malar line exceptionally long; ocelli reduced and subcircular; occipital carina joining hypostomal carina at mandible base; antenna with 35-36 flagellomeres, penultimate flagellomere quadrate.

Mesosoma. Moderately elongate; entire mesosoma deeply, densely and evenly punctate, but pronotum mid-dorsally and ventral half of speculum smooth; notaulus shallow; punctures somewhat confluent in area superomedia and area petiolaris, area superomedia elongate. Legs. Femoral tooth distinct but very weak, reduced to a barely distinct subapical point followed by minute denticles.

Metasoma. Tergite 2, apical half of tergite 1, and basal half of tergite 3 aciculate, following tergites coriaceous; thyridium subcircular; ovipositor moderately long, its apical third moderately sinuous.

\section{Male}

Unknown.

\section{Distribution}

South Africa.

Pristomerus yago Rousse, Villemant \& Seyrig, 2013

Fig. 44

Diagnosis (range of variation from Rousse et al. 2013)

Moderately sized; yellowish-orange overall, with flagellum, ovipositor sheath and tergites 1-2 black; head distinctly transverse; face moderately punctate; inner margins of eyes subparallel; clypeus transverse, sparsely and shallowly punctate; malar line moderately short; frons finely transversely striate; remainder of head coriaceous; occipital carina joining hypostomal carina at mandible base; antenna with 32-34 flagellomeres, penultimate flagellomere quadrate; pronotum, mesopleuron and metapleuron moderately to densely punctate with pronotum mid-dorsally and speculum entirely smooth; mesoscutum coriaceous, without puncture, posteriorly smoother; scutellum quite smooth; propodeum with carination strong, area superomedia stout; female femoral tooth strong and acute, distinctly higher than basally wide, followed by distinct denticles; ovipositor moderately long, apically sinuous. B 6.4-8.5; A 4.9-6.2; F 4.1-5.5; CT 1.8; ML 0.5; POL 0.8; OOL 1.2; $\mathrm{Fl}_{\mathrm{n}-1} 1.0$; ASM 1.5; OT 1.5-1.7; FFT 2. Male with inner margins of eyes diverging ventrally, ocelli enlarged with posterior ocellus very close to eye margin, metasoma entirely blackened. POL 1.0; OOL 0.2.

\section{Differential diagnosis}

Moderately sized, mostly yellowish-orange with basal tergites mostly black; differentiated from all other Afrotropical Pristomerus species by the combination of the transverse head, the hardly sculptured mesonotum and the strong femoral tooth. 


\section{Material examined}

\section{Holotype}

MADAGASCAR: q, "MADAGASCAR, Rogez, forêt côte est, II.31, EY 0000003753” (MNHN).

\section{Distribution}

\section{Madagascar.}
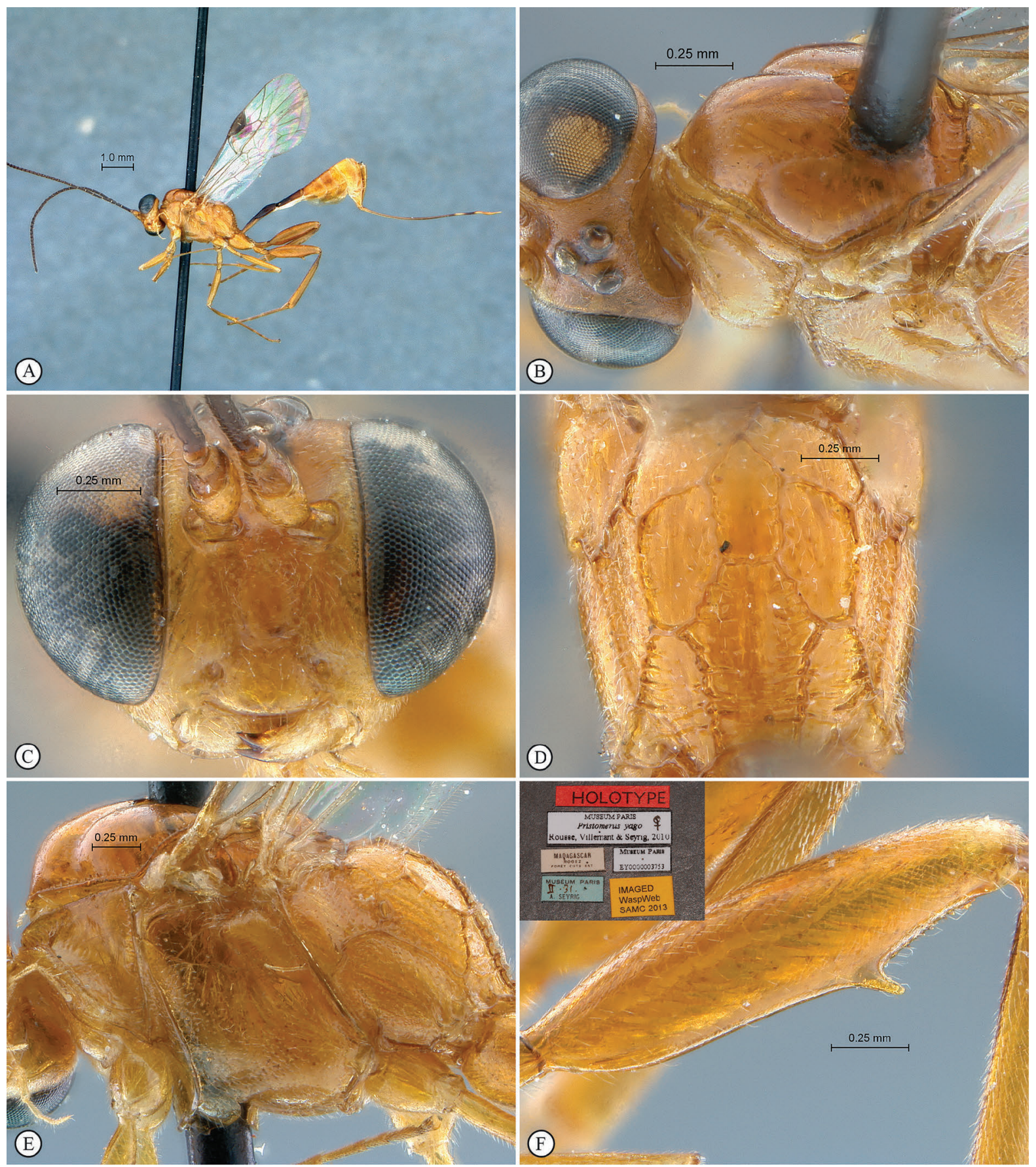

Fig. 44. Pristomerus yago Rousse, Villemant \& Seyrig, 2013. Holotype, ${ }_{\text {. }}$ A. Habitus, lateral view. B. Head, mesosoma, dorsal view. C. Head, anterior view. D. Propodeum, dorsal view. E. Mesosoma, lateral view. F. Hind tibia, lateral view (inset: data labels). 


\section{Pristomerus yakoma sp. nov. urn:1sid:zoobank.org:act:5394BBA9-A538-4FFA-986E-63A348D5B1BF}

Fig. 45

\section{Diagnosis}

Small; yellow overall; trochanters and femora apically white-dotted; flagellum multicolour, pale brown to brown, sometimes with flagellomeres 11-21 pale yellow; face moderately punctate-granulate; inner margins of eyes subparallel; clypeus strongly transverse, almost smooth; malar line very short; remainder of head coriaceous; flagellum basally thin, slightly widening toward apex, with 29-30 flagellomeres, penultimate flagellomere subquadrate; mesosoma laterally punctate with entire pronotum and ventral half of speculum smooth; mesoscutum coriaceous with notaulus punctate; scutellum quite smooth; propodeum densely punctate; area superomedia rather stout; femoral tooth strong and acute; ovipositor moderately short, apically curved and strongly sinuous. Male unknown.

\section{Differential diagnosis}

Small, entirely yellow with flagellum bicoloured or tricoloured; otherwise differentiated from most Afrotropical species by the combination of the very short malar line, the strongly transverse clypeus, the coriaceous to smooth mesonotum and the strong female femoral tooth. Pristomerus yakoma sp. nov. seems closely related to $P$. swahili sp. nov., whose flagellum is uniformly dark and clypeus significantly narrower.

\section{Type material}

\section{Holotype}

CENTRAL AFRICAN REPUBLIC: + , “Central African Republic, Préfecture Sangha-Mbaéré, Réserve Spéciale de Forêt Dense de Dzanga-Sangha, 12.7 Km $326^{\circ} \mathrm{NW}$ Bayanga, $3^{\circ} 00.27^{\prime} \mathrm{N} 16^{\circ} 11.55^{\prime} \mathrm{E}, 420 \mathrm{~m}$, 11.v.2001, S van Noort, Sweep, CAR01-S161, Lowland Rainforest, SAM-HYM-P049431" (SAMC).

\section{Paratype}

MOZAMBIQUE: + , "Mozambique Nhica "Ligne 34", 20-27.xi.2008, C. Villemant, S10 42.418' E40 12.761 alt. $92 \mathrm{~m}$ Malaise M2" (MNHN).

\section{Description}

Female (2 specimens)

B 5.4-6.0; A 3.4-3.8; F 3.4-3.7; CT 2.1; ML 0.3; POL 0.6; OOL 0.8; $\mathrm{Fl}_{\mathrm{n}-1}$ 1.0; ASM 1.7; OT 1.5-1.6; FFT 2.

CoLour. Yellow to pale yellow overall with mandible, clypeus, orbits and legs paler; tergites 1-3 barely infuscate basally; trochanters and femora apically white-dotted; flagellum dark brown, basally strongly lighter yellowish, with flagellomeres 11-21 whitish yellow in holotype only; wings hyaline, venation pale brown, anterior half of pterostigma whitish.

HEAD. Face medially bulging, moderately and shallowly punctate-granulate; inner margins of eyes subparallel; clypeus strongly transverse, sparsely punctate; malar line very short; frons, vertex and temple coriaceous; occipital carina joining hypostomal carina at mandible base; antenna with 29-30 flagellomeres, slightly widening toward apex, penultimate flagellomere quadrate.

Mesosoma. Pronotum almost entirely smooth; mesopleuron moderately punctate with most of speculum smooth; punctation on metapleuron slightly denser and coarser; mesoscutum coriaceous, finely punctate-rugose along notaulus; notaulus moderate; scutellum quite smooth, its posterior vertical face longitudinally striate; propodeum densely and shallowly punctate, area superomedia medially smoother 
and relatively short, area petiolaris transversely striate. Legs. Femoral tooth acute, longer than basally wide, followed by a row of distinct denticles.

Metasoma. Tergite 2 and apical half of tergite 1 longitudinally aciculate, following tergites coriaceous; thyridium subcircular; ovipositor moderately short, apically distinctly sinuous.
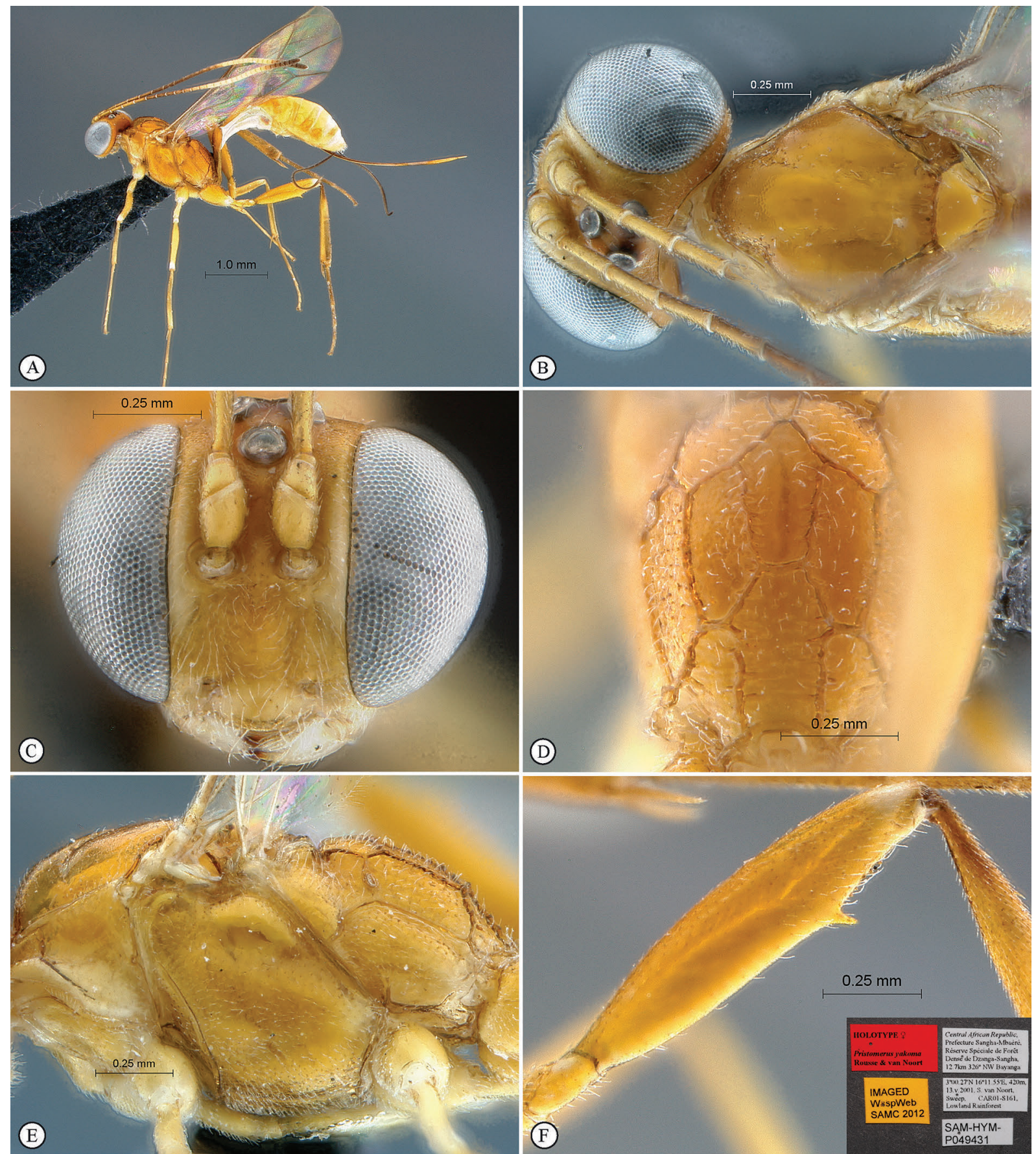

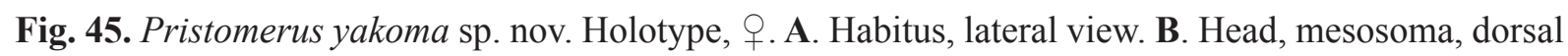
view. C. Head, anterior view. D. Propodeum, dorsal view. E. Mesosoma, lateral view. F. Hind tibia, lateral view (inset: data labels). 


\author{
Male \\ Unknown.

\section{Distribution} \\ Central African Republic, Mozambique. \\ Pristomerus yangere sp. nov. \\ urn:1sid:zoobank.org:act:3412DBAD-1BB8-41FD-960E-E98F92CC01C8
}

Fig. 46

\title{
Diagnosis
}

Large; black with metasoma orange from tergite 3; trochanters and apex of femora white-dotted; pterostigma anteriorly white; face densely punctate-granulate; clypeus more sparsely punctate, transverse; malar line long; remainder of head finely and densely punctate; antenna with 32-35 flagellomeres, penultimate flagellomere quadrate; mesosoma coarsely punctate with middle of pronotum and ventral half of speculum smooth, and propodeum punctate-rugose; female femoral tooth absent; ovipositor long, strongly sinuous apically. Male unknown.

\section{Differential diagnosis}

Large and black with metasoma partially orange; differentiated from all other Afrotropical species by the combination of the colour pattern, the large size and the absence of a female femoral tooth; it might be closely related to $P$. $k u k u$ sp. nov., which is, however, characterized by a strong frontal protuberance and a distinctly shorter ovipositor.

\section{Type material}

\section{Holotype}

CENTRAL AFRICAN REPUBLIC: +, “Central African Republic, Préfecture Sangha-Mbaéré, Réserve Spéciale de Forêt Dense de Dzanga-Sangha, $12.7 \mathrm{Km} 326^{\circ} \mathrm{NW}$ Bayanga, $3^{\circ} 00.27^{\prime} \mathrm{N} 16^{\circ} 11.55^{\prime} \mathrm{E}, 420 \mathrm{~m}$, 11.v.2001, S van Noort, Sweep, CAR01-S110, Lowland Rainforest, SAM-HYM-P049432” (SAMC).

\section{Description}

Female (holotype)

B 11.6; A 6.5; F 6.8; CT 1.8; ML 0.7; POL 0.8; OOL 1.0; Fl $1_{n-1}$ 1.0; ASM 2.0; OT 1.9; FFT 0.

CoLour. Head black with lighter pale yellow to yellowish parts: clypeus, mandible, palpi, malar space and frontal orbits; mesosoma black with tegula pale yellow; tergites 1-2 black, following tergites orange; fore and mid legs yellowish-orange; hind leg basally black, strongly infuscate from femur; all trochanters and femora apically white-dotted; antenna and ovipositor sheath dark brown; wings slightly infuscate, venation brown, pterostigma anteriorly white.

HEAD. Face densely punctate-granulate; inner margins of eyes subparallel; clypeus transverse, sparsely punctate but punctation denser along dorsal margin, distinctly convex in profile; malar line long; frons, vertex and temple finely and densely punctate; frond with a moderate mid-longitudinal ridge from median ocellus to upper face; occipital carina joining hypostomal carina at mandible base; antenna with 35 flagellomeres, penultimate flagellomere quadrate.

Mesosoma. Moderately stout; pronotum densely and finely punctate with a smooth median area; mesopleuron and metapleuron densely punctate with an oblique striate furrow below speculum, speculum ventrally smooth; mesoscutum densely and coarsely punctate-granulate, punctures confluent 
into transverse rugosities along notaulus; notaulus deep; scutellum densely punctate, its posterior vertical face longitudinally striate; propodeum coarsely punctate-rugose, laterally punctate; carination thick. Legs. Femoral tooth totally absent.

Metasoma. Tergites 2-3 and apical half of tergite 1 longitudinally aciculate, following tergites coriaceous; thyridium elliptic and wide with main axis oblique; ovipositor long, slightly down-curved, apically strongly sinuous.
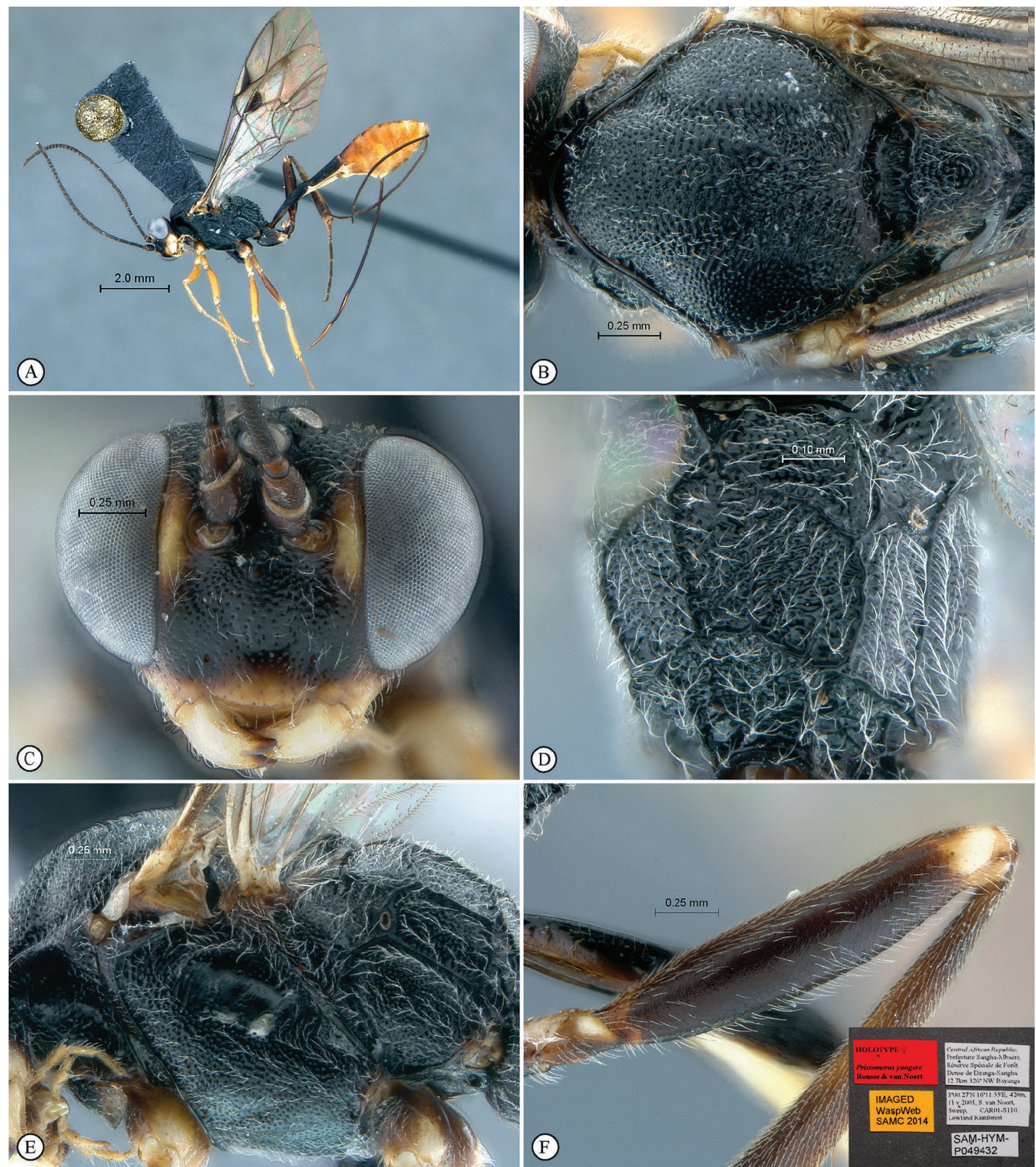

Fig. 46. Pristomerus yangere sp. nov. Holotype,, . A. Habitus, lateral view. B. Head, mesosoma, dorsal view. C. Head, anterior view. D. Propodeum, dorsal view. E. Mesosoma, lateral view. F. Hind tibia, lateral view (inset: data labels). 


\begin{abstract}
Male
Unknown.

Distribution

Central African Republic.

$$
\begin{gathered}
\text { Pristomerus yoccolo sp. nov. } \\
\text { urn:1sid:zoobank.org:act:F40E44AD-613F-4DFF-9A97-196123603381 }
\end{gathered}
$$
\end{abstract}

Fig. 47

\title{
Diagnosis
}

Moderately sized; yellowish orange overall; face moderately punctate; clypeus transverse and almost smooth; inner margins of eyes subparallel; malar line moderately short; upper head finely coriaceous; antenna with 30 flagellomeres, penultimate one slightly shorter than wide; mesosoma moderately to densely punctate but pronotum quite smooth and speculum hardly sculptured; female femoral tooth long and unusually narrow; tergite 2, apical half of tergite 1 and base of tergite 3 longitudinally aciculate; ovipositor long and straight, barely sinuous apically. Male unknown.

\section{Differential diagnosis}

Moderately sized and yellowish-orange overall; differentiated from most other Afrotropical species by the long and basally noticeably narrow female femoral tooth. Such a narrowed tooth is only otherwise found in P. afrikaner sp. nov. and P. yakoma sp. nov. The former, from South Africa, has, however, a longer malar line and longer antennae, and the latter has a coriaceous to smooth mesonotum. Pristomerus yoccolo sp. nov. is otherwise somewhat similar to P. babinga sp. nov., whose femoral tooth is distinctly stouter and in which the clypeus is more transverse and the inner orbits diverge ventrally.

\section{Type material}

\section{Holotype}

IVORY COAST: +, “Côte d'Ivoire: Aman Ikro 50 km. N. W. Abengourou J. Decelle II.1963” (MRAC).

\section{Description}

Female (holotype)

B 6.3; A 4.8; F 4.3; CT 1.9; ML 0.5; POL 0.9; OOL 1.1; Fl ${ }_{\mathrm{n}-1}$ 0.9; ASM 2.1; OT 1.9; FFT 2.

CoLour. Yellowish-orange overall, head and mesosoma barely darker dorsally, with basal infuscate markings on tergites 2 and 3; flagellum and ovipositor sheath dark brown; wings hyaline, venation brown.

HEAD. Face moderately punctate, weakly bulging mid-longitudinally; inner margins of eyes subparallel; clypeus transverse and long, almost smooth; malar line moderately short; frons, vertex and temple finely coriaceous; occipital carina joining ventrally hypostomal carina shortly above mandible base; antenna with 30 flagellomeres, penultimate flagellomere slightly shorter than wide.

Mesosoma. Moderately elongate; pronotum quite smooth; mesopleuron and metapleuron moderately densely punctate with a shallowly striate oblique furrow below speculum, speculum hardly sculptured; mesoscutum densely punctate-granulate, punctures confluent along notaulus into fine transverse rugosities; scutellum punctate; propodeum densely punctate-granulate, area superomedia moderately elongate. Legs. Femoral tooth long, narrow and acute.

Metasoma. Tergite 2, apical half of tergite 1 and base of tergite 3 longitudinally aciculate; thyridium subelliptic, its main axis longitudinal; ovipositor long and straight, barely sinuous apically. 


\section{Male}

Unknown.

\section{Distribution}

Ivory Coast.
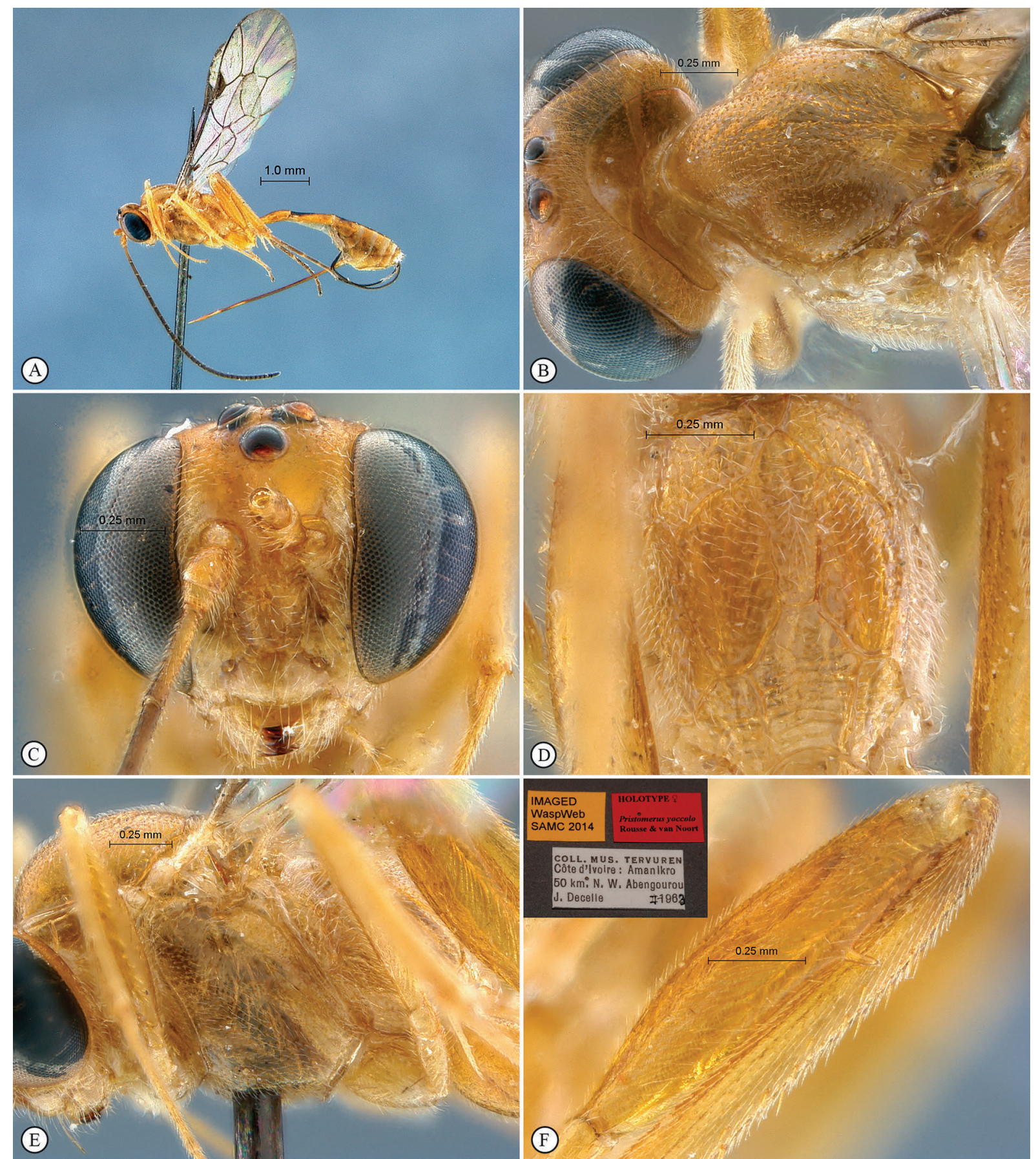

Fig. 47. Pristomerus yoccolo sp. nov. Holotype, . . A. Habitus, lateral view. B. Head, mesosoma, dorsal view. C. Head, anterior view. D. Propodeum, dorsal view. E. Mesosoma, lateral view. F. Hind tibia, lateral view (inset: data labels). 


\section{Pristomerus zande sp. nov. urn:Isid:zoobank.org:act:26CF33F4-5773-44EE-983D-F83705F42225}

Fig. 48

\section{Diagnosis}

Moderately small to small; yellowish-orange with mandible, clypeus and frontal orbits pale yellow, and variable dorsal black markings; trochanters and femora apically white-dotted; fore wing with anterior edge of pterostigma whitish; face densely punctate-granulate, clypeus almost entirely smooth, remainder of head coriaceous; clypeus strongly transverse; malar line short; antenna with 27 flagellomeres, penultimate one quadrate; mesosoma moderately to densely punctate, including sometimes pronotum and almost entire speculum, with punctures confluent into rugosities on notaulus; propodeal carination thick; female femoral tooth absent; ovipositor short, apically nearly straight. Male unknown.

\section{Differential diagnosis}

Small to moderately small and yellow to yellowish orange overall with some black markings dorsally; differentiated from all other Afrotropical species by the combination of the short malar line, the absence of a femoral tooth and the short ovipositor. Pristomerus zande sp. nov. is somewhat morphologically similar to $P$. albescens and $P$. vahaza, but is easily differentiated because both have a narrower clypeus.

\section{Type material}

\section{Holotype}

CENTRAL AFRICAN REPUBLIC: ㅇ, "Central African Republic, Préfecture Sangha-Mbaéré, Parc National de Dzanga-Ndoki, Mabéa Bai, 21.4 Km 53 NE Bayanga, $3^{\circ} 02.01^{\prime} \mathrm{N} 16^{\circ} 24.57^{\prime} \mathrm{E}, 510 \mathrm{~m}$, 6-7.v.2001, S van Noort, Malaise trap, CAR01-M38, lowland rainforest, marsh clearing, SAM-HYMP049434" (SAMC).

\section{Paratypes}

CENTRALAFRICAN REPUBLIC: 1 , same label data except: "yellow pan, CAR01-Y02 SAM-HYM-

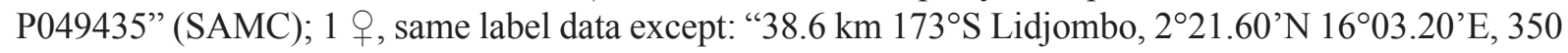
m, 22-23.v.2001, Malaise trap, CAR01-M186, lowland rainforestSAM-HYM-P049436” (SAMC).

\section{Description}

Female ( 3 specimens)

B 4.8-6.3; A 3.0-3.7; F 2.8-3.7; CT 2.0; ML 0.4; POL 0.7; OOL 0.9; $\mathrm{Fl}_{\mathrm{n}-1}$ 1.0; ASM 2.2; OT 1.2-1.3; FFT 0.

Colour. Yellowish-orange overall with mandible, clypeus and frontal orbits pale yellow, and variable black markings: frons, occiput laterally, vertex, flagellum, apex of tergite 1 and a variable basal part of following tergites; ovipositor sheath, hind tarsus, and apex and base of hind tibia infuscate; trochanters and femora apically white-dotted; wings hyaline, venation brown, pterostigma anteriorly white.

HEAD. Face densely and shallowly punctate-granulate; inner margins of eyes slightly converging ventrally; clypeus almost smooth, strongly transverse, distinctly convex in profile view; malar line short; frons, vertex and temple coriaceous; frons with a weak mid-longitudinal carina; occipital carina joining hypostomal carina shortly above mandible base; antenna with 27 flagellomeres, penultimate flagellomere quadrate.

Mesosoma. Moderately elongate; entire pronotum moderately and shallowly punctate (postero-dorsally smooth in the smallest paratype); mesopleuron and metapleuron very densely punctate-granulate, with a 
strong oblique striate furrow below speculum, speculum almost entirely shallowly punctate; mesonotum densely punctate, punctures confluent into fine transverse rugosities along notaulus; notaulus moderate; propodeal carination complete and thick, area petiolaris transversely strigose. Legs. Femoral tooth absent.

Metasoma. Tergite 2 and apical half of tergite 1 longitudinally aciculate, following tergites sparsely and shallowly punctate-granulate; thyridium subcircular; ovipositor moderately short, stout, apically slightly swollen and nearly straight.
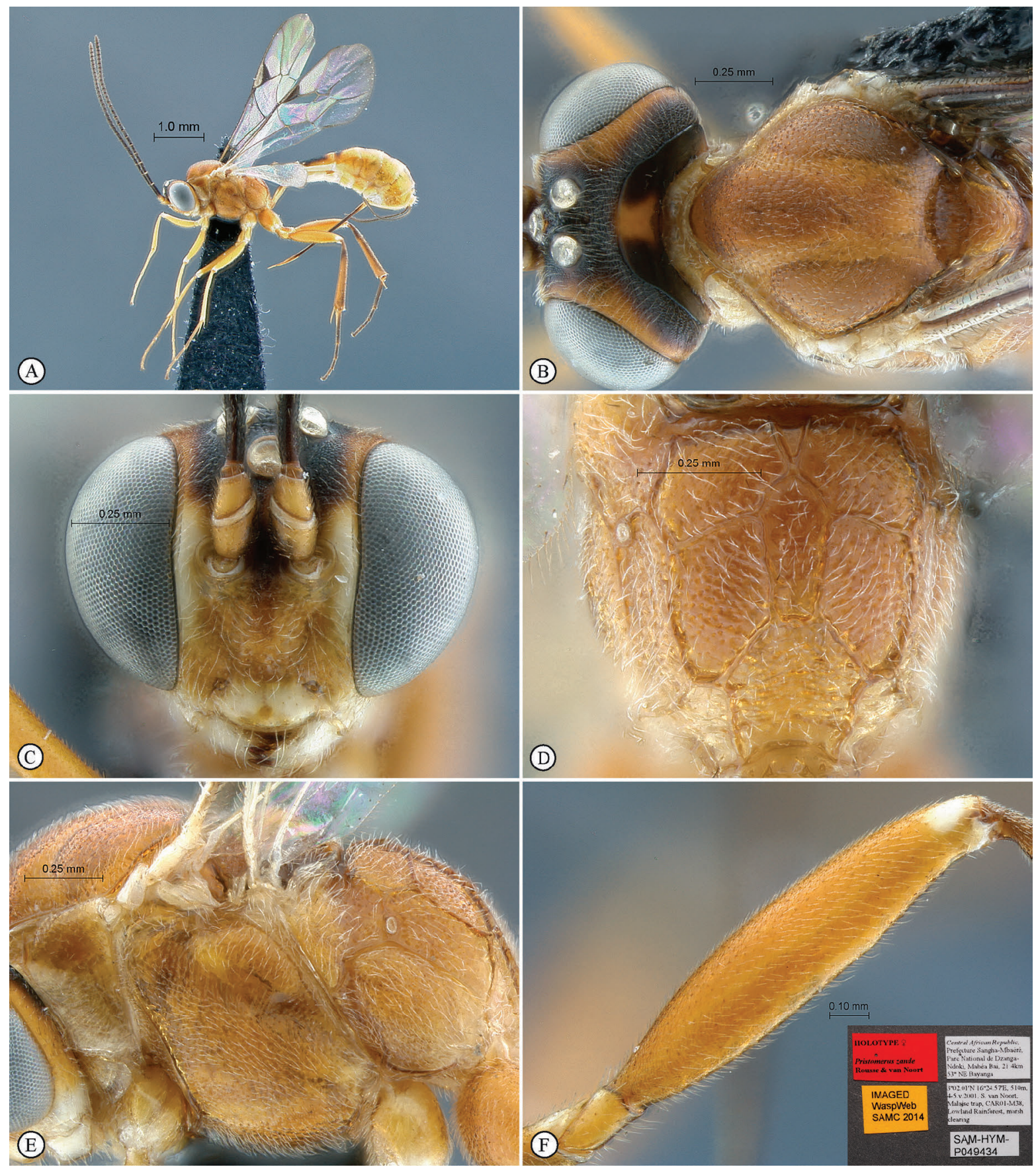

Fig. 48. Pristomerus zande sp. nov. Holotype, . . A. Habitus, lateral view. B. Head, mesosoma, dorsal view. C. Head, anterior view. D. Propodeum, dorsal view. E. Mesosoma, lateral view. F. Hind tibia, lateral view (inset: data labels). 


\author{
Male \\ Unknown.

\section{Distribution} \\ Central African Republic. \\ Pristomerus zulu sp. nov. \\ urn:1sid:zoobank.org:act:4C307073-AE10-4691-9E03-FC26E1B619E9
}

Fig. 49

\title{
Diagnosis
}

Moderately large to large; head mostly reddish-testaceous with inner orbits and lower head whitish yellow; mesosoma reddish-testaceous; metasoma black; legs testaceous with white markings on anterior margin of fore and mid tibiae, and apex of all femora and trochanters; pterostigma anteriorly white; face and clypeus moderately to densely punctate, remainder of head more finely sculptured; clypeus long, moderately transverse; inner margins of eyes subparallel; malar line short; antenna with 31-32 flagellomeres, penultimate one distinctly shorter than wide; mesosoma densely punctate but pronotum centrally and ventral half of speculum smooth; female femoral tooth strong; ovipositor moderately long, weakly sinuous apically. Male with ocelli enlarged, hind femur and femoral tooth stouter, inner margins of eyes diverging ventrally, and mesoscutum largely coriaceous.

\section{Differential diagnosis}

Rather to quite large and with an unusual colour pattern: metasoma black, head and mesosoma reddishtestaceous except orbits and lower head white, and legs largely white-maculated. That colour pattern readily distinguishes this species from almost all other Pristomerus species; P. veloma is somewhat similar in colour, but its orbits are not contrastingly pale and diverge ventrally.

\section{Type material}

\section{Holotype}

SOUTH AFRICA: + , “SOUTH AFRICA, TVL, D’Nyala Nature Res, Ellisras district, 23.45S 27.49E, 19.xii.1987, M. W. Mansell” (SANC).

\section{Paratypes}

SOUTH AFRICA: 2 우, 1 §, "Goshen, nr. Cathcart, E. Cape, Mar. 1954, SAM-HYM-P001202" (SAMC).

\section{Description}

Female (3 specimens)

B 8.2-11.1; A 4.1-5.8; F 4.6-6.2; CT 1.6; ML 0.4; POL1.0; OOL 1.1; F1 ${ }_{\mathrm{n}-1} 0.8$; ASM 2.2; OT 1.7; FFT 2.

CoLour. Head mostly reddish-testaceous with face sometimes fading to black medially, and whitish parts: inner orbits, most of clypeus, mandible but teeth, malar space and palpi; mesosoma reddishtestaceous with scutellum weakly lighter orange and sometimes an infuscate marking on metanotum; metasoma black; legs mostly testaceous with anterior margins of fore and mid tibiae, and apex of all femora and trochanters whitish; ovipositor sheath dark brown; antenna dark brown, sometimes fading to testaceous toward apex; wing hyaline, venation pale brown with anterior half of pterostigma whitish.

HEAD. Face moderately punctate; inner margins of eyes subparallel; clypeus sparsely and shallowly punctate, weakly transverse, long; malar line short; frons nearly smooth; vertex and temple coriaceous; 
occipital and hypostomal carina joining at mandible base; antenna short and stout with 31-32 flagellomeres, penultimate flagellomere distinctly shorter than wide.

Mesosoma. Pronotum mostly shallowly punctate, anteriorly crenulate and medially smoother; mesopleuron and metapleuron densely and deeply punctate, with a striate oblique furrow below speculum, speculum mostly smooth; mesoscutum densely punctate, punctation sometimes sparser on lateral lobe; notaulus
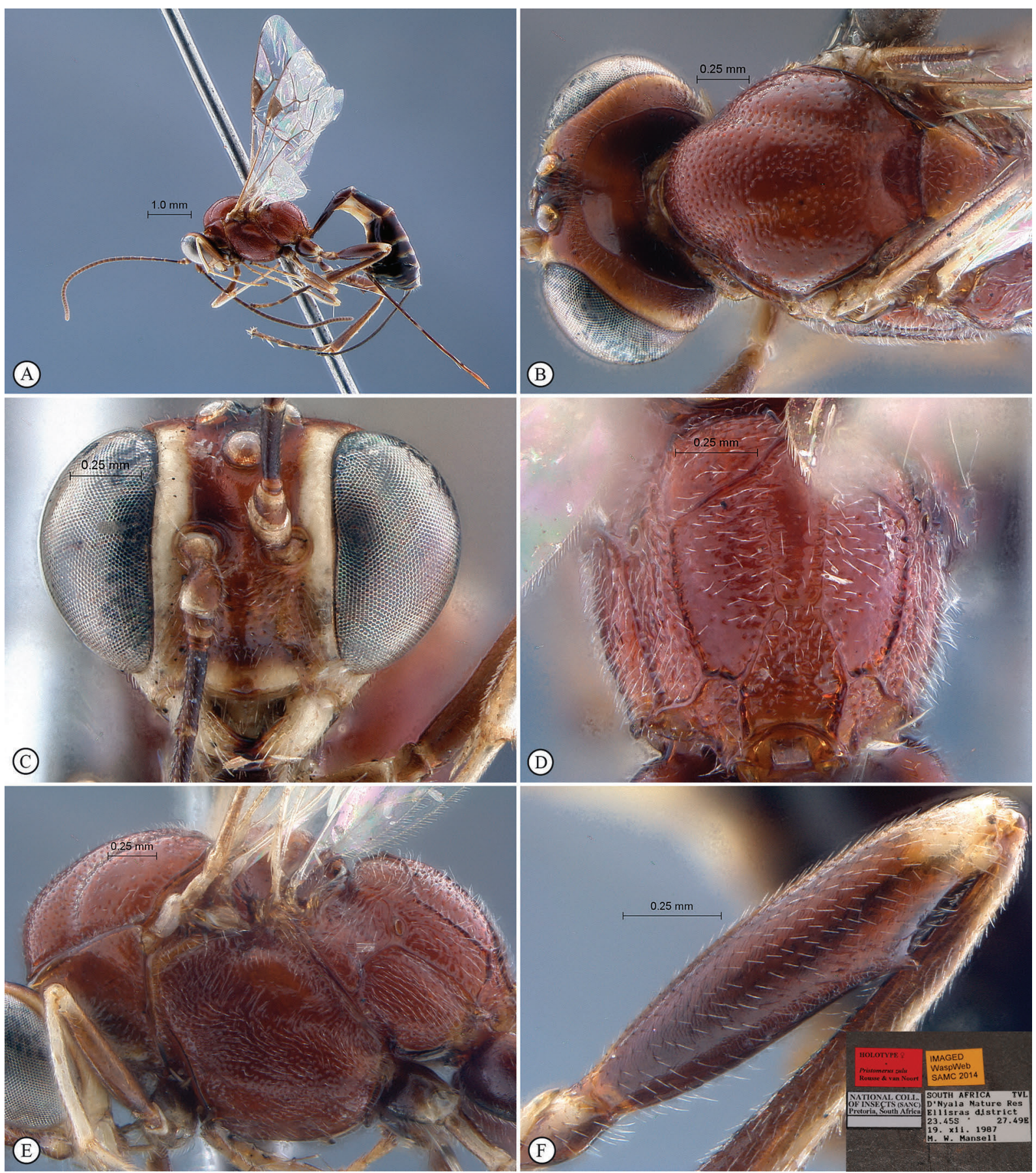

Fig. 49. Pristomerus zulu sp. nov. Holotype, ${ }_{\text {. }}$ A. Habitus, lateral view. B. Head, mesosoma, dorsal view. C. Head, anterior view. D. Propodeum, dorsal view. E. Mesosoma, lateral view. F. Hind tibia, lateral view (inset: data labels). 
moderate and rugose; scutellum densely and shallowly punctate; propodeum densely punctate, punctures somewhat confluent medially into transverse rugosities, area superomedia sometimes smoother centrally; area superomedia elongate. Legs. Femoral tooth strong, hardly to distinctly higher than basally wide.

Metasoma. Apical half of tergite 1 and entire tergite 2 aciculate, following tergites coriaceous; thyridium subcircular; ovipositor moderately long, apically weakly sinuous.

Male (paratype)

B 11.5; A 6.2; F 6.5; POL 0.6; OOL 0.4. Ocelli enlarged; inner margins of eyes distinctly diverging ventrally; mesoscutum weakly sculptured, mostly coriaceous with punctures on anterior half of median lobe and along notaulus; hind femur and femoral tooth stouter; otherwise similar to female.

\section{Distribution}

South Africa.

\section{Comments}

The three paratypes were previously reported as non-type specimens of $P$. veloma in Rousse et al. 2013.

\section{Discussion}

What else, other than pure taxonomic information, does this revision contribute to our knowledge of the genus? One of the first observations arising from this revision and the previous revision of Madagascan Pristomerus (Rousse et al. 2013) is the definition of colour patterns associated with geography or ecology. Five of the Pristomerus species from Madagascar are uniquely white-faced. No other species in Africa display such a pale face colour but two species from South Africa $(P . z u l u$ sp. nov. and another non-described male in the SAMC collections) exhibit whitish orbits on the otherwise testaceous face. We cannot associate that colour pattern with any ecological traits, mostly because Seyrig's labels do not provide information on habitat association. This correlates with a similar situation in Xanthophenax Saussure, 1892, where the white-faced species are restricted to Madagascar (Rousse, Villemant \& van Noort, in prep).

A second colour pattern is more informative. This pattern is defined by white-dotted femora and halfwhite pterostigma, usually associated with a mostly black colour overall, although sometimes combined with a lighter overall colour, a pattern that is exhibited by 20 of the 49 species. These 20 species have all been collected in tropical Africa with the noticeable exception of $P$. zulu sp. nov. and, in part, $P$. bemba sp. nov.. Furthermore, 15 of these 20 species have been collected in rainforest, and two more in dryer forest environments. We lack ecological data for P. dikidiki sp. nov., but the collection locality strongly suggests a similar rainforest habitat. Moreover, all the 15 species from rainforest habitats have enlarged ocelli in both sexes. By contrast, 22 species of the 29 non white-dotted group have ocelli that are not enlarged in females, and for some of them not even in males. The 20 white-dotted species do not appear to be closely related, since they exhibit much variation in characters which are probably of more critical importance in terms of indicating phylogenetic relationships: the size of the femoral tooth, the length of the malar line, the sculpture of the mesonotum. On the other hand, some clearly related (and possibly sister-species) (e.g. P. sara sp. nov./P. kelikely) can be differentiated only by the presence or absence of this white dot. This colour pattern is thus clearly a phenotypic convergence conditioned by the environmental parameters of a closed and humid forest habitat.

Interestingly, the general black colour of most of these white-dotted species may be compared to one of the patterns displayed by Braconinae, where the darkest species are also reported from the tropical humid forests of Central Africa, putatively for concealment purpose (Quicke 1986). Dark patterns are also often associated with high altitude and low temperatures (Gauld \& Mitchell 1978; Quicke 1997), 
though such a correlation could not be shown in Pristomerus. The comparison with the South American fauna brings further informative data. The predominant colour pattern in the Neotropical region is yellow to brown, black being an exception (Gauld 2000) even in the tropical rainforests (Sääksjaärvi pers. com.). Interestingly, most if not all of the rainforest species exhibit similar white dots on the femora (Sääksjaärvi pers. com.). What function can be hypothesized for the presence of these white marks on species in closed forest environments? To our knowledge, no other sympatric insect exhibits a similar pattern, so we can exclude the hypothesis of a mimicry complex (Quicke 1986). We suggest that the markings are involved in intra-specific communication, as contrasting markings are known to be used for this purpose in other Hymenoptera. For example, social Vespidae use individual markings for kin recognition (Baracchi et al. 2013) or minimization of conflict costs (Tibbets \& Lindsay 2008). Even though they are taxonomically distantly related, from a functional perspective many lepidopterans exhibit "white" surfaces reflecting UV flashes, hence favoring mate location (Brunton \& Majerus 1995). "Semaphore signaling" is also fairly well documented in Tephritidae (Diptera) (Sivinski et al. 2000), with the noticeable example of Eutreta diana (Osten Sacken), in which the mid femur is black and contrastingly yellow-tipped in both sexes, and is apparently involved in the mating behavior of the male (Goeden 1990). However, none of these examples provide definitive evidence to support any hypothesis for the precise function of white markings in Pristomerus, even though hypotheses of inter or intra-specific communication using body markings have been proposed and tested in Braconidae by Quicke (1984).

Finally, a third colour pattern groups the species which have a mostly yellow to orange overall colour, with various infuscate to black markings. This pattern is exhibited by most of the remaining Afrotropical species, with the exception of some very unusual species such as $P$. xhosa sp. nov., P. fynbos and P. protea sp. nov., or even $P$. sotho sp. nov. Some of the species in this colour group have the femur somewhat paler at the apex, but never as strikingly contrasting as in the white-dotted group. Species with this third colour pattern were collected in drier, open habitats. The few species known from the arid areas of the Mediterranean and Middle East regions are similarly coloured (Horstmann 1990). Here again, it makes sense to hypothesize that this colour pattern is well suited for camouflage purposes in lighter habitats with short vegetation, and/or to prevent over-heating in those often hotter environments. The perfect example supporting this dichotomy is P. pallidus, a common species with hundreds of specimens present in collections. Pristomerus pallidus is present from Madagascar to Western Africa and Southern Europe. Interestingly, very few records exist (with no ecological information) from Central Africa: this otherwise very widespread pale species appears to be largely absent from tropical rainforest.

The available data are indeed affected by a strong "agricultural bias", i.e., they largely include wasps reared from pests in cultivated areas, collected by agricultural services. Specimens of Cremastinae in collections are mostly associated with dry and open areas, at least in temperate areas (Fitton \& Gauld 1980; Gauld 2000), but the few expeditions led into the Afrotropical forests brought back many new species. In the present study and the previous revision of Madagascan species (Rousse et al. 2013), about $60 \%$ of the newly described species emanate from limited and punctuated sampling in the forests of Madagascar and tropical Africa and are described from very few individuals if not from singletons. This suggests that, although our taxonomic knowledge of the genus has been expanded by the present revision, many more species will still be unveiled by further collecting.

Assuming the lack of knowledge we have on the precise biodiversity and phylogeny of the genus, we cannot hypothesize about the geographical location of its original radiation. The pantropical distribution of this genus is a tempting, but not definitive argument to support divergence of Pristomerus before the complete breakup of Gondwana, c. 95 million years ago (Le Gall et al. 2010). Such a distribution may, however, also be the result of a more recent dispersal event through temporary inter-continental connections (Sääksjärvi et al. 2004). As a consequence, we are still in need of taxonomic and phylogenetic data to reconstruct the evolutionary history of Pristomerus and related genera within the tropics. 


\section{Acknowledgments}

We are grateful to the curators of the above mentioned museums and their teams for loaning specimens. Thanks also to Bernardo Santos and Ilari Sääksjärvi for providing helpful contributions, and thank you in advance to the courageous reviewers who will be in charge of this big baby. Simon van Noort was funded by South African NRF (National Research Foundation) grants: GUN 2068865; GUN 61497; GUN 79004; GUN 79211; GUN 81139. Part of the South African field work conducted by SvN was funded by the National Science Foundation under PlatyPBI grant No. DEB-0614764 to N.F. Johnson and A.D. Austin. Pascal Rousse was funded by SABI (South African Biodiversity Initiative) NRF postdoctoral fellowship GUN 81609 and a Claude Leon Foundation post-doctoral fellowship. Cape Nature, the Eastern Cape Department of Environmental Affairs and the Northern Cape Department of Nature and Environmental Conservation provided collecting permits for South Africa. Fieldwork in Gabon was funded by the World Bank through WWF-US and WWF-CARPO. Collecting and export permits were granted by Emile Mamfoumbi Kombila, Directeur de la Faune et de la Chasse, Libreville. The Ugandan Wildlife Authority and UNCST provided permits to conduct research in Uganda. Field work in the Central African Republic was supported by WWF-US and WWF-CARPO. The Ministers of Water, Forests and the Environment and the High Commissioners for tertiary Education and Research of the Central African Republic granted permission to carry out the inventory survey and to export the specimens as part of the WWF-US CAR field expedition conducted in 2001.

\section{References}

Ashmead W.H. 1900. Some changes in generic names in Hymenoptera. Canadian Entomologist 32 (12): 368. http://dx.doi.org/10.4039/Ent32368a-12

Athanassov A., Charmillot P.J., Jeanneret P. \& Renard D. 1997. Les parasitoïdes des larves et des chrysalides du carpocapse Cydia pomonella L. Revue Suisse de Viticulture, Arboriculture, Horticulture 29 (2): 99-106.

Aubert J.F. \& Shaumar N. 1978. Supplément aux Ichneumonides d'Egypte. Bulletin de la Société Entomologique de Mulhouse avril-juin: 13-20.

Baracchi D., Petrocelli I., Cusseau G., Pizzocaro L., Teseo S. \& Turillazi S. 2013. Facial markings in the hover wasps: quality signals and familiar recognition cues in two species of Stenogastrinae. Animal Behaviour 85 (1): 203-212. http://dx.doi.org/10.1016/j.anbehav.2012.10.027

Brunton C.F.A. \& Majerus M.E.N. 1995. Ultraviolet colors in butterflies: intra- or inter-specific communication? Proceedings of the Royal Society of London, Series B 260 (1358): 199-204. http:// dx.doi.org/10.1098/rspb.1995.0080

Buffington M.L., Burks R. \& McNeil L. 2005. Advanced Techniques for Imaging Parasitic Hymenoptera (Insecta). American Entomologist 51 (1): 50-54. http://dx.doi.org/10.1093/ae/51.1.50

Buffington M.L. \& Gates M. 2009. Advanced Imaging Techniques II: Using a Compound Microscope for Photographing Point-Mount Specimens. American Entomologist 54 (4): 222-224. http://dx.doi. org/10.1093/ae/54.4.222

Cave R.D. 1995. Manual para el Reconocimiento de Parasitoides de Plagas Agricolas en America Central. Zamorano Academic Press, Tegucigalpa.

Fitton M.G. \& Gauld I.D. 1980. A review of the British Cremastinae (Hymenoptera: Ichneumonidae), with keys to the species. Entomologist's Gazette 31 (1): 63-71.

Gauld I.D.\& Mitchell P.A. 1978. The Taxonomy, Distribution and Host Preferences of African Parasitic Wasps of the Subfamily Ophioninae (Hymenoptera, Ichneumonidae). Commonwealth Institute of Entomology, Slough.

Gauld I.D. 1985. The phylogeny, classification and evolution of parasitic wasps of the subfamily Ophioninae (Ichneumonidae). Bulletin of the British Museum (Natural History), Entomology Series 51: 61-185. 
Gauld I.D. 1991. The Ichneumonidae of Costa Rica, 1. Memoirs of the American Entomological Institute 47, American Entomological Institute, Gainesville.

Gauld I.D. 2000. The Ichneumonidae of Costa Rica, 3. Memoirs of the American Entomological Institute 63, American Entomological Institute, Gainesville.

Goeden R.D. 1990. Life history of Eutreta diana (Osten Sacken) on Artemisia tridentata Nutall in Southern California (Diptera: Tephritidae). Pan-Pacific Entomologist 66 (1): 24-32.

Horstmann K. 1990. Die westpaläarktischen Arten der Gattung Pristomerus Curtis, 1836 (Hymenoptera: Ichneumonidae). Entomofauna 11: 9-44.

Jansson R., Rodríguez-Castañeda G. \& Harding L.E. 2013. What can multiple phylogenies say about the latitudinal diversity gradient? A new look at the tropical conservatism, out-of-the-tropics and diversification rate hypotheses. Evolution 67 (6): 1741-1755. http://dx.doi.org/10.1111/evo.12089

Kerr P.H., Fischer E.M. \& Buffington M.L. 2008. Dome lighting for insect imaging under a microscope. American Entomologist 54 (4): 198-200. http://dx.doi.org/10.1093/ae/54.4.198

Le Gall P., Silvain J.-F., Nel A. \& Lachaise D. 2010. Les insectes actuels témoins des passés de l'Afrique : essai sur l'origine et la singularité de l'entomofaune de la région afrotropicale. Annales de la Société entomologique de France 46 (3-4): 297-343. http://dx.doi.org/10.1080/00379271.2010.10697672

Magretti P. 1884. Risultati di raccolte imenotterologiche nell'Africa Orientale. Annali Museo Civico di Storia Naturale 21: 523-531.

Morley C. 1912. Hymenoptera, Ichneumonidae. Transactions of the Linnean Society of London, Series 2, Zoology 15 (2): 169-179.

Morley C. 1913. A Revision of the Ichneumonidae Based on the Collection in the British Museum (Natural History) with Descriptions of New Genera and Species. Part II. Tribes Rhyssides, Echthromorphides, Anomalides and Paniscides. British Museum, London. http://dx.doi.org/10.5962/bhl.title.8761

Morley C. 1917. On some South African Ichneumonidae in the collection of the South African Museum. Annals of the South African Museum 17: 191-229.

Morley C. 1926. On some South African Ichneumonidae in the collection of the South African Museum, Part III. Annals of the South African Museum 23: 435-481.

Polaszek A., Fitton M.G., Bianchi G. \& Huddleston T. 1994. The parasitoids of the African white rice borer, Maliarpha separatella Ragonot (Lepidoptera: Pyralidae). Bulletin of Entomological Research 84 (1): 65-90. http://dx.doi.org/10.1017/S0007485300032247

Quicke D.L.J. 1984. Evidence for the function of white-tipped ovipositor sheaths in Braconinae (Hymenoptera: Braconidae). Proceedings and Transactions of the British Entomological and Natural History Society 17: 71-79.

Quicke D.L.J. 1986. Preliminary notes on homeochromatic associations within and between afrotropical Braconinae (Hym., Braconidae) and Laminae (Col., Cerambycidae). Entomologist's Monthly Magazine 122: 97-109.

Quicke D.L.J. 1991. Ovipositor mechanics of the braconine wasp genus Zaglyptogastra and the ichneumonid genus Pristomerus. Journal of Natural History 25 (4): 971-977. http://dx.doi. org $/ 10.1080 / 00222939100770631$

Quicke D.L.J. 1997. Parasitic Wasps. Chapman \& Halls, London.

Rosenberg H.T. 1934. The Biology and Distribution in France of the Larval Parasites of Cydia pomonella, L. Bulletin of Entomological Research 25 (2): 201-256. http://dx.doi.org/10.1017/S0007485300012657 
Rousse P. \& Villemant C. 2012. Ichneumons in Reunion Island: a catalogue of the local Ichneumonidae (Hymenoptera) species, including 15 new taxa and a key to species. Zootaxa 3278: 1-57.

Rousse P., Villemant C. \& Seyrig A. 2013. Ichneumonid wasps from Madagascar. VI. The genus Pristomerus (Hymenoptera: Ichneumonidae: Cremastinae). European Journal of Taxonomy 49: 1-38. http://dx.doi.org/10.5852/ejt.2013.49

Sääksjärvi I.E., Gauld I.D. \& Salo J. 2004. Phylogenetic evaluation of the tropical Camptotypus genusgroup (Hymenoptera: Ichneumonidae), with a key to the world genera. Journal of Natural History 38 (21): 2759-2758. http://dx.doi.org/10.1080/0022293032000140949

Sivinski J., Aluja M., Dodson G., Freidberg A., Headrick D., Kaneshiro K. \& Landolt P. 2000. Topics in the evolution of sexual behavior in the Tephritidae. In: Aluja M. \& Norrbom A.L. (eds) Fruit Flies (Tephritidae): Phylogeny and Evolution of Behavior: 751-792. CRC Press, Boca Raton.

Smith J.W. \& Johnson S.J. 1986. Development of Pristomerus spinator (F.), Illidops terrestris Wharton and Chelonus (Microchelonus) elasmopalpi McComb. The Southwestern Entomologist 11 (3): 131-135.

Szépligeti G. 1905. Hymenoptera. Ichneumonidae (Gruppe Ophionoidea), subfam. PharsaliinaePorizontinae. Genera Insectorum 34, V. Verteneuil et L. Desmet, Brussels.

Tibbets E.A. \& Lindsay R. 2008. Visual signals of status and rival assessment in Polistes dominulus paper wasps. Biology Letters 4 (3): 237-239. http://dx.doi.org/10.1098/rsbl.2008.0048

Tosquinet J. 1896. Contributions à la faune entomologique de l'Afrique. Ichneumonides. Mémoires de la Société Entomologique de Belgique 5, Société Entomologique de Belgique, Brussels.

Townes H.K. 1971. The Genera of Ichneumonidae. Part 4. Cremastinae to Diplazontinae. Memoirs of the American Entomological Institute 17, American Entomological Institute, Gainesville.

Townes H.K. \& Townes M. 1973. A Catalogue and Reclassification of the Ethiopian Ichneumonidae. Memoirs of the American Entomological Institute 19, American Entomological Institute, Gainesville.

Viereck H.L. 1912. Descriptions of five new genera and twenty six new species of Ichneumon-flies. Proceedings of the United States National Museum 42: 139-153.

Wahl D.B. \& Sharkey M.J. 1993. Chapter 10. Superfamily Ichneumonoidea. In: Goulet H. \& Huber J.T. (eds) Hymenoptera of the World: An Identification Guide to Families: 359-509. Research Branch Agriculture Canada Publication 1894/E, Centre for Land and Biological Resources Research, Ottawa.

Yu D.S.K., Achterberg C. van \& Horstmann K. 2012. Taxapad 2012, Ichneumonoidea 2011. Database on flash-drive.

Manuscript received: 20 October 2014

Manuscript accepted: 26 January 2015

Published on: 28 May 2015

Topic editor: Koen Martens

Desk editor: Charlotte Thionois

Printed versions of all papers are also deposited in the libraries of the institutes that are members of the EJT consortium: Muséum national d'Histoire naturelle, Paris, France; Botanic Garden Meise, Belgium; Royal Museum for Central Africa, Tervuren, Belgium; Natural History Museum, London, United Kingdom; Royal Belgian Institute of Natural Sciences, Brussels, Belgium; Natural History Museum of Denmark, Copenhagen, Denmark. 